\title{
Advanced Turbine Systems
}

Phase II - Conceptual Design and Product Development

Final Report
August 1993 - July 1996
RECE:

OCT 15 15:

OSTI

Work Performed Under Contract No.: DE-AC21-93MC30247

For

U.S. Department of Energy

Office of Fossil Energy

Morgantown Energy Technology Center

Morgantown, West Virginia

By

Westinghouse Electric Corporation 4400 Alafaya Trail

Orlando, FL $32826-2399$ 


\section{Disclaimer}

This report was prepared as an account of work sponsored by an agency of the United States Government. Neither the United States Government nor any agency thereof, nor any of their employees, makes any warranty, express or implied, or assumes any legal liability or responsibility for the accuracy, completeness, or usefulness of any information, apparatus, product, or process disclosed, or represents that its use would not infringe privately owned rights. Reference herein to any specific commercial product, process, or service by trade name, trademark, manufacturer, or otherwise does not necessarily constitute or imply its endorsement, recommendation, or favoring by the United States Government or any agency thereof. The views and opinions of authors expressed herein do not necessarily state or reflect those of the United States Government or any agency thereof. 


\section{DISCLAIMER}

Portions of this document may be illegible in electronic image products. Images are produced from the best available original document. 


\title{
Advanced Turbine Systems \\ Phase II - Conceptual Design and Product Development
}

\author{
Final Report \\ August 1993 - July 1996
}

Work Performed Under Contract No.: DE-AC21-93MC30247

For

U.S. Department of Energy

Office of Fossil Energy

Morgantown Energy Technology Center

P.O. Box 880

Morgantown, West Virginia 26507-0880

By

Westinghouse Electric Corporation

Power Geneeration Business Unit

Technology Division

4400 Alafaya Trail

Orlando, Florida 32826-2399 


\section{CONTENTS}

$\underline{\text { Section }}$

Title

$\underline{\text { Page }}$

Executive Summary.

\section{Introduction}

Background.

\section{Statement of Work}

Task 2.0 Information Required for NEPA...................................... 3-2

Task 3.0 Selection of Natural Gas Fired Advance Turbine System ... 3-3

Task 4.0 Conversion to a Coal Fueled Advanced Turbine System .... 3. 3-6

Task 5.0 Market Study...................................................................... 3-8

Task 6.0 System Definition and Analysis........................................... 3-. 3-9

Task 7.0 Integrated Program Plan ..................................................... 3-11

Task 8.0 Design and Test of Critical Components ............................ 3-13

\section{Selection of Gas Fired ATS}

Introduction

Discussion.

Cycle Analysis.

Baseline Cycle.

Component Improvements

Steam Cycle Enhancements

Rotor Air Cooler Heat Utilization

Closed Loop Steam Cooling...

Increased Compressor Pressure Ratio

4-10

Increased Turbine Inlet Temperature

4-12

Compressor Intercooling

Recuperation

4-14

Intercooling with Recuperation

4-16

Reheat Combustion Turbine

4-18

Thermochemical Recuperation.

Steam Injection.

4-20

Evaluation of Candidate Systems

Conversion of an Advanced Natural Gas Fueled

Combustion Turbine to Coal Based Fuel Application

Introduction

Selection of Coal Fired Plant Reference System ............................... 5-1

IGCC CFATS Description............................................................... $5-2$

Second Generation PFBC CFATS Description .................................. 5- 5-5

Estimate of CFATS Performance and Emissions ............................... 5- 5-6

Performance and Emissions Estimates ............................................ 5-6

Identification of Design Changes to GFATS...................................... 5- $5-10$

Conclusions ................................................................................... 5 
Advanced Turbine System Market Study

- Introduction 6-1

IGCC Analysis

Summary.

\section{System Definition and Analysis}

Introduction

Plant Configuration.

ATS Engine Conceptual Design.

\section{Design and Test of Critical Components}

Background

Technology Improvements

Turbine Improvements

$8-2$

Plant Improvements

8-3

Importance of Materials.

$8-5$

General Material Requirements

$8-5$

Gas Turbine Disc Materials

8-6

Combustion System Materials

$8-7$

Gas Turbine Vane Materials

8-8

Turbine Blade Materials.

8-9

Coatings for Hot Section Components ......................................... 8-11

Combustion

8-13

Cooling.

$8-15$

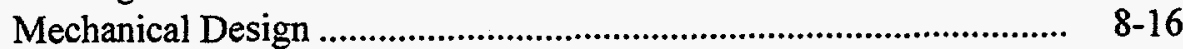

Leakage Control ....................................................................... 8-16

Design and Test Results ............................................................. 8-18

Blade Cooling ........................................................................ 8-18

Stator Cooling ....................................................................... $\quad 8-25$

Blade Materials ......................................................................... 8-27

Last Row Blade Development ................................................. 8- 8-31

Ceramics ........................................................................ 8-33

Thermal Barrier Coatings ........................................................... 8-37

Active Tip Clearance Control ..................................................... 8-45

Combustor Development ............................................................ 8-46

Combustor Noise .................................................................... 8-48

Seal Development ..................................................................... $8-54$

Diagnostics Instrumentation ...................................................... $\quad 8-60$

Forged Disc Materials............................................................... 8-63

Diffuser Design ......................................................................... 8-64

High Efficiency Compressor Design .......................................... 8-72

$9 \quad$ National Environmental Policy Act(NEPA) ................................... $9-1$ 


\section{LIST OF FIGURES}

\begin{tabular}{|c|c|c|}
\hline Figure & $\underline{\text { Title }}$ & Page \\
\hline 4-1 & 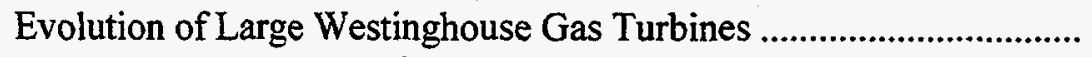 & 4-2 \\
\hline 4-2 & Selected ATS Cycle Configuration & $4-4$ \\
\hline 4-3 & High Temperature Engine Baseline Combined Cycle . & $4-6$ \\
\hline 4-4 & $\begin{array}{l}\text { Effect of Turbine Cooling and Leakage on Combined Cycle Thermal } \\
\text { Efficiency }\end{array}$ & $4-10$ \\
\hline 4-5 & Effect of Compressor Pressure Ratio on Thermal Efficiencies............. & 4-12 \\
\hline 4-6 & Effect of Compressor Intercooling on Specific Output.. & $4-13$ \\
\hline 4-7 & Effect of Compressor Intercooling on Thermal Efficiencies ................ & $4-15$ \\
\hline 4-8 & $\begin{array}{l}\text { Intercooled, Aftercooled (Evaporative), Recuperative Combined } \\
\text { Cycle }\end{array}$ & $4-17$ \\
\hline 4-9 & Thermochemical Recuperation Cycle with Steam Reforming .............. & $4-20$ \\
\hline 5-1 & 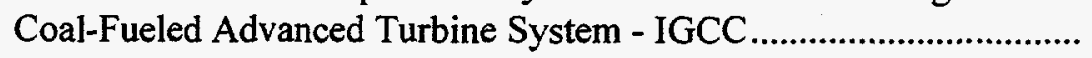 & $5-4$ \\
\hline $5-2$ & 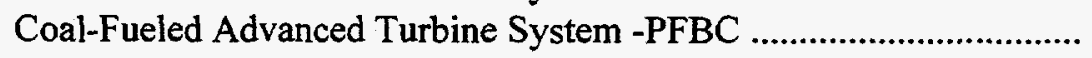 & $5-7$ \\
\hline 5-3 & 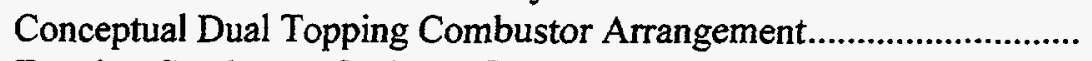 & $5-15$ \\
\hline $5-4$ & Topping Combustor Outlet to Turbine Inlet Gas Flow Concept ............ & $5-16$ \\
\hline 5-5 & Topping-PFBC Process Schematic ....... & $5-16$ \\
\hline 6-1 & 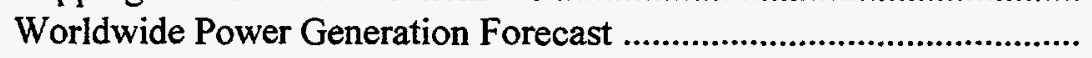 & $6-1$ \\
\hline $6-2$ & 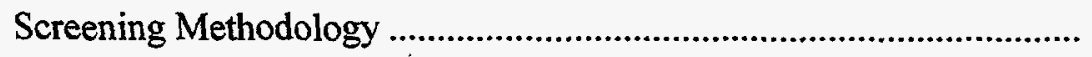 & $6-2$ \\
\hline 6-3 & ATS Cost Advantage & $6-5$ \\
\hline $6-4$ & 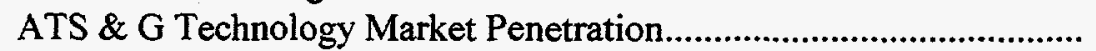 & $6-6$ \\
\hline 6-5 & 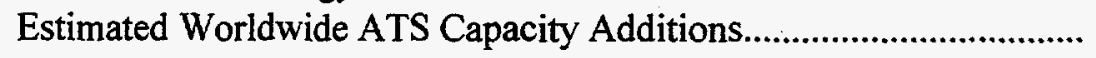 & $6-7$ \\
\hline 6-6 & 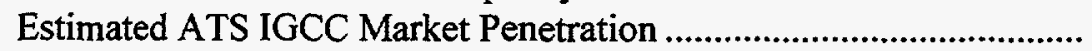 & $6-8$ \\
\hline 6-7 & 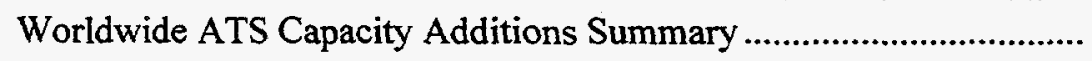 & $6-9$ \\
\hline 6-8 & ATS Market Penetration by Frame Size & $6-10$ \\
\hline $7-1$ & 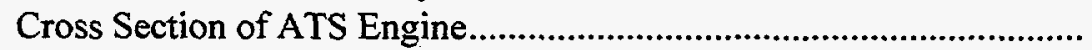 & $7-7$ \\
\hline $7-2$ & Multi -annular Swirl Combustor & $7-9$ \\
\hline $7-3$ & 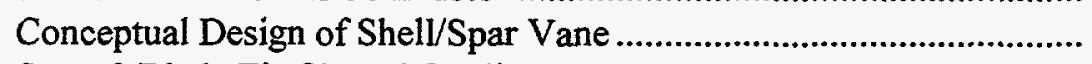 & $7-11$ \\
\hline 8-1 & 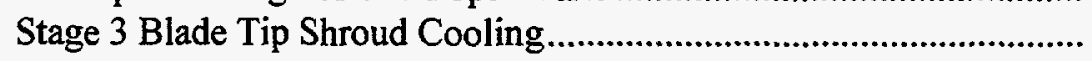 & $8-19$ \\
\hline 8-2 & Typical Serpentine Cooled Blade & $8-20$ \\
\hline 8-3 & Airfoil Cross Section of Blade & $8-21$ \\
\hline $8-4$ & 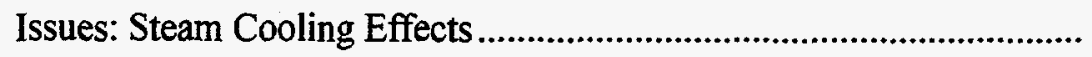 & $8-23$ \\
\hline $8-5$ & 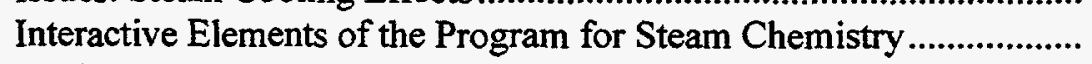 & $8-24$ \\
\hline 8-6 & Typical Vane Shroud Cooling Scheme & $8-26$ \\
\hline 8-7 & 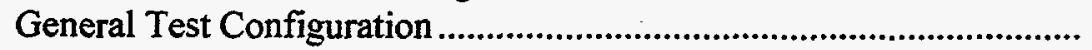 & $8-26$ \\
\hline 8-8 & CMSX-4 SC R3 Blade Casting Process Flow Chart \& Process ........... & $8-28$ \\
\hline 8-9 & Single Crystal Blade & $8-29$ \\
\hline $8-10$ & Ceramic Ring Segment Material System & $8-37$ \\
\hline 8-11 & Thermal Fatigue Life Evaluation & $8-39$ \\
\hline 8-12 & 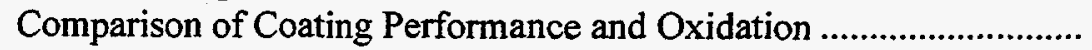 & $8-40$ \\
\hline 8-13 & Spalled APS Coating & $8-40$ \\
\hline 8-14 & HMA with APS Bond Coat & $8-41$ \\
\hline $8-15$ & New Ceramic with Improved Performance. & $8-42$ \\
\hline
\end{tabular}


Row 1 Vane

Row 1 Blades

Comparison of Simulated Pressure Signal with Actual

Combustion Fluctuation Response to Secondary Fuel Oscillations.....

High Pressure Preheated Air Test Facility

Scaled Down Test Combustor

Frequency Spectra of Oscillations Before Active Stabilization ........... 8-53

Startup Cycle for a Turbine Interstage Location

Uncoated Rotor Used in Test

Subscale Seal Design Methodology

High Speed Friction Test Rig Used in Tribological Testing............... $\quad 8-59$

First Generation Optical Probe

8-61

Second Generation Optical Probe

Two Probe CT Blade Vibration Monitor

8-63

Flow Structure on a Plane Through the Combustor Centerline ........... $\quad$ 8-65

Flow Structure on a Plane Midway Between Combustors.................... 8. 8-66

Mass Flow Distribution in the Top Hat Passage .................................. 8. 8-67

Multi-Nozzle Combustor Schematic .................................................. 8-69

Variation of Pressure Recovery Coefficient Along Pre-Diffuser......... $\quad 8$ 8-70

8-38 


\section{LIST OF TABLES}

$\underline{\text { Table }}$

5-1.

5-2

6-1

$7-1$

7-2

7-3

$7-4$

$7-5$

$7-6$

8-1

8-2

8-3

8-4

$\underline{\text { Title }}$

$\underline{\text { Page }}$

CFATS Thermal Performance ....................................................... $5-8$

CFATS Emissions Performance ..................................................... 5-11

Turbine Frame Size Preferences ...........................................................

Overall Performance of ATS Plant ................................................... $\quad 7-2$

HRSG Design Parameters ............................................................... 7-3

Fuel Gas Heater Performance Data .................................................... 7-3

Steam Piping Design Data............................................................... $\quad 7-4$

Steam Turbine Performance Parameters ......................................... $\quad 7-5$

Condenser Performance Parameters .................................................. 7-6

ATS Component Development Projects .............................................. 8-4

Qualitative Evaluation of Available CMCs for Ring Segment ............ 8-36

TBC Tests in Progress ................................................................... 8-43

Wall Pressure Recovery Coefficient at Annular Diffuser Exit ............ 8-68 


\section{LIST OF ACRONYMNS}

\begin{tabular}{|c|c|}
\hline A\&E & Architectural and Engineering \\
\hline$\overline{\mathrm{ABD}}$ & availability block diagram \\
\hline AEDC & Arnold Engineering Development Center \\
\hline APS & air plasma spray \\
\hline ASME & $\begin{array}{l}\text { American Society of Mechanical } \\
\text { Engineers }\end{array}$ \\
\hline ATS & Advanced Turbine Systems \\
\hline$\overline{\text { BOT }}$ & burner outlet temperature \\
\hline BVM & blade vibration monitor \\
\hline$\overline{\mathrm{CC}}$ & conventional casting \\
\hline$\overline{\mathrm{CDA}}$ & controlled diffusion airfoil \\
\hline CFATS & coal-fueled advanced turbine system \\
\hline$\overline{C F C C}$ & coal-fired combined cycle \\
\hline CFCCs & $\begin{array}{l}\text { continuous fiber reinforced ceramic } \\
\text { matrix composites }\end{array}$ \\
\hline$\overline{\mathrm{CFD}}$ & computational fluid dynamics \\
\hline$\overline{C L S C}$ & closed-loop steam cooling \\
\hline CMCs & ceramic matrix composites \\
\hline $\mathrm{CMU}$ & Carnegie Mellon University \\
\hline $\mathrm{CO}$ & carbon monoxide \\
\hline$\overline{\mathrm{CO}_{2}}$ & carbon dioxide \\
\hline $\mathrm{COE}$ & cost of electricity \\
\hline CVD & chemical vapor deposition \\
\hline DCFTs & direct coal-fired turbines \\
\hline$\overline{\mathrm{DLC}}$ & DuPont Lanxide Composites \\
\hline$\overline{\mathrm{DLN}}$ & dry low-NO \\
\hline$\overline{\mathrm{DOE}}$ & United States Department of Energy \\
\hline$\overline{\mathrm{DS}}$ & directionally solified \\
\hline EB-PVD & electron beam physical vapor deposition \\
\hline EGR & exhaust gas recirculation \\
\hline EH\&S & environmental safety and health \\
\hline EPRI & Electric Power Research Institute \\
\hline FBHX & fluid bed heat exchanger \\
\hline$\overline{\text { FGR }}$ & flue gas recirculation \\
\hline $\bar{G} / \mathrm{C}$ & $\begin{array}{l}\text { Gilbert/Commonwealth (now Parsons } \\
\text { Power) }\end{array}$ \\
\hline GFATS & natural-gas-fired advanced turbine system \\
\hline$\overline{G T}$ & gas turbine \\
\hline $\mathrm{HCF}$ & high cycle fatigue \\
\hline $\mathrm{HP}$ & high pressure \\
\hline HRSG & heat recovery steam generator \\
\hline HVOF & high velocity oxy fuel \\
\hline$\overline{\text { ICR }}$ & intercooled recuperative \\
\hline IGCC & integrated gasification combined cycle \\
\hline IGT & Institute for Gas Technology \\
\hline$\overline{\mathrm{IR}}$ & infrared \\
\hline ISO & International Standards Organization \\
\hline
\end{tabular}




\begin{tabular}{|c|c|}
\hline$\overline{\mathrm{Kp}}$ & oxidation rate \\
\hline KRW & $\begin{array}{l}\text { Kellog, Rust, Westinghouse fluidized bed } \\
\text { gasifier }\end{array}$ \\
\hline LCF & low cycle fatigue \\
\hline LHV & lower heating value \\
\hline LNG & Liquified Natural Gas \\
\hline $\mathrm{LP}$ & low pressure \\
\hline LPPS & low plasma spray \\
\hline MCSSB & Multiple Catalyst Swirl Stabilized Burner \\
\hline METC & Morgantown Energy Technology Center \\
\hline MTBF & mean time between failures \\
\hline MTD & Mean Temperature Difference \\
\hline MTTR & mean time to repair \\
\hline $\mathrm{MWh}$ & mega-watt hour \\
\hline NASA & $\begin{array}{l}\text { National Aeronautical and Space } \\
\text { Administration }\end{array}$ \\
\hline NASP & National Aero-Space Plane \\
\hline NDE & non-destructive evaluation \\
\hline NEC & National Energy Strategy \\
\hline NEPA & National Environmental Policy Act \\
\hline NERC & National Electricity Reliability Council \\
\hline NES & National Energy Strategy \\
\hline NIST & National Institute of Standards \\
\hline $\mathrm{NO}_{\mathrm{x}}$ & nitric oxide and nitrogen dioxide \\
\hline NPDES & $\begin{array}{l}\text { National Pollutant Discharge Elimination } \\
\text { System }\end{array}$ \\
\hline NSPS & New Source Performance Standards \\
\hline ORNL & Oak Ridge National Laboratory \\
\hline PC & pack cementation \\
\hline$\overline{\text { PC/FGD }}$ & $\begin{array}{l}\text { pulverized coal with flue gas } \\
\text { desulfurization }\end{array}$ \\
\hline PFBC & pressurized fluidized bed combustion \\
\hline PR & pressure ratio \\
\hline PVD & physical vapor deposition \\
\hline $\bar{Q}$ & Heat duty \\
\hline R\&D & Research and Development \\
\hline RAM & Reliability-Availability-Maintainability \\
\hline RBD & reliability block diagram \\
\hline RFP & Request for Proposal \\
\hline RIT & rotor inlet temperature \\
\hline $\mathrm{S} / \mathrm{T}$ & steam turbine \\
\hline $\mathrm{SC}$ & single crystal \\
\hline $\mathrm{SO}_{2}$ & sulfur dioxide \\
\hline SOW & statement of work \\
\hline STC & $\begin{array}{l}\text { Westinghouse Science and Technology } \\
\text { Center }\end{array}$ \\
\hline SwRI & Southwest Research Institute \\
\hline TAG & Technical Assessment Guide \\
\hline TBC & thermal barrier coating \\
\hline TCR & thermochemical recuperation \\
\hline
\end{tabular}




\begin{tabular}{|l|l|}
\hline TPC & total plant cost \\
\hline UA & Approximate Conductance \\
\hline UDI & Utility Data Institute \\
\hline UHC & unburned hydrocarbons \\
\hline ULE & ultra-low emission \\
\hline VPS & vapor plasma spray \\
\hline YZ & yttria-stabilized zirconia \\
\hline
\end{tabular}




\section{SECTION 1}

\section{EXECUTIVE SUMMARY}

Natural gas combustion turbines are rapidly becoming the primary technology of choice for generating electricity. At least half of the new generating capacity added in the U. S. over the next twenty years will be combustion turbine systems. The Department of Energy is cosponsoring, with Westinghouse, a program to maintain the technology lead in combustion turbine systems. The eight-year program is designed to demonstrate a highly efficient and commercially acceptable power plant, with the ability to fire a wide range of fuels. The introduction of the advanced combustion turbine systems proposed in this project, by the year 2000 , could result in energy savings equivalent to 100 million barrels of oil annually by the year 2020.

The goal of the Advanced Turbine Systems(ATS) Program is to develop an ultra-high efficiency, environmentally superior, cost competitive gas turbine system for use in the power generation market. Performance targets are centered around natural gas as a fuel and include:

- System efficiency that exceeds $60 \%$ (lower heating value basis)

- Ten percent less $\mathrm{NO}_{\mathrm{x}}$ emissions without the use of post combustion controls

- Busbar costs that are less than $10 \%$ of state of the art systems

- Reliability-Availability-Maintainability(RAM) equivalent to current systems

- Commercial systems by the year 2000

\section{CYCLE SELECTION}

Different power extraction cycles were evaluated for their potential to achieve the ATS performance targets. Various thermodynamic cycles, including thermochemical recuperation, compressor intercooling, and reheat were considered, but eliminated from consideration, in general, due to these technologies not able to support the ATS program schedule. An advanced $420 \mathrm{MW}$ combined cycle with an ATS combustion turbine and new steam turbine/generator was selected to meet the targets by the year 2000 .

The advanced combined cycle differs from state of the art combined cycle in many aspects. The firing temperature is $250^{\circ} \mathrm{F}$ higher than current production models, yielding some improvement in efficiency. Current materials and internal turbine cooling designs cannot withstand the hotter environment without damage. Better materials and different cooling design approaches are required. Reducing sealing losses also contributes to gains in efficiency. Different hot gas path 
seal designs are required to attain these gains in efficiency. Turbine inlet, exhaust and blade exit area losses can be reduced through improved design, with commensurate gains in efficiency. These changes to the state of the art combustion turbine were examined in detail. The cost of each change was compared to the worth of the incremental increase in efficiency provided by the change. Changes that demonstrated favorable economies were incorporated into the ATS engine.

\section{DESIGN IMPROVEMENTS}

The primary contributor to achieving the gains of efficiency in the advanced ATS plant came from improving the combustion turbine design. A higher efficiency generator and enhanced bottoming cycle played a minor role. The current Westinghouse production engine, the 501F, produces combined cycle efficiencies of approximately $54 \%$. The ATS plant represents a larger step in development than previous model improvements. Simultaneous advances in aerodynamic design, heat transfer and materials design are necessary to achieve the efficiency goal of greater than $60 \%$. The following design improvements to the combustion turbine were investigated:

- Advanced metal alloys

- Burner outlet temperature of greater than $2730^{\circ} \mathrm{F}$

- Closed-loop steam cooling of hot gas path components

- Single crystal and directionally solidified airfoils

- Improved thermal barrier coatings

- Improved anti-corrosion materials

- Ceramic ring materials

- Active tip clearance control

- Brush seals in critical locations

- Reduced compressor dump/combustor loss

- Increased row 4 blade exit area for reduced losses

The following plant improvements were investigated:

- Reduced inlet and outlet losses

- Fuel preheating 
- Single shaft combustion turbine, generator and steam turbine

- Advanced steam turbine technology

- Steam turbine conditions of $1800 \mathrm{psi}, 1050^{\circ} \mathrm{F}$ steam

The burner outlet temperature is designed for a range between $2730^{\circ}$ and $2800^{\circ} \mathrm{F}$. This range allows a high cycle efficiency without producing excess $\mathrm{NO}_{\mathrm{x}}$. Catalytically enhanced combustor components are employed to attain low $\mathrm{NO}_{\mathrm{x}}$ emissions at high burner outlet temperatures.

Closed-loop steam cooling is employed on hot end components(i.e., transitions, row 1 to row 3 vanes, row 1 and 2 blades, and certain blade rings). Elimination of cooling air contributed to efficiency improvement in four ways. First, the cooling air is no longer ejected in the flowpath, disrupting the flow field. Second, the cooling air itself reduces the temperature of the gas, making less heat available to do work. Third, the air must be compressed to a higher pressure than the gas path, robbing work that could be used for power generation. Last, the air creates irreversible pressure losses due to nonideal mixing of the air and hot gas.

Materials and related manufacturing technologies played a pivotal role in engine efficiency improvements. Higher temperature tolerance with superior mechanical properties are required for the ATS engine.

Turbine discs attach the turbine blading to the rotating rotor. The disc is subjected to high centrifugal stresses from the blades. Current disc materials will not have the strength capabilities at the expected higher temperatures. Superalloys, including $\mathbb{N}-718$, Udimet 729 and Waspalloy are the materials slated to replace the low alloy steels used as turbine disc material in current engines. Test materials were forged and machined. The finished test specimens were evaluated for their mechanical properties and compared to ATS specifications. Results from the comparisons appear favorable.

The combustion system consists of baskets, where the fuel and air is mixed and burned; and transitions, where the hot gases are directed to the first stage vanes. Sheet metal nickel and cobalt alloys are used in current production components. These materials are adequate for high temperature strength, but possess inadequate corrosion/oxidation resistance. The higher firing temperature produces distress in these materials and thermal barrier coatings are required to protect the base material. Westinghouse has successfully tested several thermal barrier coatings and have selected a coating system for use on the ATS engine. The use of ceramic baskets and transitions appear to be ideal. However, little design data for the ATS conditions exists for these materials. However, a laminated ceramic ring segment design was implemented. The experience gained from the development of the ring segments serves as a stepping stone toward the design of larger and more complex ceramic combustors and transitions.

Combustor basket flows are complex and are especially critical in dry ultra low $\mathrm{NO}_{\mathrm{x}}$ lean premix designs. These combustors rely upon uniform fuel/air ratios, within a narrow tolerance band, for low $\mathrm{NO}_{\mathbf{x}}$ production and operational flame stability. Flow mapping and visualization tests were performed on half scale models. The effects from struts, cooling air bleed ports, cooling air 
return piping, diffuser exit swirl, by-pass valve modulation, top hat length and other parameters revealed design deficiencies that resulted in modifications. The required flow area for exhaust gas recirculation was also established.

Turbine vanes serve to direct the flow of hot gases toward the rotating blades. Conventional vanes employ nickel or cobalt based alloys using conventional cast processes. Directionally solidified material is used selectively in the newest Westinghouse engine, the $501 \mathrm{G}$. The selection of vane material is dependent upon the cooling scheme and the temperature/stress relationship of each row. Preliminary design analysis favors nickel based alloys, such as IN-939, due to it's high strength and desirable corrosion resistance. However, slight modifications to alloying elements may be required to improve weldability. Final vane material selection will occur in Phase 3.

Production turbine blades are typically made from conventional cast(CC) nickel based superalloys, such as $\mathrm{IN}-738$. These alloys are limited to a high temperature of $1700^{\circ} \mathrm{F}$, due to creep stress. The higher temperature requirements for the ATS engine front row blades precludes the use of IN-738. CMSX-4 SC and CM247LC DS alloys have been used extensively in aero engine applications. These alloys were selected for ATS because they represent the most advanced single crystal(SC) and directionally solidified(DS) alloys commercially available and possess adequate mechanical properties for the high temperature conditions. However, grain structure control, chemical segregation and property uniformity have not been verified for large sized turbine blades. CM247LC CC material was evaluated for later stage applications, where temperatures are lower. As with vane material, the final blade material selection is dependent upon the cooling scheme employed and the temperature/stress relationship of each row. Final material selection will occur in Phase 3.

Cobalt and nickel based alloys possess superior high temperature strength, but exhibit poor oxidation resistance. Protective surface coatings are essential for these alloys to prevent oxidation resistance and improve durabilty and reliability. A development program for improving MCrAlY type overlay coatings beyond their current capability of $1650^{\circ} \mathrm{F}$ surface metal temperature has yielded some promising results. Testing in commercial engines is still in progress.

Thermal barrier coatings(TBC) are used to lower the substrate and the oxidation protective coating temperatures. TBC materials are typically yttria-stabilized zirconia(YSZ). The current method of application, air plasma spray(APS), was developed by Westinghouse in the 1970s. An improved method of application, electron beam vapor deposition(EB-PVD), was tried with promising results. EB-PVD offers more uniform coating thickness, minimized cooling hole blockage, and improved surface finish over the APS process. Field testing of APS and EB-PVD blades was conducted. Operation in commercial engines with over 16,000 hours of service showed that EB-PVD coated components survived mostly unharmed. The testing was performed in lower temperature commercial engines and further testing in hotter ATS engine temperatures is required before commercial deployment. 
Closed-loop steam cooling was employed on hot end components, resulting in the largest single improvement in operating efficiency. Different cooling schemes were employed for each stage and component type. Cooling of the stage 3 tip shroud was provided by a separate cooling passage through the blade. Complex multipass serpentine cooling passages were employed for stage 2 blading. A novel thin wall casting approach was used for row 1 blades. A peripherally fed, inward flowing pin-fin pedestal array has been selected for row 1 vane shrouds. Detailed design for these components has been completed for most of these items. Subsequent work will be continued toward manufacture of these components.

As steam passes through narrow cooling passages, impurities in steam can deposit at various locations in the system. Corrosion can erode critical thin walls, causing leaks in rotating components. A test rig was designed to determine the level of tolerance for impurities. Results from the testing will be reported in Phase 3 .

The cycle calculations determined a pressure ratio of 25:1 was required for the ATS engine. The design philosophy is based upon the advanced Westinghouse $501 \mathrm{G}$ engine, but with additional design enhancements, such as brush seals to minimize leakage under stator shrouds. Advanced aerodynamic design tools and controlled diffusion design processes are employed to minimize losses in the compressor and maximize airfoil loading. Design improvements to the compressor are expected to yield an overall design stage efficiency in excess of $91 \%$.

Two diagnostic instruments were developed to measure the performance of critical parameters. An optical probe was developed to allow measurement inside combustor baskets without disturbing the flow. The probe uses laser induced fluorescence measurement techniques. The probe was successfully tested at atmospheric pressure and high temperature. Based upon the success of the steam turbine blade vibration monitor, an equivalent model for use in high temperature combustion turbine environments was developed. An infrared sensor with a two probe sapphire lens was successfully tested at a customer site. A sixteen probe version of the monitor is available for use in the ATS engine when it becomes operational.

Brush seals were installed wherever labyrinth seals were used for a significant reduction in leakage. Applying brush seals is attractive because the turbine runs at essentially constant speed, without radial clearance excursions common when speeds change. Industrial turbines also encounter fewer transient closure cycles than their aero counterparts, prolonging seal life. Test results show brush seals would be beneficial in the turbine interstage locations. Other locations, including compressor diaphragm, turbine rim and turbine front seals appear promising. Representative results indicate incorporating brush seals would improve plant efficiency by onesixth to one-fourth of a point, depending upon location and increase power output.

Within Phase 2, an advanced combustion turbine engine was designed using advanced materials, improved design measures and higher operating temperatures. These elements were incorporated into the engine while lowering plant costs, improving operating efficiency and reducing emissions. The ATS plant costs less than current production plants and should find ready acceptance in the marketplace, once available. 
Many of the improved design measures were tested on a limited basis without the benefit of system integration into the engine. Phase 3 of the ATS program will provide demonstration of this technology.

\section{COAL-FUELED ATS}

Two coal-fueled power plant technologies were selected to power ATS-air-blown, integrated gasification combined cycle and second generation pressurized fluidized bed combustion. Both concepts are being demonstrated in major Clean Coal Technology Programs. The coal-fired ATS plants rely upon gas turbine combustors, which burn hot, low BTU coal derived fuel gas, and turbine expanders that operate effectively on combustion products cleaned at high temperatures. The differences between the two coal technologies in its adaptation to ATS is the fraction of air removed from the turbine case for coal processing and the location of the combustors. Additional development work required to retrofit ATS to coal fuels include the design of a low-BTU, low emission, fuel gas combustor; combustor outlet manifolding and turbine inlet scroll; designs to mitigate corrosion/deposition; and material selection. Preliminary calculations show that coal fired ATS plants can achieve efficiencies in the range of 52 to $54 \%$.

\section{MARKET ANALYSIS}

The gas turbine combined cycle market represents the greatest opportunity for the ATS plant. The smallest ATS frame, 100-150 MW, will be most attractive for the simple cycle market. After market introduction, ATS is expected to follow a typical S-shaped market penetration. The baseline market forecast for the total ATS market potential is estimated to exceed $93 \mathrm{GW}$ in the time frame of 2000-2014. The combined market for ATS-based technology could reach $12 \mathrm{GW}$ per year by the year 2014 , representing roughly $10 \%$ market share relative to the total global market.

The coal-fueled integrated gasification combined cycle, combined with ATS, will not become available until after 2005. After market introduction, integrated gasification appears to offer the lowest cost electricity generation for most regions where capacity factors are above $65 \%-75 \%$.

\section{CONCEPTUAL PLANT DESIGN}

In addition to the ATS hardware development, specifications for the remaining plant equipment were written during the Phase 2 program. A site arrangement and electrical one-line diagrams were drafted for the conceptual natural gas-fired ATS plant. The plant design incorporates proven flexible design features that minimize design changes usually required to tailor a plant to site constraints. 
The combustion turbine exhaust gases will pass through a three pressure level heat recovery steam generator before exhausting out the stack. The steam system is a triple pressure unit with vacuum deaeration that allows the addition of duct firing at a later date. Materials are commercial grade commonly used in today's boilers.

The steam turbine utilizes a single reheat cycle. Steam exhaust flow necessitates the use of a double-flow LP exhaust. The combustion turbine, steam turbine and generator are on a single shaft. Both turbines share a common hydrogen cooled generator.

\section{NATIONAL ENERGY POLICY ACT}

To support the work within Phase 2, a description of the environmental, safety, and health information was provided by each subcontractor to enable DOE to prepare the appropriate documentation for the project. This information included a brief description of the project, a discussion of the environmental characteristics of all sites and any potential environmental impact form the project, a discussion of the impact from the seven criteria pollutants in the Clean Air Act, impact to surface and ground water, a description of the use of land for the project, a site waste management plan, noise generation, information regarding archaeological, cultural, and historical resources that maybe effected and plans to protect worker safety and health. Future work in Phase 3 of this program will address the permitting documents required for the ATS demonstration site. 


\section{SECTION 2}

\section{INTRODUCTION}

\section{BACKGROUND}

The National Energy Strategy (NES) calls for a balanced program of greater energy efficiency, use of alternative fuels, and the environmentally responsible development of all U.S. energy resources. Consistent with the NES, a Department of Energy (DOE) program has been created to develop Advanced Turbine Systems (ATS). The technical ATS requirements are based upon two workshops held in Greenville, SC that were sponsored by DOE and hosted by Clemson University. The objective of this 8-year program, managed jointly by DOE's Office of Fossil Energy, and, Office of Conservation and Renewable Energy, is to develop natural-gas-fired base load power plants that will have cycle efficiencies greater than $60 \%$, lower heating value (LHV), be environmentally superior to current technology, and also be cost competitive. The program will include work to transfer advanced technology to the coal-and biomass-fueled systems being developed in other DOE programs.

The Advanced Turbine systems program is structured into four elements:

- Innovative Cycle Studies

- Utility Advanced Turbine Systems

- Industrial Advanced Turbine Systems

- Technology Base

Within each program element there are several planned phases. For example, the Innovative Cycle Studies element includes two phases.

- Program Definition/Planning Studies

- Concept Development

\section{PROGRAM OBJECTIVES - PHASE 2}

The objective of the ATS Program is to develop ultra-high efficiency, environmentallysuperior, and cost-competitive gas turbine systems for base-load application in utility, independent power producer, and industrial markets. Specific performance targets have been set using natural gas as the primary fuel:

- System efficiency that will exceed $60 \%$ [lower heating value basis (LHV)] on natural gas for large-scale utility turbine systems; for industrial applications, systems that will 
result in a $15 \%$ improvement in heat rate compared to currently available gas turbine systems.

- An environmentally superior system that will not require use of post-combustion emissions controls under full-load operating conditions.

- Busbar energy costs that are $10 \%$ less than current state-of-the-art turbine systems, while meeting the same environmental requirements.

- Fuel-flexible designs that will operate on natural gas but are also capable of being adapted to operate on coal, coal-derived, or biomass fuels.

- Reliability-Availability-Maintainability (RAM) that is equivalent to the current turbine systems.

- Water consumption minimized to levels consistent with cost and efficiency goals.

- Commercial systems that will enter the market in the year 2000 . 


\section{SECTION 3}

\section{STATEMENT OF WORK}

This section describes the work that was performed under the Phase 2 ATS program. The individual task descriptions that follow are a cumulative summary of all current tasks. Sections 4 through 9 provide details regarding the results of the work completed.

\section{TASK 1.0 PROJECT PLAN}

The purpose of this task is to define the plan to accomplish the work as defined in the Request for Proposal(RFP) Statement of Work(SOW), Tasks 2 through 8.

\section{Task 1.1 Develop Project Plan}

A project plan was developed by the Westinghouse Team that describe how the Phase II SOW will be accomplished as well as how the project will be controlled to ensure all work is done in accordance with requirements as described in the Management Plan. The plan, the first submittal dated October 1,1993, included a summary of the project, its objectives and the interrelationships among the major tasks to be performed in Phase II. The project organization, how the project will be managed, and the management systems used to control the project was identified. A Program Work Plan was developed as part of the project plan. The Program Work Plan presented the work breakdown structure and the SOW to the levels necessary to provide cost, schedule and technical control of the project. The technical approach to the SOW addressed a combination of innovative changes in the thermodynamic cycle, high temperature developments and gas turbine improvements, that together will achieve an ATS of greater than $60 \%$ cycle efficiency. Improvements were addressed in parallel to ensure that all system and engine changes and the conversion from natural gas to a coal-fueled system are all compatible. Barrier issues were identified along with their resolutions as the work progressed. The Program Work Plan described the technical approach, the task work, responsibilities, and deliverables for each task. Task work described for the selection and conceptual design of the Gas Fired Advanced Turbine System(GFATS) will identify the parametric as well as trade-off studies that will be done. Reliability, availability and maintainability, along with emissions and environmental compliance of the GFATS system were addressed in the work plan.

A revised program schedule was developed using project management software from which the programs performance was measured, reported and controlled. The schedule included major milestones and decision points. A cost plan was also prepared that established the basis for measurement of actual cost accumulation against planned costs and provides information for updating and forecasting budget requirements. 


\section{Task 1.2 Program Management}

The Westinghouse Program Manager and his subcontractor counterparts monitored project performance and cost to ensure compliance with the project objectives and adherence to cost estimates. The Westinghouse Program Manager was the primary interface with the customer. The subcontract lead personnel interfaced with the Deputy Program Manager on day-to-day matters pertaining to the execution of the contract.

As required, Westinghouse presented a technical paper at the DOE/METC Heat Engines Contractors' Review Meeting and at one other technical conference or symposium each year during the duration of this contract.

\section{TASK 2.0 INFORMATION REQUIRED FOR NATIONAL ENVIRONMENTAL POLICY ACT (NEPA)}

The purpose of this task is to supply DOE/ METC with the information required to prepare documentation in accordance with NEPA for the work performed under Task 8.

\section{$\underline{\text { Task 2.1 Environmental Information }}$}

A topical report was prepared and submitted to DOE within 120 days after contract award. The report included the following:

A brief description of the project was provided which included project goals, a summary schedule, a summary of the development/test plans for Task 8 , locations of tests that were conducted, along with a description of the facilities and equipment to be used in conducting the tests. A discussion was provided for the type and quantities of materials used; feedstocks, utilities, effluents, unrecovered material, and solid wastes.

For each proposed test site, current environmental characteristics and any potential environmental impacts were developed and evaluated. Information on environmental impacts included data for minimum, maximum and average values and encompass the following: air quality, water resources, land use, waste management, ecological impacts, socioeconomic impacts, archaeological, cultural and historical resources, noise, occupational safety and health and cumulative impacts.

In the topical report for each test site, all federal, state and local permits and licenses required for the project were explained. The explanation provided information on the permitting and licensing schedule and the status of each permit and license. Included in, or accompanying the explanation was discussion on the allowable releases of solid, liquid, and air pollutants under the respective permits and licenses. A list of all agencies and persons contacted to collect information on the environmental, health and safety (EH\&S) aspects of the project was provided. The list included the addresses and phone numbers of all contacts. 


\section{Task 3.0 SELECTION OF NATURAL-GAS-FIRED ADVANCED TURBINE SYSTEM (GFATS)}

The purpose of this task is to analyze and evaluate the six to eight cycles and high temperature components within the intercooled recuperative (ICR) reference system identified in the Westinghouse ATS Phase I Program. Once the candidate system configurations have been analyzed and evaluated, the most favorable system configuration from an efficiency and economic standpoint will be selected for development. In addition, those components/materials and systems determined to be critical to the successful development of the ATS will be identified as R\&D programs needed to initiate in Task 8.

\section{Task 3.1 Analyze Cycle Developments}

All potential components of the ICR cycle will be analyzed and defined with respect to maximizing effectiveness of the component and minimizing pressure drop or other losses. The following components were defined for evaluation:

Inlet Cooler: Reduction of low pressure(LP) compressor inlet temperature by evaporative cooling or chilling was investigated from a cooling effectiveness vs. energy input perspective.

Intercooler(s): Compression work is reduced when air temperature is decreased, therefore, the optimum number of cooling steps must be determined. Surface cooler(s) will be quantified in terms of effectiveness vs. pressure loss; evaporative cooling effectiveness vs. pressure loss and water separation and utilization will be addressed; and continuous (stage-by-stage) evaporative cooling potential vs. momentum mixing loss penalties were defined.

Recuperator: Recuperation of the turbine exhaust heat may be accomplished by: surface heat exchange between hot and cold air streams with effectiveness (90 to $96 \%$ ) vs. hot and cold side pressure losses ( 4 to $1 \%$ ) and cost having to be defined; evaporative plus surface heat transfer with water concentration capability vs. air side pressure losses being defined; and chemical recuperation where exhaust heat is reclaimed through the reformation of methane into $\mathrm{H}_{2}$ plus $\mathrm{CO}$ and the products burned in the turbine, with conversion performance having to be defined in terms of flows, temperatures and conversion efficiency.

Aftercooler: By saturating the air stream leaving the high pressure(HP) compressor more heat can be extracted from the combustion turbine exhaust in the recuperator; evaporative aftercooler effectiveness vs. pressure drop was defined.

Closed-Loop Steam Cooling: Reduction of cooling air flowing into the turbine gas path will increase turbine exhaust temperature, recuperative heat recovery and combined cycle efficiency. Using steam from the bottoming cycle, superheating it in the walls of stationary hot end components, and expanding the steam through the steam turbine will 
raise efficiency, thus a procedure for cooling, and a quantification of the potential gain/complexity for each of the components is required. Extending this concept to rotating blades was reviewed.

Bottoming Cycle: Maximum possible conversion of gas turbine recuperator exhaust heat to electricity must be defined using an expected year 2000 state-of-the-art bottoming cycle. A cycle using a single level or multi-level system may be specified. To recover a large portion of the latent heat of vaporization drawn from the cycle in the various evaporative options, a condensing economizer must form part of the bottoming cycle. A multi-component bottoming cycle will be investigated and its energy conversion efficiency defined.

Compressor(s): In conjunction with intercooling, the number of compressors will be defined. For each compressor the efficiency must be defined as a function of pressure ratio, and inlet temperature and flow, considering that variable vane geometry may be used. Maximum attainable efficiency using advanced computational fluid dynamics design techniques, and tight tip clearance control will be estimated.

Combustors: The effect of various dry air/moisture mixes on emissions in alternative premix lean burn systems will be considered. Overall pressure loss in the various configurations will be examined. To overcome the pressure loss penalty associated with flow through the combustion system a pressure gain pulse combustor will be defined for potential pressure gain.

Transitions: Elimination of cooling air by use of thermal barrier/ceramic coatings will eliminate or reduce momentum mixing losses and thus improve expansion potential throughout the turbine. Minimization of heat flux across the transition walls to reduce temperature pickup of compressor delivery air will be investigated.

Turbine Blade Path: Gas path efficiency as a function of cooling technology, overall loading and allowable stressing must be estimated using meantime aerodynamic analysis. Clearance control and tip treatment techniques will also be studied and their contributions to turbine efficiency estimated.

Sealing/Leakage: Leakage of air between stationary and rotating gas path components in both the compression and expansion processes, between recuperator supply and return, and from gas path to atmosphere must be minimized by use of better sealing. All opportunities for leakage reduction must be investigated, advanced sealing systems specified, and anticipated reduction in leakage quantified.

Task 3.2 Analyze High Temperature Developments

To achieve ATS efficiencies of $>60 \%$, the rotor inlet temperature (RIT) should increase from current levels to $\approx 2650^{\circ} \mathrm{F}$. Minimizing cooling air consumption and maximizing 
material capabilities will require continued development. The following components and material systems are being addressed for higher operating temperatures:

Combustor: To maintain allowable combustor metal temperatures, significant cooling air must be used. Reduction in cooling air through more efficient cooling will free air for further dilution in the lean-burn combustors and thus enhance emissions reduction. If more effective cooling could be achieved with a low pressure drop, higher cycle efficiency will result. Therefore cooling technique improvements must be studied and quantified.

Transition: Metal cooling through thermal barrier/ceramic coatings rather than air, will be specified and heat flux reductions investigated.

Discs: High strength ferritic steel discs must be maintained at $<800^{\circ} \mathrm{F}$ through the use of cooling air. More effective use of cooling air through better rim sealing and leakage treatment will be studied and quantified.

Airfoils: If closed steam loop cooling cannot be implemented, reduction in aerofoil (vane or blade) cooling quantities through more effective cooling techniques and/or thermal barrier coatings will be investigated and results quantified.

Cooling Air Supply System: Minimization of supply system leakage through design changes and innovative sealing will be assessed, and the reduction in net cooling air requirements established. Modulation of flow through computer controlled valves will eliminate excess cooling in off-design conditions.

Materials: Hot end materials (generally cast cobalt and nickel based alloys) are chosen to meet steady and alternating stress and temperature requirements specific to each row of stationary and rotating blades. Increasing RIT, and decreasing cooling air fraction necessitate the attainment of the same life requirements, but at higher metal temperatures. For each row, the increase in metal temperature which can be achieved by changing from conventional cast alloys to either of: 1) improved conventionally cast alloy, 2) directionally solidified, 3) single crystal, 4) intermetallics, and 5) ceramics, must be investigated and quantified. With this information cooling air reductions can be determined and the effects on performance calculated.

Coatings: Coatings are required in the hot end to protect the alloy from oxidation (both externally and internally) and from hot corrosion. Advances in the temperature capability of alloys are often limited by the coating's ability to survive for a minimum of 24,000 hours. Thus coating technology advances must be investigated in conjunction with material properties to determine coating/substrate operating potential. Thermal barrier/ceramic type coatings have the potential to greatly restrict heat flux into the aerofoil, therefore, in combination with bond coats and oxidation protection, should allow significant cooling air reduction and/or material temperature increase. Quantification of the increased high temperature capability of each row is to be determined. 


\section{Subtask 3.3 Evaluate Candidate System(s)}

Westinghouse developed a complete advanced turbine system performance model, connecting all components through continuity of flow, pressure, and temperature, and considering heat flux, phase change, power absorption or production, and mixture chemical composition. Accurate component models, giving realistic performance characteristics, are key to the system evaluation. At the anticipated best possible performance of each component in the year 2000, cycle pressure ratios (PR) with various component combinations will be optimized to determine the most effective configuration. Starting with the final PR, progressive improvements will be back tracked to establish an anticipated chronology of LHV efficiency improvement vs. component implementation. The evaluation will cover the complete ambient temperature and load ranges.

Westinghouse evaluated costs accompanying component performances and, then integrate the results into the optimum ATS integration to arrive at anticipated plant operational cost relationships. Components dominating the cost function were evaluated to compare cost to thermal performance (while still maintaining $>60 \%$ cycle efficiency).

Westinghouse evaluated the reliability, availability and maintainability (RAM) factors for the candidate system(s) using as a reference the current 501D5 and 501F engines.

Improvements or decrements in each component's RAM was statistically analyzed in an overall plant model.

The anticipated emissions (NOx, $\mathrm{CO}, \mathrm{UHC}$ ) from the candidate configurations was evaluated by Westinghouse for compliance with project goals. The impact of water consumption, bottoming cycle heat rejection and noise was also be addressed.

The adaptability of the candidate system to coal-derived fuel with its associated lower Btu content was reviewed by Westinghouse. Minimal hot gas path changes, practical combustor shell region changes, and low cost compressor(s) adaptability was the target.

All the above features, plus intangibles such as familiarity, historical precedent, product support and externalities was examined with regards to marketability of the ATS.

\section{Task 3.4 Identify Critical Components and Barrier Issues}

Westinghouse Power Generation (Orlando) identified those components critical to the success of the selected ATS, yet which have uncertainty associated with them, or which cannot be designed/specified from the existing knowledge base.

\section{Task 4.0 CONVERSION TO A COAL-FUELED ADVANCED TURBINE SYSTEM (CFATS)}

The purpose of this task is to determine the technical development needs for the conversion of the GFATS to a CFATS. A development program was devised for a selected, 
reference CFATS, with estimated performance and emissions on the basis of the major development issues identified.

Task 4.1 Selection of Coal-Fired Plant Reference System

A brief effort was expended to select a reference CFATS to act as the basis for this task. Westinghouse utilized its background in advanced coal-fueled power generation to provide the information needed.

Westinghouse prepared an evaluation of estimated, relative power generation thermodynamic performance, relative environmental performance, relative cost, status of technology, and relative market potential to provide a ranking of these competing technologies. The power plant concept projected to be most marketable after 2005 will be selected as the reference CFATS.

\section{Task 4.2 Estimate of CFATS Performance and Emissions}

Task Description: The selected CFATS will be described in sufficient detail to provide information that can be used to identify GFATS to CFATS conversion issues.

Westinghouse, with inputs from Carnegie-Mellon University, developed estimates for the reference CFATS thermodynamic efficiency, turbine tolerance factors (expansion gas particle loading and particle size distribution, expansion gas alkali vapor content), turbine maintenance (blade replacement and cleaning frequency), and environmental emissions (particulates, $\mathrm{NO}_{\mathrm{X}}, \mathrm{CO}, \mathrm{SO}_{2}, \mathrm{CO}_{2}$ ).

\section{Task 4.3 Identification of Design Changes to GFATS}

Westinghouse Science \& Technology Division, with inputs from CMU, performed a review of the following aspects of the CFATS:

- Combustor

- Air Compressor

- Turbine Aerofoil Geometry

- Connecting Piping

- Valving and Control

- Design Integration

The review activity produced a list of the key issues involved in modifying the GFATS to coal. 


\section{Subtask 4.4 CFATS Development Requirements}

The CFATS issues identified in Task 4.3 can be resolved by engineering design activities and/or by sub-scale test activities. The experimental and engineering activities required for each set of issues was determined by Westinghouse, with inputs from Carnegie Mellon University, and outlined as the minimum activity scope. These activities were organized within a development program framework. The activity schedules and cost were compiled based on past, similar turbine development efforts.

\section{Task 5.0 MARKET STUDY}

The market study focused on assessing the relative attractiveness of natural-gas-fired high efficiency, gas turbine based, power plants against competing sources of power among a variety of customer classes, market segments, and geographic regions within the United States.

\section{Task 5.1 Conduct Market Study}

The primary driver in determining the attractiveness of a particular generation technology is an analysis of its cost competitiveness over the life-cycle of the plant, compared with other technologies for the range of capacity factors (duty cycle) at which the plant is likely to operate. A screening curve analysis, prepared by Westinghouse, was used to make these evaluations. The screening curves plot the levelized cost of electricity in $\$ / \mathrm{kW}$-yr against capacity factors. Curves for the advanced high efficiency gas turbine plants were developed and compared to those curves which represent alternative technologies.

Environmental externality costs were evaluated. Theoretical emissions levels $\left(\mathrm{NO}_{\mathrm{X}}, \mathrm{CO}\right.$ and UHC) were provided to test against current and forecasted externality penalties imposed by federal and state governments were incorporated into the competitive economic analysis.

The screening curve analysis was conducted on a regional basis. Fuel availability and price, siting issues, load growth, load factor, etc. vary on a regional basis.

Overall demand for the new ATS based technologies will depend on an overall forecast of required new capacity additions predicated on a forecasted overall load growth rate, a projection of the number of plant retirements, intergrid diversity exchange, target utility reserves margins, load factors, and other macro considerations. These variables were also be forecasted, on a regional basis.

An estimate of optimal plant size was provided, based on regional load growth rates and target reserve margins. Comparisons on expected plant availability (reliability considerations) was compared with alternative technologies and will influence the competitive evaluation. 
The success of the initial market entry for any new technology depends upon the likelihood of early adoption for the new reference plant types to be designed. To identify early market opportunities for those regions where the screening curve analysis demonstrates an economic benefit, a telephone survey was conducted with utilities and non-utility developers to uncover those companies that would likely become early adopters of the new technology. Again, the regional generation forecast to be conducted pinpointed the geographical areas in most need of new power which provided focus to the survey conducted.

\section{Task 6.0 SYSTEM DEFINITION AND ANALYSIS}

The GFATS selected in Task 3 was analyzed and trade-off studies done to conceptually define and specify all components in the cycle.

Task 6.1 Gas Turbine Flange to Flange Conceptual Design

A conceptual design of all the gas turbine components and systems was conducted and documented by Westinghouse. Included in the design were: the advanced compressor with emphasis on aerodynamic efficiency improvements using computational fluid dynamics (CFD) techniques; clearance and leakage control using innovative sealing technology; casings designed for minimum inlet scroll disturbances and pressure loss while maintaining concentricity with the shaft and circularity; and shaft and bearings designed for minimum losses.

A new combustion system was needed to achieve the target emissions levels. Several ultra low emission (ULE) systems were pursued by Westinghouse and one of these will be chosen for the ATS engine.

Transitions will be designed to minimize the amount of cooling steam needed to keep the transition material within limits.

Turbine section components were designed to operate at higher temperatures and with lower losses. Vanes and blades emphasized materials and coatings, advanced 3-D aerodynamics, advanced cooling techniques, leakage control, and the use of closed-loop steam cooling.

Mechanical/stress analysis of all components, considering steady state and transients, was conducted to the extent necessary to ensure that sizes and material capabilities are adequate and that the severe thermal gradients accompanying full load trips can be taken by the proposed components. Rotor dynamics analysis was performed in sufficient detail to configure the number, and location of bearings and to determine that the rotor natural frequencies meet design criteria. 


\section{Task 6.2 Power Plant Equipment}

The power plant equipment, as determined in Task 3, was conceptually designed or specified.

The inlet system must prevent ingestion of airborne contaminants. A very high separation efficiency, low pressure loss filtration system will be specified to maximize retention of engine performance. A compressor cleaning system, which is effective in removing airfoil deposits, was integrated into the inlet scroll system. An inlet silencer with minimum pressure loss penalty was also be specified.

The gas turbine exhaust system was designed to diffuse the engine exhaust to the much greater face area of the Heat Recovery Steam Generator (HRSG). Exhaust ducting will redirect, decelerate and uniformly spread exhaust gas over the entire HRSG face in order to provide good flow uniformity, minimal pressure loss and no temperature loss.

The lube oil system, starting system, switchgear, and the control system was designed/specified with minimum power consumption pumps, motors, power supplies and similar equipment.

\section{Task 6.3 Balance of Plant Equipment}

Task Description: The balance of plant equipment includes the HRSG, steam turbine and the associated auxiliaries. A high efficiency steam turbine was specified by Westinghouse, based on technology anticipated to be commercially available in the year 2000. The HRSG was conceptually designed to extract the maximum possible thermal energy from the heat rejected by the engine. The HRSG will be three pressure levels, or a once through design.

\section{Task 6.4 Plant Definition}

Mechanical equipment conceptual design for plant systems, such as plant piping, plant auxiliary systems, controls and instrumentation, accessory electric plant, buildings, structures and site modifications, was completed.

Conceptual engineering calculations and sketches were made by Gilbert/ Commonwealth for the civil and structural design of the demonstration plant. Assumptions were made regarding building code requirements, area subsoil/rock conditions, building materials, and civil engineering features to provide direction for final plant design and allow for valid cost estimation.

Preliminary electrical power loads (such as motors) and the location of these loads served as the basis for developing an electrical single-line diagram, including preliminary transformer sizes, voltage levels, switchgear and motor control center sizes and location. Analysis of the power system was aided by the use of computer programs for load flow, voltage drop and short circuit. Design criteria was established for all of the systems 
associated with the electrical design, such as: power, lighting, communications, grounding, cathodic protection, emergency power, uninterruptible power supplies, dc systems, heat tracing, protective relaying, raceway systems, wire, and cable. A plant control system was developed to outline the general control philosophy and equipment intended to be used.

A conceptual plant layout was developed with three drawings being generated: site isometric, equipment arrangement, and site arrangement drawings.

\section{Task 6.5 Plant Evaluation}

ATS plant cost estimates was prepared by Westinghouse, using direct cost estimates representing the total plant scope, supplemented with allowances for indirect costs and process and project contingencies to arrive at a total plant cost (TPC). Total plant investment and total capital requirement values was determined, based on the TPC. Capital cost targets for the major items of equipment was established to determine the limiting costs for developmental items needed to achieve the target cost of electricity (COE). Operation and maintenance costs was also determined for the ATS. The COE was determined by an existing model based on EPRI Technical Assessment Guide (TAG) procedures.

Overall system performance was estimated, once system components were optimized from an efficiency and cost achievable standpoint. Emissions were estimated, based on the systems overall configuration and the type of combustion system selected. Expected improvement to be achieved through further R\&D was taken into consideration.

To estimate the ATS RAM, a quantitative analysis in the form of a Reliability Block Diagram (RBD) was performed. The RBD or Availability Block Diagram (ABD) is a quantitative reliability model of the system. Using data on mean time between failures (MTBF) and mean time to repair (MTTR) for the components, either the system reliability for a specified mission time or steady state availability can be calculated from the model. The design of the GFATS is a series of reliability models; each component in the stream must operate for the system to be functional. The reliability or availability of the system in such a case is the product of the reliabilities or availabilities of all the components. Since the facility has several modes of operation, an RBD was constructed for each mode and the models quantified.

\section{Task 7.0 INTEGRATED PROGRAM PLAN}

The Integrated Program Plan described the research and development program that, when completed, will lead to the commercialization of an ATS meeting program goals.

\section{Task 7.1 R\&D Plans for Critical Components/Barrier Issues}

In order to achieve higher operating temperatures $\left(\geq 2650^{\circ} \mathrm{F}\right)$ in gas turbines, advancements in materials capabilities need to be developed. Westinghouse has several 
material development programs in place and has identified, in addition to these, thermal barrier and corrosion resistant coatings, and ceramics as critical developments needed to make significant advancements in operating temperatures.

Critical components/technologies and barrier issues were identified after the analyses of Task 3 had been performed and trade-off studies conducted for both the potential cycle and high temperature developments. Selected R\&D programs were developed for each of these components/technologies and barrier issues. The R\&D plans described all the work necessary to develop and prove that the hardware, equipment, material and/or system is capable of operating at the design conditions of the proposed ATS. The schedule and costs associated with each of these programs was developed as well. Preliminary test plans for each of the development programs was included. The detailed test plans for each program was prepared as part of Task 8. A discussion of schedule risk and risk abatement with respect to the projected success of each program was presented.

\section{Task 7.2 Full Scale GFATS Demonstration Plan}

An Integrated Program Plan was prepared by Westinghouse. The Plan describes all the work necessary to take the selected ATS from conceptual design to commercialization by the year 2000. Included in the plan was all the research, development and demonstrations needed to accomplish programs goals. The integrated plan consisted of a series of plans, as follows:

- R\&D plans for critical components and barrier issues,

- Detailed design/specification plans for the gas turbine, power plant and balance of plant equipment.

- Manufacturing/procurement plan for the gas turbine, power plant and balance of plant equipment.

- Overall demonstration plant A\&E design plan that includes mechanical, civil and structural, and electrical design as well as balance of plant and overall plant controls.

- Site selection/permitting/financing plan.

- Plant construction plan.

- Start-up and test plan.

- Commercial demonstration plan which includes analysis of operating costs and verification of plant hardware condition at first inspection interval.

A comprehensive schedule was prepared, along with the associated costs for all activities necessary for full scale demonstration and verification of program goals. 
DE-AC21-93MC30247

\section{Task 8.0 DESIGN AND TEST OF CRITICAL COMPONENTS}

The purpose of this task is to initiate implementation of the R\&D plans to design, build and test those items that have been identified as being critical to achieving the ATS program goals.

\section{Task 8.1 Effects of Blade Cooling Alternatives on Performance}

Conventional gas turbine airfoils now use air extracted from the compressor as the coolant in a system involving internal impingement and passage convection cooling, along with film cooling of the airfoil surfaces. With increased firing temperatures, more cooling air is required, above and beyond the 20 percent that is currently used. A substantial improvement in engine performance is possible if the cooling air is reduced, or closed-loop steam cooling is employed.

An automated performance calculation system was developed to assess the effects of different cooling media and cooling schemes on cycle performance. The effects of heat transfer, energy balance, mixing losses and expansion work was integrated into the computations.

\section{Task 8.2 Chemical Recuperation}

A novel method to recapture exhaust heat thermochemically, chemical recuperation, can be used to increase turbine efficiency. The temperature range of the exhaust gas, between $1200^{\circ} \mathrm{F}$ and $1400^{\circ} \mathrm{F}$, exists at the low end where conventional catalysts typically operate. A catalyst supplier has developed several low temperature reforming catalysts. These new catalysts will be evaluated and tested. Reactor design is a major issue because temperature and flow distribution in the reformer is critical for proper reaction conversion. Tubular reactor design with catalyst coating offer several advantages over conventional fixed bed tubular design. Arrangement of hot and cold gas streams is critical for maximizing heat transfer rates. Several approaches are available, including, multi-tubular, shell and tube and flat plate. Each of these alternatives will be examined for practicality and the economic benefits of each approach evaluated.

The effort required to complete this task would extend beyond the target completion date to demonstrate ATS. Due to the length of time required to complete this work, this task was reassigned to a separate long-term project and dropped from this program.

\section{Task 8.3 Last Row Turbine Blade Development}

To achieve minimum exhaust losses, the annulus area of the last row turbine blade must be as large as possible. This results in a long and highly stressed last row blade. To avoid excessive vibratory stresses, this blade incorporates an integral interlocked tip shroud. This design presents a possibility that two blade frequencies may occur between adjacent harmonic frequencies. These two frequencies can become coupled and the resulting vibratory stresses can lead to blade failure. 
This concern was addressed through a three step program that : reviewed the design rules for last row blades; evaluated the advantages and disadvantages of interlocked shroud versus free standing last row blades; and, evaluated the effects of stimuli and damping on last row blade vibratory stresses.

\section{Task 8.5 CMSX-4 Single Crystal Blade Development}

The increase in the ATS rotor inlet temperature (RIT) requires implementation of single crystal (SC) blades with advanced coatings. The goal is to take advantage of the excellent creep strength properties of the $\mathrm{SC}$ alloys by permitting them to operate at higher temperatures with reduced cooling air, thereby increasing the ATS efficiency.

The SC experience to date has been limited to relatively small airfoils used in aircraft and industrial turbines. We evaluated the castability of CMSX-4 for the large turbine blades to be used in the ATS program. After successful demonstration of the castability(in progress), then heat treatment optimization, material property data generation and production process development will follow in subsequent phases.

The existing tooling from the Westinghouse 501FA row 1 and row 3 blades was used for the casting trials at Howmet. The blades were evaluated by grain etching and selected NDE and dimensional inspection methods to determine metallurgical soundness.

\section{Task 8.7 Ceramics}

This initial effort verified the feasibility of replacing components of the ATS with ceramic materials. This can be accomplished most economically and with a high level of confidence by focusing the analysis on a key component. More detailed analysis of the turbine system with a greater level of ceramic material integration for prototype testing will be performed in subsequent phases.

A review of ATS design concepts which could potentially incorporate ceramic components was performed. A listing was made of the performance requirements (lifetime, temperature capability, and mechanical properties) for each potential ceramic component. This information serves as the basis for the materials and component selection process. A survey was made of all current and emerging materials which are possible candidates for the selected component. This survey had taken advantage of results from past and on-going research and development programs. For instance, results from the coal-fired combined cycle (CFCC) Program was directly applicable to the material selection requirements of the ATS Program. From these candidate materials, a down select was made to only a few materials representing various types of advanced ceramics. Down select criteria included material properties, manufacturability, and sustainability. The candidate material systems included: 1) a high strength monolithic, 2) a nonoxide/nonoxide continuous fiber composite, 3) an oxide/oxide continuous fiber composite, and 4) a particulate composite material. 
Procedures were recommended for providing prototype components in subsequent phases. Documentation of manufacturing procedures for each component, identification of critical issues associated with scaling up from coupons to prototype components, recommendation of NDE techniques and suggestions for prototype testing were provided to ensure the successful demonstration of ceramic components in the ATS. A topical report on the materials selection, any design analysis which is performed, tests conducted and prototype testing plans for specified components was provided to lay the ground work for additional development and prototype testing in subsequent phases.

\section{Task 8.8 Diffuser Extraction Study}

Test models were designed and prepared to simulate the geometry of the $501 \mathrm{~F}$ engine between the compressor outlet guide vane exit and the expander nozzle inlet.

The model testing and computational analysis addressed the changes in the overall thermal performance of the Westinghouse heavy-frame gas turbine when used in an integrated Gasification Combined Cycle (IGCC) configuration. Air-extraction at the prediffuser inlet will be compared with the effects of air extraction through existing holes in the turbine shell. The Griffith diffuser was used to replace the existing outer wall of the pre-diffuser.

The effect of each of the two extraction schemes on the performance characteristics of the pre-diffuser and dump diffusers will then be studied and compared against the baseline case, where no air is extracted for gasification.

\section{Task 8.10 Stator Cooling}

The program involves incorporation of novel turbine airfoil cooling to maintain metal temperatures at acceptable levels. These temperatures will be $200^{\circ} \mathrm{F}$ to $300^{\circ} \mathrm{F}$ higher than the current state-of-the-art industrial combustion turbines.

Plastic models were employed to verify the cooling effectiveness of the new cooling procedures. The two areas that present cooling challenges, even at current firing temperatures, are the endwall region and suction surfaces of turbine stators.

The model consisted of a full flow channel, bounded by two complete airfoils. Preliminary sensitivity tests were conducted. Three film cooling jet configurations were tested, each at four cooling flow rates. The influence of Reynolds Number and inlet boundary layer thickness was examined. The resulting heat flux distributions was measured by use of thermochromic liquid crystal technology.

Development of the stator cooling design resulted in acceptable metal temperatures and with the minimum expenditure of cooling air. The cooling procedure enhanced ATS engine performance and ensure integrity of the Row 1 stators. 
Task 8.11 CM-247 Directional Solidified Blade Development

Improvements in performance and efficiency of the ATS turbine requires stators and blades to operate at much higher temperatures and in more demanding conditions than expected of current design technologies.

Directionally solidified (DS) alloys offer superior creep and fatigue strengths compared to conventional alloys. This alloy has been chosen for evaluation because of its strength, castability, existing material properties data base. Commercial availability. Industrial experience with this alloy has been limited to relatively small airfoils for air-craft engines and industrial turbines. Applicability of the process to large blades in power generation turbines have yet to be verified.

A parallel program (Task 8.5) is currently underway to evaluate CMSC-4 alloy for single crystal blade casting. Task 8.11 provides an alternate material which offers higher strength than conventional casting alloys and without the high costs and casting difficulties normally associated with SC alloys.

\section{Task 8.12 Shrouded Blade Cooling Development (Phase 1)}

An integral interlocked blade tip shroud was used to improve the operating characteristics of the ATS Row 3 turbine blade. Cooling of this long and highly twisted blade requires the development of a viable shroud cooling scheme.

One acceptable solution includes designing the blade with a large central hole. Small holes are machined through the blade tip shroud, into the central hole, to provide air for shroud cooling.

A casting development program was designed to verify the concept of using a large quartz rod for casting the mid blade chord cavity. The hole will be plug welded on the shroud outside diameter. A trial run of twelve blades were cast in this manner. Geometrical inspections and metallurgical evaluations were conducted to verify the casting process.

\section{Task 8.13 Last Row Turbine Blade Development}

To achieve minimum exhaust losses, the annulus area swept by the last row turbine blade must be as large as possible. This results in a long and highly stressed blade. To avoid excessive vibratory stresses, the blade incorporates an integral interlocked blade tip shroud. With this blade design, there is a possibility that tow blade natural frequencies may occur between adjacent harmonics. These frequencies can become coupled and result in high vibratory stresses, leading to blade failures.

To resolve the potential vibration problems on the last row turbine blade, several alternative blade designs were investigated. These alternatives included integral interlocked blade tip shroud design, shrouded design with part span shrouds, and a free standing blade design. These alternative designs were evaluated with respect to vibratory stresses, effect on rotor dynamics, mechanical integrity and performance. 
A casting development program was initiated if the part span shroud design is selected. Several blade castings were produced and geometrical inspections and metallurgical evaluations were carried out to verify the casting process.

\section{Task 8.14 Closed-Loop Steam Cooling}

The specific heat of steam is approximately twice that of air. As a result, less steam would be required to cool the hot end components than air.

Closed-loop steam cooling will eliminate the need for surface ejection of the cooling air and concomitant mixing losses. This will result in an improvement in stage efficiency. The elimination of stator cooling air ejection into main stream will result in an increase in the Row 1 turbine inlet temperature and the turbine exhaust temperature for the same burner outlet temperature. The combination of these two effects will increase the ATS plant efficiency significantly.

Incorporation of closed-loop steam cooling entails detailed investigation into the effect of steam on the heat transfer and mechanical designs, and stator material metallurgical properties.

A literature review was conducted. Calculations were performed to determine the benefits of the identified closed loop steam cooling approaches for the stators and blades. Computer codes were updated to incorporate the properties of steam and used to develop preliminary cooling designs. Risks associated with steam cooling were identified and well as the effects on reliable gas turbine operation.

\section{Task 8.15 Active Tip Clearance Control - Phase 1}

Turbine blade tip clearances have a significant effect on the performance of highly loaded front stages. Each one percent increase in clearance, based on blade height, can result in a decrease in stage efficiency of up to two percent. In a four stage turbine, this can result in approximately one-half percent decrease in the overall turbine efficiency.

Tip clearances are subject to operational characteristics. Even with initial cold blade tip clearances set at minimum values, transients such as rapid starts and emergency shutdowns, can introduce negative clearances. When either transient occurs, the blade tips are ground off, resulting in increased hot running clearances and deteriorating performance. A conceptual design of an active tip clearance control system was developed to solve this problem.

One objective of the conceptual design would be to maintain large tip clearances on startup and to reduce them to minimum acceptable values when the engine reaches steady state operation. This would be accomplished by cooling, at appropriate times, the blade ring that hold the ring segments located above the rotating blade tips. 
During Phase 2 the viability of the concept through a field test in a host engine will be conducted.

\section{Task 8.16 Flow Visualization Tests}

Flow visualization testing was performed at the Westinghouse Power Generation Engineering Laboratories in Casselberry, Florida, using both a single combustor rig and a full-scale sector rig.

These tests were carried out on a modified dry low Nox combustor using tufts attached to a specially constructed holder, in order to verify qualitatively CFD predictions. The agreement with CFD results was excellent. Effective flow area measurements were carried out on two dry low Nox combustors, multi-swirl combustor swirl plate, and multi-nozzle combustor pilot.

\section{Task 8.17 Combustion Noise Investigation}

Very lean-premix combustion will have to be employed to achieve ultra-low Nox emission in the ATS engine. This may result in flame instability, combustion generated noise and high vibratory stresses in the combustion system components as well as the downstream turbine airfoils. The objective of this program is to extend the stability range for lower emissions. An active noise control system was developed to achieve this objective.

A subscale combustion stability test section design, including modifications required for control valve mounting and for control gas introduced at the proper locations, was completed. The specification for the housing was completed, quotes for the pressure vessel were received, and fabrication of the combustion stabilization test section pressure vesselwas completed.

Two candidate methods for measuring volume velocity oscillations in fuel gas lines (i.e., hot-wire anemometers and pressure transducers) were evaluated. A shaker-driven flow modulator generates the flow oscillations that were measured at selected frequencies. These experiments were conducted in parallel with Westinghouse sponsored analytical work at Carnegie Mellon University on the development of a transfer function to predict volume velocities of combustion products resulting from auxiliary fuel inlet flow velocity fluctuations. An augmented flame transfer function was developed as a development tool. This transfer function was used as a major building block in the overall stabilization system design method. The modulated fuel flow volume velocity measurements provided the basis for the experimental confirmation of the design method.

\section{Task 8.18 Thermal Barrier Coating Field Tests}

Ceramic TBD's are useful in reducing metal temperatures of actively cooled gas turbine components. The low thermal conductivity of the TBC effectively insulates the metal substrate, thereby providing approximately $20-25^{\circ} \mathrm{F}$ reduction in temperature per mil of 
coating thickness. The two TBC coating processes have individual characteristics and disadvantages regarding coating uniformity, ease of application and cost.

Ten blades were coated with the APS coating and ten additional blades coated with the EBPVD coating. Two blades were not coated. The blades will be removed after twelve months of field operation on a commercial unit. A detail-detailed metallurgical analysis will be performed to establish the efficacy of TBC coatings under actual operating conditions in subsequent ATS work

\section{Task 8.19 Catalytic Combustion Development}

A development program was initiated to gain a theoretical understanding of the catalytic combustion. The catalytic combustion system design was prepared using a "clean sheet" approach. Initial tasks included the preliminary investigation, which involved development of combustor baskets with catalytic components.

\section{Task 8.20 Optical Diagnostics Development}

During Phase 1, an optical diagnostic probe was developed by Westinghouse and Penn State University to aid in combustion system optimization. The probe enabled evaluation of the composition and concentration of combustion products. The probe also was designed to measure velocities and flow angles.

Phase 2 of the program involved conducting engine tests with the optical diagnostic probe.

\section{Task 8.21 360 Degree Rig Flow Tests - Phase 1}

Flow mapping and flow visualization tests were conducted on a half-scale model of the $501 \mathrm{~F}$ combustion turbine cylinder. Higher order flow effects inside the combustor cylinder were investigated and detailed information on pressure, velocities and flow angles inside the combustor cylinder recorded. The investigation included observing the effect of struts, cooling bleed port, cooling air return pipes, diffuser exit swirl, by-pass valve modulation, combustor basket flow shields, top hat length, and ultra-low NOx basket on air flow.

\section{Task 8.22 Serpentine Channel Cooling Tests}

An internal blade cooling configuration specification will be prepared by Westinghouse and NASA. Plastic models will be employed to carry out selected serpentine channel cooling schemes to verify and optimize the design prior to incorporation into the engine. Two models will be tested: One model will simulate the multi-pass mid-chord region of the blade, and the second model, representing the trailing edge portion of the blade. Tests will be conducted at different cooling air flow rates and internal heat transfer coefficients and pressure losses measured. 
Task 8.23 Brush Seal Development - Phase 1

Brush seals were incorporated in appropriate locations in the turbine and compressor to reduce air leakage and the ingestion of hot gas into turbine disc cavities. This contributes to improved engine efficiency and as well as the mechanical integrity of turbine components.

The required surface treatment of the sealing surfaces for the brush seals will be investigated.

Discussions were held with a vendor to assist in the design and optimization of the brush seals.

Task 8.24 Brush Seal Development - Phase 2

The procurement of the brush seals provided the groundwork for a subsequent effort involving performance and endurance tests in a host engine.

\section{Task 8.25 High Efficiency Compressor Design}

The ATS compressor design philosophy is based on the advanced $501 \mathrm{G}$ compressor, but with additional enhancements. The $501 \mathrm{G}$ compressor is a new aerodynamic design using controlled diffusion airfoils (CDA), reduced number of stages, and reduced airfoil thicknesses. An optimization study conducted on the $501 \mathrm{G}$ compressor showed that 16 individually optimized stages will maximize efficiency for the 19:1 pressure ratio design. Continuing the gas path and stage optimization procedure downstream on an additional three stages will result in the 25:1 pressure ratio ATS design. Using advanced aerodynamic and mechanical design codes Westinghouse produced an optimized compressor design with higher efficiency and shorter blade path than was previously achievable.

\section{Task 8.26 Blade Vibration Monitor System Development}

Advanced compressor and turbine blading are highly stressed, complex-shaped structures that must tolerate a variety of forces in adverse environments. A blade vibration monitoring (BVM) system used for determining synchronous blade modes, nonsynchronous responses and interaction with rotor torsional vibrations under field operating conditions will enable valuable data collection. BVM system with a sensor mounting arrangement was used for verification of compressor and turbine blade frequencies at various engine operating conditions. Following component modifications to engine cylinders and blade rings, field testing were performed. Several compressor stages were selected for analysis, as will the row 1 and/or row 2 free-standing turbine blades. 


\section{Task 8.27 Curved Compressor Exit Diffuser Development}

Both analytical computations and experimental tests are required to optimize the compressor exit diffuser performance and to minimize the diffuser exit dump loss. As a result of the restricted axial spacing available in the combustion cylinder, the current conical diffuser exit flow is not purely axial but is deflected upward by the stagnant air under the transition duct exits. A hybrid axial-radial curved diffuser design was developed to optimize the compressor exit diffuser pressure recovery and to minimize the dump loss.

The curved compressor exit diffuser development effort consisted of: preliminary diffuser design, 2-D CFD optimization study, 2-D diffuser modeling/rig construction, testing of several diffuser variants to optimize design, 3-D curved diffuser construction, modifications to the Clemson combustion cylinder rig to incorporate the curved diffuser, testing at Clemson to verify the diffuser performance.

\section{Subtask 8.28 Stator Cooling}

Additional geometrical variations were tested in order to complete the study of all significant aspects of the complex shroud film cooling scenario. The additional geometry variations included: film effects of circumferential seal leakages, shroud film benefits resulting from the secondary flow effects on pressure side airfoil film cooling flow, and additional film hole arrays.

All testing was performed on the existing test model. The model was modified as needed to accommodate the additional test variations. The suction side film cooling portion of this test program was unchanged from the original proposal.

\section{Task 8.29 Advanced Air Sealing Development}

Phase 1 -- The preliminary investigation of applying brush seals in suitable locations in combustion turbine engines was continued. This work included evaluating the benefits and engine design implications of applying brush seals at various locations. The three engine locations have been chosen, i.e., the turbine interstage, the turbine rim, and the compressor diaphragm. The turbine interstage was selected as the first location to study applying brush seals and operational data have been calculated for that location. This work continued for a second location; the turbine rim.

Phase 2 -- This phase focuses on determining the best brush seal design for selected engine locations. It included an investigation of surface treatments, tribology testing, scaled conceptual seal design, fabrication of scaled rig seal hardware, rig performance/wear testing, and recommendation of seal design. 


\section{Task 8.30 ATS Coating Development}

New bondcoat compositions along with commercial NiCoCrAlY bondcoats with yttria stabilized zirconia and new ceramic TBC compositions, were tested in laboratory oxidation and hot corrosion environments. Post test evaluations using scanning electron microscopy, $\mathrm{x}$-ray diffraction, adhesion testing, and physical property measurements, shall be conducted to rank the various bondcoat and new ceramic TBC systems performance. Highly ranked TBC systems were selected for further characterization tests which included burner rig testing and full scale component tests. Based on these results the bondcoat and TBC system may be further optimized.

\section{Task 8.31 Closed-Loop Cooling of Turbine Airfoils}

The current ATS performance model indicates that closed-loop steam cooling (CLSC) yields higher ATS plant efficiency. However, closed-loop air cooling results in a simpler system and has the potential for higher plant efficiency provided that the cooling air rejected heat can be more fully recovered (Note, the cooling air is cooled prior to compression and reintroduction into the engine). To ensure an optimum design, closedloop steam cooling concept incorporation required a detailed investigation into the effect of steam on the heat transfer, mechanical design and turbine airfoil material metallurgical properties. The advantages of steam versus air as the coolant was evaluated in more detail. To determine the practicality of the closed-loop cooling concept, a preliminary coolant supply and return system design was completed.

Preliminary stage 1 vane and blade closed-loop cooling designs were carried out for the different cooling schemes under consideration. The cooling design includes the airfoils, as well as vane shrouds and blade platforms. Plant performance was estimated for the different cooling schemes with steam and air as the coolant. Based on the results of this investigation the preferred coolant was selected. An investigation was performed on startup and part-load operation and their effect on engine performance and on the component cooling. Finally a more detailed optimization of the selected cooling design and the coolant supply and return system design was completed.

\section{Task 8.32 Ceramic Ring Segment Development}

Development of high performance ceramic components for the ATS requires a significant investment in the development of design procedures and related technology appropriate to ceramic matrix composites.

Design and analysis of ceramic composite ring segments was conducted. Manufacturing development and sub-element testing in support of these components was performed under Task 8.7. Manufacture of prototype components, testing and evaluation is expected to be included in subsequent work. 
Subtask 8.33 Single Crystal Blade Development

Single crystal CMSX-4 alloy has been selected for ATS blade application because of its excellent creep strength and commercial availability. CMSX-4 offers a temperature advantage of about $110^{\circ} \mathrm{C}\left(200^{\circ} \mathrm{F}\right)$ as compared to the conventionally cast (CC) blading alloy IN-738. The industrial experience with CMSX-4 to date, however, is limited to small blades on aeroderivative engines. The scale-up of blade size will affect blade properties and will thus require the heat treatment to be modified to optimize the properties.

A 12 month program was carried out to support the design of CMSX-4 SC blade. The program included the following: (1) procuring cast $\mathrm{SC}$ slabs which simulate the structure of large blades; (2) optimizing post-cast heat treatment, including HIP and coating cycle; (3) generating anisotropic data, including tensile, fatigue and creep and (4) generating design curves.

\section{Subtask 8.34 Catalytic Combustor Development}

To continue the development of our advanced "clean sheet" catalytic combustor development begun in the Phase 1 of this program, Westinghouse intended to move through the detail design, build and fired testing stages during Phase 2. The detail design work will involve mechanical layout, initial mechanical analysis and prototype manufacturing coordination for the combustor. The actual combustor build-up stage involved close coordination between combustor designer and manufacturing disciplines to insure key configuration features are included in a timely manufacturing schedule. Actual testing of the combustor was performed at full scale using one or more available test rigs at Westinghouse and AEDC including atmospheric pressure, mid pressure and full pressure facilities.

\section{Task 8.35 Active Combustion Noise Control}

This program extended the conceptual work on active combustion noise control through fired full scale testing. It included a detail design task, followed by prototype manufacture and then full scale rig testing. Starting with the current conceptual design activities and lab scale tests, which are focused on small scale hardware, the new work focused on the detail design of full size hardware. This was particularly important in terms of the fuel nozzle component, the most difficult of the design tasks. Actual testing of the full scale prototype requires that the final runs be at high pressure where instabilities will most likely occur. However, the prototype system was tested in lower pressure facilities initially, to check for design flaws before the more costly high pressure tests are carried out at AEDC.

\section{Task 8.36 Optical Diagnostics Development}

In Phase 1 the optical diagnostics development project work concentrated on probe development and verification in a series of relatively simple test rigs involving cold flow 
and atmospheric pressure fired tests. Also, the effort was limited to one particular combustor design. The extension of this work permited additional tests in rigs and in an engine application. The proposed work was organized in a manner so as to permit high pressure $(>10 \mathrm{~atm})$ testing of the optical probe designs demonstrated during the current work. Initial high pressure test evaluations were planned for a small scale facility for economic reasons during shake-down. Follow-on testing was carried out at AEDC in full scale high pressure tests. Final verification will be done in an actual engine test in subsequent ATS work.

\section{Task 8.37 Ni-based Superalloy Turbine Rotor}

The work consisted of: (1) preliminary design of the ATS rotor assembly to define the geometry of each of the rotor components and material strength requirements; (2) final selection of disc/shaft material to optimize performance, producibility and cost; (3) forging process development with Alcoa, and (4) development of NDE techniques for inspecting forgings.

\section{Task 8.38 Steam Cooling Effects on Materials}

Steam physical properties and solubility of impurities at the ATS operating conditions and effects of these impurities on corrosion/ oxidation behavior and mechanical properties of ATS materials was determined by performing the following subtasks: develop a steam chemistry model to predict types and concentrations of impurities along the turbine gas path to identify the critical stage(s); conduct laboratory hot corrosion tests on turbine blade and vane alloys in the coated and uncoated conditions at atmospheric pressure for a) an aggressive (100X impurity levels predicted by solubility model), and b) mild environments (10-50X impurity levels predicted by solubility model); determine the effects of steam with contaminants on high cycle fatigue (HCF) properties of blade alloys and establish the design curves. 


\section{SECTION 4}

\section{SELECTION OF NATURAL GAS-FIRED ATS}

\section{INTRODUCTION}

The objective of Task 3 was to analyze and evaluate different cycles for the natural gasfired Advanced Turbine Systems (GFATS) in order to select one that would achieve all of the ATS Program goals. Detailed cycle performance, cost of electricity, and RAM analysis were executed to provide information on which the final selection of the GFATS cycle would be made. Innovative approaches and technological advances are required to achieve these challenging goals. Improvements in combustion, aerodynamic design, cooling design, mechanical design, leakage control, materials, and coating technologies are requisite. The ATS program goals are as follows:

- greater than $60 \%$ plant cycle efficiency (on LHV basis)

- $10 \%$ lower NOx emissions than current commercial values

- cost of electricity $10 \%$ less than current values

- $\quad$ RAM results comparable with current combined cycle plants

- demonstration by year 2000

The ATS engine will be the next model in the series of large heavy duty gas turbines developed by Westinghouse over the last 50 years. Westinghouse engineers have made significant contributions in advancing gas turbine technology, especially in the field of heavy duty engines used in industrial and electrical utility applications. Some of the innovations included single shaft two bearing design, cold end drive, axial exhaust, cooled turbine airfoils in an industrial engine, and tilting pad bearings. The improvement in gas turbine performance and mechanical efficiency was both evolutionary, where small improvements were made continuously, and revolutionary, where new designs were produced to achieve a large step change in engine output power and efficiency, as well as mechanical integrity and reliability. Figure 4-1 shows the evolution of large operating industrial and utility gas turbines developed by Westinghouse. 


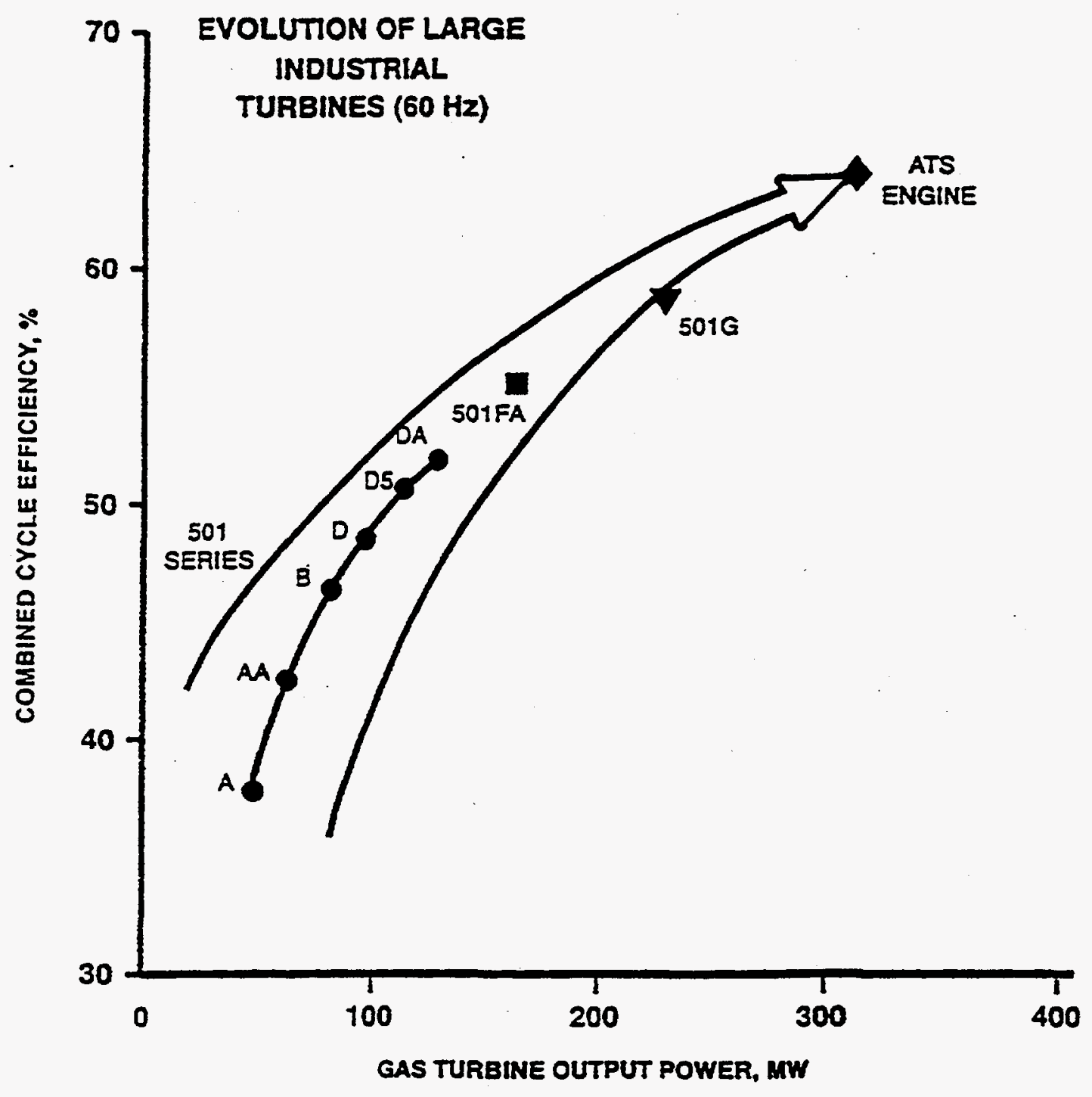

Figure 4-1. Evolution of Large Westinghouse Gas Turbines 


\section{DISCUSSION}

Various cycles were considered and evaluated for the ATS Program on the basis of plant efficiency, emissions, cost of electricity, reliability-availability-maintainability (RAM), and program schedule requirements. The main cycle concepts investigated were the advanced combined cycle, intercooled, recuperated, reheat, and thermochemically recuperated cycles. The advanced combined cycle was selected for the ATS Program because it was considered to have the best potential for achieving all of the ATS Program goals by the year 2000 .

Detailed cost and RAM analyses were carried out on six selected cycle configurations and compared to the Westinghouse $501 \mathrm{~F}$ combined cycle. These comparisons determined whether or not the evaluated cycles met the performance requirements of the ATS program.

The various cycles evaluated had combustion turbine inlet temperatures ranging from $2450^{\circ} \mathrm{F}$ to greater than $2750^{\circ} \mathrm{F}$; pressure ratios of $18: 1$ to $48: 1$; and power outputs of 243 MW to $339 \mathrm{MW}$. The advanced combined cycle selected will exceed all the ATS requirements and has a net plant output of $452 \mathrm{MW}$.

Issues critical to the successful development of the advanced combined cycle plant were identified. The achievement of the ATS plant cycle efficiency and cost of electricity goals will require higher engine firing temperatures with minimized cooling of hot end components. This, in turn, will necessitate the selection and/or development of new alloys, materials, casting processes, and coatings for the ATS engine. To ensure success of this program, a concerted development effort and technological advancements will be mandatory in combustion, aerodynamic design, cooling design, mechanical design, leakage control, and materials/coating technologies. Westinghouse plans to pursue an advanced combined cycle plant with the following features:

- Advanced aero/heat transfer/materials technology

- Burner outlet temperature in excess of $2730^{\circ} \mathrm{F}$

- $\quad$ Closed-loop steam cooling

- Single crystal and directional solidified airfoils

- Improved thermal barrier and anti-corrosion coatings

- $\quad$ Ceramic ring segments

- $\quad$ Active tip clearance control

- $\quad$ Brush seals 
- Reduced compressor dump/combustor loss

- Increased Row 4 blade exit area

- $\quad$ Reduced inlet and exhaust losses

- $\quad$ Fuel preheating

- All rotating turbine-generator power components on a single shaft

- $\quad$ Advanced steam turbine design technology

- $\quad 1800 \mathrm{psi} / 1050^{\circ} \mathrm{F} / 1050^{\circ} \mathrm{F}$ steam cycle

This advanced combined cycle power plant is designated as "ATS" throughout this report. Figure 4-2 shows the selected cycle.
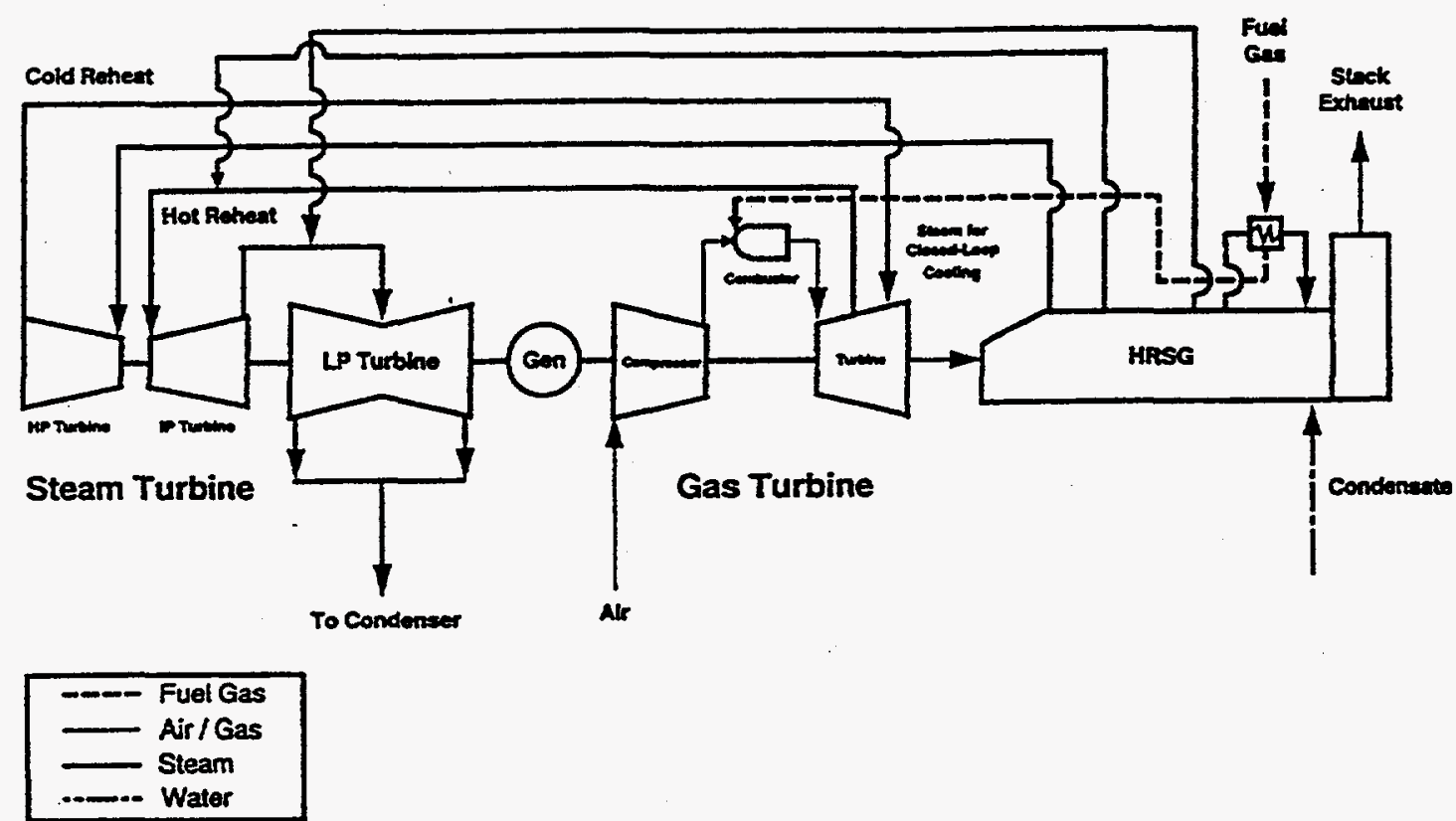

Figure 4-2. Selected ATS Cycle Configuration 


\section{CYCLE ANALYSIS}

Today, current large natural gas-fired combined cycle power generation systems are capable of efficiency levels in excess of $56 \%$. Within the ATS program, Westinghouse has been given the opportunity to re-evaluate cycle efficiencies using proven, established concepts, such as intercooling and recuperation, and newer concepts, such as thermochemical recuperation. In addition, efficiency enhancements within the ATS selected cycle are to be evaluated to determine the best approaches to raising overall thermal plant efficiencies to greater than a net $60 \%$ while adhering to the other ATS program goals. The concepts considered in the Westinghouse analyses are to be capable of demonstration within a three to four year time frame. From a baseline cycle definition, this report discusses how different concepts will affect the overall plant thermal efficiency. Our analysis indicates that a plant efficiency of greater than $60 \%$ is achievable.

\section{BASELINE CYCLE}

In order to evaluate different technologies and concepts applicable to combined cycle power generation systems, a high temperature engine baseline combined cycle configuration first had to be developed to provide a basis for comparison of all the cycle concepts and technologies to be considered. For this purpose, a conventionally configured combustion turbine coupled with a three-pressure level reheat steam cycle (Figure 4-3) was modeled to provide a high temperature engine baseline combined cycle. The combustion turbine rotor inlet temperature (RIT) was set at $2600^{\circ} \mathrm{F}$ to approximate near-term temperature capabilities. The compressor pressure ratio was set at 18 . High pressure steam conditions entering the steam turbine were specified at $1450 \mathrm{psi}$ and $1000^{\circ}$ $\mathrm{F}$ and the hot reheat steam temperature was also set at $1000^{\circ} \mathrm{F}$. Note that this configuration utilizes turbine rotor cooling air heat to produce additional low pressure steam in the steam cycle via a heat exchanger located in the heat recovery steam generator (HRSG). Also, the natural gas fuel is preheated by feedwater recirculation flow.

The ATS engine will be based on the proven technologies incorporated in the 501 frames. To exceed the ATS program plant cycle efficiency and emission goals, however, will require advancements in several key gas turbine technologies: closed-loop steam cooling, catalytic combustor components and advanced coating systems. Additional enhancements include advanced aerodynamic and sealing design active blade tip control, and materials and coatings with high-temperature capabilities. 


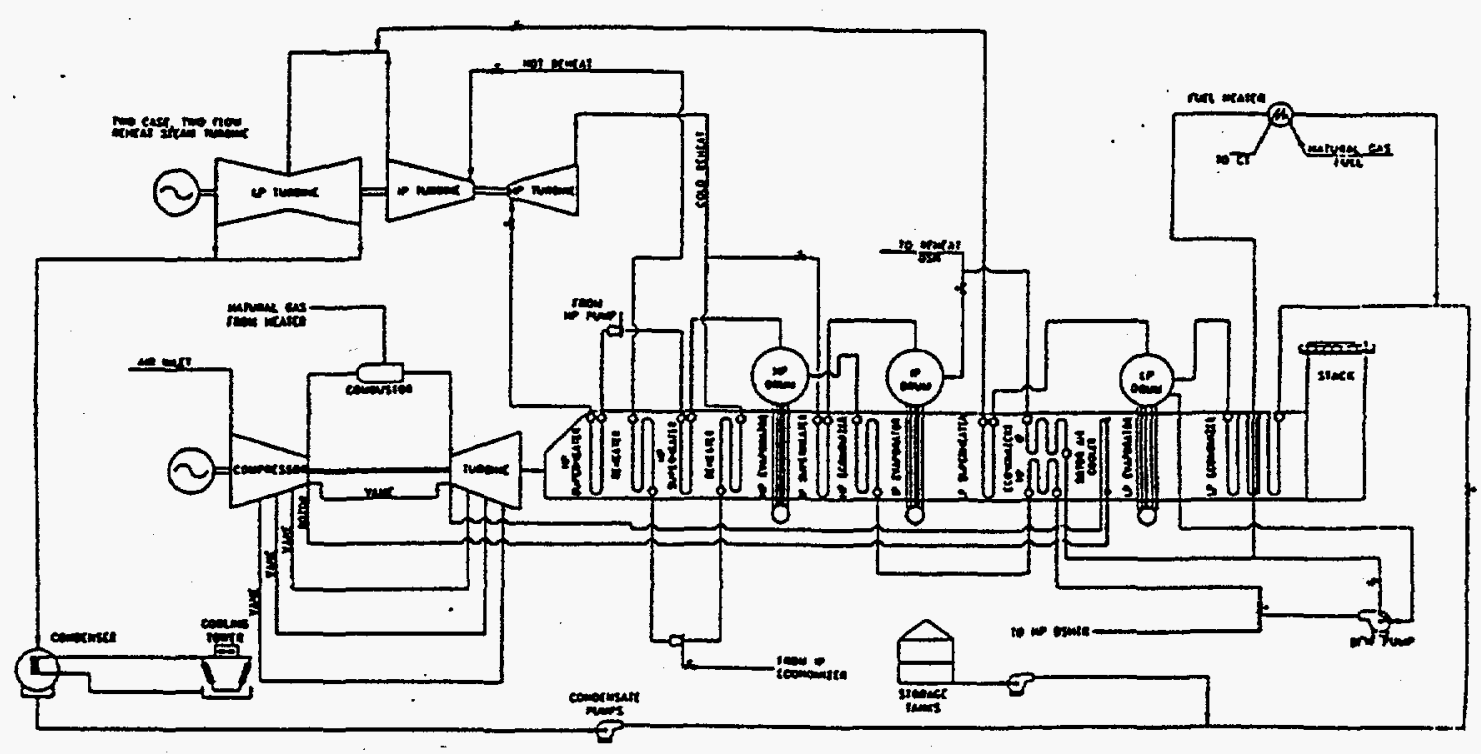

Figure 4-3. High Temperature Engine Baseline Combined Cycle

\section{COMPONENT IMPROVEMENTS}

Incorporation of several component improvements, available through recent technological developments and advanced design techniques, into the power generation system of Figure 4-3 results in significant efficiency gains. The application of advanced design tools will enable the analysis and incorporation of design changes that will increase compressor and turbine efficiencies. Blade tip and seal leakages will be minimized to further enhance efficiency. Improved materials, including ceramic components, coatings, and cooling designs will be incorporated to reduce cooling requirements and improve cycle efficiency.

There are two generators in the high temperature baseline configuration. One of these is the combustion turbine generator, while the other is the steam turbine generator. Current generator designs are capable of higher efficiency than those chosen for the high temperature baseline cycle. While the combustion turbine generator of the high 
temperature baseline configuration is of sufficient size to cost effectively apply this technology, the steam turbine generator is not. By utilizing a single shaft arrangement, however, the smaller steam turbine generator is eliminated and the remaining single generator may be designed at the higher efficiency.

When the component improvements listed above are all incorporated into the high temperature baseline cycle, the net plant thermal efficiency is increased by approximately 2 percentage points.

\section{STEAM CYCLE ENHANCEMENTS}

The basic reason for raising the steam pressure and temperature of the Rankine cycle is to improve the potential thermal efficiency. The first cycle variations investigated within this study were modifications to the high temperature baseline cycle in which the steam cycle was enhanced. Study results indicated that increasing either high pressure steam superheat temperature or reheat steam temperature by $50^{\circ} \mathrm{F}$ results in an improvement in combined cycle thermal efficiency of 0.1 percentage point. Increasing high pressure steam pressure from $1450 \mathrm{psi}$ to 1800 psi results in an increase in net plant thermal efficiency of 0.1 percentage point. A further increase in pressure to $2400 \mathrm{psi}$ yields only an additional 0.05 percentage point in thermal efficiency, while adding to the cost of the high pressure steam system. Also, since the steam turbine size is set by the exhaust energy of the combustion turbine, increasing steam pressure reduces the blade heights in the high pressure steam turbine. For $2400 \mathrm{psig}$ high pressure steam, the resulting blade heights are much smaller and less efficient than for the $1800 \mathrm{psi}$ steam. Therefore, the optimum steam cycle was determined to be at $1800 \mathrm{psi}$ with $1050^{\circ} \mathrm{F}$ high pressure superheat steam and $1050^{\circ} \mathrm{F}$ reheat steam (both $100^{\circ} \mathrm{F}$ above the baseline cycle temperature). This resulted in a 0.5 percentage point increase in net plant thermal efficiency and also in a slight increase in output due to the increased efficiency of the steam cycle. The steam temperatures were limited to $1050^{\circ} \mathrm{F}$ for this study due to steam turbine materials, reliability, and cost considerations. The steam temperature of $1050^{\circ} \mathrm{F}$ plus a reasonable steam superheater approach $\Delta \mathrm{T}$ is determined by the combustion turbine exhaust temperature and this, in turn, set the baseline cycle pressure ratio.

\section{ROTOR AIR COOLER HEAT UTILIZATION}

The Westinghouse $501 \mathrm{~F}$ combustion turbine combined cycle provides two options for rotor air cooler heat utilization. The first option is an air-to-air cooler to cool the rotor cooling air after it exits the compressor and prior to its introduction into the rotor. The rotor air heat is rejected to the atmosphere via an air-to-air cooler. The other option is to cool the rotor air via an air-to-exhaust gas heat exchanger located in the HRSG upstream of the low pressure evaporator, as was done in the high temperature baseline cycle. With this configuration, the rotor air cooler heat is recovered by the steam cycle, which 
this configuration, the rotor air cooler heat is recovered by the steam cycle, which produces low pressure steam. This results in higher plant efficiency than that of the airto-air cooler method, since the rotor air cooler heat is recovered by the low pressure steam system.

Another concept involves removing the HRSG rotor air cooler used in the high temperature baseline configuration and installing a rotor air cooler which exchanges heat with the incoming natural gas fuel (after the fuel has been preheated). This returns the rotor air heat back to the combustion turbine, which then requires less fuel to achieve the desired rotor inlet temperature. Therefore, the rotor air heat is recovered at the combustion turbine efficiency (typically about $40 \%$ ), which is much higher than the low pressure steam system efficiency. This is, therefore, a much more effective recovery of the heat than is obtained via low pressure steam production, and results in an increase in net plant thermal efficiency of 0.4 percentage point over the high temperature baseline configuration.

\section{CLOSED-LOOP STEAM COOLING}

Most current gas turbine engines utilize air to cool the turbine vanes and blades. This allows the turbine inlet temperature to be increased beyond the temperature at which the turbine material can be used without cooling, thus increasing the cycle efficiency and power output. However, the cooling air itself is a detriment to cycle efficiency in four ways. First, it is ejected from the turbine airfoils, thereby causing a disruption in the surrounding flow field. This increases the airfoils' irreversible pressure losses and results in a reduction in turbine efficiency. Secondly, since the cooling air is ejected from the airfoil into the gas path, the resulting mixing of the cooling air into the gas path results in irreversible pressure losses due to the non-ideal mixing of the streams, which have very different velocity vectors. The third loss mechanism is caused by the reduction in gas path temperature that accompanies the mixing of the cooling air into the gas path. This reduction in temperature reduces the work output of the turbine and, therefore, compromises cycle efficiency. Finally, the turbine cooling air must be pumped to pressures significantly higher than that of the gas path pressure at the location it is injected. This is done to assure that the cooling flow rate will be sufficient during certain operating conditions where the ratio of coolant pressure to gas path pressure drops below its design level. While some of this pressure is recovered by the turbine, there are internal losses as the cooling air passes from the compressor to the turbine gas path. The additional pumping work required to raise the cooling air to the required pressure is the associated loss.

The effect of cooling air on cycle efficiency is shown in Figure 4-4. This figure shows the potential increase in combined cycle thermal efficiency for fractional reductions in cooling or leakage flows. In this figure, the lines labeled 'Fixed P/P' show the effect for fixed compressor pressure ratio (i.e., the turbine expander is increased in size to handle the additional flow resulting from the reduction in cooling or leakage) and the lines 
labeled 'Fixed Expander' show the effect for fixed expander size (the compressor pressure ratio is allowed to rise so that the additional flow caused by the reduction in cooling or leakage can be accommodated by a turbine of the original size). Note that, although turbine leakage generally carries a larger efficiency penalty than turbine cooling per given amount of flow, the fact that the amount of leakage flow is far less than the amount of cooling flow results in far less efficiency benefit from reducing turbine leakage flows a given fractional amount compared to reducing turbine cooling flows by the same fraction of their baseline value.

By using closed-loop steam cooling, the loss mechanisms described above can be largely eliminated, while still maintaining turbine material temperatures at acceptable levels. In combined cycles, the steam used for cooling the combustion turbine hot parts is usually taken from the steam bottoming cycle. This steam is then returned to the bottoming cycle after it has absorbed heat in the closed-loop steam cooling system. For an advanced bottoming steam cycle, closed-loop steam cooling would route cold reheat steam from the exit of the high pressure steam turbine to the combustion turbine vane casing and rotor. The steam is passed through passageways within the vane and rotor assemblies and through the vanes and rotors themselves, then collected and sent back to the steam cycle intermediate pressure steam turbine as hot reheat steam. This approach to turbine cooling relies solely on convective heat transfer. Since no steam or cooling fluid is ejected from the airfoils, aside from a small amount of steam leakage through the rotor seals, there is very little influence of the cooling steam on the airfoil flow fields, and hence minimal mixing losses. Also, the reduction in gas path temperature is minimized, since the convective heat flux across the airfoils is relatively small. Typically, first vane cooling air mixing reduces the gas path temperature approximately $100^{\circ} \mathrm{F}$ to $150^{\circ} \mathrm{F}$. For closedloop steam cooling however, the reduction in gas path temperature is only about $10^{\circ} \mathrm{F}$ to $15^{\circ} \mathrm{F}$, or one tenth of the reduction of conventional cooling techniques. Application of closed closed-loop steam cooling to the baseline configuration yields a 2 percentage point increase in combined cycle efficiency.

Closed-loop steam cooling of the transitions, which is used on the ATS engine, will result in a small (about .05 percentage point) penalty in cycle efficiency due to heat extraction from the combustion gases.

However, both closed-loop exhaust gas cooling and impingement air cooling of the transitions will result in a higher loss in cycle efficiency. The closed-loop exhaust gas cooling will be less efficient because of the work of compression. The impingement air cooling will be less efficient because of the higher combustor pressure loss requirement for this type of transition cooling scheme. 


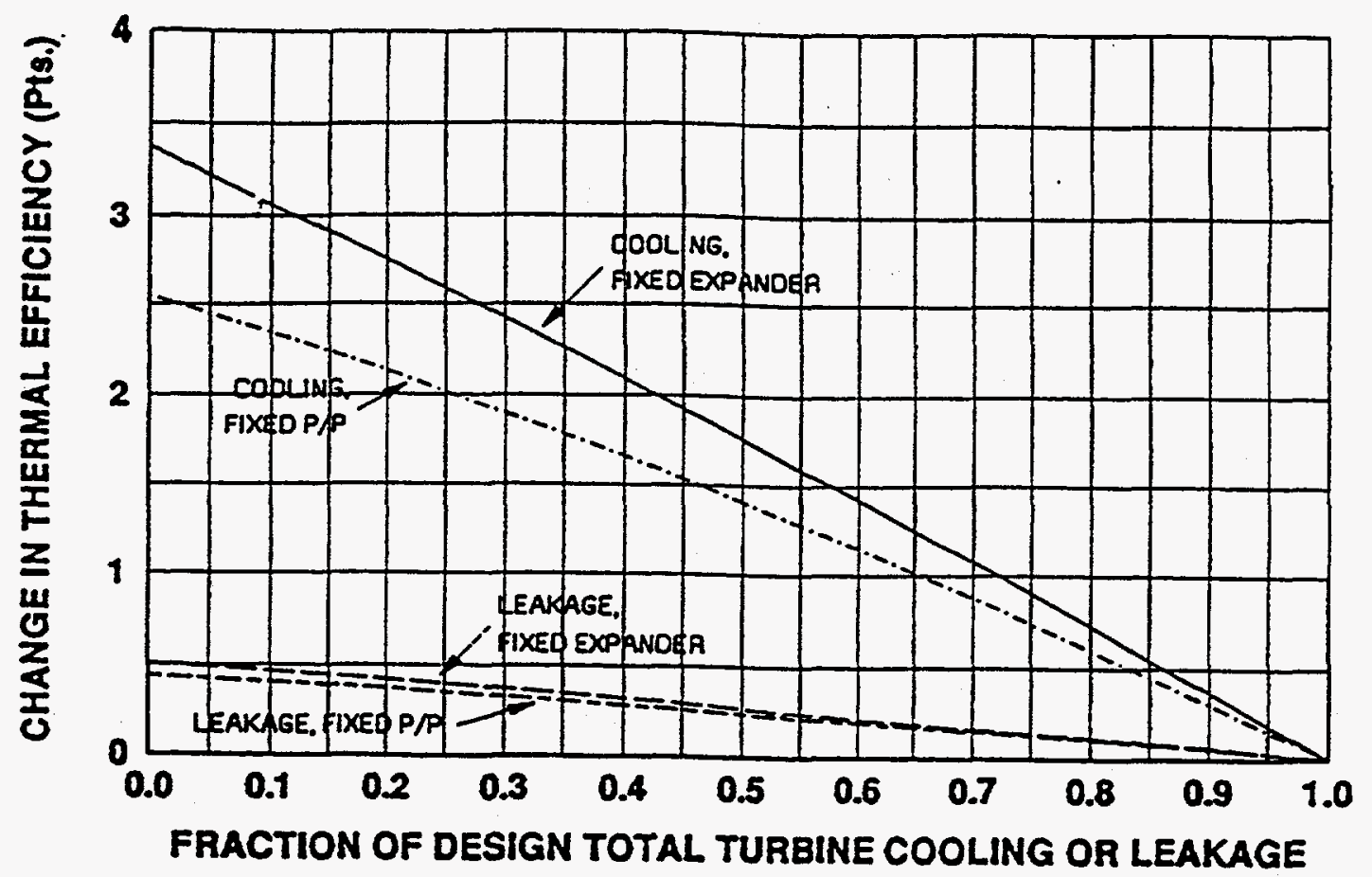

\section{INCREASED COMPRESSOR PRESSURE RATIO}

Commercial aircraft gas turbine engines are designed with high overall pressure ratios, to maximize the simple cycle efficiency. For the ideal Brayton gas turbine cycle, the cycle efficiency is a function solely of the cycle pressure ratio and increases with cycle pressure ratio. In real cycles, the effect of non-ideal components causes the peak efficiency pressure ratio to decrease significantly from that of the Brayton cycle. Figure 45 shows the effect of compressor pressure ratio on simple cycle performance for a family of engines based on the high temperature combustion turbine of the baseline configuration. Also included in Figure 4-5 are the corresponding steam cycle and combined cycle efficiencies. Note that the simple cycle efficiency curve is relatively flat above a pressure ratio of approximately 40 . This indicates that it is nearing the peak simple cycle efficiency. The steam cycle efficiency is seen to decrease with increasing combustion turbine pressure ratio. This is due to the reduction in combustion turbine exhaust temperature, which in turn reduces the maximum steam temperature and pressure and the steam's availability, and results in lower steam cycle efficiency. The effect of all of this on combined cycle efficiency is that it peaks around a pressure ratio of about 20 , but 
remains approximately constant for a relatively large increase in compressor pressure ratio.

Reducing the compressor pressure ratio below the baseline value of 18 results in a significant decrease in combined cycle efficiency. This is due to the fact that, since the maximum steam temperature considered for this study was $1050^{\circ} \mathrm{F}$, any decrease in pressure ratio below the baseline value of 18 , where the maximum steam temperatures are reached, will increase the turbine exhaust temperature while maintaining the steam temperatures at $1050^{\circ} \mathrm{F}$. This results in a much smaller increase in steam cycle efficiency than that obtainable by allowing the steam temperatures to rise with the turbine exhaust temperature. Figure $4-5$ shows the significant reduction in the slope of the steam cycle efficiency line at this point, which causes the combined cycle efficiency decrease.

The maximum work output of the Brayton cycle occurs at a significantly lower value of pressure ratio than that for the peak efficiency. Figure 4-5, which includes intercooled cycle characteristics to be discussed later, shows the specific output of the cycles in Figure 4-3 (solid lines). The simple cycle peak specific output occurs at a pressure ratio of approximately 18. Also, note that the steam cycle specific output is reduced as pressure ratio is increased, since there is less exhaust energy available to the steam cycle. The combined cycle specific output, which is merely the sum of the simple cycle and steam cycle specific outputs, decreases for increasing pressure ratio across the entire range shown.

The optimum pressure ratio design point involves the selection of the lowest pressure ratio at which the peak combined cycle efficiency level is obtained. Selecting the design point in this manner allows both efficiency and output to be maximized and the cost of electricity to be minimized (the high temperature engine baseline cycle is designed in this fashion).

The results of the above analysis apply to air cooled combustion turbines. To determine the optimum pressure ratio for closed-loop steam cooled turbines, the effects of the closed-loop steam cooling must first be considered. Since the turbine gas path temperature is reduced less for closed-loop steam cooling than for air cooling, the combustion turbine exhaust temperature is higher for closed-loop steam cooled turbines than air cooled turbines operating at the same pressure ratio. Application of closed-loop steam cooling to the baseline configuration results in an increase in turbine exhaust temperature of approximately $100^{\circ} \mathrm{F}$. Therefore, since Figure 45 indicates that cycle pressure ratio should be set so that turbine exhaust temperature is equal to the maximum steam temperature plus margin for the superheater approach, cycle pressure ratio must be increased to reduce the turbine exhaust temperature $100^{\circ} \mathrm{F}$. In the baseline cycle, this corresponds to increasing cycle pressure ratio from 18 to 25 . Note that the steam cycle will still have the same efficiency as the optimum steam cycle, but the combustion turbine simple cycle efficiency has been increased by approximately 3 percentage points (see Figure 4-5). This results in a further increase in combined cycle efficiency of 1.6 
percentage points, bringing the total combined cycle efficiency increase due to application of closed-loop steam cooling to 3.6 percentage points.

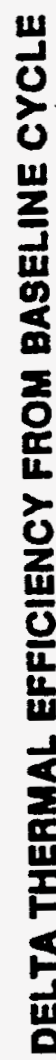

10

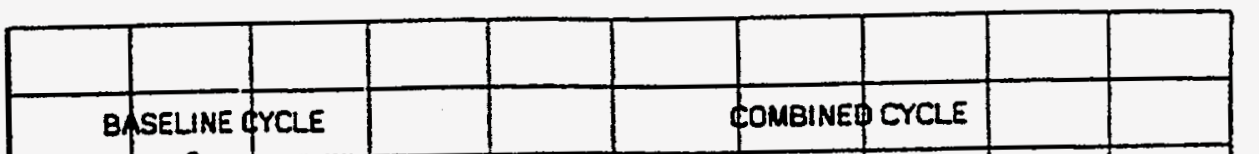

$-10$

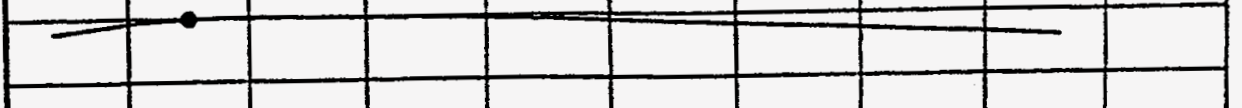

20

$-30$

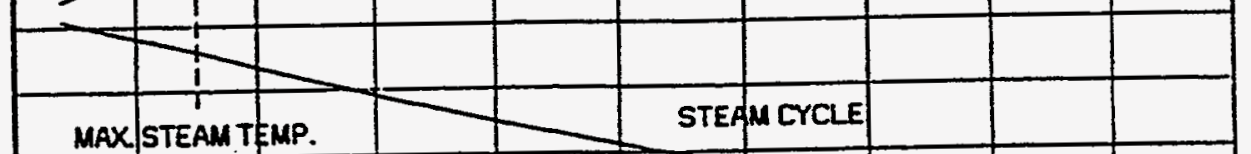
SIMPLE GYCLE

$-40$

MAX STEAM TEMP.

$-50$

10

20

40

50

60

COMPRESSOR PRESSURE RATIO

Figure 4-5. Effect of Compressor Pressure Ratio on Thermal Efficiencies

\section{INCREASED TURBINE INLET TEMPERATURE}

Since thermal efficiency increases with increasing turbine inlet temperature, the potential benefits of increased turbine inlet temperature were investigated. The RIT for the high temperature engine baseline cycle was increased $300^{\circ} \mathrm{F}$ to $2900^{\circ} \mathrm{F}$. This resulted in a cycle output increase of $10 \%$, and combined cycle thermal efficiency increase of slightly more than 1 percentage point. The reason that the performance increase was relatively small for such a large increase in turbine rotor inlet temperature is that, since the cooling technology remained constant as the temperature was increased, large amounts of additional turbine cooling air were required to maintain turbine material operating temperatures at acceptable levels. This increase in cooling flow decreased cycle efficiency by the three mechanisms described earlier, and this significantly offsets the 
benefit of increasing the turbine rotor inlet temperature. Therefore, since efficiency and output would have been increased much more if turbine cooling was held at the same level as in the baseline cycle, increased turbine operating temperature must be accompanied by corresponding advancements in turbine cooling. However, even if cooling technology advancements were available to allow operation at much higher rotor inlet temperatures, the formation of $\mathrm{NOx}$ at these higher temperatures would result in unacceptable emissions characteristics.

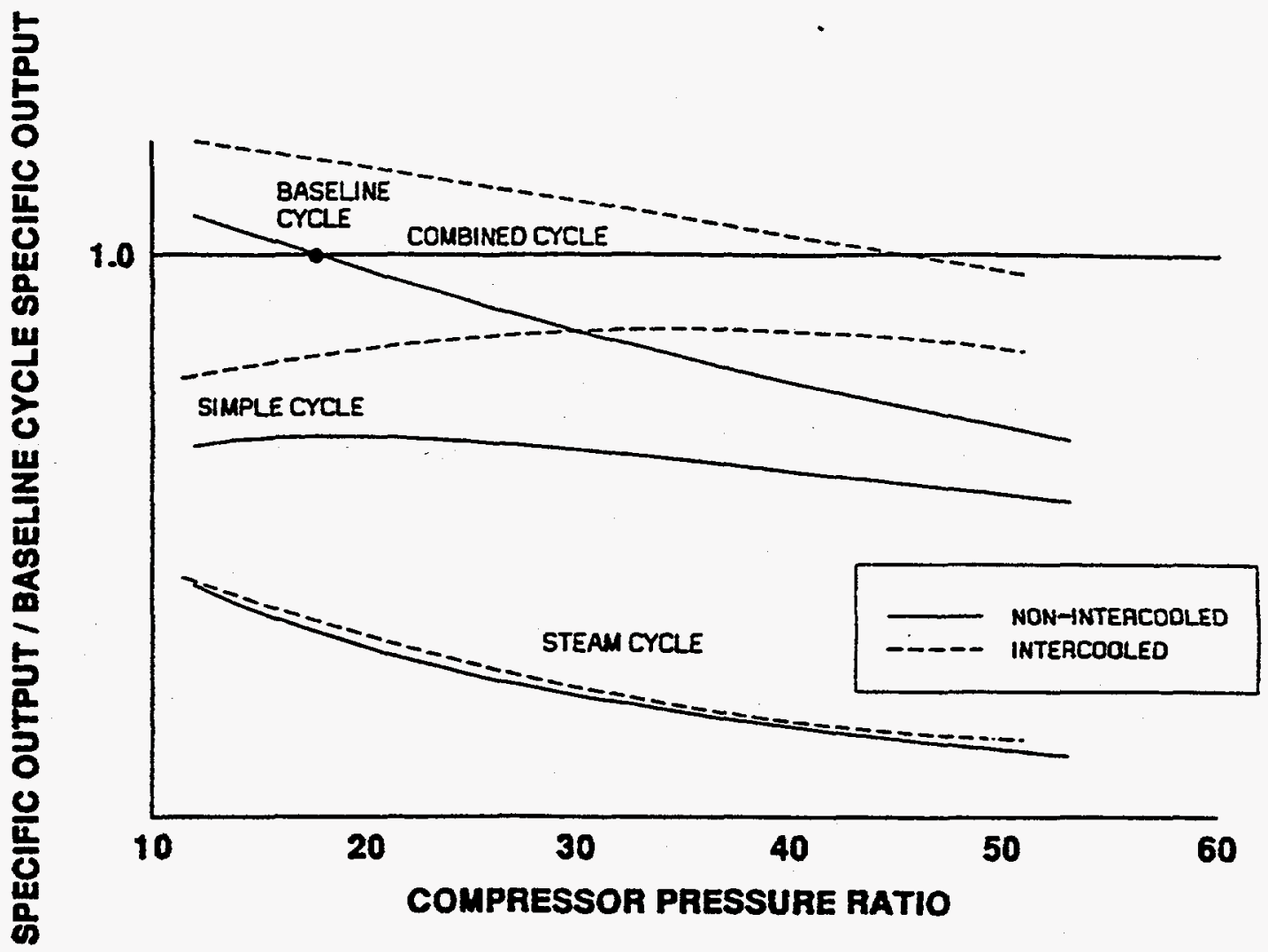

Figure 4-6. Effect of Compressor Intercooling on Specific Output

\section{COMPRESSOR INTERCOOLING}

The typical arrangement for compressor intercooling involves removing the compressor air flow partway through the compressor temperature rise, sending it through an air-towater heat exchanger, and then returning it to the compressor for further compression to combustor inlet pressure. The heat removed from the compressor air flow by the intercooler is rejected to the atmosphere, because, at the pressure ratios considered in this study, the heat is of too low a quality to be of use to the cycle. 
Another intercooling concept is to spray water droplets into the compressor. As the air is compressed and increases in temperature, the water evaporates and absorbs heat. This results in a continuous cooling of the compressor. Note that for this concept the heat absorbed by the water is also rejected to the atmosphere, since this water is never condensed by the cycle but instead exhausted with the stack gases as low pressure steam.

Compressor intercooling reduces the compressor work, because it compresses the gas at a lower average temperature. Since the combustion and steam turbines produce approximately the same output as in the non-intercooled case, the overall cycle output is increased. However, since the compressor exit temperature is lowered, the amount of fuel that must be added to reach a given turbine inlet temperature is greater than that for the non-intercooled case. The ratio of the amount of compressor work saved to the amount of extra fuel energy added is about equal to the simple cycle efficiency. It can therefore be concluded that intercooling adds output at approximately the simple cycle efficiency. Since combined cycle efficiencies are significantly greater than simple cycle efficiencies it would be expected that the additional output at simple cycle efficiency would reduce the combined cycle net plant efficiency for the intercooled case. Figure4-7 verifies this expectation and shows that this trend is the same for a wide range of cycle pressure ratios. Note that the simple cycle shows almost no change in efficiency for intercooling, which is expected since output is added at approximately the simple cycle efficiency.

Figure 4-6 shows the effect of intercooling on specific output. Since the compressor work requirement is reduced while the gas and steam turbine work outputs remain approximately the same as in the non-intercooled case, the net power output of both the simple and combined cycles is increased. Also, since the turbine exhaust temperature is increased slightly due to the aforementioned exhaust gas composition effects, the steam cycle specific output is also increased slightly.

\section{RECUPERATION}

In recuperative cycles, turbine exhaust heat is recovered and returned to the combustion turbine combustor, usually via a heat exchange between the turbine exhaust gases and the compressor exit air flow. The discharge from the compressor exit is piped to an exhaust gas-to-air heat exchanger located aft of the combustion turbine. It is then heated by the turbine exhaust and returned to the combustor. Since the resulting combustor air inlet temperature is increased above that of the non-recuperated cycle, less fuel is required to heat the air to a given turbine inlet temperature. Because the turbine work and the compressor work are approximately the same as in the non-recuperated cycle, the decrease in fuel flow results in an increase in thermal efficiency. This is especially true for the simple cycle, since the heat recovered by recuperation is rejected to the atmosphere in the non-recuperative case. For combined cycles the efficiency is also increased, because the combustion turbine recovers the recuperated heat at the simple 
cycle efficiency, which is larger than the 30 to $35 \%$ thermal efficiency of the bottoming steam cycle, which recovers this heat in the non-recuperated case.

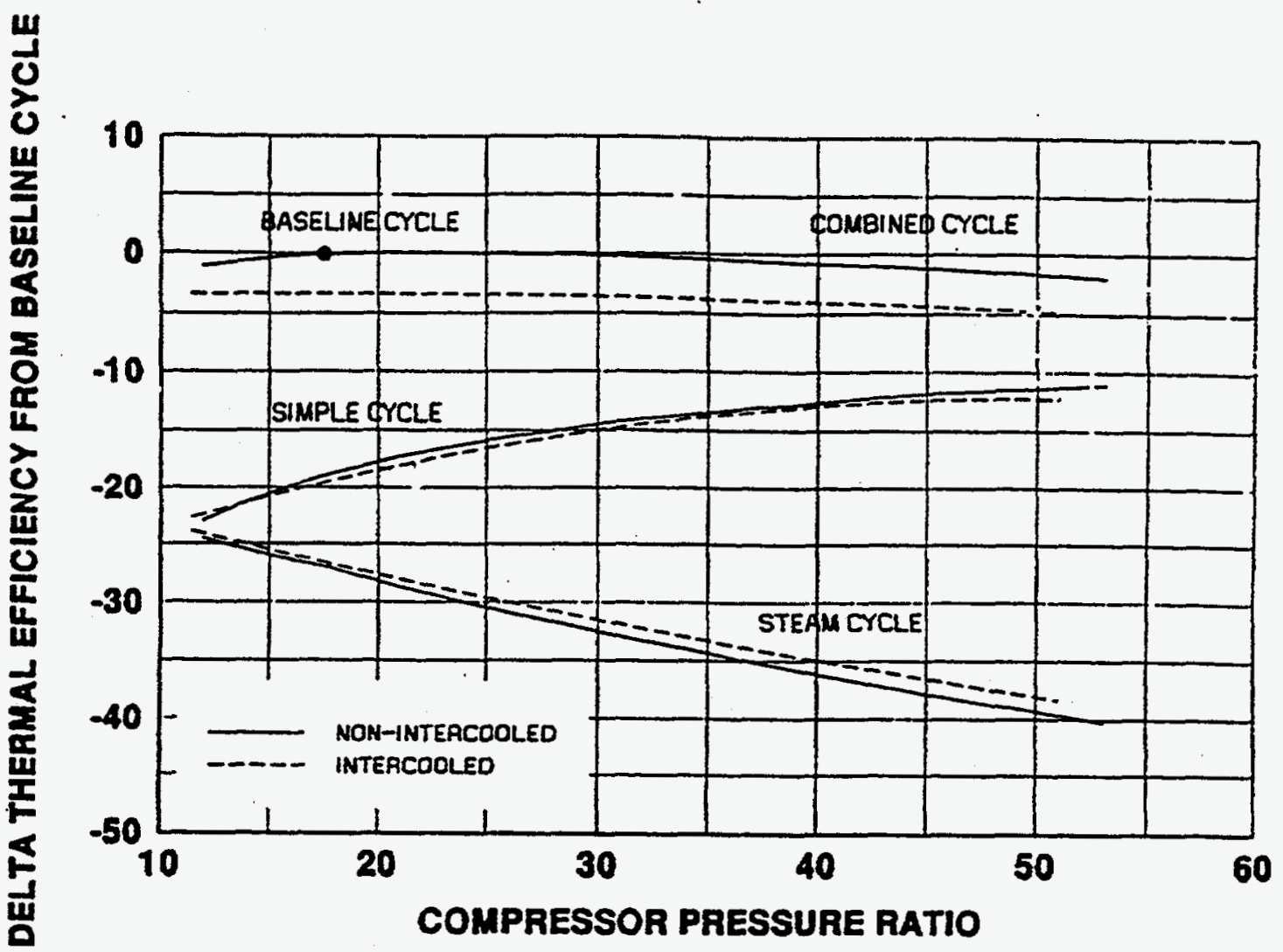

Figure 4-7. Effect of Compressor Intercooling on Thermal Efficiencies

Installation of a recuperation system on the baseline configuration results in an increase in thermal efficiency of 1 percentage point. The steam cycle in this recuperated cycle has a lower efficiency than the steam cycle in the baseline configuration, because the recuperator exit temperature is significantly lower than the turbine exhaust temperature. However, the effect of reduced steam cycle efficiency is smaller than the effect of recovering the recuperated heat at the combustion turbine efficiency.

Since the combustor inlet flow is smaller than the turbine exhaust flow (due to the removal of the turbine cooling air prior to combustion) and has a higher specific heat (due to the combustion of the fuel), the heat capacity of the turbine exhaust flow is somewhat higher than that for the burner inlet flow. This means that the recuperated cycle described above does not fully utilize the quantity of heat available in the turbine exhaust. By placing a steam superheater in parallel with the recuperator, the remainder of the available turbine exhaust heat can be recovered at its maximum quality. The maximum steam 
temperature can then be raised to that of the baseline cycle $\left(1000^{\circ} \mathrm{F}\right)$, and the cycle efficiency is increased by an additional 0.1 percentage point.

Since recuperative cycles return exhaust energy to the combustion turbine, less energy is available to the steam cycle, and the resulting steam turbine output is lower than that of the baseline configuration. However, the combustion turbine output is approximately the same as in the baseline cycle (minus losses in the recuperation system). This means that recuperative cycles carry a significant output penalty, with this penalty being proportional to the amount of recuperation performed.

\section{INTERCOOLING WITH RECUPERATION}

For a simple cycle, the combination of intercooling with recuperation eliminates the problem of the reduced combustor inlet temperature associated with intercooled cycles. The simple cycle then gets the benefit of the reduced compressor work and, at all but high pressure ratios, actually has a higher burner inlet temperature than the corresponding nonintercooled, non-recuperated cycle. This results in a dramatic increase in the simple cycle efficiency.

However, the bottoming cycle receives even less energy than in the recuperated cycle, since the recuperator removes much more heat from the turbine exhaust than in the recuperated, non-intercooled cycle. The additional heat removed corresponds to the heat rejected to the atmosphere by the intercooler. This means that we have merely displaced the lost energy of the intercooler by taking energy from the bottoming cycle. This is in addition to the energy already removed from the bottoming cycle in the non-intercooled, recuperative cycle. This results in a very low recuperator exit temperature, which in turn translates into a low generated steam pressure (low availability) and a low efficiency steam bottoming cycle. The result is that, while simple cycle efficiency can be increased to over $50 \%$, the combined cycle efficiency is reduced for the entire useful range of compressor pressure ratios. For conventional air-to-water heat exchanger intercooling of the compressor, the combined cycle efficiency is reduced approximately 1.9 percentage points at the baseline cycle pressure ratio. For continuously cooled compressors utilizing water droplet spraying into the compressor, the combined cycle efficiency is reduced by 0.4 percentage point.

Since the continuously cooled compressor with recuperation is not far below the baseline level of combined cycle thermal efficiency, it is worth investigating further optimization of the steam cycle in this case. As mentioned earlier, steam may be superheated in parallel with the recuperator, yielding more efficient recovery of the heat available to the steam cycle. Utilizing this approach, along with a two pressure level steam cycle, results in an increase in net plant efficiency of 0.8 percentage point over the baseline efficiency level.

Another approach to optimizing the intercooled recuperative cycle is to place a saturator between the compressor exit and the recuperator entrance, as illustrated in the combined cycle shown in Figure 49. This saturator, also called an aftercooler, evaporates water 
into the compressor exit flow, resulting in a lower temperature, higher mass flow entering the recuperator. While this may be seen as a way to better balance the heat capacities of the hot and cold streams in the recuperator and thereby increase the amount of heat recuperated by the combustion turbine (in addition to the fact that the air flow is at lower temperature), it is important to realize that all of this additional recuperation is accomplished by the evaporation of water in the saturator. Since this water is never condensed by the cycle but instead is rejected through the stack as low pressure steam, the additional amount of energy recuperated is not recovered anywhere in the cycle. Furthermore, the recuperator exit temperature is reduced even further than in the intercooled recuperative cycle, resulting in an even lower efficiency steam cycle.

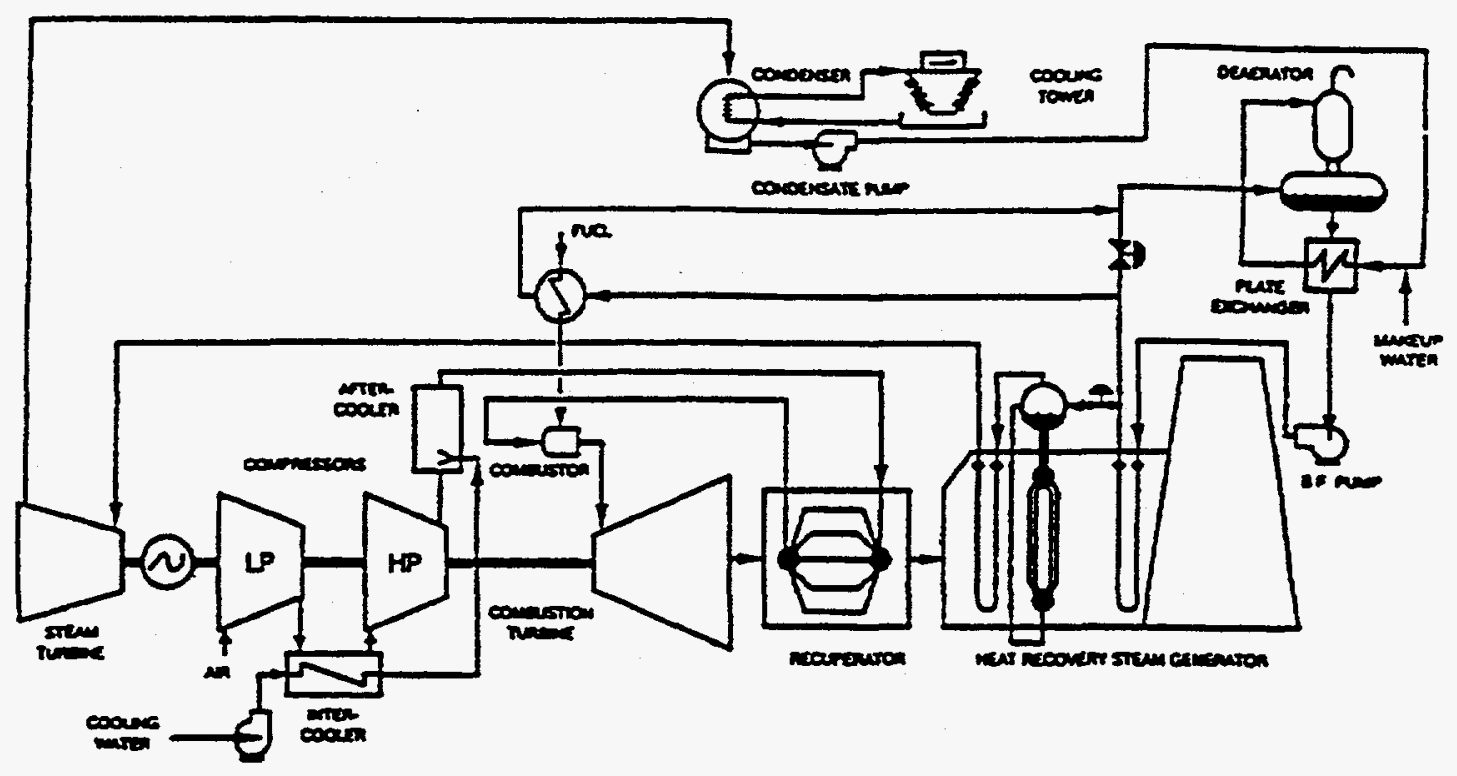

Figure 4-8. Intercooled, Aftercooled (Evaporative), Recuperative Combined Cycle 
Finally, since the heat capacity of the cold side recuperator flow now closely matches that of the hot side flow, parallel steam superheat cannot be utilized to increase the steam cycle efficiency. The application of this concept to the baseline cycle results in a decrease in thermal efficiency of 2 percentage points.

\section{REHEAT COMBUSTION TURBINE}

Reheat combustion turbines utilize a two step combustion process in which the air is compressed, combusted, expanded in a turbine to some pressure significantly greater than ambient, combusted again in a second combustor, and finally expanded by a second turbine to near ambient pressure. For a fixed turbine rotor inlet temperature limit, the simple cycle efficiency is increased for a reheat combustion turbine compared to a nonreheat cycle operating at a pressure ratio corresponding to the second combustor's operating pressure. This is because the reheat cycle performs some of its combustion and expansion at a higher pressure ratio, which increases simple cycle efficiency (see section on increased compressor pressure ratio). From a purely thermodynamic standpoint, the average temperature at which heat is added is raised, thus raising the Carnot efficiency of the cycle. For combined cycles the turbine exhaust temperature can be controlled by the selection of second turbine inlet temperature and expansion ratio. This in turn allows control over the efficiency of the steam bottoming cycle.

Another beneficial feature of reheat combustion turbine cycles is that they exhibit higher output for a fixed compressor flow rate and turbine inlet temperature than non-reheat cycles. This is due to the fact that they burn sequentially with an expansion between the combustors. This allows for the addition of more fuel (in the second combustor) without violation of the turbine rotor inlet temperature limit. Also, since this results in a higher fuel-to-air ratio than in non-reheat cycles, they burn closer to stoichiometry and exhaust lower concentrations of excess oxygen.

Applying combustion turbine reheat to the baseline cycle, with the second combustor operating at the exit pressure and temperature equal to those of the baseline cycle, results in nearly identical turbine exhaust temperatures, and therefore the steam cycle of the combustion turbine reheat case is not compromised and is identical to the steam cycle of the baseline cycle. However, the compressor pressure ratio has been increased to 36 . This necessitates the addition of 6 compressor stages, and an additional combustor and turbine stage located upstream of the second combustor. The simple cycle efficiency is increased nearly 2 percentage points from the baseline simple cycle level. Since steam cycle efficiency remains at the level of that in the baseline cycle, the combined cycle efficiency is increased 1.3 percentage points.

An investigation was made into the application of intercooling and recuperation to reheat combustion turbine cycles with the same, reduced efficiency results as for non-reheat combined cycles. 


\section{THERMOCHEMICAL RECUPERATION}

In a thermochemical recuperation power plant, a portion of the stack exhaust (flue) gas is removed from the stack, compressed, mixed with natural gas fuel, heated with exhaust heat from the combustion turbine, and mixed with the compressor exit air as it enters the combustor. As the mixture of natural gas and flue gas is heated by the combustion turbine exhaust, an endothermic reaction occurs between the methane and the carbon dioxide and water in the flue gas. This reaction occurs in the presence of a nickel-based catalyst, and results in the production of hydrogen and carbon monoxide. For complete conversion of the methane, the effective fuel heating value is increased approximately $30 \%$. Therefore, the natural gas / flue gas mixture absorbs heat thermally (as it is heated) and chemically (via the endothermic reaction), resulting in a larger potential recuperation of exhaust energy than could be obtained by conventional recuperation, which recovers energy by heat alone. In fact, with full conversion of the natural gas fuel to hydrogen and carbon monoxide, up to twice the energy recuperated by the standard recuperative cycle may be recovered.

The endothermic reaction described above is accelerated for low excess oxygen in the reacting mixture, low pressures, and high mass ratios of recirculated flue gases to methane. Therefore, in order to take full advantage of this concept, the engine is controlled by running the combustor at near stoichiometric fuel-to-air ratios $(10 \%$ excess air at the combustor exit) and using flue gas recirculation to quench the combustion products down to the desired turbine inlet temperature. This maximizes flue gas recirculation and minimizes excess oxygen in the flue gas. For typical cycles utilizing this control philosophy, the resulting recirculation rate of flue gas is over $50 \%$ of turbine flow. This means that both the air compressor flow rate and stack exhaust flow rate are less than half that of conventional cycles with the same turbine size.

Another advantage of the thermochemical recuperation / flue gas recirculation (TCR/FGR) concept is that, because the fuel has a low adiabatic flame temperature, it contains a significant amount of hydrogen and operates with very low levels of excess oxygen in the exhaust, the resulting emissions of NOx and $\mathrm{CO}$ are much lower than those for conventional design power plants.

When applied to the baseline configuration, thermochemical recuperation yields a combined cycle thermal efficiency over 2 percentage points greater than that of the baseline cycle for several different TCR/FGR configurations. There are many possible cycle configurations, other than those described above, which can utilize thermochemical recuperation. One of these, using steam reforming, is illustrated in Figure 49. 


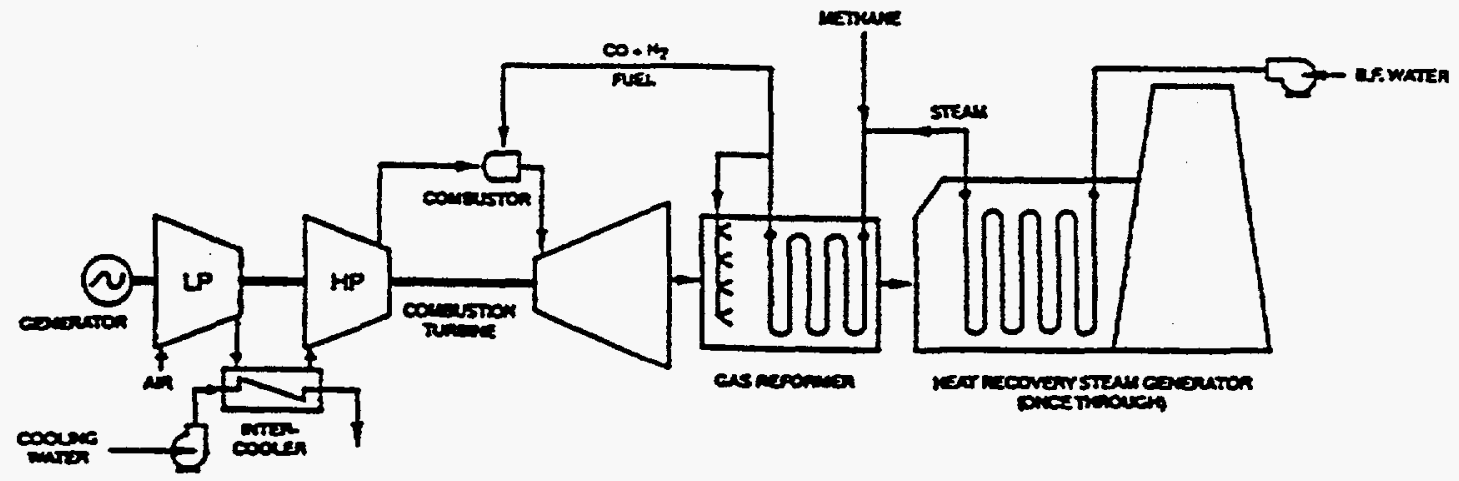

Figure 4-9. Thermochemical Recuperation Cycle with Steam Reforming

\section{STEAM INJECTION}

To apply steam injection to the baseline configuration, both the high pressure and low pressure steam systems are eliminated, leaving only the intermediate pressure steam system. The intermediate pressure superheated steam is then routed into the combustion turbine combustor inlet. Therefore, all steam turbines are eliminated, along with the condenser and the cooling tower. This results in a cycle which is significantly less expensive to build than the baseline cycle and it provides a means to reduce NOx emissions via the large amount of steam injection. However, the cost associated with demineralization of the large cycle make up flow must also be considered.

For a given turbine flow area, the compressor flow size must be reduced significantly, due to the addition of a large amount of steam, which now must pass through the turbine in addition to the compressor exit air flow. Since the steam is generated with exhaust heat, which is not used in a simple combustion turbine cycle, this concept provides a 
significant portion of the combustor inlet gas flow with very little work requirement (a small amount of energy is needed to run the feedwater pumps which pump the water to the intermediate steam pressure). Therefore, from a simple cycle standpoint, the work of compression is much reduced due to the fact that some of the combustor inlet gas flow is compressed as a liquid. Also, the turbine output is increased significantly, since the average specific heat of the working fluid is increased considerably by the presence of the steam. The simple cycle efficiency and output are therefore increased by steam injection.

Compared to combined cycles, however, elimination of the high pressure steam system results in generation of more intermediate pressure steam, but this steam is at significantly lower availability due to its lower pressure. Also, since the low pressure steam system has been eliminated as well, the exhaust stack gas temperature is much higher, as is the associated heat loss. Finally, since the steam injected into the gas turbine is effectively throttled to its partial pressure upon mixing with the compressor exit air without doing any work, and is only expanded to its partial pressure in the exhaust stack (which is significantly higher than typical low pressure steam turbine exit pressure), the resulting steam expansion ratio is much smaller than that of the conventional steam turbine cycle. These losses result in a reduction in combined cycle efficiency in the range of 5 to 8 percentage points. Net plant output, while much higher than the baseline configuration simple cycle output, is less than the combined cycle output.

\section{EVALUATION OF CANDIDATE SYSTEMS}

Seven natural gas-fired combustion turbine power plants were selected to be evaluated using Version 6 of the Electric Power Research Institute (EPRI) Technical Assessment Guide (TAG). A RAM analysis was also performed for each plant configuration.

Westinghouse, Gilbert/Commonwealth (G/C) and EPRI data bases were used to estimate the cost of advanced and commercially available systems. The EPRI TAG was then used to calculate the levelized Cost of Electricity (COE) for each plant. The levelized COE is a sum of five levelized components (i.e., carrying charges [a function of capital cost], fixed and variable operating and maintenance expense, variable operating and maintenance expense, cost of consumables, and fuel costs).

The following assumptions were made for all seven plant configurations:

\section{Location - Ohio River Valley}

Capital Cost Year Dollars - 1994 (January)

Delivered Cost of Natural Gas - \$3.00/MBtu

Land Area/Unit Cost - 12.5 acre $(\$ 8,000 /$ acre $)$

Project Book Life - 30 years 
Project Tax Life - 20 years

Tax Depreciation Method - Reform

Property Tax Rate - $1.0 \% /$ year

Insurance Tax Rate - $1.0 \% /$ year

Federal Income Tax Rate - $34.0 \%$

State Income Tax Rate - $6.0 \%$

Weighted Cost of Capital - $10.8 \%$

General Escalation - 4.0\%/year

Fuel Price Escalation - 6.5\%/year

For the seven natural gas-fired combustion turbine cycles evaluated, a capacity factor of $90 \%$ was assumed. The plant configuration designated ATS with a $25: 1$ pressure ratio was selected as the best economical choice that also has a plant RAM (92\%) equivalent to today's commercial practice. (The combustion turbine RAM for ATS is $95 \%$ which again matches today's commercial practice.)

This ATS plant was compared against the Reference Plant (a combined cycle which uses a Westinghouse $501 \mathrm{~F}$ combustion turbine), a new high temperature combustion turbine with a standard Rankine cycle, a new high temperature combustion turbine with an improved Rankine cycle, an ATS plant with a $(35: 1)$ pressure ratio, a recuperative cycle, and a reheat combustion turbine cycle. The calculated levelized COE for the selected ATS plant is $52.25 \$ / \mathrm{MWh}(5.23$ cents $/ \mathrm{kWh}$ ) versus $60.36 \$ / \mathrm{MWh})$ for the Reference Plant, a $13.4 \%$ reduction in $\mathrm{COE}$.

Evaluation showed that the ATS plant had the lowest COE. Comparisons were also made, separately, which showed how the capital and plant efficiency can vary and still maintain a $10 \%$ COE margin. For example, the capital cost for ATS could increase $13 \%$, but the COE for ATS would still be $10 \%$, less than the Reference Plant. For the recuperative cycle a $10 \%$ decrease in capital cost is required to lower the COE margin from $6.7 \%$ to $10.0 \%$. 


\section{SECTION 5}

\section{CONVERSION OF AN ADVANCED NATURAL GAS-FUELED COMBUSTION TURBINE TO COAL-BASED FUEL APPLICATION}

\section{INTRODUCTION}

Currently, development and demonstration programs are under way that are applying advanced, coal-fueled technologies for clean, effective power generation using the current generation of combustion turbines. Integrated gasification combined cycles (IGCC), pressurized fluidized bed combustion (PFBC), and second-generation PFBC are examples of advanced, coal-conversion technologies that will be demonstrated in the next 5 to 10 years.

Today's gas turbine systems feature high fuel-to-electricity efficiencies. Efficiencies, on a lower heating value (LHV) basis, for large natural-gas-fired combined-cycle systems for the utility market have been demonstrated at $54 \%$. Cycle innovations, plus gas turbine design advancements will achieve LHV efficiencies greater than $60 \%$ for natural gas-fired utility machines. Within the United States, a 250-year coal reserve has been identified. Therefore, developing advanced systems that can use coal or biomass derived fuels are candidates to ensure that the United States will have cost-effective, and environmentally sound options for supplying post 2000 power generation needs.

A natural gas-fired advanced turbine system (GFATS) combined cycle reference system has been selected and described by Westinghouse. This GFATS meets the established advanced turbine systems (ATS) program goals for power plant thermal performance ( $>60 \% \mathrm{LHV}$ ) and emissions (NOx $<10$ ppmvd at $15 \%$ oxygen. This paper discusses the conversion of GFATS to a coal-fueled advanced turbine system (CFATS). Two coalbased applications are described. Their development issues and emissions and performance levels are reviewed.

\section{SELECTION OF COAL-FIRED PLANT REFERENCE SYSTEM}

A number of advanced, coal-fired power generation technologies have been under development that could be applied to the GFATS. These include a broad range of coal gasification technologies (fixed bed, fluid bed, and entrained bed), second-generation pressurized fluidized bed combustion (PFBC), and direct coal-fired turbines (DCFTs), and indirectly coal-fired, heated air turbines. Two advanced, coal-fueled technologies have been selected for consideration as CFATS: air-blown integrated gasification combined cycle (IGCC), with hot gas cleaning, based on the Kellog, Rust, Westinghouse (KRW) fluidized bed gasifier; and second-generation PFBC. 
The selection of a coal-fired reference system for the conversion of the GFATS to a CFATS has been made based on performance potential ( high efficiency and low emissions), cost potential, and state of development. The air-blown IGCC technologies with hot gas cleaning, and second-generation PFBC appear to have the greatest thermal performance and cost potential based on published process evaluations and cost comparisons. Their respective status of development is categorized as early demonstration, which is suitable for the ATS program.

Air-blown IGCC with hot gas cleaning, and second-generation PFBC have outstanding environmental performance. The solid waste from these technologies without sorbent regeneration is higher than that from several other advanced technologies, but is lower than that from conventional, coal-fired power plants. Solid waste disposal, potential byproduct uses and sorbent are development issues.

Air-blown, fluidized bed coal gasification processes with hot gas cleaning [e.g., the KRW gasifier (Sierra Pacific, Pinon Pine Project) and second-generation PFBC (Air Products, Four Rivers Energy Modernization Project)] are scheduled to be demonstrated in Clean Coal Technology Programs. Both of these technologies are considered for CFATS because they pose very similar conditions and constraints on the combustion turbine and are both involved in major demonstration programs that will lead to commercialization.

These selected technologies also provide greater challenges to the combustion turbine than other advanced technologies such as oxygen-blown gasification with cold gas cleaning, because: 1) air-blown, hot gas cleaning systems deliver a high-volumetric flow of low-Btu fuel gas to the combustion turbine at a high temperature, requiring large manifolding/combustion systems adapted to high-temperature duty; and, 2) hot gas cleaning produces fuel gas conditions with potentially higher contaminant contents than do low-temperature cleaning systems. Successful development of the selected CFATS implies that adaptation to the other coal-fueled and biomass technologies can be achieved.

\section{IGCC CFATS DESCRIPTION}

An IGCC, CFATS process flow diagram, illustrated in Figure 5-1, is representative of several types of air-blown, coal gasification plants with hot gas cleaning being developed in Clean Coal Projects, such as the Sierra Pacific, Pinon Pine Project (KRW fluid bed gasifier), the Tamco Power Partners, Tom Creek Project (Institute of Gas Technology fluid bed gasifier), and the Springfield Project (ABB Combustion Engineering entrained gasifier). Estimates of plant cycle performance and emissions were made for a specific $\mathrm{KRW}$ fluid bed gasification process using process design information reported in a recent DOE/METC study. 
In the process diagram, coal and a sulfur sorbent, limestone or dolomite, are prepared (sized and dried) for feeding using conventional handling and preparation equipment. The coal and sorbent are pressurized and distributed to the fluid bed gasifier by a commercial feeding system in either dry or slurry form. The gasifier generates a low-Btu fuel gas that has been partially desulfurized by the in-bed sorbent.

The fuel gas is pre-cleaned by conventional cyclones and the captured ash, char and sorbent particles are either recycled to the gasifier or removed for solid waste processing. The fuel gas is cooled by indirect, high-pressure steam heat exchanger, to a temperature of $800^{\circ}$ to $1000^{\circ} \mathrm{F}\left(427^{\circ}\right.$ to $\left.538^{\circ} \mathrm{C}\right)$, as dictated by the zinc-based, sulfur removal process. After cooling, the fuel gas sulfur content is reduced to an acceptable level by a regenerative, zinc-based, fluid bed sulfur removal process. The sulfur removal process may either produce a sulfur by-product, or recycle the regenerator sulfur stream to the gasifier; or to solid waste processing. The desulfurized fuel gas then passes through a ceramic barrier filter for final particle removal before entering the combustor. Fuel gas particle content is limited to a total solids content and maximum particle size acceptable to the turbine expander, as well as to environmental standards.

Air provided by the turbine compressor burns the fuel gas and produces combustion products at the desired temperature. The combustor is a dry, low-NOx design that is closely integrated with the turbine. A portion of the turbine compressor air also is boosted in pressure for gasifier oxidant supply. The combusted fuel gas is expanded in the turbine, and steam is generated in the heat recovery steam generator (HRSG) for the steam bottoming cycle. A portion of the high-pressure, cold reheat steam is consumed in the gasifier, assisting the coal gasification reactions. High-pressure steam is also heated in the fuel gas cooler. The stack gas temperature exiting the HRSG is limited by the gas dew point for its prevailing acid-gas content.

Waste solids from the gasifier, the cyclones and the ceramic barrier filter are treated in a waste process facility to utilize the waste solids fuel content and sensible heat content, and to render the waste environmentally acceptable.

The coal gasification process chosen for study is the KRW process. It utilizes a bed of char and ash with limestone sorbent added for fuel gas desulfurization and volatile product cracking. The bed is fluidized by the air and steam required for carbon conversion and temperature adjustment. The ash is agglomerated to facilitate its removal. The fuel gas leaving the fluidized bed is cleaned hot. The possible cleaning steps include:

- $\quad$ absorption of residual $\mathrm{H}_{2} \mathrm{~S}$ and alkalis $(\mathrm{Na}$ and $\mathrm{K}$ compounds carried in the gas) by solid sorbents,

- reduction of the $\mathrm{NH}_{3}$ content by catalytic decomposition,

- removal of particulates by a filter. 


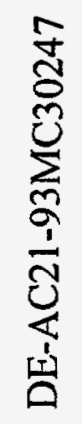

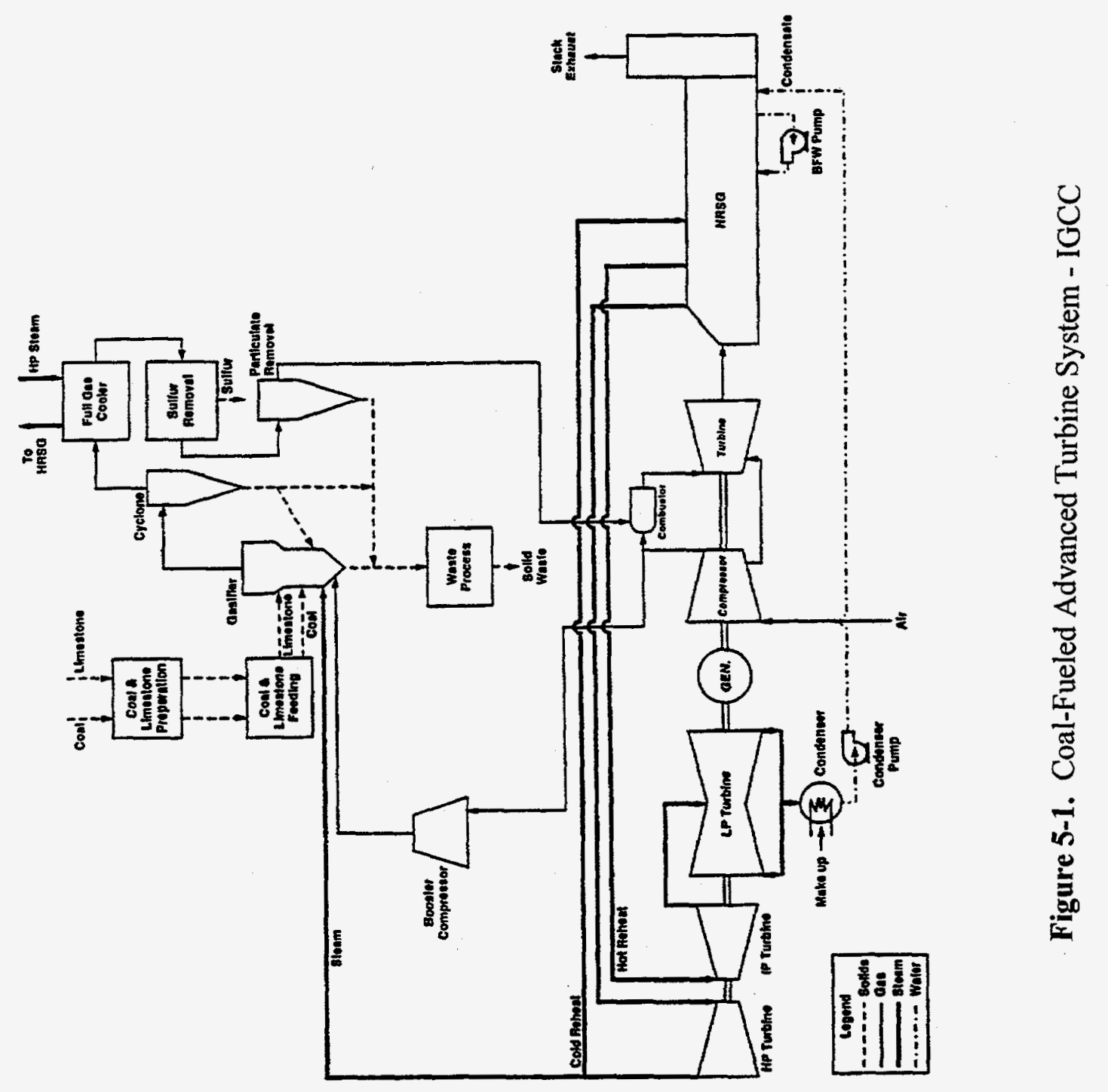


The temperature of the fuel gas between the gasifier and the turbine is lowered for cleaning and for delivery to the turbine at $1000^{\circ} \mathrm{F}$. This reduction is accomplished either by a steam quench or preferably by heat interchange for best efficiency, with the steam and/or air fed to the gasifier.

The ash and sorbent solids removed from the bed are oxidized with air to recover their carbon content as heat and to convert the sulfided limestone based sorbent to a sulfate, suitable for disposal. The temperature of the process must be carefully controlled to prevent the release of sulfur from the sulfided sorbent as $\mathrm{SO}_{2}$. An alternative process carries out the oxidation of the ash and sorbent at pressure with the return of the hot gases to the gasifier. In this instance, the heat is efficiently recovered in fuel production, and the escape of $\mathrm{SO}_{2}$ is effectively prevented.

\section{SECOND-GENERATION PFBC CFATS DESCRIPTION}

The process flow diagram in Figure 5-2 illustrates the general second-generation PFBC configuration adapted for the CFATS. Specific plant performance and emissions estimates were prepared for the specific configuration of the technology.

In the process diagram, coal and a sulfur sorbent, limestone or dolomite, are prepared (sized and dried) for feeding using conventional handling/preparation equipment. The coal and limestone are pressurized and distributed to the carbonizer with a commercial feeding system in either dry or slurry form. The carbonizer generates a low-Btu fuel gas that has been substantially desulfurized by the in-bed sorbent. The carbonizer differs from a gasifier in that it produces a large flow of char that must be burned separately. The carbonizer fuel gas acts as a topping fuel for the char combustor. Char drained from the carbonizer and captured by the cyclones and ceramic barrier filter is circulated to a fluidized bed combustor. In this combustor, char is burned, sulfur released from the char is captured by the sorbent contained in the solids from the carbonizer, and steam is generated in the fluid bed heat exchanger (FBHX).

The fuel gas and combustion gas streams are pre-cleaned by conventional cyclones. Neither the fuel gas or the combustion gas is cooled before final particle control is performed by ceramic barrier filters. Additional sulfur removal is not required. Particle penetration is limited to total content and particle sizes acceptable to the turbine expander. Alkali removal may be required from the fuel gas or vitiated air streams.

Vitiated air from the fluid bed combustor fires the fuel gas to a desired temperature of $2700^{\circ} \mathrm{F}$. The combustor is a dry, low-NOx design configured to utilize the hot fuel gas and the hot, vitiated air. A portion of the turbine compressor air is boosted in pressure for carbonizer oxidant supply. The fired fuel gas is expanded in the turbine, and steam is generated in the heat recovery steam generator for the steam bottoming cycle. A small portion of the high-pressure, cold reheat steam may be consumed in the carbonizer, 
preventing coking from occurring. The stack gas temperature in the HRSG is limited by the gas dew point at its prevailing acid-gas content.

Waste solids from the fluid bed combustor, the cyclones and the ceramic barrier filter are cooled to use waste solids sensible heat content. No treatment is required to render the waste environmentally acceptable.

\section{ESTIMATE OF CFATS PERFORMANCE AND EMISSIONS}

Performance and emissions estimates for IGCC (air-blown, fluidized bed gasifier with hot gas cleaning) and second-generation PFBC have been made using prior process studies for these technologies. The power cycle conditions in the prior studies were modified to the conditions of the CFATS, and process material and energy balances were developed to estimate the modified power plant performance. In both cases, significant increases in plant performance were obtained, while environmental emissions were maintained at low levels.

\section{PERFORMANCE AND EMISSIONS ESTIMATES}

The performance and emissions of the selected CFATS have been estimated by modifying the process designs found in the reference studies for these two technologies (Southern Company Services, 1990 and Foster Wheeler Corporation, 1989). Table 5-1 lists the power plant thermal performance for both the reference studies and the CFATS cases, along with the steam cycle conditions and the combustion turbine conditions. The fluidized bed IGCC system presented in the reference study has the following unique features:

- The moist coal is dried and preheated at atmospheric pressure prior to feeding into the fluidized bed gasifier. Hot combustion product gases from a combined carbon burnup/sorbent sulfation operation are used in this process and exhausted to the stack.

- The coal feed and the char recycle streams are transported with cooled, cleaned, and compressed fuel product gases. The recycle fraction is not quantified in the flow sheet, but calculations indicate that between $30 \%$ and $45 \%$ of the fuel product is recycled for coal and other transport. The recycle stream also provides most of the water vapor, steam, required to moderate the operating temperature of the gasifier. 


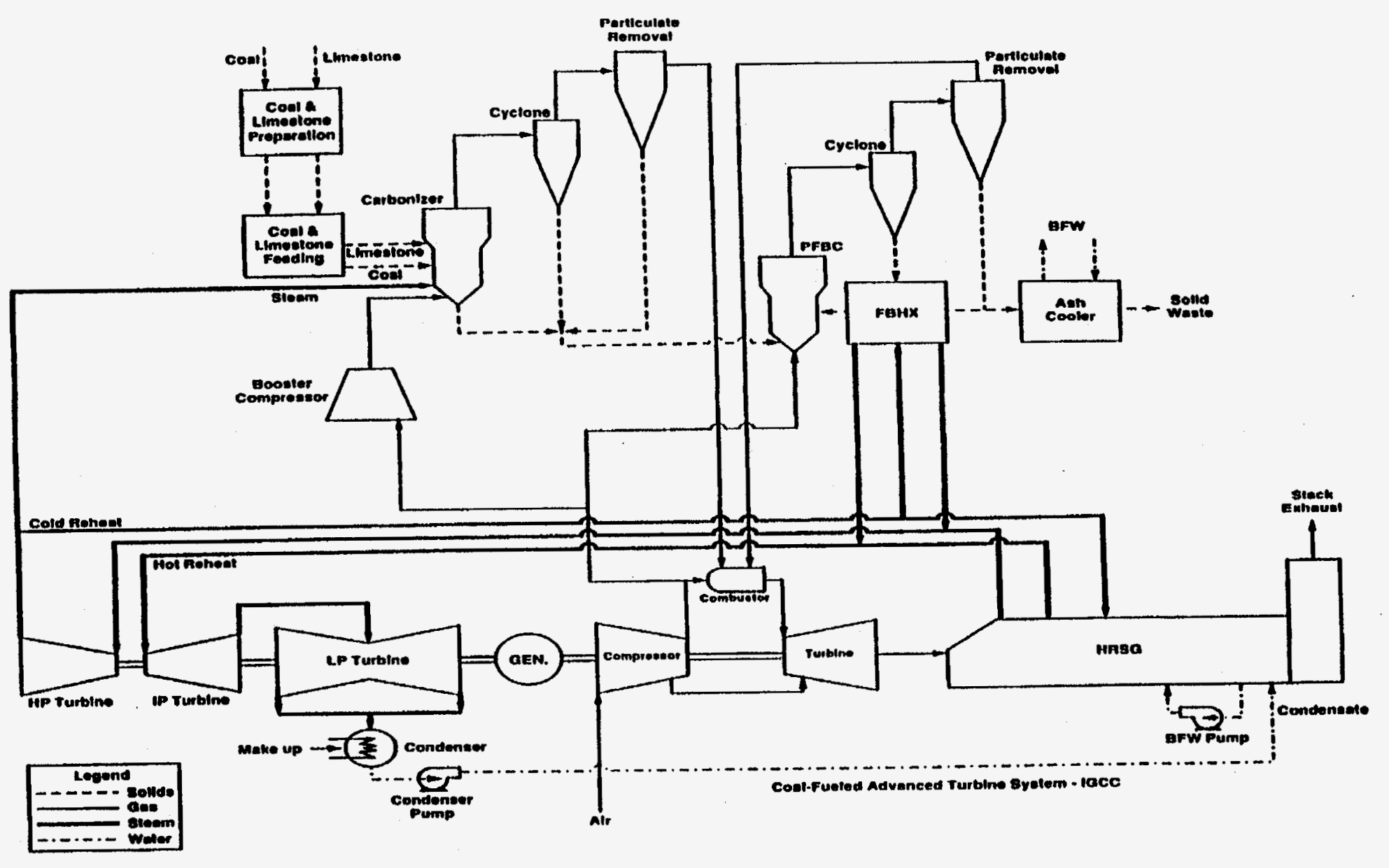

Figure 5-2. Coal-Fueled Advanced Turbine System -PFBC 
- $\quad$ The product fuel gas is cleaned -- $\mathrm{H}_{2} \mathrm{~S}, \mathrm{NH}_{3}, \mathrm{Na}, \mathrm{K}$, and $\mathrm{Cl}$; and particulate -- and cooled to $1000^{\circ} \mathrm{F}$ in preparation for recycle \&nd for feed to the turbine. Fuel gas cooling is completed with heat exchange, generating steam and hot boiler feed water for the bottoming Rankine cycle, and of steam quench, enhancing the steam content of the product gas for recycle to the gasifier and feed to the turbine.

The air/coal ratio is $3.4 \mathrm{lb} / \mathrm{lb}$. The steam/coal ratio estimated to be in the range 0.4 to 0.7 $\mathrm{lb} / \mathrm{lb}$. The $\mathrm{Ca} / \mathrm{S}$ mol ratio for the sorbent feed is 3.0 .

\section{Table 5-1 CFATS Thermal Performance}

$\begin{array}{cc}\text { IGCC } & \text { Second-Generation } \\ \text { (KRW gasifier) } & \text { PFBC }\end{array}$

\section{REFERENCE STUDY}

Steam turbine conditions

Temperature $\left({ }^{\circ} \mathrm{F}\right)$

Pressure (psig)

Combustion turbine conditions

Combustor outlet temperature $\left({ }^{\circ} \mathrm{F}\right)$

Expansion ratio

Stack gas temperature $\left({ }^{\circ} \mathrm{F}\right)$

Plant net efficiency (LHV)

Gasifier cold gas efficiency (LHV)

\section{CFATS PERFORMANCE}

Turbine frame

Steam turbine conditions

Temperature $\left({ }^{\circ} \mathrm{F}\right.$

Pressure (psig)

Combustion turbine conditions

Combustor outlet temperature $\left({ }^{\circ} \mathrm{F}\right)$

Expansion ratio

Stack gas temperature $\left({ }^{\circ} \mathrm{F}\right)$

Plant net efficiency (LHV)

Gasifier cold gas efficiency (LHV)

Gasifier hot gas efficiency (LHV)

$\begin{array}{cc}1000 & 1000 / \\ 1600 & 2400 \\ & \\ 2350 & 2800 \\ 14 & 12 \\ 280 & 280 \\ 41.5 & 48.7 \\ 72.1 & --\end{array}$

\section{Modified Process*}

ATS

ATS

1100

1100

1800

1800

2700

18

2700

280

18

50-53

280

86.8

95.8
$52-53$

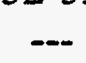

* Process was modified to incorporate coal drying, carbon burnup, and sorbent processing within the gasifier. Steam used for coal and char transport rather than recycle gas. Fuel gas cooling produced steam fed directly to the gasifier. 
A modified fluidized bed coal gasification process has been proposed and evaluated for the CFATS, having these distinct features.

- The moist coal and recycle char are fed to the gasifier in superheated steam. No cooled, cleaned, compressed fuel gas is recycled.

- Burnup of carbon from the ash and sulfation of the spent sorbent are carried out with air at system pressure, the hot gases are routed to the gasifier.

- The product fuel gas is cleaned as previously, but cooling is accomplished in exchangers which provide superheated steam (and perhaps also heated air) for gasification. No steam is exported to the bottoming Rankine cycle.

The air/coal ratio is $3.0 \mathrm{lb} / \mathrm{lb}$; the steam/coal ratio is $0.8 \mathrm{lb} / \mathrm{lb}$. The $\mathrm{Ca} / \mathrm{S}$ mol ratio is 2 . The gasification temperature is $1800^{\circ} \mathrm{F}$, the product fuel gas temperature, $1000^{\circ} \mathrm{F}$. Material and energy balances have been carried out for this process based on the Illinois No. 6 coal feed selected for the reference study described above.

The fuel gas quantity and composition have been calculated for this modified fluidized bed coal gasification process. Both the hot and the cold gas efficiencies are significantly increased by the process modifications. Further increases in efficiency, to the extent practical in the design and operation of the plant, might by obtained by:

- increasing the temperature of the product fuel gas fed to the gas turbine;

- reducing the air/coal, steam/coal, and sorbent/coal ratios; and,

- increasing the pressure and reducing the temperature of the gasification process.

The overall performance of a CFATS plant in power generation has been estimated based on the modified fluidized bed coal gasification process described above and on the selected GFATS cycle selected by Westinghouse for development. The Westinghouse GFATS cycle calculations have been used to define three work terms:

- compression of the air used in combustion, dilution, and gasification -assumed proportional to the mols of air;

- compression of the air used in turbine vane, blade, and rotor cooling -assumed proportional to the mols of hot gases entering the turbine;

- generation and expansion of steam in the bottoming Rankine cycle -assumed proportional to the mols of diluted combustion product gases times their specific heat times the temperature difference between inlet and outlet gases. 
The gasification and combustion calculations for the gasification process described above have been used to determine the proportionality factors described above and in turn to estimate the work quantities associated with the compressor, expander turbine, and bottoming cycle of a CFATS plant from those of the Westinghouse GFATS. The work of the booster compressor for air feed to the gasifier from the turbine compressor has been calculated based on an assumed efficiency and inlet temperature. Mechanical, electrical, and windage losses and auxiliary power for the generation section have also been estimated from the Westinghouse GFATS study and auxiliary power for the gasifier and coal feed sections, from the reference study, previously cited.

The second-generation PFBC reference study was a recent evaluation of a commercial plant using a high temperature turbine performed by Foster Wheeler and Gilbert/Commonwealth Associates. A major modification to this study was a significant reduction in the turbine air cooling needs. The CFATS conditions result in significant performance improvements over the reference studies.

Environmental performance estimates are listed in Table 5-2 for the CFATS cases. Comparison is also made with conventional, coal-fired power plants and with conventional, natural gas-fired power plants in the table. The basis of reporting the emissions in this table is per unit of net power output, $\mathrm{lb} / \mathrm{hr} / \mathrm{MWe}$, rather than the current per unit of fuel energy input, lb/MBtu. A large improvement for the CFATS relative to representative commercial coal-fueled technology is shown in this table.

\section{IDENTIFICATION OF DESIGN CHANGES TO GFATS}

While the two coal-based power systems differ significantly in their major process conditions, power cycles, process designs and equipment arrangements, both pose a similar set of requirements on the fuel gas combustion and the combustion gas expansion equipment. Both require effective use of the turbine compressor air supply with minimal compressor modifications. With both, a hot low-Btu fuel gas is generated that must be efficiently combusted, with acceptable NOx and $\mathrm{CO}$ emissions, producing the designated $2700^{\circ} \mathrm{F}\left(1482^{\circ} \mathrm{C}\right)$ combustor outlet temperature, uniformly distributed over the inlet of the turbine expander.

The GFATS consists of several functional components that must be modified for the CFATS: the air compressor, the combustor inlet fuel gas and oxidant gas manifolds, the flow controls, the combustor, the turbine inlet scroll, and the turbine expander. The GFATS compressor can be modified by standard techniques to provide the air requirements for the coal processing steps and for the low-Btu fuel gas combustor. Some $20 \%$ to $30 \%$ of the air leaving the combustion turbine compressor must be boosted in pressure and ducted to the coal gasifier. Customarily, the booster compressor, with associated cooling and heat recovery exchangers, is a device independent of the combustion turbine. Low pressure loss takeoffs for gasification air, as well as for turbine cooling air, are required. Also, because higher combustion product flows and higher gas temperatures in the turbine result from replacing natural gas fuel by coal gas, slightly 
Table 5-2 - CFATS Emissions Performance

\begin{tabular}{lllll}
\multicolumn{5}{c}{ Emission $(\mathrm{lb} / \mathrm{hr} / \mathrm{MW})$} \\
$\mathrm{NO}_{\mathrm{x}}$ & $\mathrm{SO}_{2}$ & $\mathrm{CO}_{2}$ & Particulate & Solid Waste
\end{tabular}

CFATS

IGCC (air-blown) ${ }^{\mathrm{a}}$

$1.4 \quad 0.64$

$1409 \quad 5.4$

212.3

2nd-Gen. PFBCb

1.3

1.55

1366

5.2

190.2

Conventional

\begin{tabular}{|c|c|c|c|c|c|}
\hline $\mathrm{AFBC}^{\mathrm{C}}$ & 2.8 & 4.45 & 1959 & 22.2 & 257.3 \\
\hline $\mathrm{PC} / \mathrm{FGD}^{\mathrm{d}}$ & 5.7 & 4.45 & 1959 & 22.2 & 244.6 \\
\hline Gas Simple-Cycle $\mathrm{f}^{\mathrm{f}}$ & 0.8 & -- & 1061 & --- & --- \\
\hline $\begin{array}{l}\text { Gas Combined- } \\
\text { Cyclef }\end{array}$ & 0.7 & $\cdots$ & 843 & --- & -- \\
\hline
\end{tabular}

a: $\mathrm{NO}_{\mathrm{x}} 0.2 \mathrm{lb} / \mathrm{MBtu}$, sulfur removal $98 \%, \mathrm{Ca} / \mathrm{S}$ ratio 1.8 , particulate $0.01 \mathrm{lb} / \mathrm{MBtu}$

b: $\mathrm{NO}_{\mathrm{x}} 0.2 \mathrm{lb} / \mathrm{MBtu}$, sulfur removal $95 \%, \mathrm{Ca} / \mathrm{S} 1.8$, particulate $0.01 \mathrm{lb} / \mathrm{MBtu}$

c: $\mathrm{NO}_{\mathrm{x}} 0.3 \mathrm{lb} / \mathrm{MBtu}$, sulfur removal $90 \%, \mathrm{Ca} / \mathrm{S} 2.5$, ESP particulate $0.03 \mathrm{lb} / \mathrm{MBtu}$

d: $\mathrm{NO}_{\mathrm{x}} 0.6 \mathrm{lb} / \mathrm{MBtu}$, sulfur removal $90 \%, \mathrm{Ca} / \mathrm{S} 1.1, \mathrm{ESP}$ particulate $0.03 \mathrm{lb} / \mathrm{MBtu}$ These represent current NSPS for coal-fired power plants.

f: Low- $\mathrm{NO}_{\mathrm{x}}$ burners with $25 \mathrm{ppmv} \mathrm{NO}_{\mathrm{x}}$ (at $15 \%$ oxygen)

higher airflows may need to be extracted from the compressor for turbine cooling. This is a modification that can be accomplished by available engineering design and evaluation techniques.

The IGCC, low-Btu fuel gas can be efficiently burned by internal, rich-lean combustor baskets located within the turbine cylinder, much like the GFATS, but adapted to the high temperature fuel gas conditions. The flow of air to the gas turbine combustor is reduced by some $20 \%$ to $30 \%$ due to the airflow extracted for the coal gasification process; thus, there is less air available for combustor cooling. But the maximum stoichiometric, 
adiabatic flame temperature associated with coal gas is much lower than that with natural gas. Therefore, the reduction in the quantity of combustor cooling air may not be critical. The lower flame temperature will reduce the formation of thermal NOx, but is sufficiently high to limit the conversion of fuel-bound nitrogen to NOx in the rich zone. The volumetric flow rate of the coal gas is higher than that of the natural gas fuel by a factor from 6 to 9 . The temperature of the coal gas is $1000^{\circ} \mathrm{F}$; that of the natural gas, $670^{\circ} \mathrm{F}$. The volumetric flow of the fuel is thus greatly increased, and redesign of the fuel nozzle and mixing arrangements is required. Flame stability in the combustor does not appear to be a problem because of the high $\mathrm{H}_{2}$ content of the coal gas fuel. If this larger cylinder exceeds the maximum shipping dimensions, the engine would have to be shipped without the top half.

The second-generation PFBC combustor conditions may require that the multiple, internal combustor baskets of the GFATS be replaced by external combustor chambers, as shown in the illustration of Figure 5-3, due to the large size of the combustor chambers required. Two combustion chambers, each with eight combustor modules, would be located externally to the main engine cylinder, one on each side, as shown. Hot, low-Btu fuel gas, and combustion vitiated air, would be distributed to these combustors uniformly to achieve the required combustion performance. The external combustion requires that an inlet scroll be designed, with an appropriate cooling scheme, to introduce the combustion gas into the turbine.

The combustors must be designed with minimal structural cooling, to burn the low-Btu fuel gas efficiently and with acceptable pressure drop, acceptable outlet temperature uniformity, acceptable metal surface temperatures, low $\mathrm{CO}$, soot and unburned hydrocarbons, low conversion of fuel-bound nitrogen to NOx, acceptable turndown performance, and with multiple fuel capability.

The combustion turbine cylinder from the compressor discharge to the turbine inlet would require major design changes for the second-generation PFBC case. The casing inlet, manifold/inlet scroll and outlet arrangement would be modified from the GFATS to duct the combustion products by transition liners into a uniform annular flow, as is shown in Figure 5-4. Engineering analysis must be performed, considering heat transfer analysis, stress analysis, pressure drop analysis and computational fluid dynamic analysis. Engine thrusts must be reviewed and thrust bearings redesigned, if required. The combustion turbine bedplate mounting will also be substantially modified, in the secondgeneration PFBC case, from the GFATS. Similar considerations of the combustion turbine casing for the IGCC case must be made, but under much less challenging conditions. The substitution of coal gas from the $\mathrm{KRW}$ or the modified fluidized bed process for natural gas fuel increases the volumetric flow of the combustion product gases by some $13 \%$ to $24 \%$, depending on specifics of gasifier operation. This flow increase and the higher specific heat of the coal gas combustion products, with their higher $\mathrm{CO}_{2}$ content, increases both the work output from the turbine by $15 \%$ to $28 \%$ and the temperature of the expanding gases within the turbine -- by as much as $80^{\circ} \mathrm{F}$ at the 
turbine exit. The blade design and blade cooling arrangements must be adequate to cover these increased loads and temperatures.

Special consideration must be given to the operation and control of the integrated coal gasification, hot gas cleaning, coal-fired advanced turbine system, CFATS. Operation includes startup, load follow, and shutdown -- planned and emergency. Control includes maintaining steady optimal operation. Startup of the plant will probably require special provisions for natural gas firing of the gas turbine(s) -- fuel nozzles and perhaps auxiliary combustors. Emergency shut down, for example on load loss, will require quick acting valves to isolate the gasification and gas cleaning systems from the turbine to prevent overspeed and blow back into the compressor.

Load follow and control of the turbine with its integrated coal gasification, hot gas cleaning fuel supply will require coordinated adjustment of the coal, air, and steam feed to the gasifier. A single fuel flow valve, customary for a natural gas fired turbine, is not adequate to provide load follow and to protect the turbine from excessive combustion temperatures. A fuel flow control may need to be omitted due to the high temperatures and flows involved. In this case the coal, air, and steam valves on the gasifier feeds will be required to provide both the turbine and gasifier control functions. Flow controls may be placed in differing positions in the CFATS plant, so that they may provide control over lower-temperature streams located upstream of the major coal processing steps. For example, in second-generation PFBC, vitiated air control to the combustor may be achieved by air control to the fluid bed combustor, providing valves that operate at commercially available temperatures. Similarly, over speed protection valves must be supplied for the CFATS that are placed in acceptable locations that may differ substantially from the those of the GFATS. Compressor air bypass, through the turbine startup burner, to the combustor may be used to cool the expansion gas and promote turbine speed reduction, as is shown in Figure 5-5.

The piping to and from the coal to fuel processing system must be designed to reduce and control thermal expansion stresses and pipe reactions on the turbine cylinder. The requirement for the use of by-pass valves to prevent turbine overspeed in the event of sudden load loss must be studied and the piping arrangement will be evaluated to minimize piping cycle flow pressure losses. The control system functions should be similar except where changes are required to account for the considerable larger fuel flow. The control concept must be reviewed to identify modifications. Many of the control issues are being evaluated within the current advanced, coal-fuel technology development programs and do not need to be considered in the ATS program.

The turbine airfoil geometry and casing sections themselves will not be substantially modified from the GFATS, although the Row 1 vane spacing must be increased to accommodate differences in flow between the GFATS and the CFATS, providing acceptable pressure reduction. The airfoil materials may also be substantially modified. The combustion products will contain vapor and solid/liquid contaminants that are known to induce turbine aerofoil material corrosion: sodium, potassium, vanadium, lead, 
calcium, lithium, phosphorous, silica, chlorine, iron, copper, and nickel. These may reduce the life of key turbine components and increase system maintenance requirements. Not only must hot corrosion when selecting appropriate thermal barrier and corrosion resistant coatings, induced by deposition of slag-like particles and condensable vapors, be considered, but cold-end corrosion due to acidic mists, condensates and slurries must also be considered. The effectiveness of hot gas filters should make turbine airfoil erosion a secondary concern. Particle deposition may be more severe in the CFATS than in the current coal-fired turbine cases because of the higher firing temperature and resulting adherence of particles. Available on-line and off-line airfoil cleaning methods may need to be optimized for the CFATS. Specific turbine airfoil base materials and thermal barrier coatings will need to be specified for the CFATS that are tolerant of the gas contaminants both during steady operation, during off-design conditions, turndown, startup and shutdown transients, as well as during off-line conditions.

It is expected that the material for the main cylinder, horizontal joint, and vertical flange bolting will be the same as used in the GFATS. The hot gas containment system in the second-generation PFBC case could present the most critical challenge for this design. This containment system represents a large area to maintain at acceptable metal temperatures, control leakages at the juncture to the turbine inlet, and minimize distortion to stay within acceptable limits. Materials would need to be the same as used in state-ofthe-art combustion turbine combustors and transition pieces, or possibly even using new concepts, such as ceramics, in some areas.

The possible arrangement of the second-generation PFBC combustor system into two offboard combustor housings, as opposed to the conventional in line, on-board combustors of the GFATS will require a design effort as reported in a previous paper. The extended surface of the hot gas flow path is much greater in area than would be the surface of the transition pieces in the GFATS. All of this surface must be cooled by compressor discharge air. The cooling required will be much more than can be achieved by surface convection, which has been the conventional way of cooling the transitions.

Impingement cooling of ceramic tiles lining the interior of the extended hot gas flow path means a significant amount of compressor discharge air will by-pass the combustion process within the combustors, thereby reducing the amount of air available for the combustion process, cooling the combustor wall surface, and the profiling of combustion products for uniform turbine inlet temperature for the first row vanes. It is difficult in an off-board combustion system arrangement, to have any real final control of turbine inlet temperature profile, because of the lack of control of the mixing process in the large volume of space between the exit of the combustor and the inlet to the turbine.

Critical structural problems exist that differ from those of the GFATS. Both stationary and rotational parts must consider short-term loading, fatigue, creep, and embrittlement failure mechanisms. These considerations especially must be made for the combustors (primarily thermal fatigue due to overheating and shocking), and the turbine disks, blades, and nozzle vanes. The critical structural problem in the CFATS is thermal stress and distortion caused by temperature differences between the compressor and combustor 
legs and the mating leg from the turbine cylinder. Also, a similar problem exists for the hot gas duct containment cylinder, and inlet scroll that guides the hot gases into the turbine inlet. An extensive finite element heat transfer analysis will be required to redesign the cylinders, flanging, and the interior hot gas flow system to insure that stress and distortion limits are met.

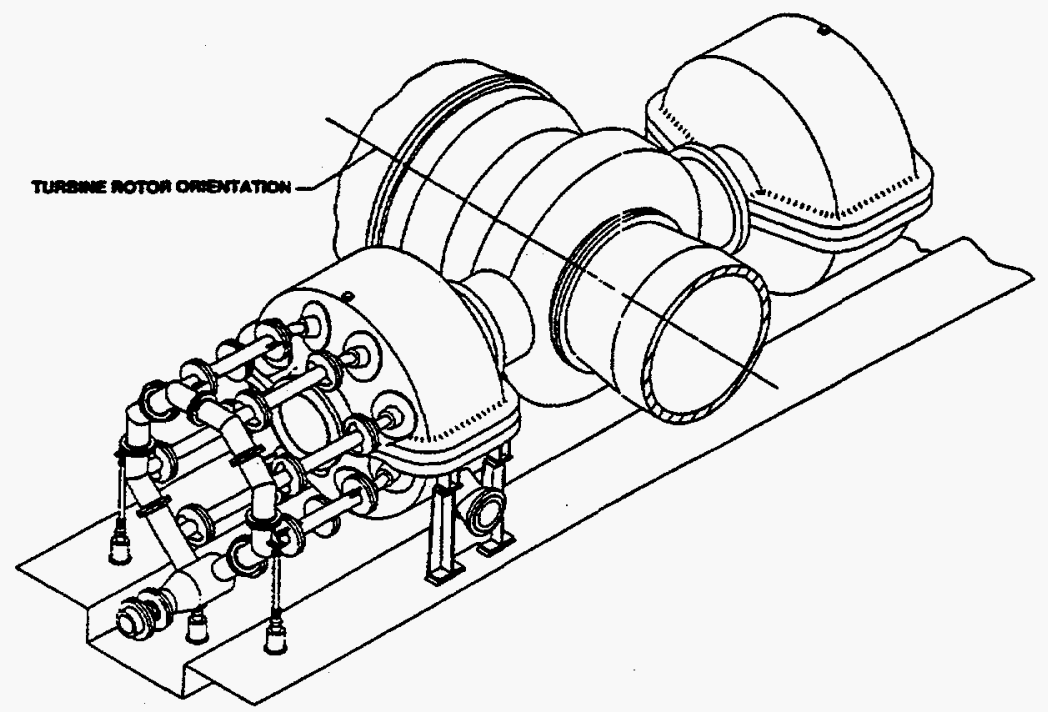

Figure 5-3. Conceptual Dual Topping Combustor Arrangement 


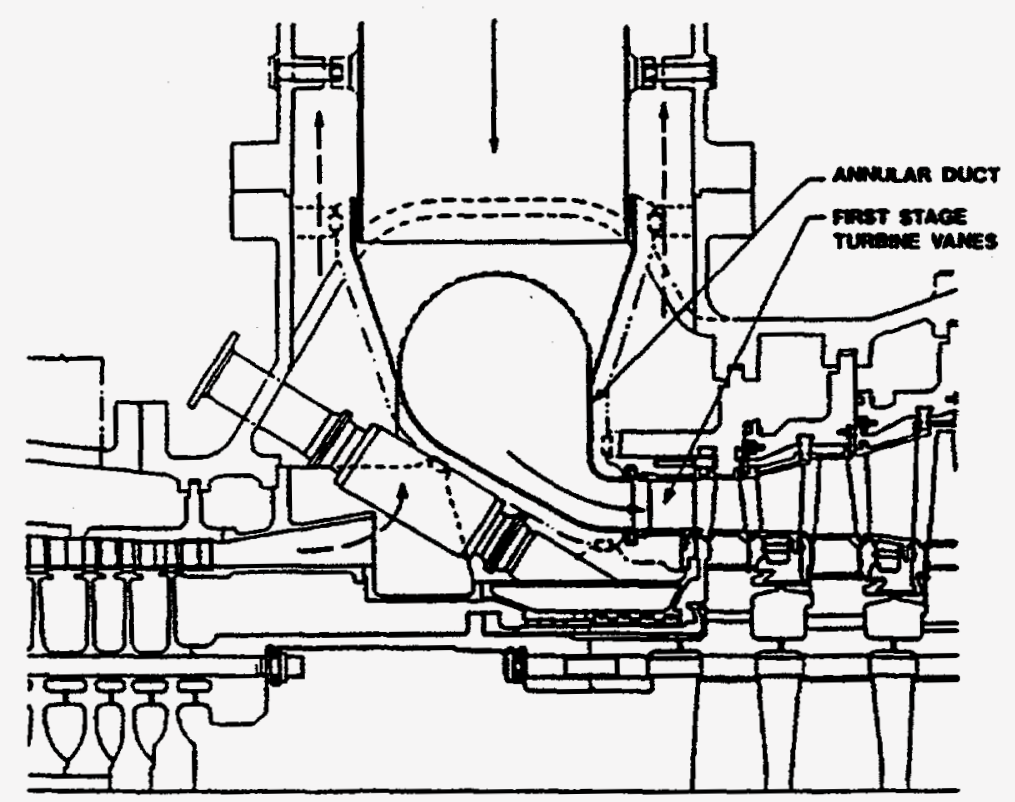

flow of compeseon Dectunes an musucte of cometsmen

Figure 5-4. Topping Combustor Outlet to Turbine Inlet Gas Flow Concept

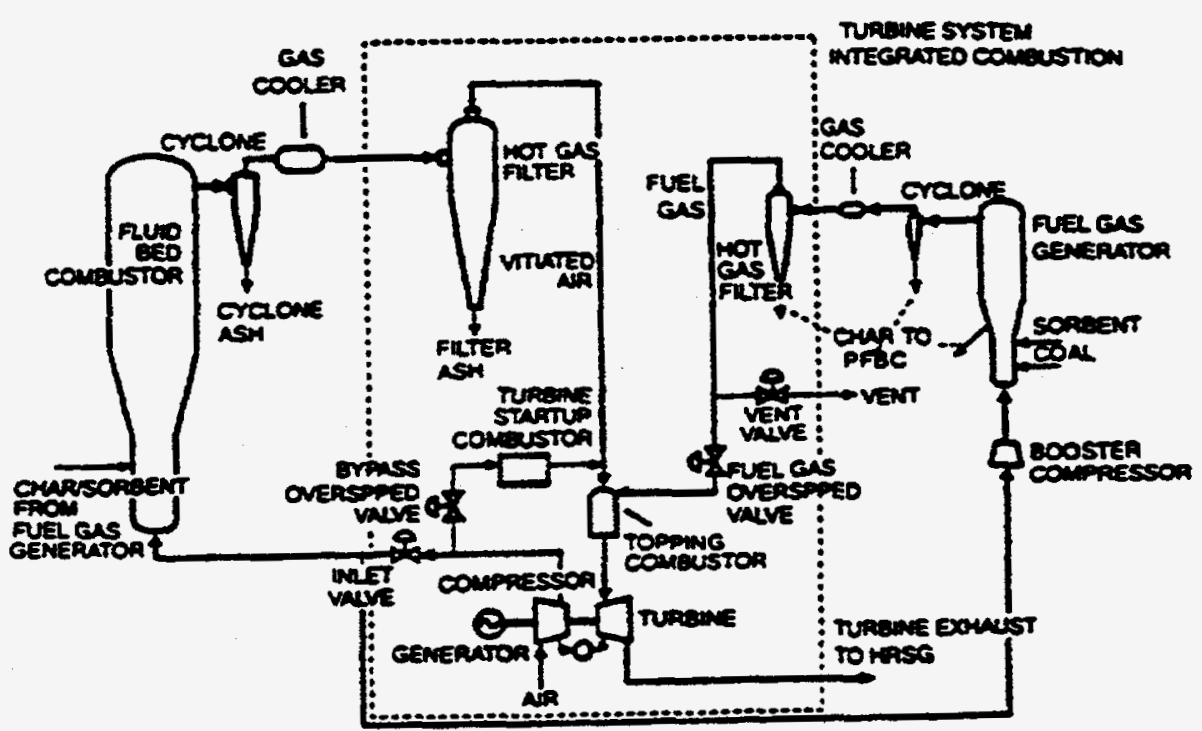

Figure 5-5. Topping-PFBC Process Schematic 


\section{CONCLUSIONS}

Two coal-fueled power plant technologies were selected to represent the CFATS -- airblown, fluidized bed gasification using hot gas cleaning, and second-generation PFBC. Both of these concepts are currently being demonstrated in major Clean Coal Technology Programs, and both have high performance and improved emissions control potential in the CFATS.

Both of these CFATS cases require gas turbine combustors which cleanly burn hot, low Btu coal derived fuel gas and turbine expanders which operate effectively on combustion products of gases cleaned at high temperature. The cases differ in the fraction of air removed from the turbine casing for coal processing and in the location of the turbine combustors -- internal or external to the casing. The IGCC case can utilize rich-lean, low-Btu fuel gas combustion baskets located within the combustion turbine cylinder. The second-generation PFBC case may require the use of external combustors due to the large size of the combustor chambers required by the use of hot, depleted air from the PFBC unit.

Major development areas directly relating to the conversion to the CFATS, in addition to those areas already identified in current coal-fueled technology development programs, are:

- low-Btu, low-emission, fuel gas combustor design,

- combustor outlet manifolding and turbine inlet scroll design,

- turbine corrosion deposition; and materials selection.

The technology developed under the GFATS program will be transferred to the CFATS, as applicable. With GFATS cycle efficiencies greater than $60 \%$ (LHV), it should be possible to obtain CFATS cycle efficiencies in the range of $52 \%$ to $54 \%$. 


\section{SECTION 6}

\section{ADVANCED TURBINE SYSTEM (ATS) MARKET STUDY}

\section{INTRODUCTION}

The market potential for the Advanced Turbine System (ATS) gas turbine was assessed using analytical screening curves, product introduction life cycle curves, market demand forecasts by world region, and appropriate fuel cost scenarios. The markets for the ATS in simple cycle, combined cycle and integrated gasification combined cycle (IGCC) application were separately evaluated. Three unit sizes were postulated and economic and market comparisons performed with respect to " $G$ " and " $F "$ technology. In the context of this report, it is to be recognized that ATS "technology" is first being introduced and demonstrated in what are referred to as " $G$ " machines to demonstrate technical feasibility. In this respect the overall DOE ATS program benefits comprise the current and future success of both the "G" and the "ATS". Under Westinghouse direction and using Westinghouse defined gas turbine cost, maintenance and performance data, a subcontractor performed the analysis. Regular review and interaction by Westinghouse occurred throughout the effort.

Worldwide power generation capacity additions are expected to exceed $100 \mathrm{GW}$ per year in the forecast period, led by Asia/Pacific:
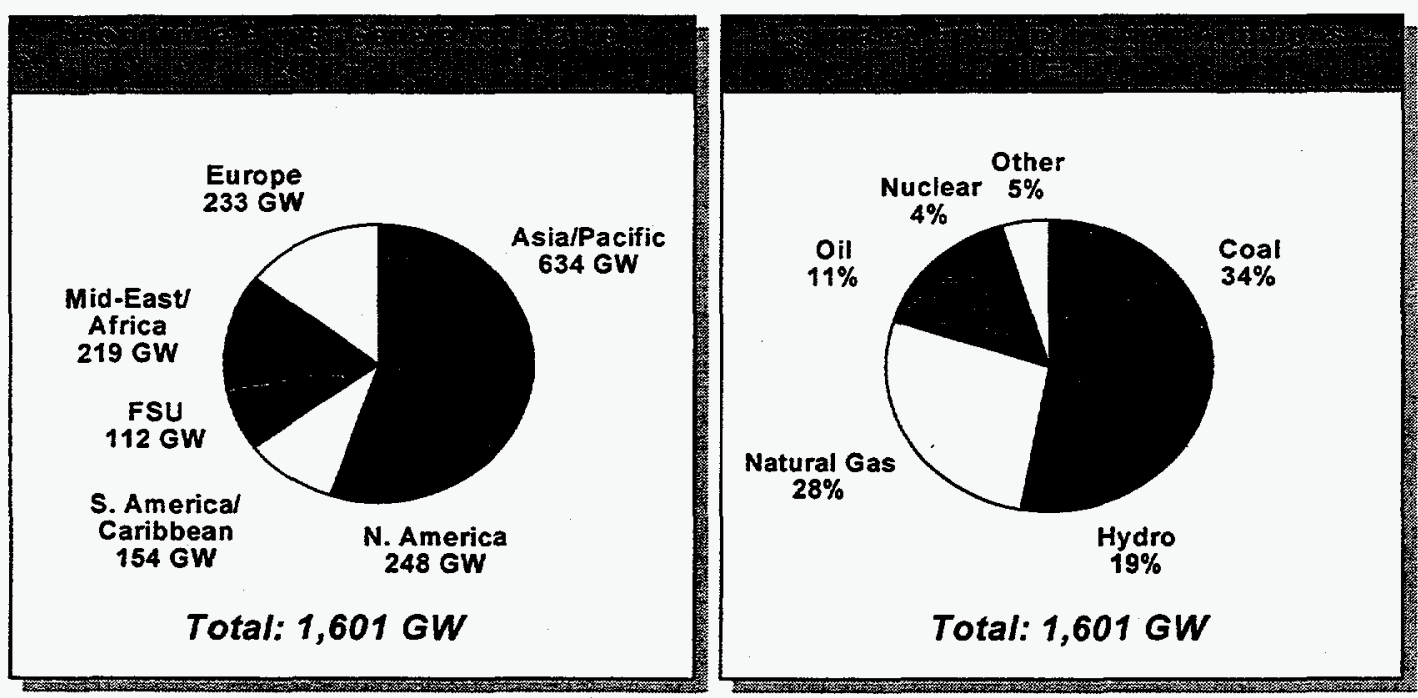

Figure 6-1. Worldwide Power Generation Forecast 
The ATS will compete for a portion of projected natural gas, oil and coal additions, which represent more than $70 \%$ of the total market. The simple cycle and combined cycle technical market potential was estimated by screening out segments which will not be accessible to ATS technology. Markets inaccessible to the ATS are:

- Markets for fuel other than natural gas and distillate oil.

- Small regional markets unable to absorb large capacity increments.

- Markets traditionally served by small gas turbines (e.g. small cogeneration).

- Gas and oil markets served by non-GT technologies (e.g. oil-fired steam turbines, reciprocating engines, fuel cells).

A similar screening analysis was conducted for coal markets.

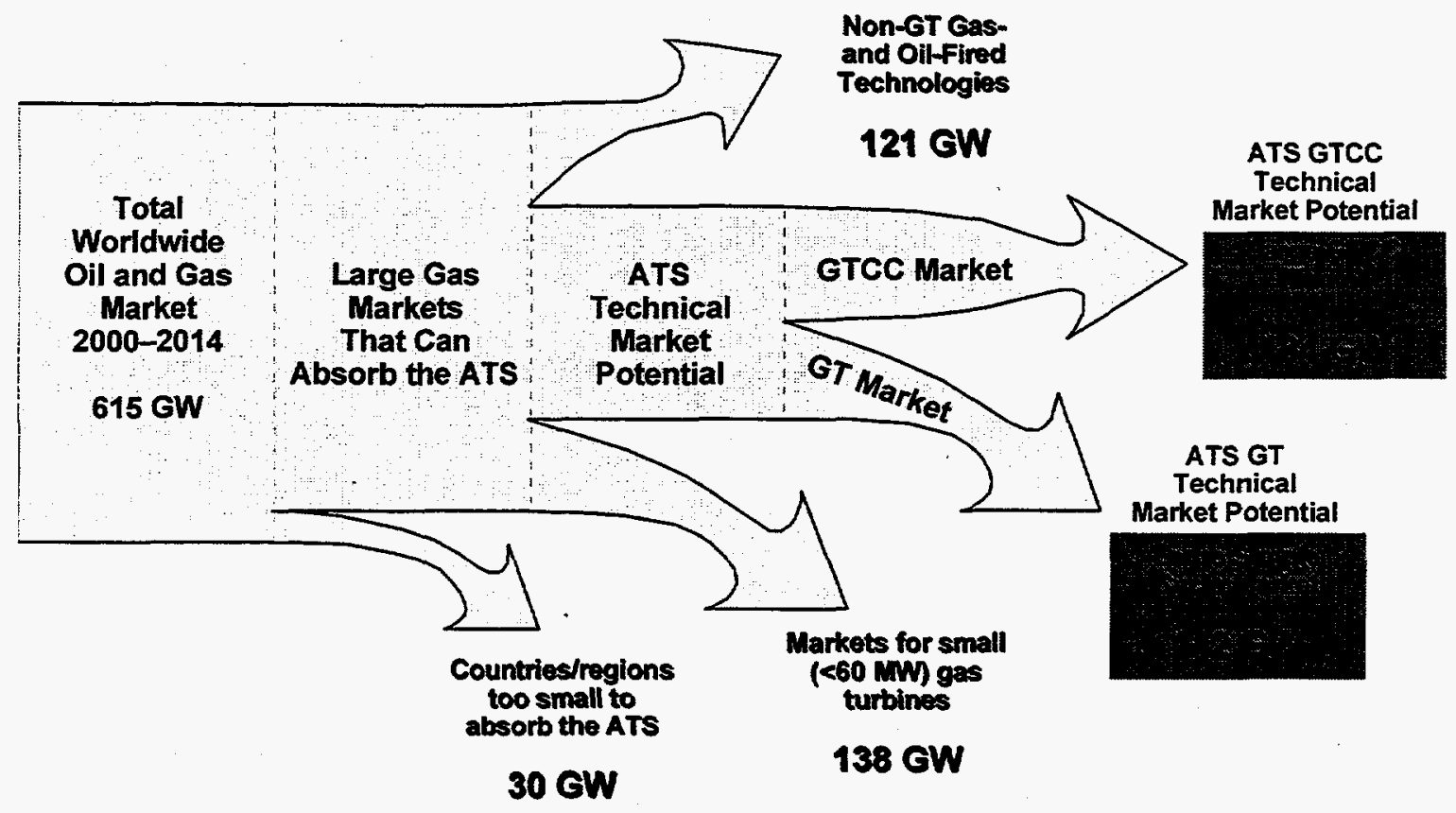

Figure 6-2. Screening Methodology 
Relative size categories used in the study vary by frame technology, line frequency and project classification.

$\begin{array}{llll} & \underline{\text { Small }} & \underline{\text { Medium }} & \underline{\text { Large }} \\ \text { ATS } 50 \mathrm{~Hz} & 170-240 \mathrm{MW} & 240-285 \mathrm{MW} & >285 \mathrm{MW} \\ \text { ATS } 60 \mathrm{~Hz} & 100-150 \mathrm{MW} & 170-235 \mathrm{MW} & >235 \mathrm{MW} \\ \text { Combined cycle } & <300 \mathrm{MW} & 300-500 \mathrm{MW} & >500 \mathrm{MW}\end{array}$

The market potential of each GT frame size was estimated by examining project and frame size preferences worldwide.

- Historical gas turbine sales data, National Electricity Reliability Council (NERC) forecasts and Utility Data Institute (UDI) forecasts were used to assess the likely size distribution of gas turbine projects for different countries and regions. The result was four different market types representing key regional differences.

The same data sources were used to make an assessment of the relative attractiveness of the different GT frame sizes for a given project size. For example, historical data indicates that large GTCC projects have typically made use of the largest available frame size. This distribution was assumed to be the same for each market type.

From these two analyses, the technical market potential of each ATS and " $G$ " frame size (as a percent of the total technical market potential) was calculated.

This was supplemented by information obtained during contractor conducted interviews and by contractor estimates of future trends. 
The following table summarizes the results.

\begin{tabular}{|c|c|c|}
\hline 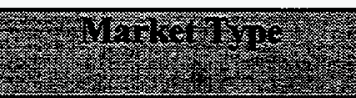 & 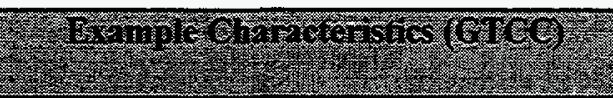 & 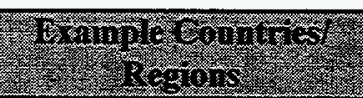 \\
\hline USATYPe & $\begin{array}{l}\text { Few large projects }(>500 \mathrm{MW}) \\
\text { - Focus on small to medium sized } \\
\text { projects }(100-500 \mathrm{MW}) \\
\text { - Modest load growth }\end{array}$ & $\begin{array}{ll}\text { - } & \text { North America } \\
\text { - } & \text { Western Europe }\end{array}$ \\
\hline $\begin{array}{l}\text { Large Gas-Fined } \\
\text { Projects }\end{array}$ & $\begin{array}{ll}\text { - } & \text { Large GTCC projects predominate } \\
\text { ( }>500 \mathrm{MW}) \\
\text { - } & \text { LNG importing regions } \\
\text { - } & \text { High load growth }\end{array}$ & $\begin{array}{ll} & \text { Japan } \\
\text { - } & \text { India } \\
\text { - } & \text { Thailand } \\
\text { - South Korea }\end{array}$ \\
\hline $\begin{array}{l}\text { SmanMedium Gas. } \\
\text { Fired Projects }\end{array}$ & $\begin{array}{ll}\text { - } & \text { Few large projects ( }>500 \mathrm{MW}) \\
\text { - } & \text { Smaller gas markets } \\
\text { - } & \text { Lack of gas infrastructure }\end{array}$ & $\begin{array}{ll}\text { - } & \text { South America } \\
\text { - } & \text { Bangladesh } \\
\text { - } & \text { Pakistan } \\
\text { - } & \text { FSU }\end{array}$ \\
\hline Miadle Eastifrica & $\begin{array}{l}\text { Trend towards larger projects ( }>500- \\
600 \mathrm{MW}) \\
\text { - } \\
\text { - Shple gas supplies } \\
\text { plants continues }\end{array}$ & $\begin{array}{ll}\text { - } & \text { Saudi Arabia } \\
\text { - } & \text { Syria } \\
\text { - } & \text { Iran }\end{array}$ \\
\hline
\end{tabular}

Table 6-1. Turbine Frame Size Preferences 
Cost of Electricity comparisons are shown in the following chart.

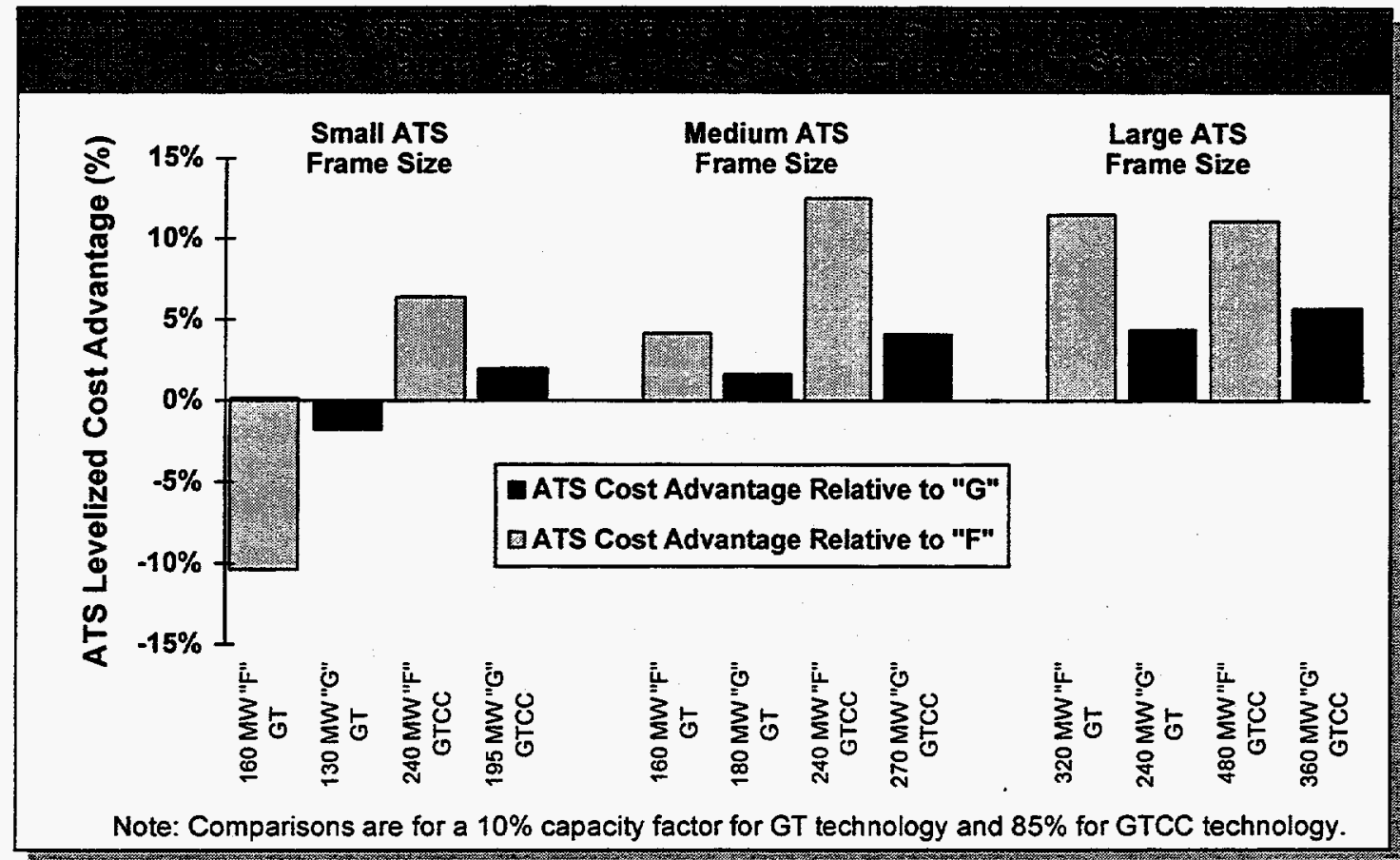

Figure 6-3. ATS Cost Advantage

The medium and large ATS frame sizes have the greatest cost advantage over both "F" and "G" technology; the small ATS frame size is less competitive.

Under the model assumptions, the medium and large ATS GTCC configurations, operating at an $85 \%$ capacity factor, are expected to have levelized electricity costs which are 4-6\% lower than those of competing "G" GTCC technology, and more than $10 \%$ lower than the "F" GTCC. The small ATS GTCC is 1-5\% lower in cost than the small "G" GTCC and 5-10\% lower in cost than the "F" GTCC.

In simple cycle ( $10 \%$ capacity factor), the large ATS frame size enjoys a $10 \%$ cost advantage over a comparably sized plant based on " $F$ " technology, and a $4-5 \%$ advantage over the "G" simple cycle.

The cost advantage for the medium frame size ATS GT simple cycle is only $1-2 \%$ relative to the medium frame size "G" GT and $-1 \%$ to $5 \%$ relative to the "F" GT. Neither the small frame size ATS GT nor "G" GT appears competitive with the "F" simple cycle, with levelized costs $7-20 \%$ higher in peaking applications (5-10\% capacity factor). 
The total ATS and "G" market sizes were assumed to be functions of both ultimate market share and the rate of market penetration. For the ATS products with a $10 \%$ or greater cost advantage over " $F$ " technology, an ultimate market penetration of $50 \%$ is expected. Where the ATS has a smaller economic advantage, a lower ultimate market share was assumed. Because of its earlier introduction the " $G$ " will be farther along its market penetration curve when the ATS is introduced. Thus, within the forecast period of 2000-2014, the total market for "G" technology is comparable to that of the ATS, even though the ultimate penetration of the ATS is assumed to be higher. The maximum market penetration for the ATS and "G" are expected to occur at different times. The market for " $F$ " and previous technology makes up the remainder of the market.

The following charts depict the market dynamics and penetration.

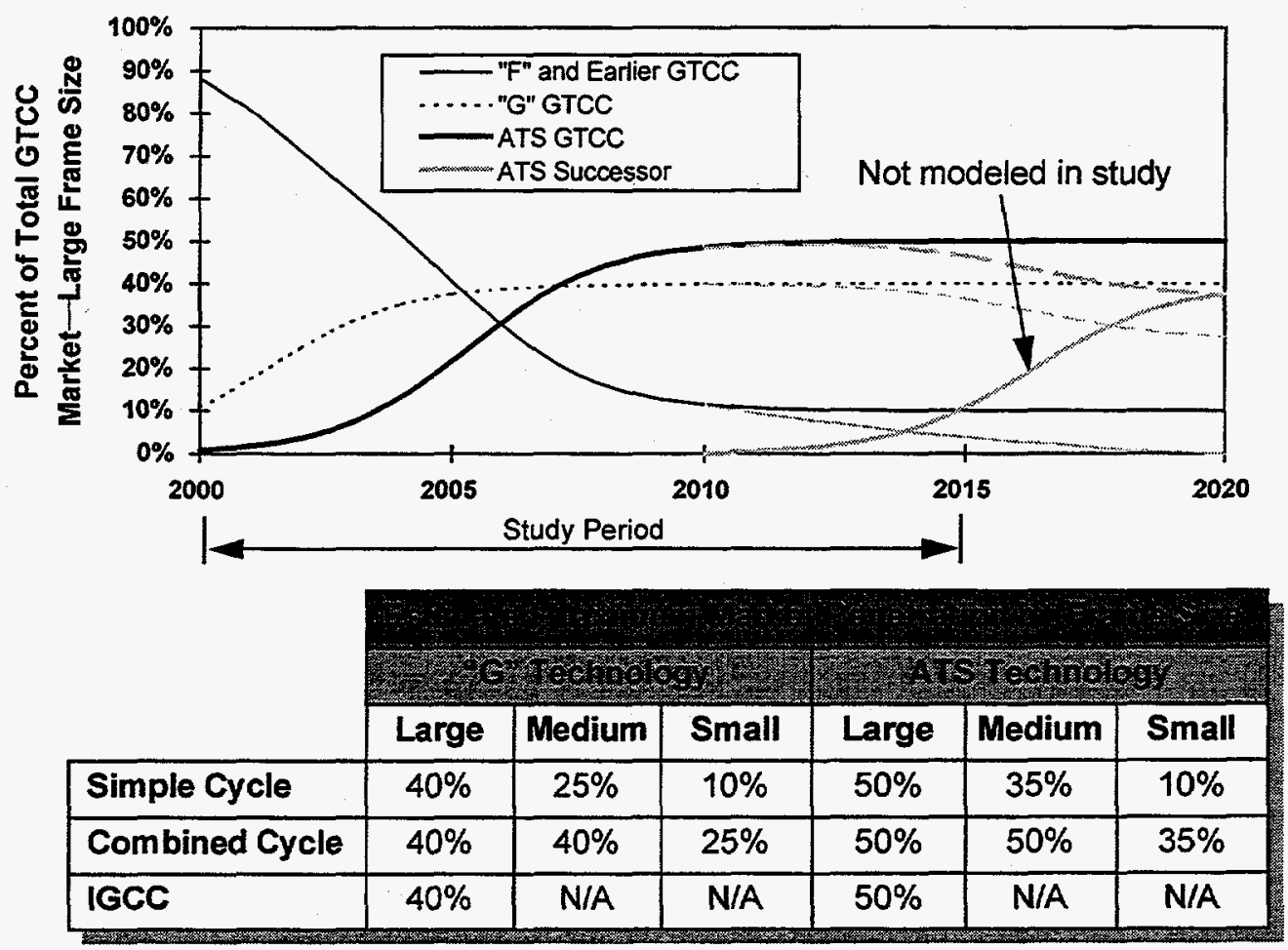

Figure 6-4. ATS \& G Technology Market Penetration

In the baseline forecast the total ATS market potential exceeds $75,000 \mathrm{MW}$ in the 20002014 time frame. Including the "G" as part of the ATS technology program, the market is about $155,000 \mathrm{MW}$, corresponding to half the market. 

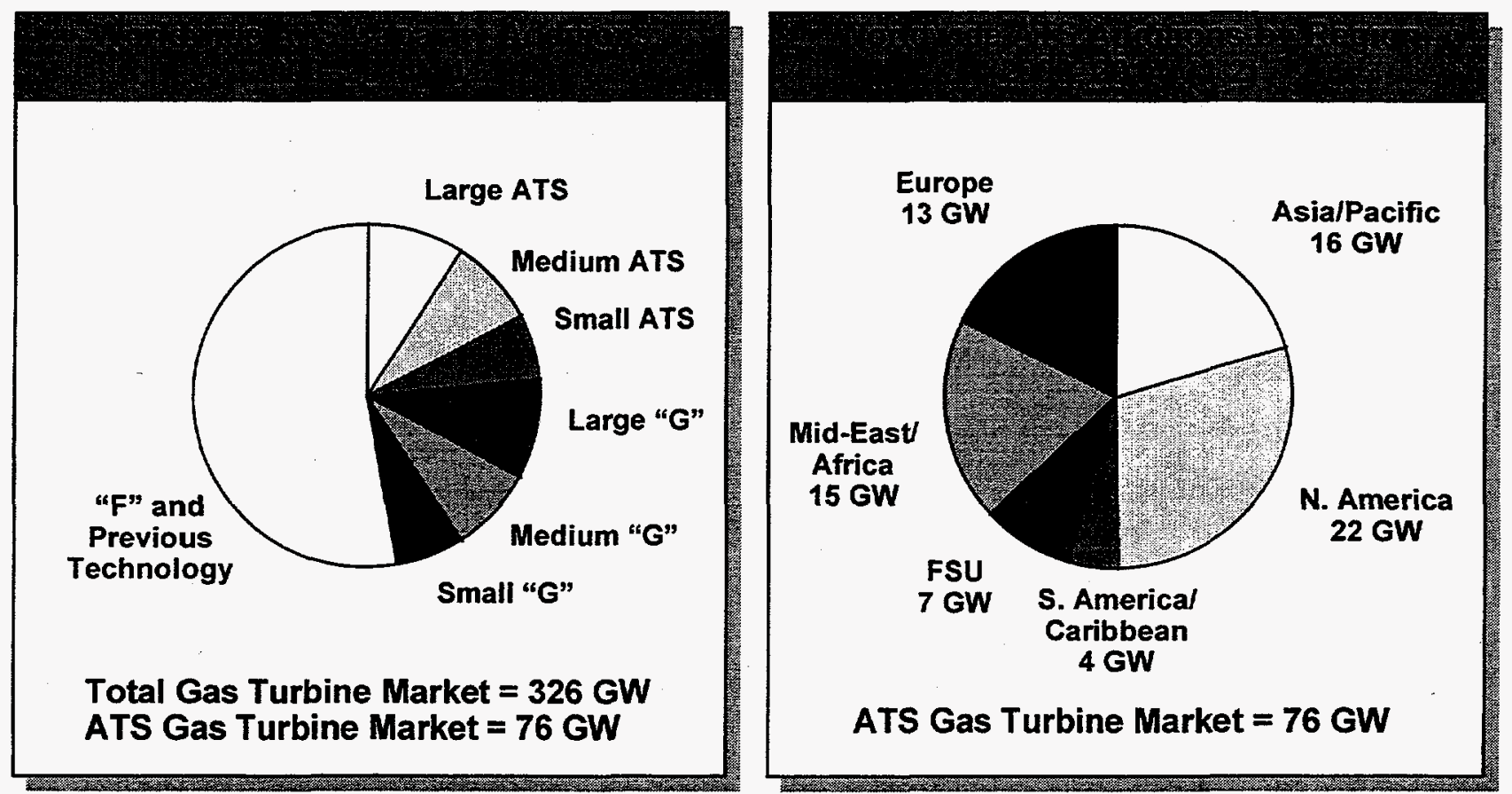

(1) Includes simple and combined cycle applications for both oil and gas. GTCC capacity is total plant capacity.

(2) All ATS products are assumed to exist simultaneously.

\section{Figure 6-5. Estimated Worldwide ATS Capacity Additions}

Relative to "F" technology, the ATS will have a $10 \%$ or greater cost advantage in large baseload GTCC applications and a 5-10\% cost advantage in medium to large peaking applications, making it a highly competitive alternative to " $F$ " technology. Given the study's assumptions, the smallest ATS frame size does not appear to be competitive with existing " $F$ " technology in simple cycle peaking applications due to the lower projected capital cost of the "F" GT.

North America and Asia/Pacific appear to be the most attractive geographic regions. North America will rely on gas turbines for the majority of new capacity additions in the forecast period. Asia/Pacific is expected to experience rapid growth in power generation capacity in the forecast period.

Based on the assumptions regarding size class segmentation and market penetration, the large and medium ATS frame sizes achieve the highest market shares, with the small ATS being slightly less attractive. In a sensitivity case it was concluded that the U. S. market for larger power projects may increase as a result of deregulation. 
Circumstances leading to increased natural gas-based power generation could increase the demand for the ATS by up to $20,000 \mathrm{MW}$ in the forecast period, and would likely favor the largest ATS frame size.

\section{IGCC ANALYSIS}

The baseline ATS IGCC forecast of 27 units (over 9 years) reflects the assumption that roughly $15 \%$ of new coal additions in the forecast period will be IGCC using F, G, or ATS technology, It is also assumed ATS technology will not be available until 2005.
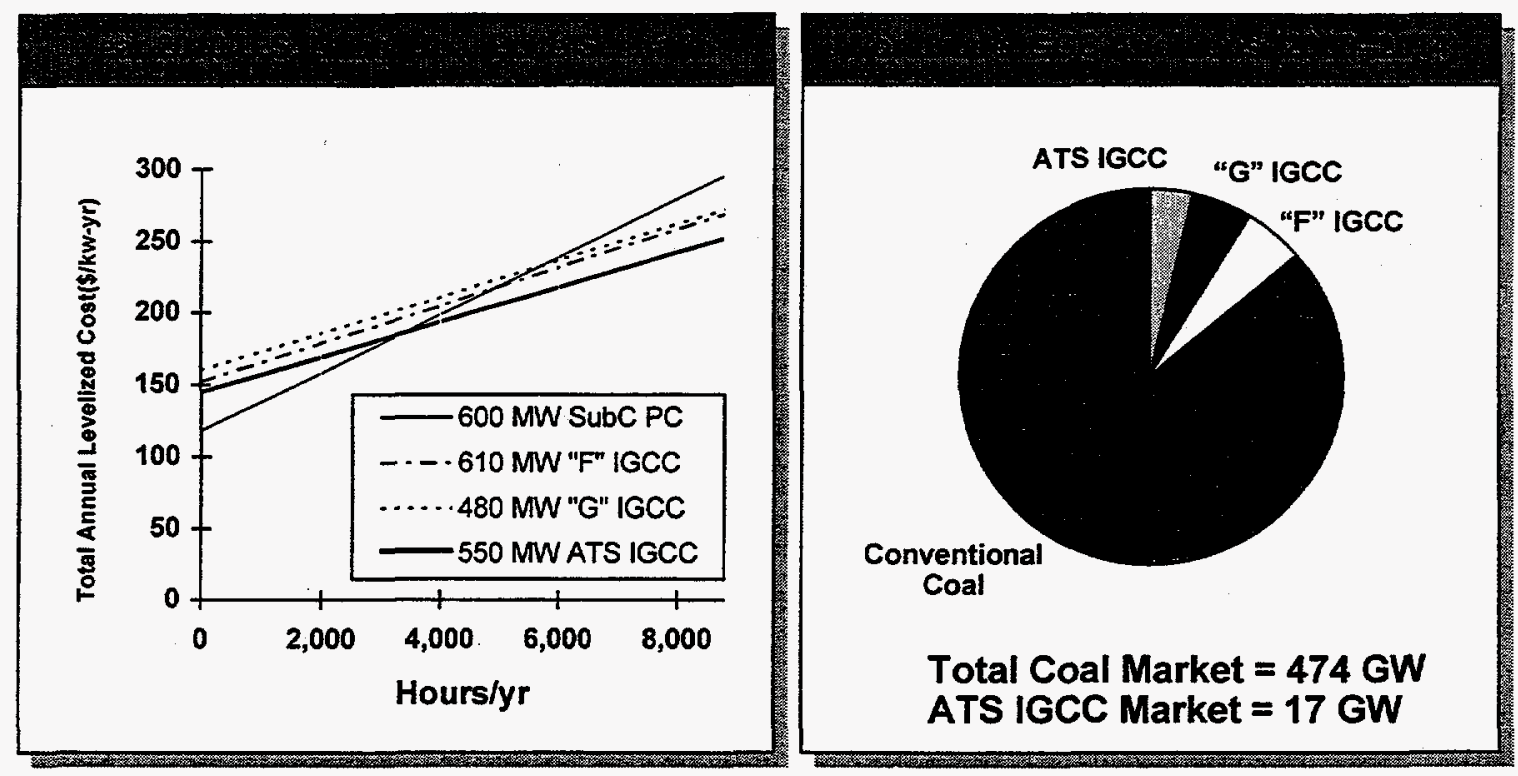

Figure 6-6. Estimated ATS IGCC Market Penetration

The ATS IGCC appears to become the lowest cost technology in most regions above capacity factors of $65-75 \%$. In order for the cost advantage to become significant, capacity factors of $85-95 \%$ will be required.

Total ATS IGCC market potential is limited in the forecast period by the assumption that it will not be commercially available until 2005 . Nevertheless, the maximum market penetration of the ATS is higher than that of the " $G$ " IGCC due to more favorable economics.

The $50 \mathrm{~Hz}$ IGCC markets are likely to develop earlier and ultimately become the largest market segment for the ATS IGCC. In an optimistic scenario, demand for the ATS grows by $50 \%$ to a total of 40 units, driven by increased market share. 


\section{SUMMARY}

In the baseline forecast the total ATS market potential exceeds $93 \mathrm{GW}$ in the 2000-2014 time frame.

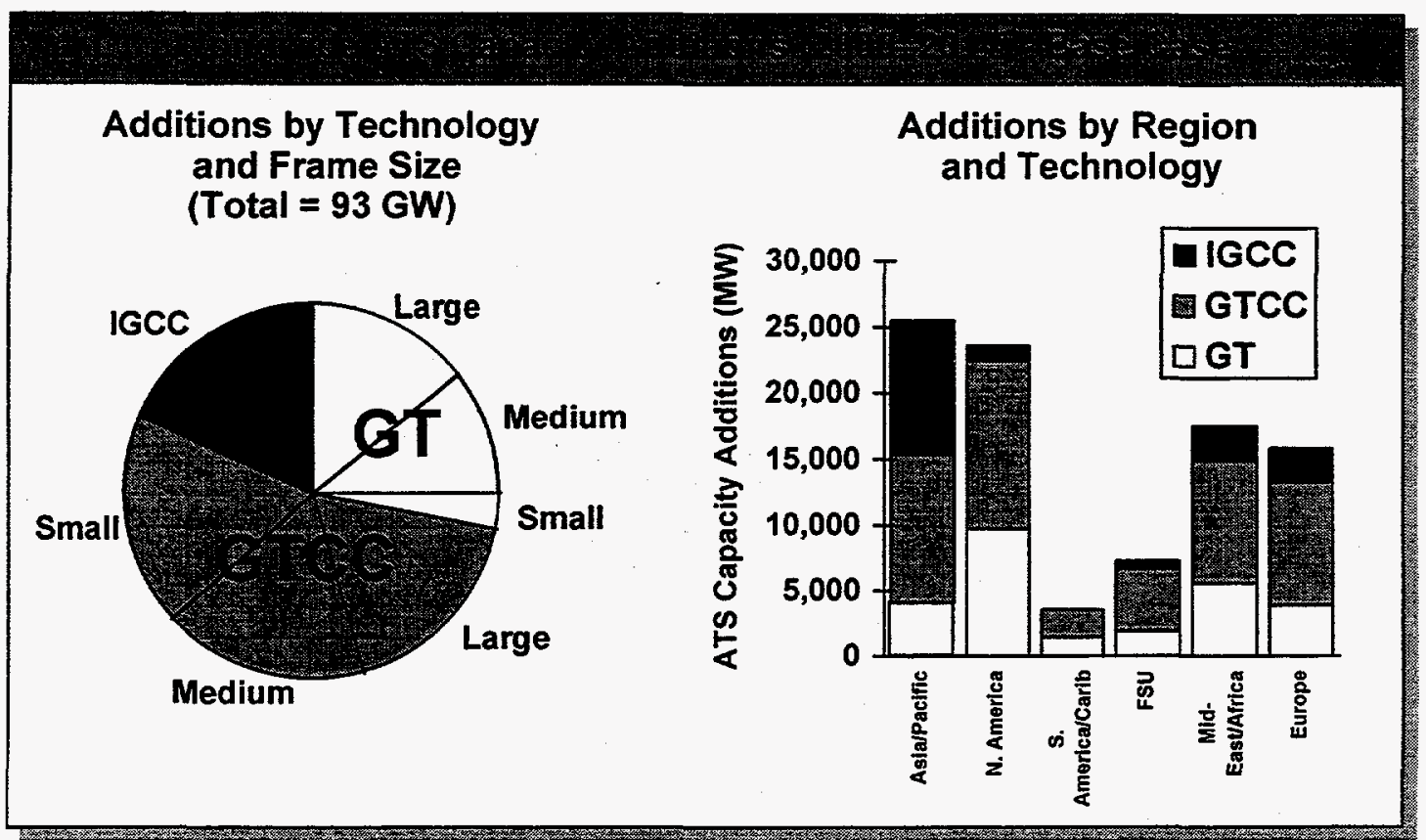

Note: Values represent total plant capacity. All Frame Sizes are assumed to exist simultaneously.

Figure 6-7. Worldwide ATS Capacity Additions Summary

The GTCC market represents the greatest opportunity for the ATS, in part because this is the application in which the ATS will likely have the greatest economic advantage. All three ATS frame sizes appear equally attractive, but uncertainties due to deregulation and the rate of infrastructure development in some regions may change this "base case" result.

In the simple cycle market, the largest potential opportunity is for the smallest frame size, but because of more attractive economics, the larger frame sizes are more likely to capture a substantial market share.

Although the total coal market is substantial, the ATS IGCC market is limited by the assumption that it does not become available until late in the forecast time period (i.e., in 2005). The greatest opportunity for IGCC technology may be beyond the year 2015 . 
Following one or two years of successful demonstration, the ATS market is expected to follow a typical S-shaped penetration curve.

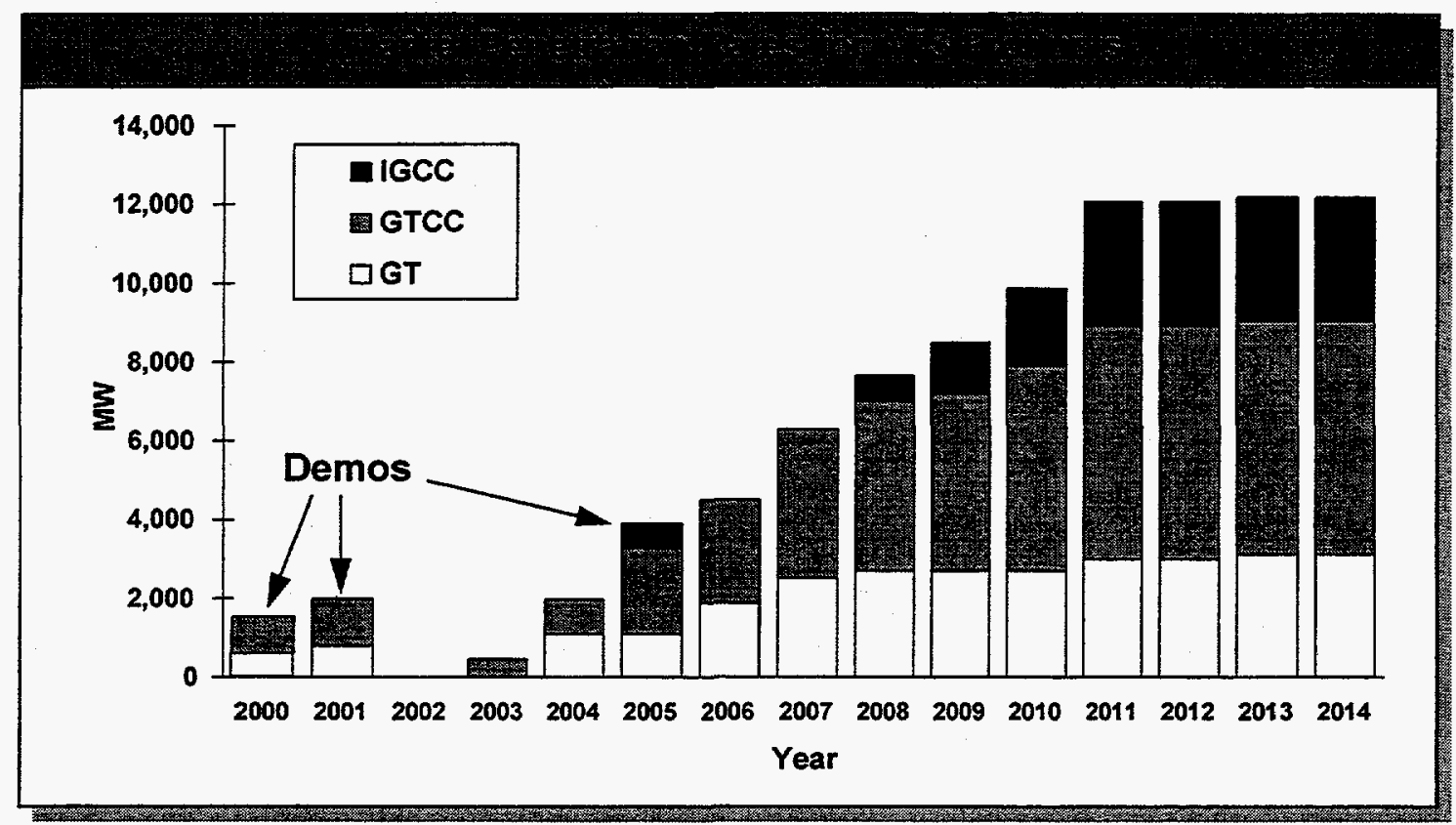

Note: All three frame sizes are assumed to exist simultaneously, each with its own demonstration projects.

Figure 6-8. ATS Market Penetration by Frame Size

The combined market for ATS-based technology could reach $12 \mathrm{GW}$ per year by the end of the forecast period, representing roughly a $10 \%$ market share relative to the total global power market.

Each ATS product is expected to achieve its maximum market penetration approximately 7-10 years after initial demonstration. The ATS IGCC is expected to follow a similar penetration curve to the ATS GT and GTCC, but it will reach its ultimate market share at the end of the forecast period due to its later introduction. The ATS IGCC market is also limited by the assumed growth and size of IGCC markets in general, which limits the technical potential to a portion of the total coal market.

Finally, a comparison of the study's overall market forecast was made against both published studies and Westinghouse's internal model. Westinghouse's analysis of future overall power generation demand, the baseline forecast used by the subcontractor may be 
conservative. Based on combinations of higher overall power demand, coupled with a higher proportion of that demand being met by gas turbine based capacity, the volume for ATS and "G" could range higher. 


\section{SECTION 7}

\section{SYSTEM DEFINITION AND ANALYSIS}

\section{INTRODUCTION}

A conceptual design for critical and noncritical components of the gas fired combustion turbine system was completed. The conceptual design included specifications for the flange to flange gas turbine, power plant components, and balance of plant equipment. The ATS engine used in the conceptual design is an advanced $300 \mathrm{MW}$ class combustion turbine incorporating many design features and technologies required to achieve ATS Program goals.

Design features of power plant equipment and balance of plant equipment are described. Performance parameters for these components are explained. A site arrangement and electrical single line diagrams were drafted for the conceptual plant.

ATS advanced features include design refinements in the compressor, inlet casing and scroll, combustion system, airfoil cooling, secondary flow systems, rotor and exhaust diffuser. These improved features, integrated with prudent selection of power plant and balance of plant equipment, have provided the conceptual design of a system that meets or exceeds ATS program emissions, performance, reliability-availability-maintainability, and cost goals.

\section{PLANT CONFIGURATION}

The Advanced Turbine Systems plant conceptual design and layout is based on a recently completed combined cycle plant design. This state of the art 240-MW 501F Reference Plant incorporates flexible proven design features that minimize design changes usually required to tailor the plant to site specific constraints. The power trains of both plants include one combustion turbine and one multi-pressure steam turbine. The 240MW Reference Plant is a multishaft design. The ATS Plant utilizes a single shaft design with a common generator between the combustion turbine and steam turbine. Both plants are fueled by natural gas and utilize mechanical draft cooling towers. The ATS plant generates considerably more power at a higher efficiency than the 240 MW Reference Plant, mainly because of the increased power and efficiency of the ATS combustion turbine and the higher throttle pressure and reheat temperatures of the steam turbine.

Overall performance parameters for the ATS plant are given in Table 7-1 at ISO $\left(59^{\circ} \mathrm{F}, 14.696 \mathrm{psia} \& 60 \%\right.$ relative humidity $)$ conditions: 


\begin{tabular}{|l|c|}
\hline \multicolumn{1}{|c|}{ Performance Parameters } & ATS Plant \\
\hline Approximate Combustion Turbine Power & $290,000 \mathrm{~kW}(\mathrm{e})$ \\
\hline Approximate Steam Turbine Power & $130,000 \mathrm{~kW}(\mathrm{e})$ \\
\hline Approximate Plant Output & $420,000 \mathrm{~kW}(\mathrm{e})$ \\
\hline Net Plant Efficiency, LHV & $>60 \%$ \\
\hline Fuel Type & Natural Gas \\
\hline Cooling Tower & Forced Draft \\
\hline Combustion Turbine Inlet Air Flow & $1,196 \mathrm{lb} / \mathrm{hr}$ \\
\hline Approximate Rotor Turbine Inlet Temperature & $2700^{\circ} \mathrm{F}$ \\
\hline Turbine Exhaust Temperature & $1,130^{\circ} \mathrm{F}$ \\
\hline
\end{tabular}

Table 7-1 Overall Performance of ATS Plant

\section{Combustion Turbine}

The combustion turbine of the ATS plant is larger and more efficient than the $501 \mathrm{~F}$ model used in the 240 MW Reference Plant because of its advanced aerodynamic cooling and mechanical design, higher mass flow and firing temperature, and pressure ratio. The gas fuel is preheated, using recovered low-grade heat from the heat recovery steam generator(HRSG). Turbine airfoils are steam-cooled, using higher-grade heat recovered in the bottoming cycle. Additional details of the ATS combustion turbine are given in Section 3. Key combustion turbine parameters of the ATS turbine are shown in Table 7-1.

\section{$\underline{\text { Heat Recovery Steam Generator }}$}

The HRSG for the ATS plant is a natural circulation, triple pressure unit with vacuum deaeration. The HRSG configuration allows the addition of duct firing at a later date. Customer requirements often dictate the need for additional steam that duct firing can provide. The duct firing option has the same performance level as the HRSG without the duct firing option in the unfired operational mode. The HRSG will operate over the entire operating range of the combustion turbine. Materials are commercial grade commonly used in boilers today. Design criteria are conventional engineering practice, applying ASME Pressure Vessel Code design guidelines. Key design parameters are given in Table 7-2. 


\begin{tabular}{|l|c|}
\hline Performance Parameters & Value \\
\hline Turbine Exhaust Temperature & $1,130^{\circ} \mathrm{F}$ \\
\hline CT Exhaust \& Gas Flow & $1,196 \mathrm{lb} / \mathrm{sec}$ \\
\hline Number HRSG Pressures & 3 \\
\hline Deaerator Type & Vacuum \\
\hline Approximate HRSG Duty & $1,050 \mathrm{MBtu} / \mathrm{hr}$ \\
\hline HRSG Exhaust Temperature & $207.9^{\circ} \mathrm{F}$ \\
\hline
\end{tabular}

Table 7-2 HRSG Design Parameters

\section{Fuel Gas Heater}

Natural gas entering the ATS plant is heated to $800 \mathrm{oF}$ before entering the combustion turbine. This fuel pre-heating is done in two stages: heating with feedwater and heating with CT exhaust. The thermal performance data for the fuel gas heater is tabulated in Table 7-3:

\begin{tabular}{|l|r|r|}
\hline HEATING FLUID & Feedwater & HRSG Gas \\
\hline Approximate methane flow & $121,000 \mathrm{lb} / \mathrm{h}$ & $121,000 \mathrm{lb} / \mathrm{h}$ \\
\hline Methane inlet temp & $59^{\circ} \mathrm{F}$ & $204.3^{\circ} \mathrm{F}$ \\
\hline Methane exit temp & $204.3{ }^{\circ} \mathrm{F}$ & $800^{\circ} \mathrm{F}$ \\
\hline Methane pressure & $500 \mathrm{psia}$ & $500 \mathrm{psia}$ \\
\hline Approximate Water/gas flow & $75,000 \mathrm{lb} / \mathrm{h}$ & $4,500,000 \mathrm{lb} / \mathrm{h}$ \\
\hline Water/gas inlet temp & $271.8^{\circ} \mathrm{F}$ & $941.2^{\circ} \mathrm{F}$ \\
\hline Water/gas exit temp & $147.4^{\circ} \mathrm{F}$ & $903{ }^{\circ} \mathrm{F}$ \\
\hline Water/gas pressure & $800 \mathrm{psia}$ & $15 \mathrm{psia}$ \\
\hline Heat duty (Q) & $9.3 \mathrm{MBtu} / \mathrm{h}$ & $47.5 \mathrm{MBtu} / \mathrm{h}$ \\
\hline Mean Temp Diff.(MTD) & $77.5^{\circ} \mathrm{F}$ & $349^{\circ} \mathrm{F}$ \\
\hline Approximate Conductance (UA) & $120,000 \mathrm{Btw} / \mathrm{hr}-{ }^{\circ} \mathrm{F}$ & $136,000 \mathrm{Btu} / \mathrm{hr}-{ }^{\circ} \mathrm{F}$ \\
\hline
\end{tabular}

Table 7-3 Fuel Gas Heater Performance Data 


\section{Steam Piping}

The main steam piping transfers high-pressure throttle steam from the superheater to the HP turbine inlet. The exhaust from the HP turbine is combined with slightly superheated IP steam from the HRSG, reheated in the steam-cooled stators of the ATS combustion turbine, then piped to the inlet of the IP steam turbine. Low-pressure steam piping carries induction steam from the LP superheater to the IP/LP crossover piping.

Piping design, size selection and wall thickness is based upon ASME B31.1. Pipe sizing remains the same, regardless of duct firing option. Only the wall thickness varies. This philosophy keeps the piping layout and hanger design constant.

The design parameters for the steam piping are listed in Table 7-4:

\begin{tabular}{|l|c|c|c|c|c|}
\hline Line Identifier & Main Steam & Cold Reheat & IP Induction & Hot Reheat & LP Induction \\
\hline From & $\begin{array}{c}\text { HP } \\
\text { Superheater }\end{array}$ & $\begin{array}{c}\text { HP Steam } \\
\text { Turbine }\end{array}$ & IP Superheater & $\begin{array}{c}\text { ATS Cooled } \\
\text { Stators }\end{array}$ & LP Superheater \\
\hline To & $\begin{array}{c}\text { HP Steam } \\
\text { Turbine }\end{array}$ & $\begin{array}{c}\text { ATS Cooled } \\
\text { Stators }\end{array}$ & $\begin{array}{c}\text { ATS Cooled } \\
\text { Stators }\end{array}$ & $\begin{array}{c}\text { IP Steam } \\
\text { Turbine }\end{array}$ & $\begin{array}{c}\text { IP/LP } \\
\text { Crossover }\end{array}$ \\
\hline Line Size & 16 inches & 20 inches & 6 inches & 24 inches & 14 inches \\
\hline Wall Thickness & 1.75 inches & 0.75 inches & 0.375 inches & $\mathbf{0 . 8 7 5}$ inches & 0.375 inches \\
\hline Flow & $615,967 \mathrm{lb} / \mathrm{h}$ & $610,707 \mathrm{lb} / \mathrm{h}$ & $55,543 \mathrm{lb} / \mathrm{h}$ & $666,250 \mathrm{lb} / \mathrm{h}$ & $67,032 \mathrm{lb} / \mathrm{h}$ \\
\hline
\end{tabular}

Table 7-4 Steam Piping Design Parameters

\section{$\underline{\text { Steam Turbine }}$}

The steam turbine cycle for the ATS plant utilizes a single reheat cycle. The steam turbine exhaust flow of the ATS plant necessitates the use of a double-flow LP exhaust. Operational design parameters include up to 50 starts per year and 8000 hours per year base load operation. Table 7-5 shows the primary steam turbine performance parameters. 


\begin{tabular}{|l|c|}
\hline Performance Parameters & Value \\
\hline Approximate S/T Power & $130,000 \mathrm{~kW}(\mathrm{e})$ \\
\hline Approximate S/T Throttle Flow & $616,000 \mathrm{lb} / \mathrm{hr}$ \\
\hline Approximate S/T Throttle Temperature & 1,050 F \\
\hline Approximate S/T Throttle Pressure & $1,800 \mathrm{psig}$ \\
\hline S/T Exhaust Flow Type & Double Flow \\
\hline Number Reheat Passes & 1 \\
\hline
\end{tabular}

Table 7-5 Steam Turbine Performance Parameters

\section{Generator-Exciter}

The combustion turbine and steam turbine are on a single shaft. Both turbines share a common hydrogen cooled generator. Generator design will be conventional design. Dimensions for the generator are:

- length of generator and exciter is 611 inches, with a width of 174 inches

- height above foundation is 137 inches

- depth below foundation is 40 inches

\section{Condenser/Cooling Tower}

The ATS plant steam turbine requires a double flow back end. For design convenience, a side entry saddlebag condenser was modeled rather than a conventional vertical type. The saddlebag condenser imposes a lower height and shorter overall length requirement on the building. A tabular listing of performance parameters for the condenser and cooling tower is shown in Table 7-6. 


\begin{tabular}{|l|c|}
\hline Performance Parameters & ATS Plant \\
\hline S/T Exhaust Flow Type & Double Flow \\
\hline Condenser Duty & $700.4 \mathrm{MBtu} / \mathrm{hr}$ \\
\hline Cooling Tower Type & Mechanical Draft \\
\hline Cooling Tower Cells at Design & 8 Cells \\
\hline
\end{tabular}

Table 7-6 Condenser Performance Parameters

\section{$\underline{\text { Site Arrangement }}$}

The arrangement of generation equipment and peripheral equipment needed at the plant site is shown in the Site Arrangement drawing. Peripheral balance-of-plant equipment includes:

- An 8-cell cooling tower

- A 1.8-million-gallon (3-day supply) fuel storage tank

- A 1.5-million-gallon (3-day supply) condensate storage tank

- A 1.5-million-gallon (3-day supply) demineralized water storage tank

- Provisions for other optional equipment

The footprint of the plant measures $828^{\prime}$ by $682^{\prime}$. The ATS Plant layout is aiso shown in the Site Isometric drawing.

\section{Generation Equipment Layout}

The layout of the generation equipment reflects the single-shaft arrangement of the HRSG, combustion turbine, generator, and steam turbine. The low-pressure steam turbine is flanked by twin side-entry saddlebag condensers. The plan view of the primary power generation equipment is shown in the Equipment Arrangement drawing. 


\section{ATS ENGINE CONCEPTUAL DESIGN}

A conceptual design was carried out to define the preliminary configuration of the ATS engine (see Figure 7-1). The ATS engine is an advanced $300 \mathrm{MW}$ class design incorporating many proven design features used in previous Westinghouse gas turbines and new design features and technologies required to achieve the ATS Program goals. The compressor design philosophy is based on that used in the advanced $501 \mathrm{G}$ compressor. The combustion system uses 16 combustors of lean-premixed multistage design. Closed-loop steam cooling is used to cool the combustors and transitions. The four-stage turbine design is an extension of the advanced $501 \mathrm{G}$ turbine design, employing 3D design philosophy and advanced viscous analysis codes. To further enhance ATS plant efficiency, the turbine airfoils are closed-loop cooled.

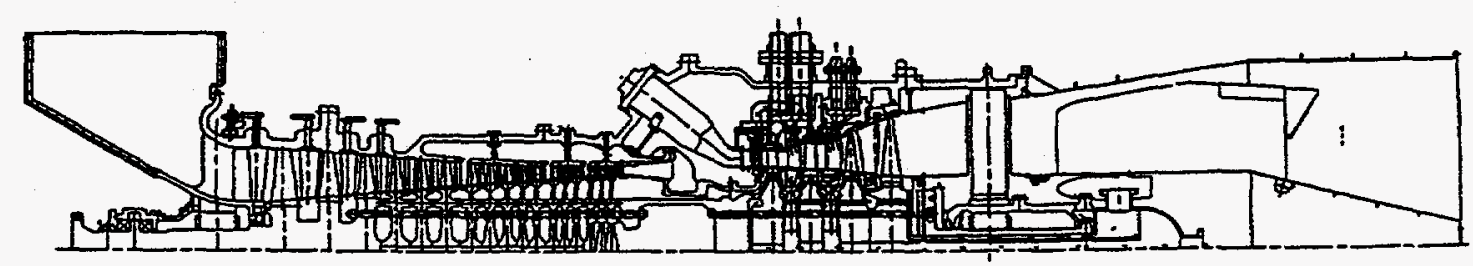

Figure 7-1. Cross Section of ATS Engine

$\underline{\text { Inlet }}$

The compressor inlet is through side entry. The inlet casing, incorporating the front engine supports, is the scroll bellmouth type. The bellmouth surface profile is generated with the aid of a 3D viscous code to ensure optimum surface velocity distributions, and hence minimum inlet losses. The flow path surfaces of the inlet casing, which is a nodular iron casting, are coated with a ceramic coating to provide a smooth surface finish and, and therefore, further reduce the inlet losses and improve the velocity profile into the compressor. 


\section{Compressor}

The ATS compressor design pressure ratio is $25: 1$. The design philosophy is based on that used in the advanced $501 \mathrm{G}$ compressor, but with additional design enhancements such as the incorporation of brush seals to minimize leakage under the stator shrouds. Advanced aerodynamic design tools and controlled diffusion design process are employed in order to minimize loss and maximize airfoil loading. In addition, airfoil thickness is reduced to the minimum allowable from mechanical considerations to reduce diffusion and shock losses. Abradable coatings are applied to the outer shroud to minimize blade tip clearances. As a result of the $25: 1$ pressure ratio, variable stators are incorporated in the front stages to improve starting and part-load operation.

The front- and middle-stage compressor discs are made of conventional material forgings. Due to the increased compressor exit air temperature in the ATS application Ni-based alloy disc material is used in the back stages. The compressor rotor is joined to the turbine rotor through a torque tube. The front part of the compressor cylinder, which is horizontally split (as are all the other engine cylinders), is made of cast steel. Blade rings, which are intermediate cylinders, are used in the back end to minimize eccentricity and hence blade tip clearances. The blade rings are made of $2-1 / 2 \% \mathrm{Cr}-1 \% \mathrm{Mo}$ low alloy steel. The compressor blades, which are attached to the discs by a dove tail root design, are made of $17-4 \mathrm{PH}$ and $12 \% \mathrm{Cr}$ steels. The stators are made of similar material as the blades and all, except for the variable stators, are fabricated into diaphragms.

\section{Combustion System}

The combustion system incorporates 16 can-annular combustors of lean-premixed multistage design with catalytic components as necessary to meet emissions requirements and ensure good stability. Figure 7-2 shows the multi annular swirl ultra low NOx combustor, which is one of the candidate combustors for the ATS engine. To obtain less than 10 ppmvd NOx emissions, nearly all of the compressor delivery air must be premixed with the fuel. Therefore, closed-loop steam cooling is used to cool the combustors and transitions, which duct the hot combustion gases into the turbine. The cooling stream is supplied and extracted through manifolds located on the stage 1 and 2 turbine blade ring.

Conventional Ni-based sheet materials are used in the manufacture of the combustors and transitions. 


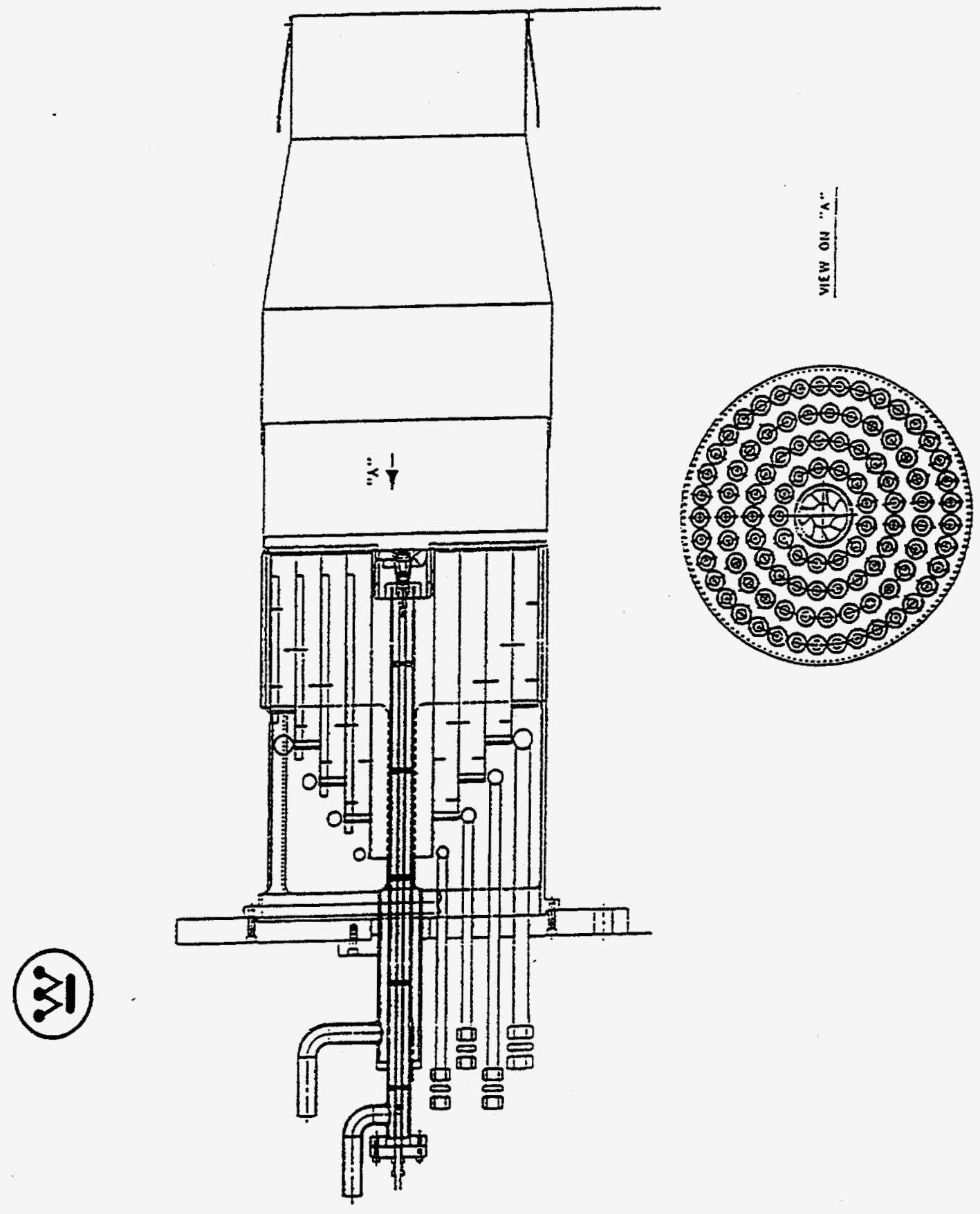

Figure 7-2. Multi -annular Swirl Combustor 
$\underline{\text { Turbine }}$

The ATS turbine is an extension of the advanced four-stage turbine designed for the $501 \mathrm{G}$ engine. The $501 \mathrm{G}$ turbine efficiency was increased over that of $501 \mathrm{~F}$ by applying $3 \mathrm{D}$ design philosophy and advanced viscous analysis codes. The airfoil loadings were increased above previous levels to optimize airfoil efficiency while minimizing airfoil solidity. The reduced airfoil solidity resulted in reduced cooling requirements and enhanced plant efficiency. The ATS turbine design incorporates the following additional enhancements: closed-loop cooling of vanes and blades, blade tip clearance control on the first two stages, and airfoil clocking (optimum circumferential alignment of airfoils in downstream stage with respect to those in the upstream stage.

To improve plant efficiency closed-loop steam cooling (CLSC) is used to cool some turbine airfoils. The heat capacity of steam is almost double that of air. Less steam than air is thus required to cool the turbine components. The major benefit of CLSC is the elimination of cooling air ejection into the flow path. This results in an increase in gas temperatures downstream of the first-stage vane and hence an increase in gas energy level during the expansion process. A secondary benefit is the elimination of mixing losses associated with cooling air ejection into the gas path. The combination of the above effects results in a significant increase in ATS plant efficiency. In addition, the NOx emissions are reduced because more air is available for lean-premix combustor at the same burner outlet temperature.

Achieving acceptable blade metal temperatures in a closed-loop cooling design is a challenge due to the absence of cooling air film to shield the turbine airfoil and shroud wall, and no shower-head or trailing edge ejection to provide enhanced cooling in the critical leading and trailing edge regions. To produce an optimized closed-loop cooling design, the following approaches are utilized: (1) airfoil aerodynamic design tailored to provide minimum gas side heat transfer coefficients, (2) minimum coolant inlet temperature, (3) thermal barrier coating applied on airfoil and end wall surfaces to reduce heat input, (4) maximized cold side surface area, (5) turbulators to enhance cold side heat transfer coefficients, and (6) minimum outside wall thickness to reduce wall temperature gradients and hence the internal heat transfer coefficients required to cool the airfoil.

The shell/spar cooling concept will be considered for cooling stage 1 vanes and blades (see Figure 7-3). This concept consists of a cast airfoil-shaped support structure (spar) around which a thin sheet of superalloy (shell) is diffusion bonded. The outside surface of the spar incorporates chordwise grooves that form small, closely spaced cooling channels under the shell. Thus, the shell/spar configuration achieves the desired qualities of a thin outside wall and a favorable cold-to-hot surface area ratio. The airfoil spar contains three cavities: the fore and aft cavities supply the cooling steam, and the midcavity discharges the spent cooling steam. Cooling channels extend in a chordwise direction from a supply cavity to the discharge cavity. Holes drilled through the spar connect the cooling channels with the cavities. The trailing edge is cooled by spanwise holes. 
Recent advances in casting technology have produced cooling configurations with thin outside walls and internal cooling passages suitable for CLSC. To increase cold-side heat transfer, turbulence promoters can be incorporated in the cooling channels. The peripheral radial cooling hole concept will also be evaluated.

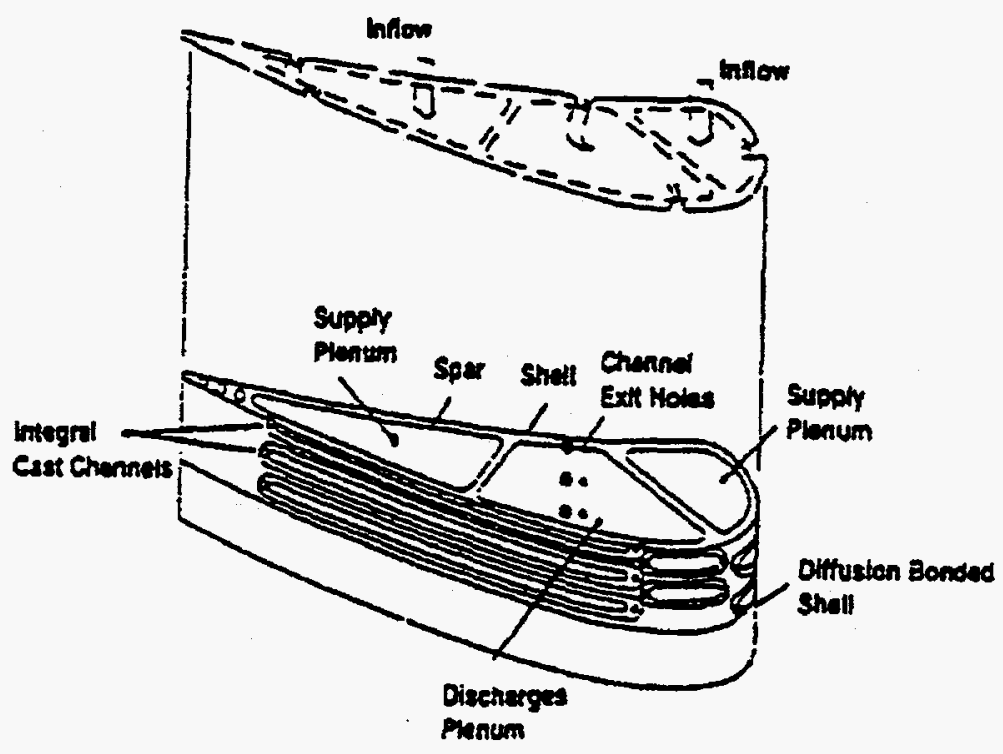

Figure 7-3. Conceptual Design of Shell/Spar Vane

The heat load on stage 2 vanes will permit steam-impingement-cooled castings to be used. Impingement cooling will be applied to the airfoil fore and aft cavities, with convection cooling via spent stream return flow in the midcavity. Heat load on the stage 2 blade will also permit a conventional serpentine cooling design. The stage 3 vane will use a serpentine cooling design. Stage 4 airfoils will be uncooled.

\section{Secondary Flow System}

The engine secondary flow system consists of air and steam flows. These two fluids are isolated from each other and supplied to the proper locations with minimum leakage. Airflow from the compressor exit passes through the torque tube seals and cools the front face of the row 1 turbine disc. This air is then cascaded through the rotating rotor to the stage 2 interstage region to prevent entry of hot gas in front of and behind the stage 2 vane. Air leakage is reduced by using brush seals in the critical sealing areas. 
Cooling steam is supplied to the stationary parts through pipes passing through the turbine cylinder and into a circular manifold. Reheated steam is returned through a similar manifold/piping system. Pipes are connected to the manifolds by flanges with piston ring seals, which seal tightly and accommodate thermal growth. The system is designed to provide parallel cooling steam flow to stage 1,2 , and 3 vanes.

The steam flow system for the rotating blades consists of an inlet manifold at the turbine end of the rotor shaft; a rotating axial annular passage inside the rotor shaft that conducts steam from the manifold area to the discs; a series of holes and slots in the rotor discs to supply steam from the rotating passage to the roots of the cooled blades; another series of holes and slots in the discs to carry the reheated steam from the blades to a hole in the center of the rotor discs; and finally, a steam exhaust from this center bore into a plenum at the rotor stub end.

\section{Rotor System}

The turbine rotor is constructed from a series of individual turbine discs, spacer discs, and a stub shaft attached by a single set of spindle bolts and weldments. The turbine discs are of conventional design, except for a rotor bore used as a steam passage and the additional downstream blade groove sealing hardware. Ni-based components are used, as required, to cater to the exhaust steam temperature.

\section{Exhaust Diffuser}

The ATS engine has an axial exhaust diffuser similar to that used in previous Westinghouse designs. It consists of the exhaust cylinder and an exhaust manifold. The exhaust cylinder carries the hot end journal bearing, which is contained in the front part of the inner tailcone. This portion of the tailcone is supported by tangential or radial struts. This strut system allows for thermal expansion without changing the bearing centerline location. The struts are protected from the hot gases by airfoil type shielding. The exhaust manifold has two access ports for lube oil, seal air, and steam piping. One of the ports has provision for accessing the hot end bearing. The materials used in the exhaust are Ni-based sheet metals. 
DE-AC21-93MC30247

\section{SECTION 8}

\section{DESIGN AND TEST OF CRITICAL COMPONENTS}

\section{BACKGROUND}

New technologies must be developed and existing technologies extrapolated beyond the state-of-the-art in order to achieve the challenging ATS Program performance and emissions goals. A considerable improvement in gas turbine engine performance is necessary to achieve the required plant efficiency level. The engine performance enhancement requires improvements in firing temperature, aerodynamic design, cooling design, and in sealing. All of the above need technological development and innovation. In this section, the component development required to make ATS a reality is discussed. It is known that higher firing temperature operation necessitates developments in technologies related to improved materials, such as directionally solidified and single crystal airfoils, improved coatings, such as TBC, improved corrosion/oxidation protection coatings, and improved or novel cooling schemes. Technological developments are needed in the flow visualization, optical diagnostics, combustion noise, and catalytic combustion fields to reduce combustion emissions at the higher firing temperatures required for the ATS engine. An active blade tip clearance control system and brush seal technology will be incorporated in the appropriate locations in the compressor and the turbine to improve the turbine efficiency. A brief review of the state-of-the-art is presented. This is followed by a discussion of results from the individual component development projects completed in Task 8 of the ATS Phase 2 program .

A strategy was developed to achieve the ATS Program plant cycle efficiency target of greater than $60 \%$. The foundation of this strategy is based on the advanced combined cycle concept, which incorporates an advanced engine design, as well as improvements in the bottoming cycle and the generator. The selection of this cycle was based on performance criteria, including overall plant efficiency, cost of electricity, practicability, reliability-availability-maintainability, and the time frame of the ATS Program. Some of the options considered in the ATS cycle evaluation, such as recuperation, reheat, and thermochemical recuperation, had potentially higher plant cycle efficiency, compared to the advanced combined cycle concept. However, they were not selected for further development due to a low ranking in one of the performance criteria.

The primary contributor to achieving the ATS Program objectives is an advanced gas turbine design, with the enhanced bottoming cycle and high efficiency generator playing a minor role. The new components and technologies developed in this program has advanced the state-of-the-art for gas turbine design to a new plateau. There is also a synergism with gas turbine designs in other applications, such that benefits derived from the ATS Program can enhance the performance of gas turbines designed for use in aero, marine, pipeline and industrial applications. 


\section{TECHNOLOGY IMPROVEMENTS}

When the ATS project started, the current Westinghouse production engine, the $501 \mathrm{~F}$, represented the latest step change in engine performance. The output power is $160 \mathrm{MW}$. The simple cycle efficiency is about $36 \%$. In a combined cycle applications, the efficiency exceeds $54 \%$. This performance level was achieved by increasing firing temperature approximately $200^{\circ} \mathrm{F}$ over the previous commercial engine design, advanced aerodynamic design of both the compressor and the turbine, enhanced cooling design of hot end components, and improved materials.

In 1994, Westinghouse introduced its latest engine model, the $501 \mathrm{G}$. The $501 \mathrm{G}$ possesses an output power of about $230 \mathrm{MW}$ and a net combined cycle efficiency of about $58 \%$. The large improvement in efficiency results from an additional $250^{\circ} \mathrm{F}$ increase in firing temperature and advancements in aerodynamic design, cooling design, and hot end materials.

The ATS engine will represent a larger step in the development cycle than previous improvements. Additional simultaneous advances in aerodynamic design, heat transfer, and materials technologies are necessary to achieve the required improvement in efficiency of greater than $60 \%$. The following improvements were targeted to ensure the efficiency goal was achieved:

Turbine Improvements

- Advanced aero/heat transfer/materials technology

- $\quad$ Burner outlet temperature(BOT) $>2730^{\circ} \mathrm{F}$

- $\quad$ Closed-loop steam cooling

- Single crystal and directionally solidified airfoils

- Improved thermal barrier and anti-corrosion coatings

- Ceramic ring segments

- Active tip clearance control

- $\quad$ Brush seals

- Reduced compressor dump/combustor loss

- Increased Row 4 blade exit area 


\section{Plant Improvements}

- $\quad$ Reduced inlet/exhaust losses

- $\quad$ Fuel preheating

- $\quad$ Single shaft: Combustion Turbine - Generator - Steam Turbine

- $\quad$ Advanced steam turbine design technology

- $1800 \mathrm{psi}, 1050^{\circ} \mathrm{F} / 1050^{\circ} \mathrm{F}$ steam cycle

State-of-the-art aerodynamic, heat transfer and materials technologies are deployed in the design of the ATS engine. The burner outlet temperature is between $2730^{\circ} \mathrm{F}$ and $2800^{\circ} \mathrm{F}$. This temperature range allows a high cycle efficiency, but still low enough to attain emissions goals. Catalytically enhanced combustor components have been employed to attain low NOx emissions at the high burner outlet temperatures.

Closed-loop steam cooling will be employed on hot end components(i.e., transitions, Rows 1 to 3 vanes, Rows 1 and 2 blades, and some of the blade rings) to optimize plant cycle efficiency. Single crystal casting technology are deployed on Rows 1 to 3 blades and directionally solidified casting technology on Row 1 vane. Improved or advanced alloys are used in these castings. Improved thermal barrier and anti corrosion/oxidation coatings are applied to the turbine airfoils to allow long term operation at surface metal temperatures approaching $1800^{\circ} \mathrm{F}$.

Active tip clearance control was developed for Rows 1 and 2 turbine blades, to reduce blade tip leakage losses. Better blade tip control improves efficiency and significantly reduces turbine performance deterioration with increasing operating time. Blade tip clearance is held to smaller gaps because of fewer tip rubs, reducing losses. Brush seals are installed in the appropriate locations in the turbine and compressor to reduce leakage, as well as hot gas ingestion into turbine disc cavities.

Design changes initiated by flow tests on a model of a combustion cylinder and the elimination of showerhead cooling on turbine airfoils can reduce compressor exit dump losses and the combustor pressure losses significantly. Row 4 turbine exit area will be increased by about $12 \%$ compared to that of the latest design to reduce the turbine exhaust diffuser losses.

Improvements were made in the plant design to attain the overall efficiency objective. Inlet and exhaust systems were designed to minimize duct losses without incurring excessive costs. Fuel preheating is employed to recover exhaust heat. The single shaft concept was used, with the gas turbine, the generator and the steam turbine connected together. A high efficiency generator will be designed specifically for the ATS plant. Advanced aerodynamic design technology is applied to the steam turbine design to 
optimize its efficiency. A three-pressure level steam cycle, with $1800 \mathrm{psi}$ and $1050^{\circ} \mathrm{F}$ high pressure steam and $1050^{\circ} \mathrm{F}$ reheat steam, is employed.

The estimated ATS plant cycle efficiency will be greater than $60 \%$ with the planned improvements in the gas turbine and plant design. An extensive development effort in all of the major gas turbine technologies is required to achieve this efficiency level. These projects are grouped under the following main headings: combustion, cooling, mechanical design, leakage control, diagnostics and materials/coatings. Listed in Table $8-1$, these projects were started in Phase 2 to support the design and test of critical ATS components. Some of the projects were completed in Phase 2, while others were carried forward into Phase 3 of the ATS program. A foundation explaining current technology of materials, coatings, combustion, cooling, mechanical design and leakage is presented before proceeding to a discussion about each of the component development projects.

TABLE 8-1

ATS COMPONENT DEVELOPMENT PROJECTS

\begin{tabular}{|c|c|}
\hline TECHNOLOGY & PROJECTS \\
\hline I $\quad$ Combustion & $\begin{array}{l}\text { Flow Visualization } \\
\text { Combustion Noise Investigation } \\
\text { Catalytic Combustion }\end{array}$ \\
\hline II $\quad$ Cooling & $\begin{array}{l}\text { Airfoil/Shroud Cooling } \\
\text { Integral Shroud Cooling } \\
\text { Serpentine Channel Cooling } \\
\text { Closed-loop Steam Cooling }\end{array}$ \\
\hline III Mechanical Design & $\begin{array}{l}\text { Last Row Turbine Blade } \\
\text { Diffuser Design } \\
\text { High Efficiency Compressor }\end{array}$ \\
\hline IV Leakage Control & $\begin{array}{l}\text { Active Tip Clearance Control } \\
\text { Brush Seals }\end{array}$ \\
\hline V Materials/Coatings & $\begin{array}{l}\text { Directionally Solidified Castings } \\
\text { Single Crystal Castings } \\
\text { Thermal Barrier Coatings } \\
\text { Ceramic Components }\end{array}$ \\
\hline VI $\quad$ Diagnostics & $\begin{array}{l}\text { Blade Vibration Monitor } \\
\text { Optical Diagnostics Probe }\end{array}$ \\
\hline
\end{tabular}




\section{IMPORTANCE OF MATERIALS}

Materials and related manufacturing technologies play a critical role in achieving the efficiency goals of the ATS program. Theoretically, there are two approaches to increase the turbine efficiency. In the first approach, the efficiency can be increased partly by improving cooling technology, thus using less cooling air to achieve the same amount of temperature reduction required to maintain the component temperatures within the capability of the materials. However, increasing cooling efficiency alone is not sufficient. The second approach is to utilize materials that have higher temperature capabilities, so that components can operate reliably at higher temperatures with reduced cooling air usage. It is only by the contribution of improved cooling technology and advanced materials combined that maximum efficiency increase can be realized. Materials with higher temperature capabilities and advanced cooling provisions will be key contributors toward meeting the ATS efficiency goals.

The high performance of the Westinghouse $501 \mathrm{G}$ engine can claim part of its heritage from the ATS program. Specifically, the $501 \mathrm{G}$ engine incorporates:

- Thermal barrier coatings with improved reliability

- Directionally solidified airfoils

- Enhanced airfoil cooling design

- $\quad$ Reduced leakage(brush seals)

General Material Requirements

Hot section components for land based turbines typically require materials with superior mechanical properties and good corrosion/oxidation resistance at elevated temperatures. Conventional Ni- and Co-based superalloys, which are extensively used in the current land based turbines, were considered. In addition, the protection of hot section components by oxidation/corrosion resistant coatings and thermal barrier coatings (TBC) has become a necessity.

Advanced materials, such as single crystal (SC) and direction solidification (DS) alloys, which have been developed for aeroderivative engines with proven service experience, were evaluated for large land-based turbine applications. Furthermore, the higher firing temperature of ATS warrants the evaluation of emerging materials, such as ceramic materials and intermetallic materials for future ATS plants. These materials have emerged from their development stage to become viable engineering materials ready to be evaluated for implementation in land-based turbines. Understandably, the development risk associated with these relatively new materials will be higher than that of the metallic alternatives. But, the potential benefits offered by these emerging materials in efficiency improvement and emission reduction are commensurably compelling. Therefore, Westinghouse, in the future, intends to take advantage of the high 
temperature capabilities of these two emerging materials and evaluate them for implementation in the ATS turbine. More detailed analysis and the rationale for the material selection for the major components are discussed in the following paragraphs.

\section{Gas Turbine Disc Materials}

Turbine disc materials are critical, because they are subjected to high centrifugal stresses resulting from the load applied by the blades which are attached to the rim. The requirements for the disc materials include strength, ductility, toughness, resistance to embrittlement, and resistance to corrosion.

High strength, low alloy steels are common for disc applications in the land based turbine industry; although nickel-based superalloys, such as IN-706, have been used by some manufacturers in recent turbine designs. High strength, low alloy steel discs are used in the turbine section of the Westinghouse $501 \mathrm{~F}$ turbine, which has a rotor inlet temperature of about $2300^{\circ} \mathrm{F}$, through the use of the cooling air to minimize in-service temper embrittlement and to assure long-term reliability of these discs.

Superalloys have superior strength at elevated temperatures compared to low alloy steels. Therefore, they can be used at higher service temperatures with reduced or eliminated cooling air, thus allowing improved turbine efficiency. Candidate disc materials under consideration are Discalloy (an iron-based superalloy similar to A286), $\mathbb{N}-901, \mathbb{N}-706$, IN-718, Waspalloy, and Udimet 729. The last three materials are difficult to forge in large discs, using state-of-the-art forging and melting technologies, without producing segregation and/or casting defects. Such characteristics would adversely affect the reliability and service life of the discs. In the 1970s, Westinghouse evaluated Discalloy, $\mathbb{N}-901$, and $\mathbb{N}-706$ alloys for disc applications. Large forgings could be made with these alloys. Discalloy is less expensive compared to the latter two alloys, since it is an ironbased alloy, whereas IN-901 and IN-706 are nickel-based alloys. Large Discalloy discs have been implemented successfully in the Westinghouse 101, 191, and 301 gas turbines, and accumulating extensive field experience. During the mid-1980's, Westinghouse in collaboration with a forging supplier, successfully produced a full size $\mathbb{I N}-706$ rotor forging for the EPRI sponsored Superconducting Generator Program. Welding and machining techniques for IN 706 were also developed in this program for the fabrication of the large rotor assembly.

Low alloy steels will be considered for ATS turbine discs because of their low cost and extensive design and manufacturing experience developed in the past decades. However, with the increased RIT in the ATS, there is a strong possibility that the disc temperature may increase to a level which would exceed the strength capability of low alloy steels. In that case, superalloys will be needed in order to meet the more demanding ATS disc design requirement. Upon the completion of a detailed design analysis, a superalloy material will be selected, design data generated and forging and other necessary manufacturing processes developed. 


\section{Combustion System Materials}

The combustion system components include baskets and transitions. Inside a combustor basket, fuel and air are mixed and burned to produce hot gases. The hot gases are then directed through a transition section, then onward to the first stage vanes. Baskets and transitions are subjected to low stresses due to their static condition. The key material requirements for these components are creep strength, LCF strength, corrosion/oxidation resistance, thermal fatigue resistance and ease of fabrication.

Sheet metal $\mathrm{Ni}$ - and Co-based alloys are the most common choice of materials for these applications by turbine manufacturers. These alloys include Hastelloy X, IN-617, Haynes 230 , Nimonic 75, Nimonic 86 and Haynes 188 . Westinghouse has satisfactory experience using Ni-based superalloys in the baskets and transitions. However, with the recent increase in firing temperatures in the latest turbine models, the use of TBC coatings has become mandatory to avoid distress due to excessive steady-state and transient temperatures. For the ATS combustor basket and transition applications, the current Ni-based alloys with corrosion/oxidation coatings and TBC coating are considered as the baseline design.

However, combustors and transitions appear to be ideal for ceramic application because of its chemical stability at high temperatures. Modern monolithic ceramic materials provide higher strength, better creep resistance and far better reliability than those of a few years ago. The addition of high strength continuous ceramic fibers woven into a two or three dimensional preform in a ceramic matrix makes the composite system even tougher and more strain tolerant than monolithic ceramics. These ceramic matrix composites (CMCs) are already in use in military aircraft engines as afterburner flame holders and exhaust nozzles. Experience gained through the development of these components has resulted in the improvement of materials, design and manufacturing methods.

The use of ceramic materials can benefit future ATS design in two important areasincreasing efficiency through less cooling medium usage, and, reducing NOx emissions due to more uniform combustor temperature distributions. Therefore, the design of combustors and transitions with ceramic materials was pursued as a more favorable option, although the risk will be higher than that of the metallic counterpart. A design of ATS ring segments with ceramic matrix composites was undertaken. A two layer ceramic laminate was evaluated, having an outer structural layer and an inner, thermally insulating layer. The experience gained from the development of the ring segments serves as a stepping-stone toward the design of the larger and more complex ceramic combustors and transitions. 


\section{Gas Turbine Vane Materials}

Turbine vanes primarily serve the function of directing the flow of hot gasses towards rotating blades. The design requirements imposed on the vanes are not as stringent as on the rotating blades due to their static nature. However, the vanes are subjected to gas temperatures higher than the rotating blades in the same row. Therefore, resistance to corrosion/oxidation, creep, low cycle fatigue (LCF) and thermal fatigue are the most desired properties for vane alloys. Weldability, both for fabrication and repair, is also an important factor.

The land based turbine vanes are typically made of $\mathrm{Ni}$-based or Co-based alloys using a conventional casting process (CC). DS vanes are used in Westinghouse's new 501G model engine. The use of $\mathrm{SC}$ vanes has not been introduced in land based turbines to date. In general, Co-based alloys exhibit superior weldability and hot corrosion resistance due to their higher $\mathrm{Cr}$ contents. Westinghouse has been using Co-based alloys, such as X-45, since the mid-1960s, and has switched to a Westinghouse patented alloy, ECY-768, since the 1970s. ECY-768 is a Co-Cr-Ni-W alloy, which exhibits significantly higher creep strength than X-45. In order to improve the low cycle fatigue strength of ECY-768, Westinghouse has recently optimized its carbon content, and the resulting alloy was WES-100. WES-100 vanes are now standard in the Westinghouse 501F engines. Co-based alloys, such as ECY-768 and WES-100, in combination with more efficient cooling schemes and the use of oxidation/corrosion coatings and thermal barrier coatings, were considered for the ATS vane application.

In addition to the Co-based alloys, $\mathrm{Ni}$-based alloys were considered. Ni-based alloys, in general, are inferior to Co-based alloys in hot corrosion resistance, but they are more difficult to weld. However, Ni-based alloys have stronger creep strength than Co-based alloys in the CC condition. Furthermore, Ni-based alloys can be cast in the DS condition, which typically shows 5 to 8 times improvement in LCF life and also an increase in creep temperature capability as compared to the corresponding alloys in the $\mathrm{CC}$ condition. Cobased alloys are not used in the DS condition. IN-939 and IN-738 alloys, which contain high $\mathrm{Cr}$ for corrosion resistance and are widely used by European turbine manufacturers, were considered for use in these vanes. CM247LC in DS condition were also be considered. Due to the higher firing temperatures of the ATS, the hotter stages, Rows 1 and 2 for example, may require the creep and LCF strengths of the DS Ni-based alloys. These alloys can be cast in the DS condition to further enhance the creep and LCF properties of the vanes, if needed. All vanes will be coated with corrosion/oxidation resistant coatings and thermal barrier coatings because of the high temperature environment.

The selection of vane material will depend on the cooling scheme and the corresponding stress and temperature requirements of each individual row of vanes. Preliminary design analysis appears to favor Ni-base alloys which contain high $\mathrm{Cr}$, such as IN 939, due to their high strength and desirable corrosion resistance. However, its chemistry may need 
to be modified in a later development program to enhance its weldability for the ATS vane application.

\section{Turbine Blade Materials}

Based on the latest design stress analysis, Ni-based superalloys are considered to be the primary candidate for rows 1 to 3 blades. The row 4 blades, which are expected to be subjected to higher fatigue and creep stresses, may require intermetallic materials. The analysis and rationale are presented below:

\section{Rows 1 to 3 Blade Alloys}

Turbine blades of modern land based turbines are primarily made of $\mathrm{Ni}$-based superalloys, such as IN-738 castings (cast by conventional casting process) and Udimet 520 forgings. These alloys are typically limited to the blade application up to $1650^{\circ} \mathrm{F}$ or $1700^{\circ} \mathrm{F}$ metal temperature range due to creep. Materials with higher temperature capability are needed for the ATS. Reducing cooling air to increase efficiency requires that the blades operate at higher temperatures. Within the time frame of development of the ATS engine, the most viable candidate materials are high strength $\mathrm{Ni}$-based alloys, and alloys which can be cast with DS and SC casting processes, in combination with oxidation/corrosion resistant coatings and thermal barrier coatings.

Westinghouse has long recognized the need for high temperature blading alloys. Work on developing corrosion resistant DS and SC Ni-based alloys for turbine blade applications has been ongoing. In these development alloys, $\mathrm{Cr}$ content is maintained at a significantly higher level than that of current aeroderivative SC and DS alloys to promote corrosion resistance, which is more a concern for land based turbines than for aero engines. Preliminary test data from the DS blade development indicates that these new DS alloys offer a substantial temperature advantage over conventionally cast equiaxed IN-738. Castability studies of these alloys are in progress. The Westinghouse DS alloys were expected to have better corrosion resistance than the current commercial aeroderivative $\mathrm{Ni}$-based blade alloys due to their higher $\mathrm{Cr}$ contents, but it is not certain that the creep strength would meet the ATS design requirements.

Westinghouse has been evaluating experimental SC alloys. The objective of this program is to develop a corrosion resistant SC blade material with an extra $50^{\circ} \mathrm{F}$ to $100^{\circ} \mathrm{F}$ temperature capability compared to the corresponding DS blade materials. SC slabs and bars have been cast from these alloys and the materials were tested. The Westinghouse $\mathrm{SC}$ development program is still in the early stages of development. Advanced SC materials from the program may not be available in time for ATS deployment. Therefore, to assure that materials are available to meet the schedule, it became necessary to evaluate aeroderivative SC and DS materials.

CMSX-4 SC alloy and CM247LC DS alloy have been used extensively for airfoil applications in aero engines and small industrial gas turbines. These alloys were selected for ATS blade development. CMSX-4 is a second generation single crystal superalloy 
containing 3\% rhenium ( $\mathrm{Re}$ ). CM247LC is a derivative of the MAR-M-247 alloy, specially designed for aeroderivative DS turbine blades and vanes. These materials offer excellent creep strength, long-term stability and castability (for small airfoils), and represent the most advanced SC and DS alloys commercially available to date. CM247LC in the DS condition and CMSX-4 in the SC condition offer approximately $90^{\circ} \mathrm{F}$ and $200^{\circ} \mathrm{F}$ temperature advantages, respectively, at typical operating stress levels, as compared to the current land based blade material IN-738 in the conventional casting condition.

The industrial experience with both CM247LC DS and CMSX-4 SC alloys to date has been limited to relatively small airfoils primarily for aircraft engines or small industrial turbines. The castability of these alloys and their applicability to large size blades used in industrial power generation turbines have yet to be verified, because of concerns about grain structure control, chemical segregation and property uniformity. A castability study of CMSX-4 SC blades using 501F blade design as a prototype is now underway with a leading casting supplier. A similar castability study will be needed for the CM247LC vanes and blades. If the results of the castability studies are favorable, further work, such as heat treatment and hot isostatic pressing (HIP) process optimization, design property data, corrosion/oxidation characterization and coating compatibility, is required.

The merit of $\mathrm{CC}$ alloys can never be ignored due to easier castability and lower cost, even with the temperature advantages offered by the DS and SC alloys. CM247LC (CC) were evaluated for applications in the latter stages, where temperatures are lower and DS properties may not be needed. CM247LC, the low carbon version of the MAR-M-247 alloy, in the CC condition, has been used for airfoils and disks in the aeroderivative engines. Although it was originally developed for the DS processing, the lower carbon content plus other alloy modifications are also beneficial to the castability and mechanical properties of the CC castings. Therefore, CM247LC is selected for the blade CC casting because its creep rupture strength is superior to that of the $\mathrm{CC}$ casting alloys used in the land based turbines. However, further development effort is required. Whether the alloy can be cast in large size land based blades with intricate cooling schemes and shroud overhangs has yet to be demonstrated.

Two approaches were used in selecting the best blade materials. The first approach had taken advantage of the existing successful experience in the aeroderivative alloys, CM247LC (in both CC and DS conditions) and CMSX-4 (SC) alloys. The second approach evaluated Westinghouse SC and DS developmental alloys for the ATS turbine applications. The CMSX-4 SC alloy offers the greatest temperature advantage, but the cost will be the highest because of the high reject rate normally associated with the SC process. The CM247LC alloy with CC processing offers the lowest cost option, but the relatively lower creep strength most likely will limit the use of this alloy to the latter turbine stages. Understandably, the CM247LC DS alloys offer a middle ground between the $\mathrm{SC}$ and $\mathrm{CC}$ options in terms of temperature capability and cost. The blades must be protected with corrosion/oxidation resistant coatings and TBC coatings since they will be subjected to a high temperature environment. The final selection of alloys and casting 
processes will depend on the temperature and stress requirements corresponding to the cooling scheme of each stage. By making the CC, DS and SC options available for ATS blade design, and tailoring the cooling scheme for each individual row of blades, an optimization between component cost and system efficiency can be achieved.

\section{Row 4 Blade Alloys}

The ATS engine row 4 blades will operate at a higher temperature than those in the $501 \mathrm{~F}$ and $501 \mathrm{G}$ engines. In addition, the ATS engine will employ larger/longer row 4 blades in order to minimize exhaust loss and improve efficiency. Since the blade operating stress is proportioned to its length, this results in highly stressed blades. The combination of high temperature and stress therefore requires a material which exhibit higher creep and fatigue strengths than the current $\mathrm{IN}-738$ material. Other conventional Ni-based superalloys, such as CM247 may not meet the creep and fatigue strength requirement either. CM247 in the $\mathrm{CC}$ condition offers about $50^{\circ} \mathrm{F}$ advantage in creep resistance and $15 \%$ higher HCF strength as compared to IN-738. CM247 in the DS condition does not improve the HCF strength over the CC condition. Therefore, it is necessary to develop a new material for the subject application.

Intermetallic materials offer a high strength to weight ratio which make them very attractive for high temperature rotating component application. These materials have not found industrial applications, because the first available materials suffered from low ductility. However, in the last decade, significant advancements has been made in understanding these materials and overcoming the brittleness problem. Today, a number of intermetallic compositions have emerged. Among them, Ti-Al and Ni-Al intermetallics appear to be most promising and are considered for the ATS row 4 blade application.

\section{COATINGS FOR HOT SECTION COMPONENTS}

The Co- and Ni-based alloys used in the hot section components have less than desirable corrosion/oxidation resistance in the turbine environment. The reason for this is that they are primarily designed for high temperature strength, and the chemistries required for strength and corrosion/oxidation resistance are not the same. Therefore, protective surface coatings are essential for reliable and durable performance of hot gas path components. Coatings used for land based hot section components fall into the categories of corrosion/oxidation resistant and thermal barrier. As the name implies, the former is applied for corrosion and oxidation protection, while the latter is used to reduce the heat transfer between the gas stream and the substrate of the coated component.

The corrosion/oxidation resistant coatings used in the land based turbines are of two types: diffusion and overlay coatings. Diffusion type coatings include various aluminides 
and slurry coatings. These coatings are applied by a pack cementation process (PC) or by a chemical vapor deposition (CVD) process. In diffusion type coatings, final coating composition depends strongly on the substrate chemistry. Overlay coatings are applied to component surfaces by electron beam physical vapor deposition (EB-PVD), thermal spray techniques such as low plasma spray or vapor plasma spray (LPS or VPS), high velocity oxy fuel (HVOF) spray, or air plasma spray (APS) processes. Substrate chemistries do not have significant influence on the final compositions of overlay coatings.

Land based turbine manufacturers have been using aluminide type diffusion coatings and $\mathrm{MCrAlY}$ (Where $\mathrm{M}$ can be $\mathrm{Ni}, \mathrm{Co}, \mathrm{Fe}$ or a combination thereof) type overlay coatings on the hot section components since the 1970s. The only differences in the use of these coatings are the selection of minor alloying additions and the methods of application. The use of an efficient cooling scheme permitted Westinghouse to use MCrAlY coatings to about $1650^{\circ} \mathrm{F}$ surface metal temperature with a service life of about 24,000 hours. A development program directed toward advanced corrosion/oxidation resistant coatings is in progress at Westinghouse to further improve the temperature capability of these coatings. Promising compositions were identified to meet a set of target properties. These compositions are being evaluated in laboratory cyclic corrosion tests and burner rig tests. Westinghouse has selected the best available MCrAlY coating for ATS application in terms of temperature capability and long-term durability.

TBC is used to lower the temperatures at the substrate as well as the MCrAlY coating. The most commonly used TBC in land based turbines is yttria-stabilized zirconia (YSZ). The YSZ coating can provide a temperature gradient greater than $100^{\circ} \mathrm{F}$ for a .010 inch thickness, in typical operating conditions. Westinghouse developed a YSZ coating under a DOE program in the 1970 s, and this system, applied predominantly with an APS process, is still used in current turbines. With the advancement of the EB-PVD process, it is possible to reduce the coating thickness variation, minimize cooling hole blockage, and especially improve the coating surface finish. But other characteristics, such as foreign object damage and erosion resistance, have yet to be evaluated in comparison with the APS TBC. Field testing on blades which are coated with both the APS and EBPVD processes were conducted. The results from this engine test, discussed later in this section, provided a better understanding about both the process capability and field performance.

Westinghouse field experience indicated that present MCrA1Y coatings typically used by the turbine manufacturing industry may not provide reliable long term protection for substrate materials at the target RIT of the ATS engine. Since a reliable coating system is critical to the success of meeting the ATS goal, a three-prong approach to improve the coating reliability was undertaken.

The first approach was to develop an advanced bond coat and TBC system that is capable of operating at a $1800^{\circ} \mathrm{F}$ metal temperature for 24,000 hours. Westinghouse has been developing a corrosion-resistant bond coat with an $1800^{\circ} \mathrm{F}$ capability. Tests at $1850^{\circ} \mathrm{F}$ in 
a $\mathrm{Na}_{2} \mathrm{SO}_{4}$ environment have demonstrated the superior environmental resistance of this bond coat as compared to CoNiCrA1Y (RT122). Westinghouse also has identified a series of TBC stabilizers (e.g., $\mathrm{Sc}_{2} \mathrm{O}_{3}$ ), new ceramic compositions and structural modifications aimed at improving the thermal stability, corrosion resistance and spalling resistance of TBC.

The second approach is to perform field and laboratory testing to estimate the reliability of current coating systems. Westinghouse has been field testing coated components for several years. The reliability of TBC coatings applied by air plasma and electron beam from physical vapor deposition (EB-PVD), on IN-738 rotating blades, were tested. Field testing to date has been carried out in units with relatively lower firing temperatures. It is recommended that field testing in a unit with a firing temperature closer to that of the ATS, be considered. This additional testing will confirm the long term TBC stability, and bond coat interaction with CMSX-4 and CM247 blade substrates, which contain lower $\mathrm{Cr}$ than $\mathrm{IN}-738$. Additional lab testing to determine the effects of phase change, fatigue, creep and corrosion on TBC spalling should also be pursued.

The third approach is to develop a computer based life prediction model with the ability to predict cycles to failure for bond coat and TBC. Westinghouse has developed a life prediction model for uncoated cast airfoil alloy with excellent results. This model can be extended or modified to include coating systems. A reliable life prediction model for complex coated components can provide a systematic understanding and control of coating degradation and contribute to the more reliable application of coatings.

\section{COMBUSTION}

Combustion is one of the critical areas requiring significant development efforts because of the higher firing temperatures and the strict emissions requirements for the ATS engine. The following combustion development programs were undertaken to achieve ATS objectives: combustor flow visualization, combustion optical diagnostics probe development, combustion instability/noise investigation, and catalytic combustion components development.

Air flows inside the combustor cylinder and into the combustor baskets are very complicated. These flows have a pronounced effect on pressure losses that directly translates into lower engine performance. The combustion process is directly influenced by the flow distribution inside the combustor baskets. Combustor basket flow patterns are especially critical in dry ultra low NOx lean premix combustors. These combustors rely upon the uniform fuel/air ratios, within a very narrow tolerance band, for low NOx production and operational flame stability. Flow tests were carried out on plastic models 
of the ultra low NOx baskets in the single can rig and the sector rig. Flow visualization and detail flow mapping tests are required. Hot wire anemometry, as well as conventional measurement techniques are employed.

Flow mapping and flow visualization tests were performed on a half-scale plastic model of the $501 \mathrm{~F}$ combustor cylinder at Clemson University. Higher order flow effects inside the combustor cylinder were investigated. Detail information on pressure, velocities and flow angles inside combustor cylinder, and especially around the combustor baskets, were obtained. The effect of struts, cooling air bleed port, cooling air return pipes, diffuser exit swirl, modulation of the by-pass valve, flow shields around the combustor baskets, top hat length, ultra low NOx basket, and curved compressor exit diffuser were investigated. In addition to studying and optimizing the flow around the combustor baskets, efforts to optimize the performance of the compressor exit diffuser and reduce the diffuser exit dump loss were undertaken.

Optical diagnostics allow measurement of pertinent parameters, such as the composition and concentration of combustion products, in addition to velocities and flow angles, without disturbing the main flow. An optical diagnostic probe needs to be developed to aid in combustion system optimization. Rig and engine tests, using the optical diagnostic probe, were conducted.

High firing temperatures are required to achieve the very challenging performance goals of the ATS program,. The higher firing temperature promotes NOx generation, making attainment of NOx emissions goals more difficult. Lean premix combustion systems are required. The very lean combustion requirements, along with its inherent flame instability, increases combustion generated noise. The combustion induced noise manifests vibration problems in the combustion system as well as in the downstream components. A program to develop the theoretical background on combustion instabilities, carry out experiments to aid in the understanding of the problem, develop a generalized analysis procedure, and develop stability criteria for a particular combustor basket is a requisite part of developing a low NOx combustor for the ATS program.

NOx production rises with increasing flame temperature. Catalytically enhanced combustion will play an important role in achieving ultra low NOx emissions at firing temperatures in the range of $2500^{\circ} \mathrm{F}$ and higher. The catalyst allows ultra lean premix (fuel and air) combustion without flame instability and flame outs. A development program is needed to gain theoretical understanding of catalytic combustion, to design a catalytic combustion system and to develop a practical catalytic combustor. Combustor baskets with catalytic components can provide the key to attaining low NOx emissions. 


\section{COOLING}

The development of new cooling technologies is of paramount importance to the success of the ATS Program. The increased firing temperature will require cooling of components which previously did not need cooling. Parts already cooled require more cooling to maintain acceptable material behavior. Closed-loop steam cooling is used on most of the hot end components because of the resulting large increase in plant cycle efficiency. However, film cooling tests were performed in the event closed-loop steam cooling does not provide adequate cooling on some components, such as the trailing edge regions of the row 1 vane.

The airfoil end walls or shrouds present a cooling design challenge even at current firing temperatures. Model tests were completed to optimize the cooling design of vane shrouds. Even with closed-loop steam cooling, sections of the row 1 vane may have to be film cooled. The same model tests can be used to optimize vane section surface film cooling design.

Row 3 turbine blade will incorporate an integral interlocked tip shroud, as used on the $501 \mathrm{~F}$ and $501 \mathrm{G}$ engines, to improve performance and reduce blade vibratory stresses. The tip shroud and the very large blade height may make it very difficult to develop the $\mathrm{SC}$ casting process in time for the first ATS engine. As a contingency, the blade will be designed with cooling to maintain the blade metal temperature at an acceptable level. It will be especially difficult to cool the tip shroud. Alternative cooling designs and manufacturing processes were evaluated. A blade casting development program for the selected design was undertaken.

Multi-pass serpentine cooling schemes are required to achieve the blade metal temperatures acceptable for the blade material. Plastic model tests were completed on the selected serpentine channel cooling schemes to verify and optimize the design prior to incorporation into the engine. Two models were tested: one model simulating the multipass mid chord region of the blade, and the second model representing the trailing edge portion of the blade. Tests were carried out at different cooling air flow rates. The internal heat transfer coefficients and pressure losses were measured.

One modification that results in the greatest improvement in the ATS plant cycle efficiency is the closed-loop steam cooling system. The heat capacity of steam is about 1.3 times that of air. Therefore, less steam is required to cool the hot end components than air. Closed-loop steam cooling negates the surface ejection of the cooling air and hence, the mixing losses. An improvement in stage efficiency is noted. Elimination of row 1 vane cooling air ejection into the main stream results in an increase in row 1 turbine blade inlet temperature and the turbine exhaust temperature for the same burner outlet temperature. A combination of the above effects will increase the ATS plant efficiency significantly. There are several challenges that must be overcome before a successful closed-loop steam cooling systems is developed. These include maintaining acceptable airfoil surface metal temperatures without outside film cooling, high wall 
temperature gradients, effect of steam on metal components over long periods of time, bringing steam to and out of rotating components, leakages, and cold start before steam from the downstream HRSG is available.

\section{MECHANICAL DESIGN}

The last row turbine blade is another component requiring a substantial development effort. The annulus area of the last row turbine blade must be as large as possible to minimize exhaust losses. This results in a long, highly stressed, last row blade. This blade incorporates an integral interlocked tip shroud to avoid excessive vibratory stresses. There is a possibility that two blade natural frequencies may occur between adjacent harmonics in this type of a blade design. These two frequencies can become coupled, and the resulting vibratory stresses can cause blade failure. Three tasks must be completed to design a durable last row blade. The initial task consists of a preliminary investigation, which will cover a review of the design rules for last row turbine blades, the reevaluation of advantages/disadvantages of interlocked shroud versus free standing last row blades, and the evaluation of the effect of stimuli and damping on last row blade vibratory stresses. The next task requires the evaluation of alternative blade and shroud designs, including part span shrouds, and a blade casting development program on the selected design. Finally, a vibration test of the last row blade is required to verify the design. The Blade Vibration Monitoring (BVM) technique, developed by Westinghouse, is employed to measure vibration characteristics of individual blades during engine operation.

\section{LEAKAGE CONTROL}

Turbine blade tip clearance has a pronounced effect on the performance of highly loaded front stage blades. Stage efficiency may decrease by up to $2 \%$ for each $1 \%$ tip clearance increase (based on blade height). For a four-stage turbine, overall turbine efficiency decreases about $1 / 2 \%$ for the same $1 \%$ increase in tip clearance. Even if the initial cold blade tip clearances are set at minimum values, during transients, such as rapid starts and emergency shutdowns, the blade tips are ground off. This results in increased hot running blade tip clearances, which get progressively worse with time. An active tip clearance control system was developed to solve this problem. The system maintains large tip clearances on start-up and reduces clearances to a minimum acceptable value when the engine has attained steady state operating conditions. This can be accomplished by cooling, at appropriate times, the blade ring holding the ring segments located above the 
rotating blade tips. A conceptual design of an active tip clearance control system was completed. Field tests on a host engine is required to verify the viability of the concept.

Brush seals can be incorporated in the appropriate locations in the turbine and compressor to reduce air leakage, as well as hot gas ingestion into the turbine disc cavities. This results in an improvement of engine efficiency as well as mechanical integrity of the turbine components. The incorporation of an effective, reliable, and long-lasting brush seal system into a heavy duty industrial combustion turbine requires development. 


\section{DESIGN AND TEST RESULTS}

\section{$\underline{\text { Blade Cooling }}$}

Development of cooling technology for hot gas path components is critical to the success of the ATS design. Closed-loop steam cooling is used in some hot components to provide an increase in cycle efficiency. Airfoil end walls or shrouds need more cooling than previous designs because of higher firing temperatures. Multipass serpentine cooling schemes are used to maintain blade metal temperatures below acceptable limits for the blade material. Impurities in steam could possibly clog cooling passages, causing overheating. These problems were investigated concurrently. Results from each program are explained below.

\section{Shrouded Blade Cooling Development}

The stage 3 turbine blade must meet a unique combination of requirements. Exceptional performance, mechanical and thermal goals must be attained simultaneously. Cooling of the tip shroud is a design challenge because the blade is long and thin. Three cooling options were considered:

- Cool the tip shroud with spent airfoil cooling air

- $\quad$ Provide a separate cooling air passage through the airfoil to the tip

- Inject cooling air toward the tip shroud from the stationary outer diameter of the blade path

The last option was rejected early in the program. severe performance penalties suffered from excessive use of coolant in this option. Alternatively, the first option produced the minimum impact on performance, but would have limited cooling capacity.

The second option, shown in Figure 8-1, was selected because of its versatility and reliability. The airfoil cooling scheme consists of a cast blade with two (2) cored cooling passages extending from the bottom of the root to the blade. Airfoil cooling is provided by electrochemically machined holes extending from the tip into the two cored cooling passages. Most of the coolant flow through the blade to the tip shroud is provided by a separate large round hole extending the entire length of the blade. The tip shroud cooling scheme consists of holes drilled through the shroud to mate with the large cored hole in the blade. The use of a large diameter round hole located between the airfoil cooling passages prevents overheating of the coolant during the traverse to the tip shroud.

The thermal analysis results of the cooled tip shroud indicates the cooling scheme meets temperature limit criteria. Comparison of the running temperature distribution and the allowable temperature distribution necessary to meet blade creep life requirements 
indicates that the creep life requirement has been met. A conceptual design for cooling of the tip shroud has been completed.

Although the mechanical and thermal constraints for the blade and shroud have been satisfied in the conceptual design, manufacturing the hardware may alter the final design. The next phases of the ATS program will focus on the final design and the ability to manufacture these components cost effectively.
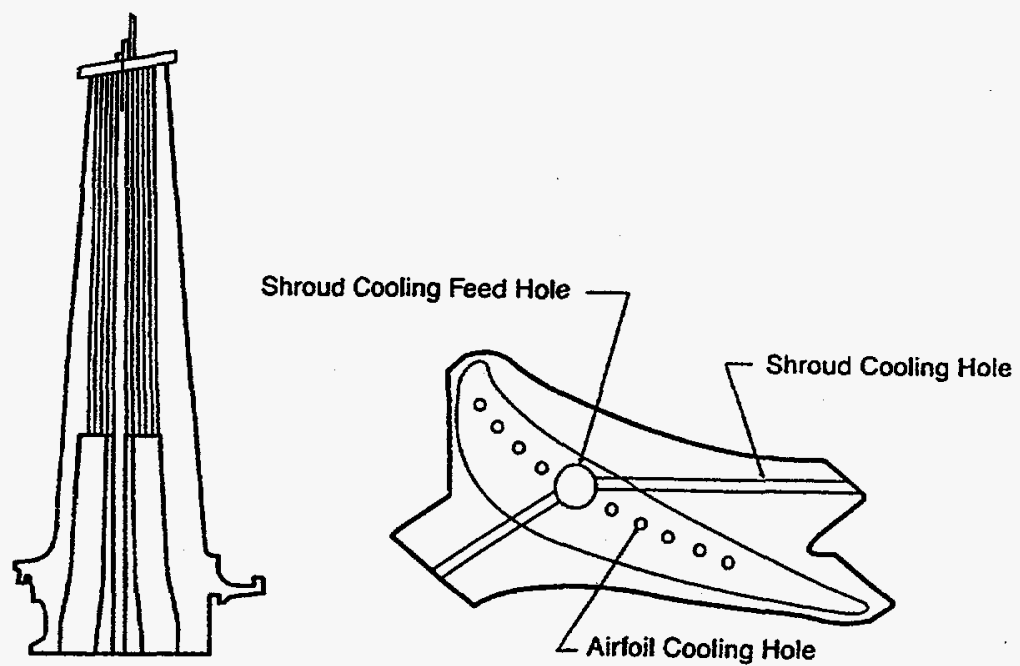

Figure 8-1. Stage 3 Blade Tip Shroud Cooling

\section{Serpentine Cooling Tests}

Complex multipass serpentine cooling schemes were developed to maintain low blade metal temperatures. Plastic models were constructed to determine the feasibility of the concepts prior to incorporating then into the blade design. Two models were tested, each representing different regions of the blade. The models were painted with thermochromic paint for thermal mapping.

The models were tested in a flow chamber. Heat transfer and pressure loss data were created from the flow tests. This data was used to optimize serpentine blade cooling design. The data revealed several specific areas of concern:

- Serpentine reverse turns

- Thermal and flow benefits of turbulators in reverse turns

- Local effects within the passages as affected by:

- aspect ratio 
- film cooling holes

- film cooling flow rate

A hidden line view of a typical serpentine cooled blade is shown in Figure 8-2. An airfoil cross section of the blade is shown in Figure 8-3. The blade cooling system consists of three (3) circuits: 1) a single pass leading edge circuit, 2) a triple pass mid circuit, and 3) a single pass trailing edge circuit. It was decided to conduct test programs on the mid and trailing edge circuits. The mid circuit would provide the reverse turn and basic film hole data, and the trailing edge circuit would provide the high aspect ratio data.

Preliminary conclusions from these tests indicate that serpentine cooled blade design will not provide adequate cooling for row 1 turbine blading. The most likely candidate for using the serpentine cooling scheme would be row 2 blades. Another novel cooling design approach, thin wall casting, will be tested in Phase 3 for row 1 blades.

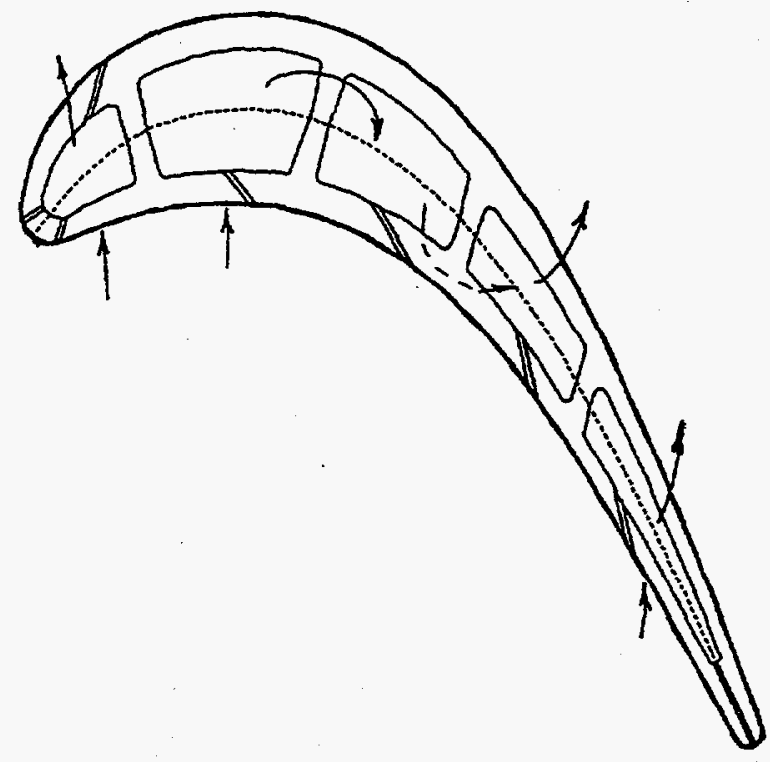

Figure 8-2 Typical Serpentine Cooled Blade 


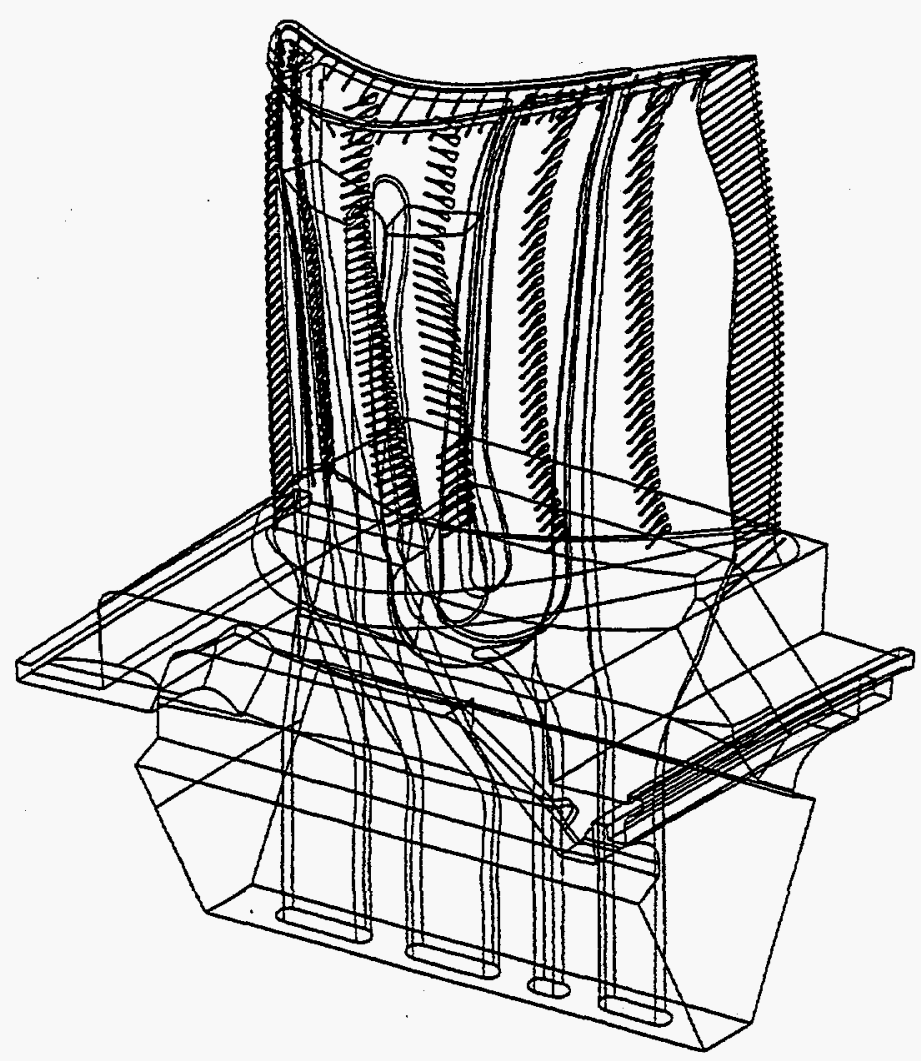

DE-AC21-93MC30247

Figure 8-3 Airfoil Cross Section of Blade

\section{Closed-Loop Steam Cooling - Row I Vane}

For closed-loop cooling to be successful, the following are required:

- Thermal barrier coatings with high surface temperature and high bond coat temperature capability, along with high temperature gradient capability must be available

- High capacity coolants and/or low coolant supply temperature must be used

- Minimal airfoil wall thickness to reduce required coolant heat transfer coefficients and improve fatigue life is required

- Enhanced cold side heat transfer characteristics for higher effective coolant heat transfer coefficients through increased surface area, i.e., turbulators, and localized impingement must be examined

Three primary closed-loop cooling schemes have been analyzed for use on the row 1 vane airfoil. These are: (1) peripherally placed spanwise radial hole design, (2) thin-wall 
chordwise channel design, and (3) radial flow thin-wall pedestal bank array. The chordwise channel design scheme has been selected for the following reasons:

- cooling geometry is highly configurable, which is important to allow use with multiple coolant types

- excellent cold side heat transfer characteristics

- demonstrated manufacturability

The trailing edge is an area of particular concern due to limited area, high external heat transfer coefficients, and concentrated heat loading due to cylindrical geometry. Several cooling schemes were considered for the trailing edge, with two particular techniques emphasized; a chordwise wrap-around channel design, and a midspan fed spanwise radial hole design. The former, the chordwise channel design, has been selected for various reasons, but primarily due to high pressure losses associated with the latter.

A peripherally fed, inward flowing pin-fin/pedestal array has been chosen for the row 1 vane shrouds. This scheme utilizes impingement cooling at the shroud outer edges where the external thermal boundary conditions are severe. It takes advantage of the natural reduction in flow area from the shroud periphery to the vane to passively increase the coolant heat transfer coefficient. This compensates for the increase in coolant temperature through the pedestal array.

Detailed designs have been generated for both the airfoil and shroud. A concurrent engineering design philosophy, with continuous input and feedback from mechanical, aerodynamic, performance, and manufacturing disciplines, has been followed. Subsequent work will be continued toward the manufacture of this component.

\section{Closed-Loop Steam Cooling(CLSC) Effects}

As steam passes through cooling passages, impurities in steam can deposit at various locations within the system. Corrosion can erode critical thin walls, causing steam leaks in rotating components. Potential deposition and corrosion of materials could lead to lower reliability (Figure 8-4). 


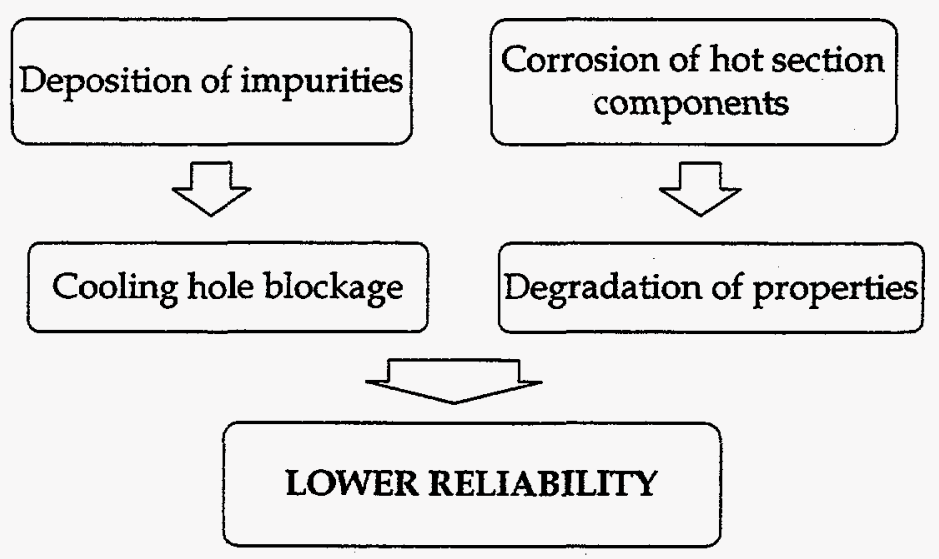

Figure 8-4. Issues: Steam Cooling Effects

An understanding of the corrosion/deposition mechanisms must be acquired. The consequences of corrosion and deposition in steam cooling circuit must be known. A test plan was developed to gain this understanding. Elements of the test plan include:

- Develop a steam chemistry model which will predict the type and quantities of impurities as a function of temperature and pressure

- Evaluate the effects of steam chemistry on deposition and corrosion of materials

Testing will be completed in subsequent work. Portions of the testing hardware have been constructed. Details of the test plan are explained below.

A solubility model of common dissolved solids will be developed to predict deposition. The purpose of the steam chemistry model is to predict types and concentration of impurities along the cooling passages. Model verification requires lab testing with simulated impurities and cooling passages. A closed loop model with controlled pressure, temperature and quality will provide the ability to simulate almost any operational environment likely to be encountered. The first set of tests will be aggressive, i.e. higher level of steam impurities than would normally be expected.

The following tasks were identified for the proposed program:

- Define design parameters of the steam cooling system

- Review of impurities and corrosion data

- Identify potential corrosive and occlusive compounds

- Define the preliminary test environments

- Evaluate the solubility and stability of expected compounds

- Develop a steam chemistry model 
- Define steam chemistry requirements

- Perform deposition/corrosion tests

- Evaluate test results

- Report

Design conditions of CLSC system have been obtained. A list of impurities that could lead to deposition/corrosion was generated. These impurities were classified into three categories (high, medium and low priority), based upon their potential for deposition/corrosion. The solubility of impurities as a function of temperature and pressure will be correlated. Thermodynamic stability of likely impurities has been reviewed. All common contaminants are stable in the CLSC range of conditions. The scope of a dynamic deposition model has been prepared.

Facilities have been selected for performing tests. The test rig design has been completed. Test specimen design for the deposition/corrosion study has been completed. Materials have been procured for the deposition/corrosion tests. All the components for test rig manufacture have been procured.

Preliminary steam chemistry requirements will be obtained based on the steam chemistry model. Five deposition/corrosion tests are planned for subsequent work in Phase 3 . The first test will be performed with high levels of impurities to evaluate deposition.

Following evaluation of the first test results, subsequent tests will be performed with appropriate levels of impurities. The level of impurities used for testing will depend upon predictions made by the steam chemistry model, the CLSC system design and materials selections. The final steam chemistry recommendations will be determined, as depicted in Figure 8-5.

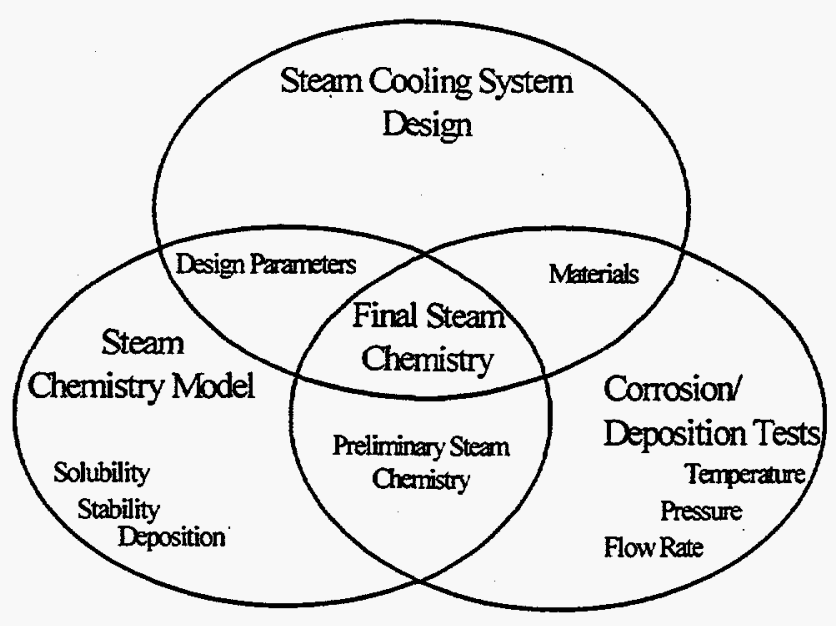

Figure 8 -5. Interactive Elements of the Program for Steam Chemistry 


\section{Stator Cooling}

Heat transfer data on the hot side surfaces of combustion turbine stators is required for design purposes. The surfaces of primary interest were the shroud surfaces, however, airfoil film cooling effects were also investigated. A scale model of the stator sections was constructed. Laboratory flow tests of the model provided heat transfer data used for stator cooling design.

The model stator employed a thermochromic liquid crystal technique which produced both convection heat transfer coefficient distributions and film effectiveness distributions. Figure 8-6 illustrates a typical vane shroud cooling scheme. Figure 8-7 shows a plan view of the general test configuration.

The test program was sequenced to produce the individual effects of each of the many elements which influence hot side heat transfer. A test plan was developed for collecting the required data.. Results of the testing will be reported in subsequent ATS work.

The test program included:

- Basic configuration with no gas path surface interruptions or film effects

- Boundary layer sensitivity

- $\quad$ Reynolds number sensitivity

- $\quad$ Surface discontinuities from combustor transition seals, shroud edges, etc.

- Film effectiveness from transition seal film hole array

- $\quad$ Film effectiveness produced by leakage between circumferential gaps between adjacent shrouds

- $\quad$ Film effectiveness of airfoil film holes on airfoils

- $\quad$ Film effectiveness of airfoil film holes on shrouds

- Film effectiveness of several shroud film hole arrays 


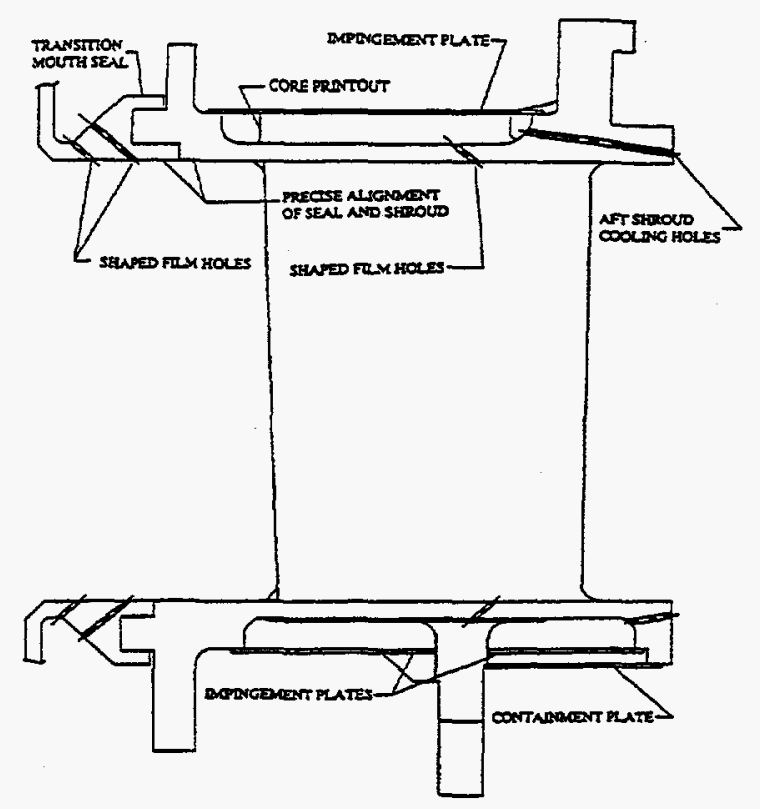

Figure 8-6. Typical Vane Shroud Cooling Scheme

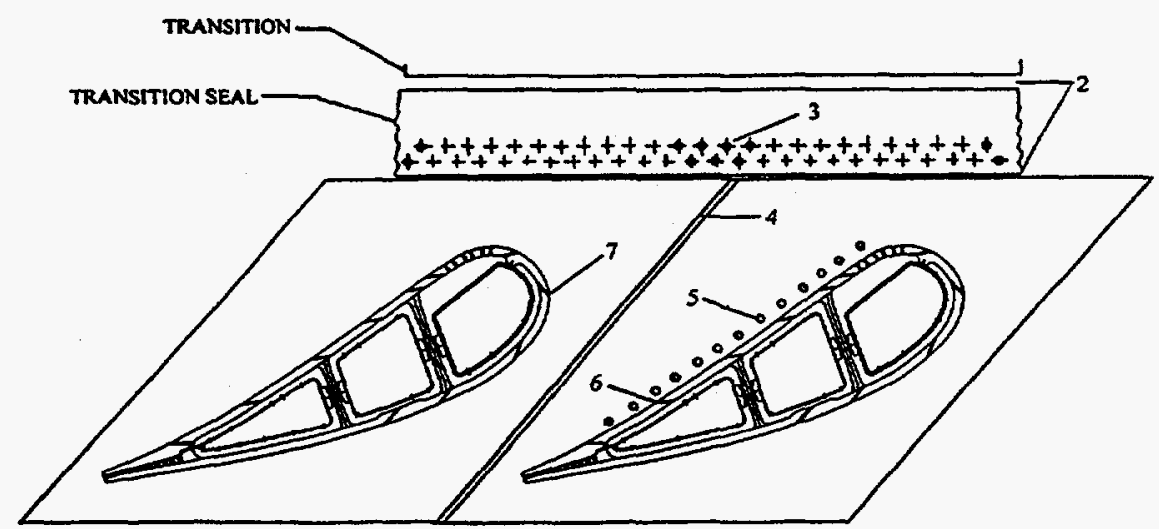

Figure 8-7. General Test Configuration 


\section{$\underline{\text { Blade Materials }}$}

The latest stress design information indicates DS and SC nickel based alloys potentially offer the best tradeoffs in performance and manufacturability for ATS blades. Row 4 blades may require some intermetallic elements for better fatigue and creep stress performance. Design data for these materials must be generated for a thorough evaluation of these materials at ATS conditions. Laboratory testing of specimens provided much of this data.

\section{Single Crystal Blade Material}

CMSX-4, a second generation Re containing SC alloy, was selected for the large ATS SC blade development because of its mechanical strength and its castability demonstrated in small aircraft engine blades. The castability of CMSX-4 alloy in large land-based SC turbine blades has not been attempted to date. Two large Westinghouse blade designs, $501 \mathrm{~F}$ row 1 and row 3 , were used in the casting trials to evaluate its castability,. The row 1 and row 3 blades are currently made of conventionally cast superalloy in the equiaxed grain condition. The row 1 blades are shorter and thicker (approximately 12 in. long with a weight of $18 \mathrm{lb}$.), whereas the row 3 blades are longer and thinner (approximately $18 \mathrm{in}$. long with a weight of $14 \mathrm{lb}$.). Both blades have internal cooling cores.

The experimental procedure included the fabrication of mold assemblies and casting trials. The patterns used in the evaluation were those used for the production of the equiaxed version of the blades. Core bodies were specially manufactured from high temperature ceramics in order to sustain the high temperature SC processing. Each mold assembly contained multiple blades. During casting trials, various gating configurations, blade orientations, shell procedures, and casting parameters were evaluated in order to achieve optimum casting quality. Figure 8-8 outlines the SC casting process and the key variables that were considered.

Row 1 Blade Casting Results

A series of four sets of row 1 blades were cast. Freckles and chains of equiaxed grains were found to be present in all the experimental blades. The freckling appeared to be more severe at the root areas and less prominent at the airfoil areas. Some freckles at the root and airfoil caused the initiation and growth of secondary grains. It was concluded that the current process was not capable of achieving acceptable SC row 1 blade casting. Further development efforts are required to produce blades in the size and configuration similar to the row 1 blade. 
Row 3 Blade Casting Results

A series of five sets of row 3 blades were cast with varying parameters. SC blades of different qualities were produced. One cored blade and one solid blade (cast without a core) with the best quality were selected for further NDE inspection. Figure 8-9 shows one of the SC blades in contrast with a conventionally cast blade. The blades were processed through the same visual, fluorescent penetrant, and radiographic inspections required for the conventionally cast row 3 blades. The blades passed all inspections. The cored blade was also evaluated by ultrasonic instrumentation for core retention and wall thickness. Results indicated acceptable wall thickness and excellent core retention.

The grain structure was evaluated based on generally accepted industrial standards for single crystal components. Primary grain orientation, low angle boundaries and striation properties from one small sliver grain were examined by visual and X-ray diffraction methods. All grain properties were within the acceptable ranges. Slight freckles were found in the root area, but were removable by a subsequent machining operation.

\section{Conclusions}

The results from this castability study have demonstrated that large SC blades of row 3 configuration can be cast in CMSX-4 single crystal. Further process optimization will be needed to achieve acceptable product yield. For the row 1 blade configuration, which is thicker and heavier than row 3 , further casting development is required to obtain acceptable blade quality. The row 3 casting development work is expected to be continued in Phase 3.

OPERATION

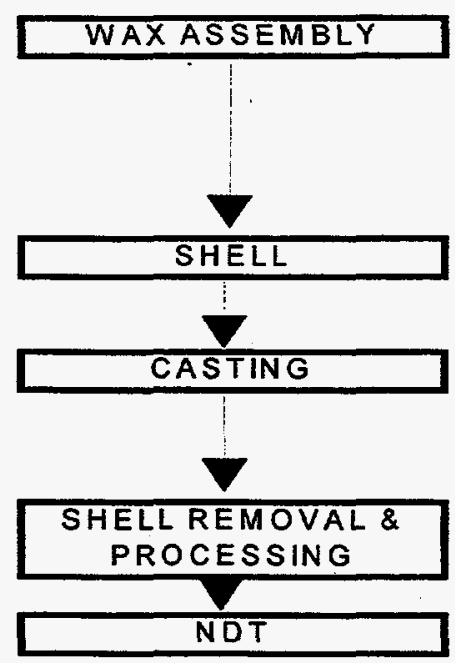

VARIABLES

ASSEMBLY

PATTERN ORIENTATION

GATING

CERAMIC CORE

NUMBER OF DIPS
FACE COAT

METAL TEMPERATURE

MOLD TEMPERATURE

WITHDRAWL RATE

FLUORESCENT PENETRANT
RADIOGRAPHIC INSPECTION
GRAIN ETCH
ULTRASONIC INSPECTION
LAUEIXRAY DIFFRACTION

Figure 8-8 CMSX-4 SC R3 Blade Casting Process Flow Chart and Process Variables 


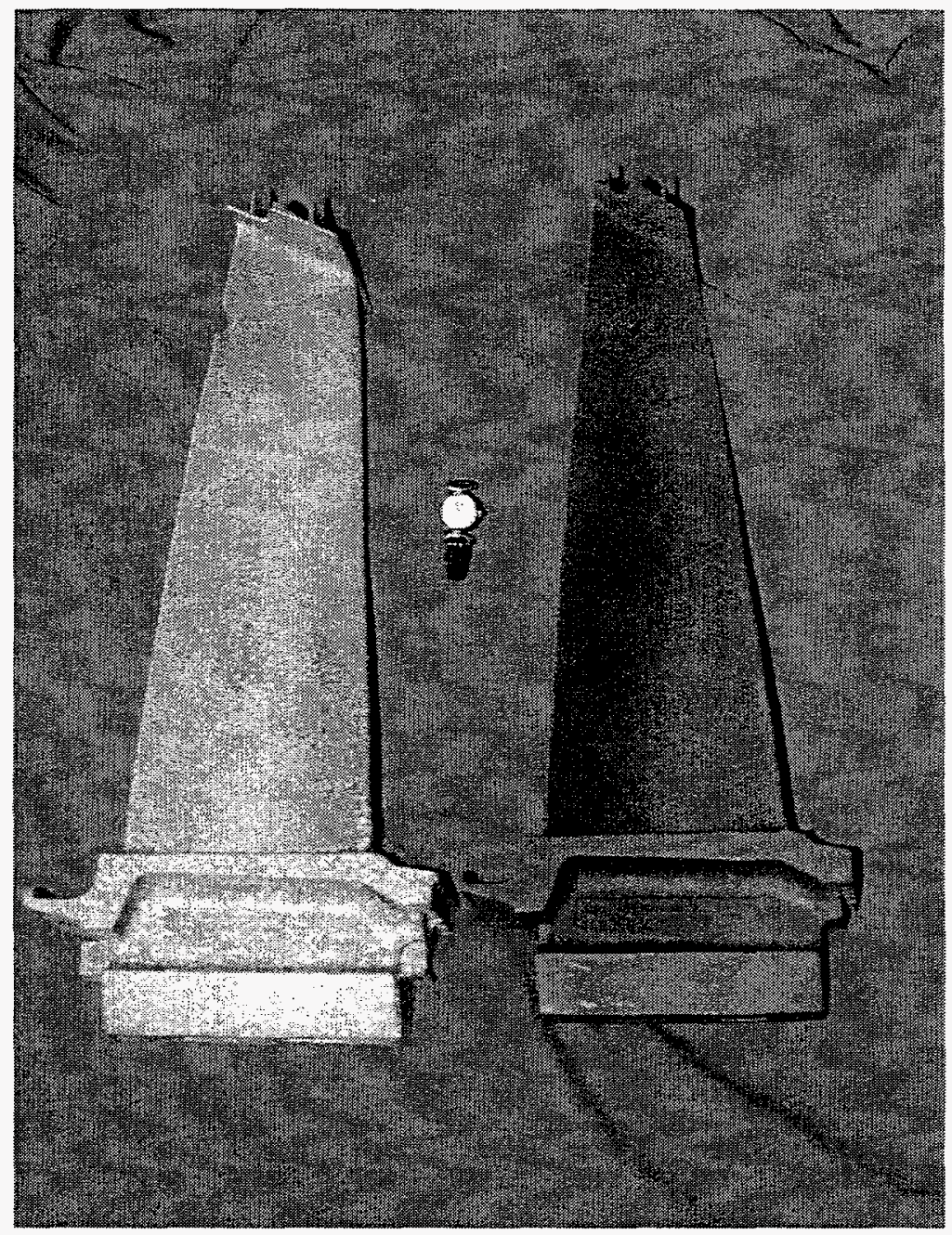

Figure 8-9. Single Crystal Blade. A single crystal 501F R3 blade (right) in contrast with a conventionally cast equiaxed blade (left) is shown. A wristwatch is centered between the blades for size comparison.

\section{Directionally Solidified Blade Material}

Preliminary test results from earlier work indicates that DS alloys offer a substantial temperature advantage over conventionally cast equiaxed IN-738 currently used in turbine blading. Material property data is required to analyze the feasibility of DS blading. Material properties, including tensile, $\mathrm{LCF} / \mathrm{HCF}$ and creep rupture data must be generated for blade and vane designs. Specifically the following efforts are included to establish a comprehensive data base for design with DS materials.

- Evaluate the effects of alloy chemistry (CM247LC vs. Mar-M-002)

- Include conventionally cast materials as baseline for comparison with DS materials 
- Evaluate the effects of DS casting withdrawal rate.

- Generate long term creep rupture data.

- Characterize oxidation behavior of base metals.

- Evaluate the effects of coating on mechanical properties.

- Verify test data generated from cast slabs by destructive testing of cast blades.

Results

A partial set of material properties for directionally solidified CM247LC and Mar-M002 has been generated. This data includes:

- Long-term creep rupture with some specimens exceeding 10,000 hours of testing time.

- Strain controlled LCF tests and stress controlled HCF tests were performed at selected design temperatures. The effects of orientation on the fatigue properties were included in the tests.

- $\mathrm{CM} 247 \mathrm{LC}$ material was tested at $1750^{\circ} \mathrm{F}$ and $1850^{\circ} \mathrm{F}$ in a burner rig up to 1000 hours and oxidation rate was determined by metallographic examination of the test specimens

- DS slabs cast with three different withdrawal rates have been received. The slabs have been heat treated and machining of test specimens is in progress

- Two Westinghouse 501 row 1 blades have been successfully cast, heat treated and NDE inspected; and machining of specimens is in progress. Two Mar-M002 row 1 blades were ordered for future testing.

Material properties for continuous cast CM247LC were generated, including:

- Tensile, HCF and LCF testing has been completed

- Creep rupture testing is proceeding

Additional material property generation will continue in Phase 3 work. 


\section{$\underline{\text { Last Row Blade Development }}$}

\section{Design Obstacles}

The annulus area of the last row blade must be as large as possible to achieve minimum exhaust losses. As blades become longer and more highly stressed, design methods become more precise and sophisticated to meet the demand for more efficient blades. Mechanically over-designed blades to compensate for imprecise design/calculation methodology are not acceptable.

The design of a long turbine blade is determined by thermodynamic efficiency and mechanical adequacy. The airfoil must be designed to have the optimum inlet angles and geometry to efficiently convert thermal energy into useful shaft torque. Mechanical materials properties, such as creep deformation and resistance to high-cycle fatigue (HCF) failures, must be evaluated.

A primary concern in blade design is the resistance of the material to high-cycle fatigue failure from time-dependent stresses. The primary excitation forces on a turbine blade are aerodynamic and can be either synchronous or nonsynchronous. The nonsynchronous forces are a result of turbine transients and the influence of combustors. The synchronous forces arise because the blade is rotating through a circumferentially non-uniform field which is fixed in space. This produces harmonic blade excitation forces which have frequencies which are integer harmonics of the turbine spindle rotational frequency. The magnitude of the vibratory excitation tends to be larger for the lower harmonics. Consequently, it is usually impractical to design long turbine blades strong enough to withstand resonance within the lower multiples of running speed. The lower modes are tuned to have their natural frequencies fall approximately halfway between the multiples of running speed. This will minimize the occurrence of high magnitude vibrations. Higher blade modes and complicated mode shapes make tuning impractical because manufacturing tolerances and material variability effect yields. The blades must be designed with sufficient strength so that potential vibratory stresses will not exceed the fatigue strength of the blade.

Historically, long combustion turbine blades were designed for reliability by extrapolating previous successful designs. Blade strength was evaluated on the basis of steady stresses, since vibratory stresses could not be determined. The acceptability of a design was determined by evaluating design indices, which were compared with allowable values. The historical design index for HCF is the Magnification Factor(MF). $\mathrm{MF}$ is the ratio of local fatigue strength to the gas bending stress. This has been an adequate index for design of blades of similar construction. It does not explicitly consider the effects of damping or tuning.

The high cycle fatigue analysis and successful design of turbine blades requires a thorough knowledge of vibratory stresses and blade fatigue strength. Vibratory stress is a function of frequency, mode shape, unsteady loading and damping. In recent years, technology has advanced to the point where 3-D finite element analysis is fast and 
efficient enough to be used as an effective design tool. Determination of vibratory stress is now a practical calculation procedure.

Testing methods have also improved. Verification and technology development testing on full-size turbines has provided important information on blade unsteady loads and blade damping. Numerous fatigue tests have been performed to determine the fatigue strengths of blading alloys at various temperatures and environments.

The stimulus method for estimating an index for HCF was selected. In this method, a design upper bound turbine vibratory force level, the "turbine stimulus", is defined. Stimulus is the ratio of unsteady loading to steady loading, at a given harmonic. The use of such an index implies that unsteady blade stress is approximately proportional to the turbine end loading. Vibratory stresses resulting from the upper bound force level are compared with the minimum material fatigue strength to determine a factor of safety (strength/stress). This approach considers damping and the modal characteristics of the blade in the calculation. The upper bound force levels, used in the design to ensure a minimum of 100,000 hour life, are deduced from turbine tests. Another way of estimating turbine stimulus is through an analysis of field experience of existing designs. The excitation force level can be estimated from a knowledge of failure location, fatigue strength and the steady loading on the blade. The turbines stimulus level must be equal to or greater than the level required to produce a failure, for those cases where failures have occurred.

Having established a rational method for evaluating the vibratory stresses in blades, it becomes possible to examine the benefits of various types of construction for a given application. Selecting the optimum configuration also requires consideration of the processes involved in manufacturing. An iteration process between acceptable mechanical design and manufacturability continues until a safe practical blade is found.

\section{Design Approach}

The objective of this effort was to develop an optimized last row blade with acceptable reliability and improved performance. Rational HCF design rules for combustion turbine blades are established in the process.

The available test data for interlocked blade damping and vibratory force levels was collected and reviewed. A design value for damping and turbine upper bound turbine vibratory force (stimulus) was proposed. Failure stimulus (safety factor) calculations for interlocked combustion turbine blade designs with operating experience were completed. This verification step was necessary to validate the proposed values against operating experience. Less successful designs failed the proposed criteria and were rejected. 


\section{Design Results}

Conceptual designs were performed for freestanding and interlocked blades with and without midspan snubbers. The reliability, efficiency, manufacturability and ease of assembly of each design concept was evaluated. An interlocked blades design was selected over the freestanding blade because of higher damping and better strength-toweight ratio. The higher damping manifests lower vibratory stresses due to both forced and self-excited (flutter) vibration. The smaller physical size results in lower rotor stresses.

The final selected design is an interlocked blade with midspan snubber. This is the first known application of a midspan snubber to a cast combustion turbine blade. Midspan snubbers are widely used on steam turbine blades, which are generally longer than combustion turbine blades. The midspan snubber becomes more advantageous as blades become longer. A disadvantage for the snubber is the loss in performance from the snubber obstruction in the flow-path. An interesting factor was revealed during the design process. The airfoil can be better aerodynamically optimized with the snubber than without, which tends to offset the snubber loss. In fact, for the geometries considered in the evaluation, the midspan snubber design had overall better performance than the unsnubbered design.

Since this was the first application of a snubber to a cast turbine blade, manufacturability was a concern. Casting trails were performed using a similar existing airfoil and a mocked-up snubber to determine if the snubber design was feasible. The casting experiments were a success and, consequently, the design was completed.

The manufacture of the die for the wax patterns, tooling and gages has been completed. A representative sample of row 4 blades in the final design configuration has been manufactured. These blades have been dimensionally and metallurgically examined to determine if the manufacturing process is qualified to produce acceptable blades. It took several trial castings before a metallurgically acceptable blade was produced. Casting trials were successful and a manufacturing process developed. The manufacturer has been qualified. The production of the prototype row 4 blade can proceed to the next phase.

\section{$\underline{\text { Ceramics }}$}

The use of ceramic materials in the ATS engine offers potential performance benefits. Ceramics are capable of withstanding higher temperatures than those represented by today's metallic superalloys. Higher temperatures translate into higher thermal efficiencies. An estimated $15 \%$ to $20 \%$ of the total inlet airflow in a land based combustion turbine is diverted to cooling hot section metallic components. Ceramic 
components may alleviate the need for much of this cooling air. The selection process for identifying parts suitable for ceramic conversion progressed as follows:

1. Selection of candidate hot gas path components

2. Selection of the ceramic material

3. Manufacturing feasibility in association with a material supplier

4. Preliminary design studies on the selected component

\section{Selection of hot gas path components suitable for conversion to ceramics}

The hot gas path components in combustion turbines exposed to the highest temperatures reside in or near the combustion zone:

- Combustor

- Transition

- Stationary ring segment

- Vane

- $\quad$ Blade

Each of these components use cooling air in different amounts to maintain temperatures below specified values. While detailed analyses are required to accurately predict the benefits in cooling air savings, engineering judgment indicates that the above order represents components with increasing potential for performance improvement through the use of ceramic materials. Vane and blade materials must survive very challenging operating conditions in a combustion turbine environment - too demanding for the ceramic materials available today. The thermo-mechanical fatigue conditions, the cyclic stress patterns and attachment technologies warrant that these two components not be given serious considerations at this time. The stationary ring segment is considered to be the best choice for ceramic conversion because of its relatively smaller and simpler size, ceramic manufacturing experience with similar components, and a moderate amount of performance benefit to be expected. Combustor and transition components need the benefit of lower manufacturing costs before being considered for conversion to ceramics. 


\section{Selection of the ceramic material}

Monolithic ceramics can perform at considerably higher temperatures than can advanced metallic alloys, however, they are brittle. This brittleness precludes using this material in locations where the part is subjected to shock loads, high stress or vibration. Another class of ceramics, called continuous fiber reinforced ceramic matrix composites (CFCCs) or simply ceramic matrix composites (CMCs), have evolved in recent years as a possible material for high temperature, moderate stress level applications in combustion turbines. CMCs comprise of ceramic fibers with fiber-matrix interface coating intricately connected to a ceramic matrix by proprietary processes. Westinghouse considered several of today's available CMCs and evaluated these against the required and desired properties. Results of this evaluation are shown in Table 8-2.

Based on this evaluation, the selected material for the first application of CMCs in the ATS engine is Nicalon ${ }^{\circledR}$ Alumina which is silicon carbide ( $\mathrm{SiC}$ ) fibers in an alumina $\left(\mathrm{Al}_{2} \mathrm{O}_{3}\right)$ matrix manufactured by a proprietary process by DuPont Lanxide Composites (DLC) Inc. Nicalon Alumina CMC is suitable for use at temperatures up to $2100^{\circ} \mathrm{F}$ in low stress applications.

For more demanding applications such as vane or blade, this CMC (non-oxide/non-oxide) is not considered to be a good candidate. Rather, oxide/oxide CMCs are considered to be best suited for higher temperature, higher strength applications. While industry research is progressing to develop good oxide/oxide CMCs, none is currently available for combustion turbine component application. They need considerable development before being seriously considered for combustion turbines.

\section{Manufacturing Feasibility}

Westinghouse has worked with DLC to better understand the capabilities and limitations of the DIMOX process which DLC uses to make Nicalon Alumina components. The most important manufacturing constraints for component shape are (1) composite preforming and tooling requirements; and (2) the DIMOX growth process limitations. Requirements for bend radii, $T$-sections, flanges, section thickness, tolerances, surface finish and machining have been identified and published for the benefit of the CMC component designer.

\section{Preliminary Design Studies}

Initial design studies considered both ring segments and combustors for ATS. because of limited benefit expected from a CMC combustor, After completing a cost benefit analysis, it was decided that only the ring segment design should be studied in detail. The material system concept selected for the ring segment is shown in Figure 8-10. In its simplest form, the ring segment structural CMC substrate is a plate with a slight curvature; bonded to it is a ceramic abradable layer. The abradable layer serves two purposes: one is to provide thermal insulation to the CMC and second is to provide an abradable surface for the blade tip to rub against the ring segment. 
Several design concepts were evaluated. Creating an acceptable design, that limits the thermal and mechanical loading stresses to the maximum allowable, has proven to be a major challenge. CMC mechanical properties and low thermal conductivity restrict the design options available. A parametric evaluation of two CMC materials with different compositions and properties was completed. This provided an understanding of what properties (mechanical strength, thermophysical properties etc.) are important in the $\mathrm{CMC}$ and how they affect the component design. Further detailed design work will proceed in later phases of the ATS project.

Table 8-2. Qualitative Evaluation of Available CMCs for

Ring Segment Application, $(\checkmark=$ acceptable, ?=unknown, blank=unacceptable)

\begin{tabular}{|l|c|c|c|c|c|}
\hline Requirement & $\begin{array}{c}\text { Nicalon/A } \\
\text { lumina }\end{array}$ & $\begin{array}{c}\text { Nicalon/ } \\
\text { SiC-CVI }\end{array}$ & $\begin{array}{c}\text { SCS-6/ } \\
\text { Silcomp }\end{array}$ & $\begin{array}{c}\text { Enhanced } \\
\text { SiC/SiC }\end{array}$ & $\begin{array}{c}\text { SCS-6/ } \\
\text { Si3N4 }\end{array}$ \\
\hline Short Term Database & $\checkmark$ & $\checkmark$ & & $\checkmark$ & $\checkmark$ \\
\hline $\begin{array}{l}\text { Intermed Term Properties (< } \\
1000 \text { hrs) }\end{array}$ & $\checkmark$ & $\checkmark$ & & $\checkmark$ & $\checkmark$ \\
\hline $\begin{array}{l}\text { Long Term Properties (ca.10,000 } \\
\text { hrs) }\end{array}$ & In process & & & & \\
\hline Abradable Layer & $\checkmark$ & & & & \\
\hline Bonding Method & $\checkmark$ & & & & \\
\hline Bondability & $\checkmark$ & & & $\checkmark$ & \\
\hline Experience Base & $\checkmark$ & $\checkmark$ & $\checkmark$ & $\checkmark$ & $\checkmark$ \\
\hline Commercial Supplier & $\checkmark$ & $\checkmark$ & & $\checkmark$ & $\checkmark$ \\
\hline Defined Process & $\checkmark$ & $\checkmark$ & & & $\checkmark$ \\
\hline Improvement Potential & $\checkmark$ & $\checkmark$ & $\checkmark$ & $\checkmark$ & $\checkmark$ \\
\hline Availability & $\checkmark$ & $\checkmark$ & & $\checkmark$ & $\checkmark$ \\
\hline Inert to Metals & $?$ & & & & $?$ \\
\hline Corrosion Resistant & $?$ & & & & $?$ \\
\hline
\end{tabular}

\begin{tabular}{|l|c|c|c|c|c|}
\hline Desirable Property & $\begin{array}{c}\text { Nicalon/AA } \\
\text { umina }\end{array}$ & $\begin{array}{c}\text { Nicalon// } \\
\text { SiC-CVII }\end{array}$ & $\begin{array}{c}\text { SCS-6/ } \\
\text { Silcomp }\end{array}$ & $\begin{array}{c}\text { Enhanced } \\
\text { SiC/SiC }\end{array}$ & $\begin{array}{c}\text { SCS-6/ } \\
\text { Si3N4 }\end{array}$ \\
\hline High Conductivity & & & $\checkmark$ & $\checkmark$ & $\checkmark$ \\
\hline High Matrix Cracking Strength & & & $\checkmark$ & & $\checkmark$ \\
\hline Low Elastic Modulus & $\checkmark$ & & & $\checkmark$ & \\
\hline Strain Tolerance & $\checkmark$ & & & $\checkmark$ & \\
\hline Notch Insensitivity & $\checkmark$ & & & $\checkmark$ & \\
\hline Machinability & $\checkmark$ & $\checkmark$ & $?$ & $\checkmark$ & $?$ \\
\hline Machining Database & $\checkmark$ & $\checkmark$ & & $\checkmark$ & \\
\hline No External Coating Req'd & $\checkmark$ & & $?$ & $?$ & \\
\hline Manufacturability & $\checkmark$ & $\checkmark$ & & $\checkmark$ & \\
\hline Low Cost & $\checkmark$ & $\checkmark$ & & $\checkmark$ & \\
\hline Creep Resistance & & & & & $\checkmark$ \\
\hline Surface Engineering & $\checkmark$ & $?$ & $?$ & $?$ & $?$ \\
\hline Oxidative Stability & $\checkmark$ & & $\checkmark$ & $\checkmark$ & \\
\hline
\end{tabular}




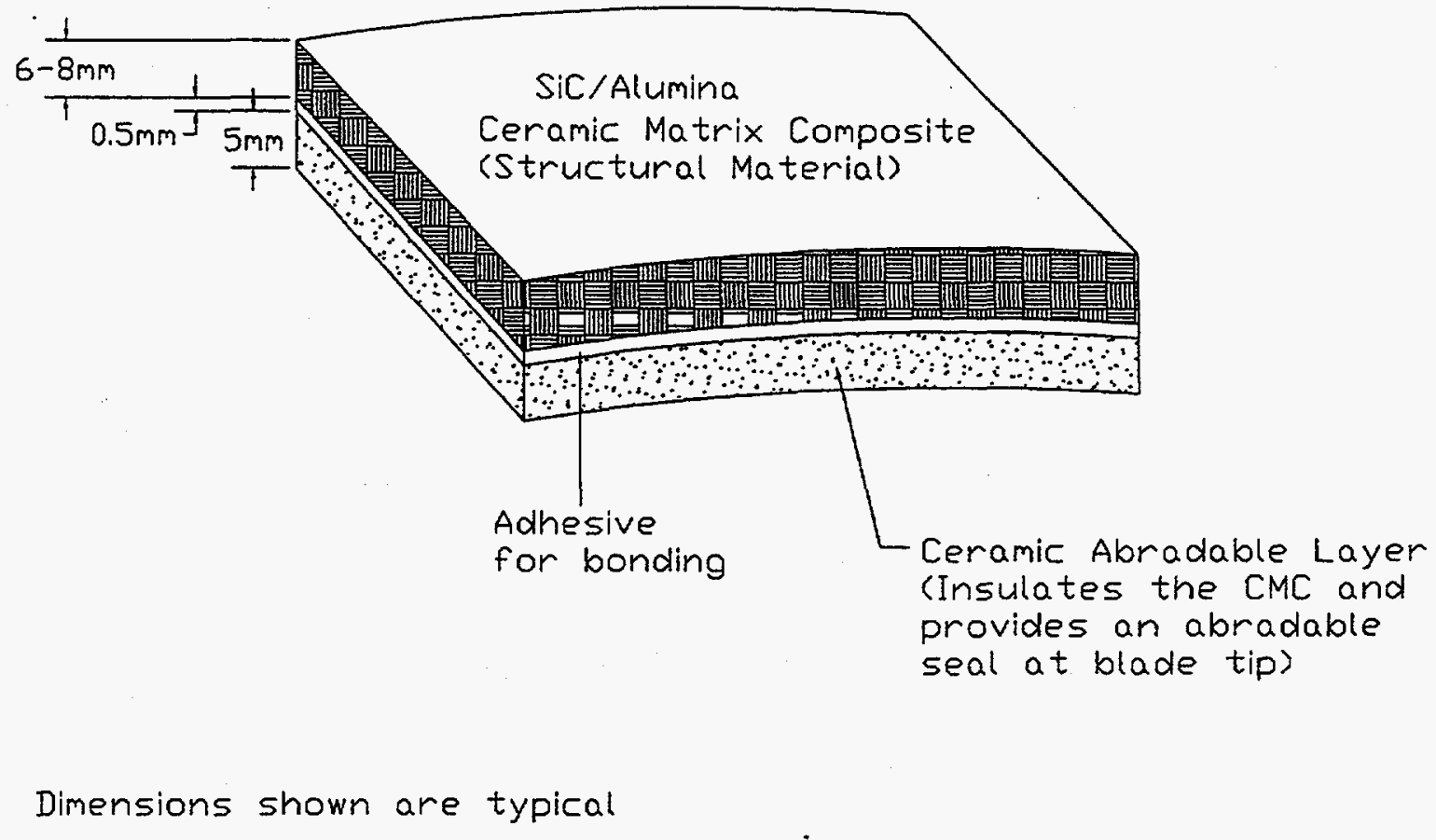

Figure 8-10 Ceramic Ring Segment Material System

\section{Thermal Barrier Coatings}

The application of uniform and durable TBC on the turbine airfoil and end wall surface is critical to the design of closed-loop cooling systems. The protection provided by the cooling air film, in previous blade/vane/ring segment designs, is no longer available. The thermal barrier provided by the TBC will be important in maintaining low surface metal temperatures in the ATS engine, without the need for high rates of internal cooling.

Ceramic TBC must be capable of operating a minimum of 24,000 hours. Various ceramic coatings were evaluated, using innovative bond coats and deposition methods. Field tests of a select set of coatings were made in various Westinghouse combustion turbines.

The performance of several bond coats were evaluated for use in the ATS combustion turbine. Air plasma sprayed(APS) and electron beam physical vapor deposition(EBPVD) applied $8 \%$ yttria stabilized zirconia thermal barrier coatings to the bond coats. The life-limiting failure mode in both air plasma sprayed and electron beam - physical vapor 
deposition coating systems is the oxidation of the bond coat. The coating life is related to the growth rate and morphology of the thermally grown oxide.

A systems approach to improving coating performance must also consider the ceramic thermal barrier. The use of $8 \%$ yttria stabilized zirconia has demonstrated performance in the aerospace industry. It has many desirable properties, thermal stability at high temperature, high thermal expansion and low thermal conductivity. The life-limiting failure mechanism remains oxidation of the bond coat. It can be argued that improvements in the ceramic TBC performance under these circumstances is of secondary importance. The influence of ceramic TBC properties on coating durability will increase, as bond coat developments provide increased oxidation resistance. Further development of ceramic TBC will be limited by bond coat materials.

\section{Experimental}

Three nickel base superalloys were selected as substrate materials for the evaluation of several commercial TBC systems. Each of these alloys received a conventional bond coat. Coatings were deposited onto $0.315 \mathrm{in} .(8 \mathrm{~mm})$ diameter rods, approximately 4.75 in. $(12 \mathrm{~cm})$ in length. The coated rods were sectioned into $1.0 \mathrm{in} .(2.5 \mathrm{~cm})$ test pieces.

Coating performance was based on the time to failure in furnace tests. Furnace exposure tests were conducted at $2100^{\circ} \mathrm{F}$. Samples were cooled to room temperature in static air once every 24 hours. Samples were removed from the test at prescribed intervals for metallographic inspection. At least three specimens for each system were tested to failure. Coating failure was defined as significant spallation of the coating.

Metallographic sections were prepared for each sample. The test pins were cross sectioned, mounted using epoxy vacuum infiltration techniques, polished and ground. The oxide thickness, morphology and chemistry were examined using scanning electron microscopy and wavelength dispersive spectroscopy. Oxidation rates were determined from oxide thickness measurements.

\section{Results and Discussion}

The relative performance of each trial system is shown graphically in Figure 8-11. As expected, failure of the coating system is directly related to the oxidation of the bond. The growth of the oxide during service exposure introduces stresses into the system, which manifests spallation of the coating. The thermal stresses, associated with heating and cooling from ambient to operating temperatures, introduce additional degradation. Creep of the bond coat, bond coat mechanical properties and TBC compliance will certainly contribute to the overall stress state of the system. The critical life-limiting factor remains oxidation of the bond coat.

The oxidation rate is dictated by the capacity of the bond coat to form an impermeable, adherent alumina oxide scale. Diffusion of elements from the substrate influences the ability of the coating to form a protective oxide scale. 
The oxide growth rate, as determined by measurements of oxide thickness, are presented in figure 8-12 for each of the TBC systems. If the substrate played no role in determining the oxidation rate of the bond coat, then the three systems should have nominally equivalent life as measured by hours to failure. These systems, with the same bond coat have measurably different oxidation rates. The performance of the coating system on substrate $\mathrm{IN}-939$ illustrates the axiom that having the highest oxidation rate has the lowest life.

\section{Thermal Fatigue Life of Bond Coat Candidate Materials Oxidation Exposure}

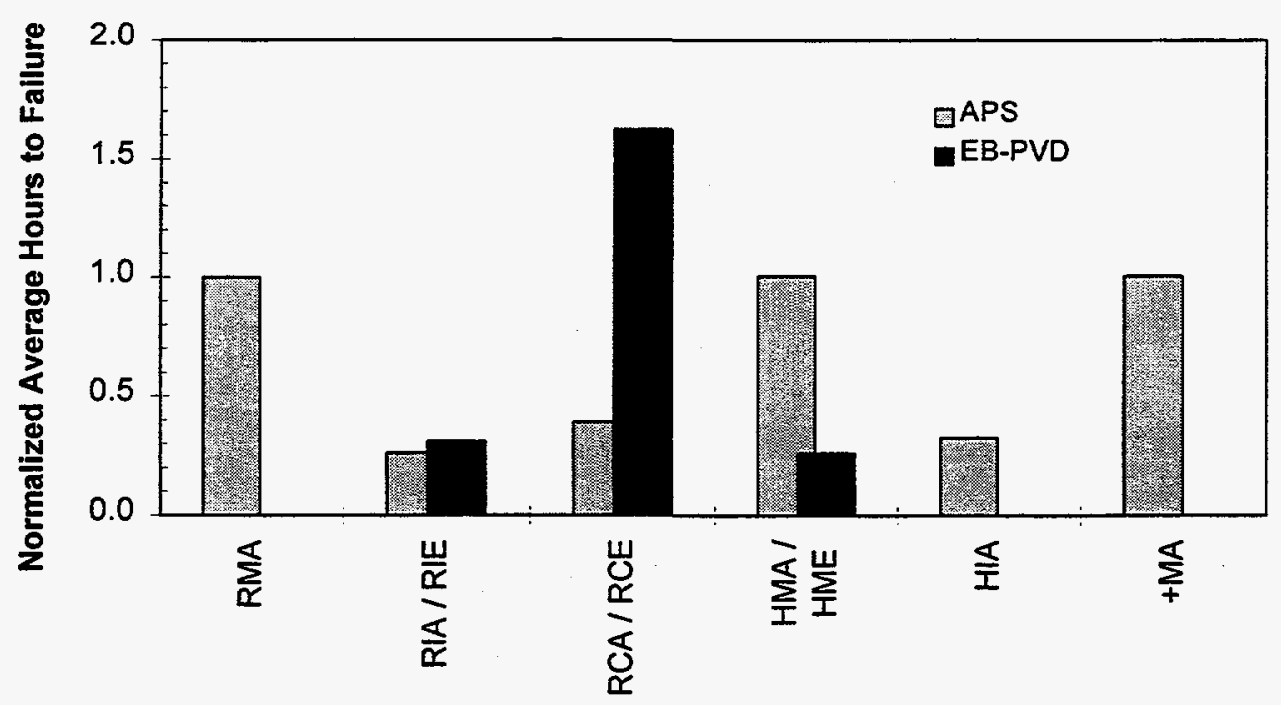

Thermal Barrier Coating System

Figure 8-11. Thermal Fatigue Life Evaluation Performance of each of the TBC systems evaluated as determined by furnace evaluations at $2100^{\circ} \mathrm{F}$, samples were cycled to room temperature once every 24 hours. 


\section{Comparison of Coating Performance and Oxidation}

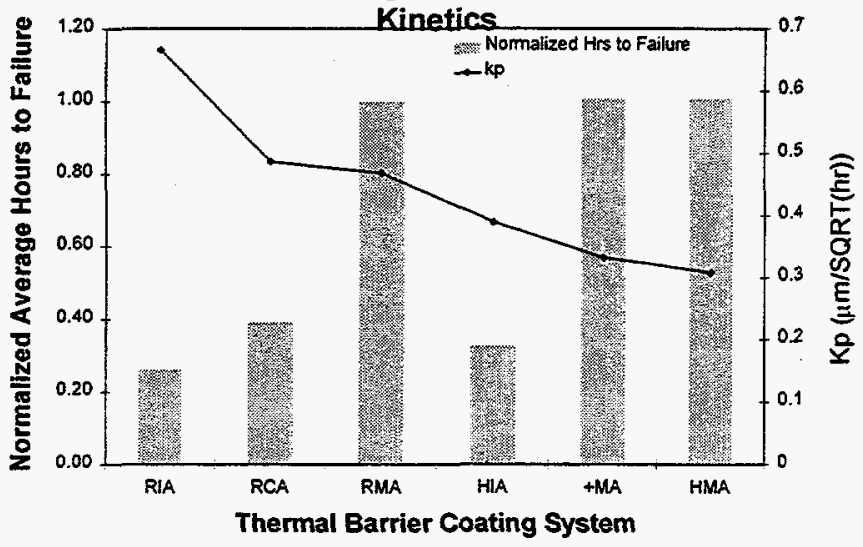

Figure 8-12. Comparison of Coating Performance and Oxidation. A comparison of oxidation rate, $\mathrm{Kp}$, versus time to failure for the APS coating systems. The oxidation rates were determined from oxide thickness measurements.

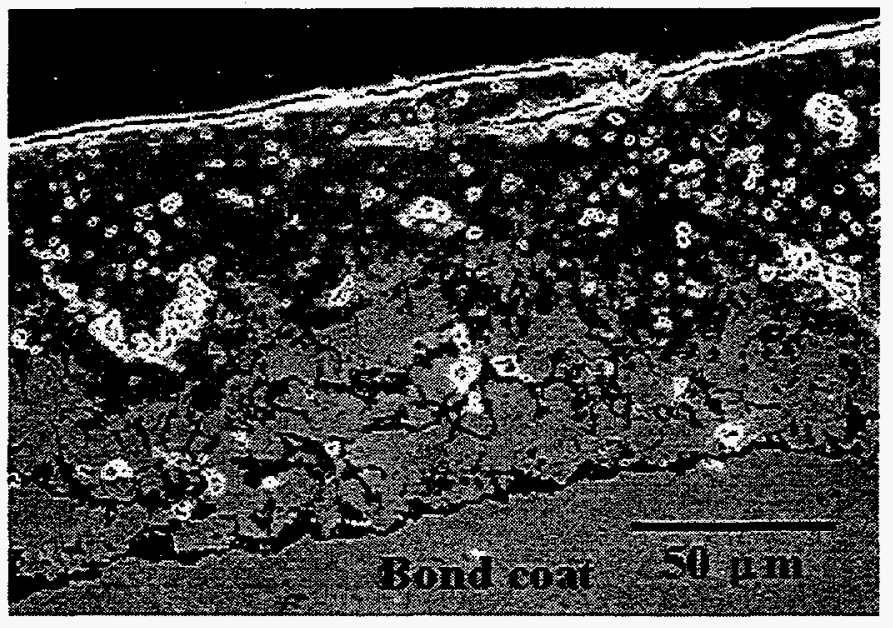

Figure 8-13. Spalled APS Coating. Characteristic oxide formed on RIA with APS coating. 


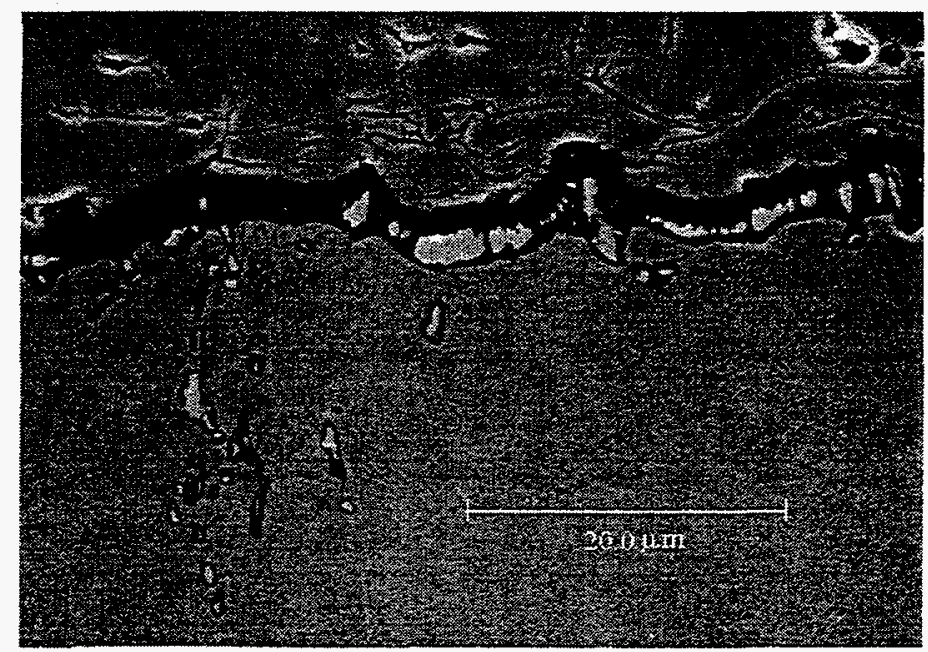

Figure 8-14. HMA with APS Bond Coat. A significant number of hafnia pegs combined with insufficient surface roughness reduced the performance of this coating system.

The furnace tests revealed that substrate chemistry influences oxide formation and morphology. Figure 8-13 shows a specimen that experienced the longest life. The oxide formed on this system is characterized by an adherent, pure alumina layer. The micrograph in figure 8-14 shows a specimen that developed a thin alumina scale with large amounts of hafnia. The hafnium diffused into the alumina scale and compromised the protective capacity of the scale.

\section{New Ceramics}

Several new ceramic compositions have been selected for evaluation. These ceramics were selected based on the potential to reduce thermal conductivity, or their increased thermal stability. One system, a scandia stabilized zirconia, has exhibited improved life over that of the standard $8 \%$ YSZ when evaluated on the same bond coat and substrate materials(see Figure 8-15). As oxidation resistance of the bond coat increases the impact of the ceramic TBC system life will increase. The use of scandia stabilized zirconia may provide a means of increasing TBC system life. 


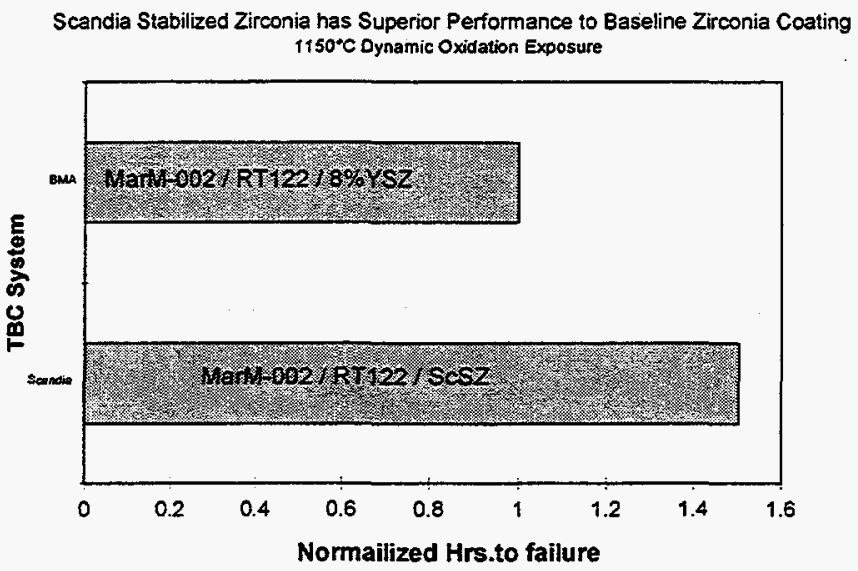

Figure 8-15. New Ceramic with Improved Performance Relative comparison of Scandia stabilized zirconia and conventional $8 \%$ YSZ TBC.

\section{Thermal Barrier Coating Field Tests}

Westinghouse has been field testing coated components for several years. Results from the TBC field test program provided information on the longevity and effectiveness of different coating systems. The tests were designed to compare coating longevity and effectiveness of air plasma sprayed and physical vapor deposition (PVD) TBC.

Tests on ring segments and blades with different coatings was initiated. These tests are in progress in Westinghouse 501D5 engines, and periodic inspection of these components is made visually. In addition to the tests, service performance of TBC coated 501D5 transitions, row 1 vanes and row 1 blades, has continued.

\section{Test Plan}

Twelve 501D5 Stage 1 turbine blades were coated and installed for long term field testing. Three coating configurations, of four blades each, were placed into service for field testing:

4 - blades with MCrALY bond coat and APS TBC

4 - blades with MCrALY bond coat and EB-PVD TBC

4 - blades with MCrALY bond coat only

Visual inspection of these blades was completed. Eight row 1,501F blades have been placed in service. Field testing of TBC coated 501D5 ring segments is also underway. After 8000 hours of operation, a limited visual inspection of the ring segments was made. 
Table 8-3 describes components, component alloys and coatings that are included in the test sequence. Tests in Table 8-3 are conducted jointly with customers of Westinghouse 501D5 units. Additional ongoing tests in other Westinghouse frames with row 1 blades and vanes along with coated transitions are in progress. In the later tests, the substrate material is varied to verify bond coat strength.

Table 8-3. TBC Tests in Progress

\begin{tabular}{|c|c|c|}
\hline Component & Component alloy & Coating \\
\hline Row 1 blades & U520 & BC1 \\
\hline & U520 & BC1 \\
\hline & U520 & BC2 \\
\hline & U520 & BC2 \\
\hline & U520 & BC2 \\
\hline & U520 & BC2 \\
\hline & U520 & BC3 \\
\hline & U520 & BC3 \\
\hline & U520 & BC3 \\
\hline Row 1 Ring segments & U520 & BC1 \\
\hline & CM247(CC) & BC1 \\
\hline & IN738 (CC) & BC1 \\
\hline & SAS4 (DS) & BC1 \\
\hline & CM247(CC) & BC3 \\
\hline & IN738(CC) & BC3 \\
\hline & CM247(CC) & BC1 \\
\hline & N7738 (CC) & BC1 \\
\hline & CM247(CC) & BC1 \\
\hline & IN738 (CC) & BC1 \\
\hline & X-45(CC) & BC1 \\
\hline
\end{tabular}

\section{Test Results}

Ring segments were visually inspected(see Figure 8-16) after about 8000 hours. Only one segment, coated with CoNiCrAlY + EB PVD TBC, exhibited coating flaking at a corner (see Figure 8-17). The ring segments will be destructively inspected after 16,000 hours.

Row 1 blades will be inspected visually after 8,000 hours.

The transitions, row 1 vanes and row 1 blades were visually inspected. Photos of these parts are shown in Figures 8-18 and 8-19. Service hours are indicated in each figure caption. 


\section{Conclusions}

Results from the ring segment tests are encouraging, however, further testing is required. One out of 6 ring segments with EB PVD TBC exhibited modest corner flaking in about 8,000 hours of operation. All the remaining coated segments had coating in tact.

The transition inspections were favorable. TBC coating on the inner side of transitions extended the transition life significantly, and eliminated distortion.

Positive results from the coatings on blades and vanes are promising. APS TBC on row 1 vanes extended the normal refurbishment interval. EB PVD TBC on row blades was in tact after 16,000 hours.

Inspections shall continue as more operating hours are accumulated on the test pieces.

It is important to note that the tests were performed on commercial combustion turbines, not the ATS. The ATS will employ higher hot gas part temperatures and the performance of the coatings may not be the same. Additional testing on ATS engines are required before deployment into the commercial market.

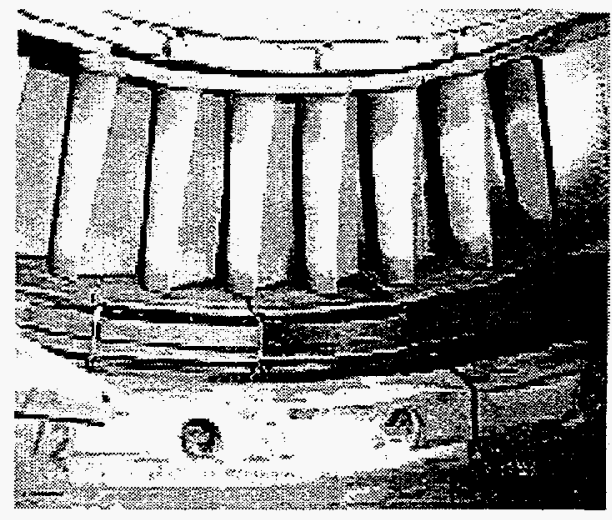

Figure 8-16. Coated Ring Segments General appearance, no coating loss $(\approx 8000$ hours)

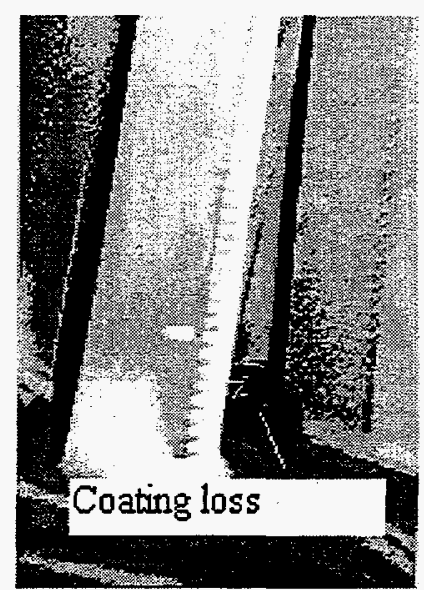

Figure 8-17. EB PVD TBC

Some loss $(\approx 8000 \mathrm{hrs})$ 


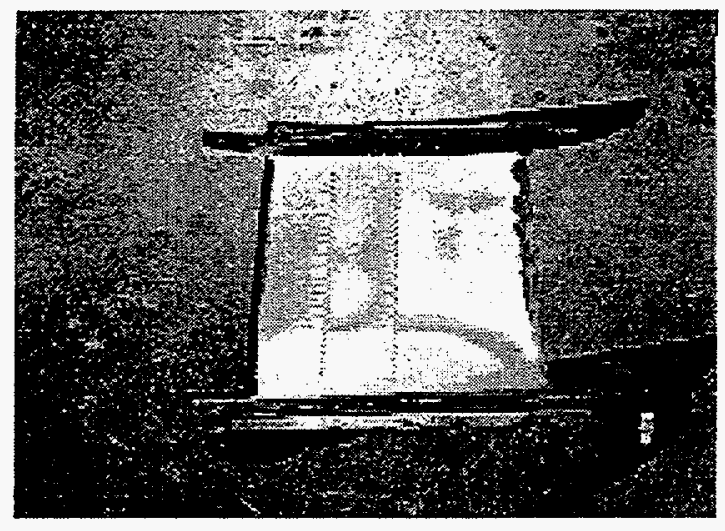

Figure 8-18. Row 1 Vane. After 16,000 hours.

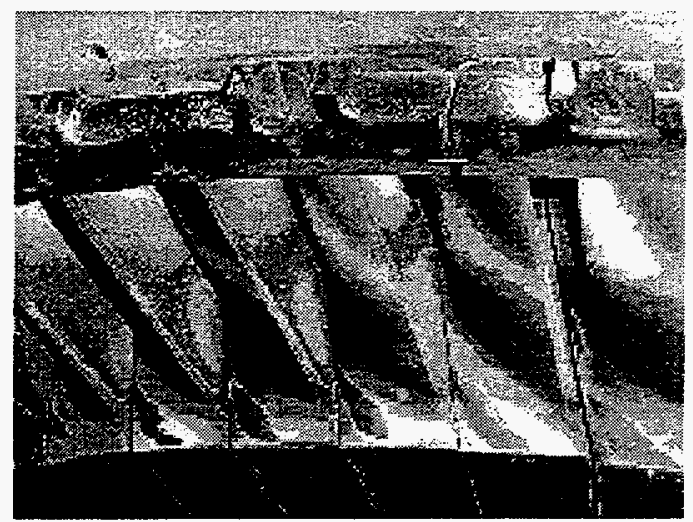

Figure 8-19. Row 1 Blades. After 16,000 hours.

\section{Active Tip Clearance Control}

Turbine blade tip clearance has a pronounced effect on the highly loaded front stages of the turbine. As a rule of thumb, each $1 \%$ tip clearance increase is accompanied with a decrease in stage efficiency of $2 \%$. The ideal active tip control system would maintain large tip clearances during startup, then decrease the clearance to minimum values when the turbine has achieved steady state operation.

\section{Conceptual Design}

A conceptual design of a thermally actuated tip clearance control system was completed. The design consisted of an outer ring, which supports the high temperature segments that define the outer gas path around the rotating blades. The limiting point in setting tip clearance occurs at startup, when the maximum clearance is needed to prevent tip rubs. Before engine start-up had commenced, the ring was to be heated by an external steam supply, thereby expanding and increasing tip clearance. Heating the ring would effectively increase the tip clearance during the short lived start-up transient. Once the engine reached steady state the external steam supply could be removed. A limitation to this approach is evident. An external boiler is required to create steam before the engine came on line and before steam was available through the HSRG. The complexity of the steam heating manifold was further complicated by the obstruction of closed loop cooled vanes. 
In addition to the actuating system development, testing of ceramic abradable coating was completed. These coatings are on the order of 0.050 inch thick. They provide: (1) thermal insulation for the mating, stationary ring segment to minimize required cooling air flow, and (2) a surface for the rotating blade tips to rub against without excessive wear. Such coatings have been under development for over 15 years by aero gas turbine engine manufacturers and their vendors. They are used in several production aero engines.

\section{Test Results}

A coating vendor was selected to coat 501D engine row 1 turbine ring segments for field testing. These pieces were installed in a 501D5 engine and tip clearance measurements were recorded for future comparison. Tests are in progress.

The vendor also coated and shock tested two test pieces. Testing was performed on a cyclic thermal rig capable of simulating engine heat flux levels. Test results demonstrated that the coating exceeded the vendor's coating specification shock resistance.

In addition to shock testing, the vendor completed abradability testing of samples with their coating applied. The test determined wear coatings characteristics of coatings and blade tips with simulated incursion rates and temperatures. Test results indicate that with the low incursion rates encountered in large industrial gas turbines, blade tip treatments would be beneficial in keeping blade tip wear within acceptable limits. Only a few blades in a given stage would need to be treated in order to minimize wear of all blades. Tip treatments would be unnecessary for designs where little rubbing would be expected.

\section{Combustor Development}

Catalytic combustion must play an important role in achieving ultra-low $\mathrm{NO}_{\mathrm{x}}$ emissions at advanced firing temperatures, especially in light of the exponential increase in $\mathrm{NO}_{\mathrm{x}}$ production with higher firing temperatures. A program to develop the theoretical background on combustion instabilities, carry out experiments to aid in the understanding of the problem, develop a generalized analysis procedure, and develop stability criteria for a particular combustor basket is a requisite part of developing a low NOx combustor for the ATS program.

\section{Initial Investigation}

An investigation regarding the application of catalytic combustion to advanced ultra-low $\mathrm{NO}_{x}$ combustors was initiated. Initial efforts focused on the relationship between catalyst effect and recirculation, flow turndown and durability. Catalyst light-off temperature for lean-premixed methane mixtures is typically greater than the compressor discharge temperature. Therefore, the combustor design must incorporate a method to raise the 
inlet gas temperature (such as exhaust gas recirculation [EGR]), raise the monolith surface temperature, decrease the catalyst light-off temperature (by enhancing fuel reactivity), or use an integrated combination of these approaches. Based on the ATS combustor conditions and geometry, the feasibility of several different integrated combustor designs was considered.

A combustor design using EGR was determined feasible by recirculating about $20 \%$ exhaust gas from $50 \%$ to $100 \%$ of base load. Several concepts were considered to extend the catalytic combustor operating range below $50 \%$ load. These included multiple pilots, variable EGR, heating the catalyst substrate and enhancing the fuel quality. One promising approach was to pre-react part of the fuel in a fuel-rich catalytic reactor to produce a highly reactive warmer effluent gas similar to syntheses gas production from methane.

$N O_{x}$ Prediction

A computer program was written to predict $\mathrm{NO}_{\mathrm{x}}$ formation for a plug flow catalytic reactor with a downstream stabilization region. Various methane and $\mathrm{NO}_{\mathrm{x}}$ reaction mechanisms were examined for use in the model. The required reactor code modifications to predict emissions from a catalytic combustor with exhaust gas recirculation were investigated.

\section{Preliminary Design}

Preliminary designs of several catalytic combustors were completed. In one concept, called the Multiple Catalyst Swirl Stabilized Burner(MCSSB), a catalytic pilot was integrated into the catalytic combustor. The pilot flame aids in stabilizing the premixed fuel/air mixture partially reacted in the catalytic reactor section. Two catalytic upper stages were envisioned to provide wider turndown. A second concept, the Advanced Catalytic Combustor, incorporated a catalytic reactor(s) into the pilot, to eliminate the diffusion flame fuel flow at higher load conditions. In another design approach, a fuel pre-activator design was examined to eliminate EGR as a requirement.

Conceptual designs were completed and drawings were produced for the Multiple Catalyst Swirl Stabilized Burner (MCSSB) and Advanced Catalytic Combustor with integrated catalytic pilot and EGR. 


\section{Flow Dynamics and Visualization}

Two and three-dimensional Fluent CFD modeling of two EGR concepts were completed. The computational and combustor venturi geometries were the same, however, the complex combustor swirler geometry was not modeled. Overall the $6^{\circ}$ conical diffuser was predicted to do better than the elliptical diffuser design for both static pressure loss and mass of combustor gas recirculated. Static pressure losses were about one third less for the conical diffuser design.

Two EGR designs were provided for construction of the appropriate plastic model. Model construction required additions to an existing multi-swirl flow rig for atmospheric rig testing. Flow visualization tests were carried out on one model of the EGR combustor. The required flow area for $10 \%$ exhaust gas recirculation was established.

\section{Combustor Noise}

The combustor is one of the primary sources of noise in a power plant. The very lean premix combustion necessary to achieve ultra-low- $\mathrm{NO}_{\mathrm{x}}$ emissions compounds the noise problem. Very lean premix increases the likelihood of combustion instabilities with resultant noise and high vibratory stresses in the combustion system components and in the turbine blading. The objective of combustion stabilization is to extend the range of equivalence ratios over which low-emission combustion can occur without instabilities. Specific goals for the fulfillment of this objective included:

- the development of an active combustion stabilization control system in collaboration with Georgia Tech;

- the design, assembly, and installation of a sub-scale combustion stabilization test section at the Westinghouse Science and Technology Center to provide an evaluation platform for the stabilization control system; and

- a successful sub-scale demonstration of the active stabilization of gas-fuel, leanpremix combustion at turbine operating conditions using the control system and test section developed in this program.

\section{Stabilization System Description}

The concept of Georgia Tech's noise control system is to damp out combustion oscillations by modulating a secondary flow of fuel that is injected in close proximity to the flame. This system incorporates the following features in control technology:

- state observer software that can ascertain the frequency content of pressure or luminosity transducer signals within a few cycles of combustion oscillation; and 
- a magnetostrictively actuated fuel flow modulator than can respond to control signal frequencies approaching $1 \mathrm{kHz}$.

Results from the observer software is illustrated in Figure 8-20. The figure is a reconstruction of an unstable-combustion pressure signal generated from output of the state observer software. The solid line is the original time-history recording from a full scale, single-combustor test during a period of instability; the dashed line is the reconstructed version. The observer software has been integrated into a controller module for the control evaluation tests. Analog control signals generated by this module are amplified and input directly to the secondary fuel flow modulator. By driving the modulator with continuously updated signals of appropriate magnitude and phase, the controller introduces additional components of volume velocity fluctuation of the combustion gases such that the burning-rate oscillations are canceled.

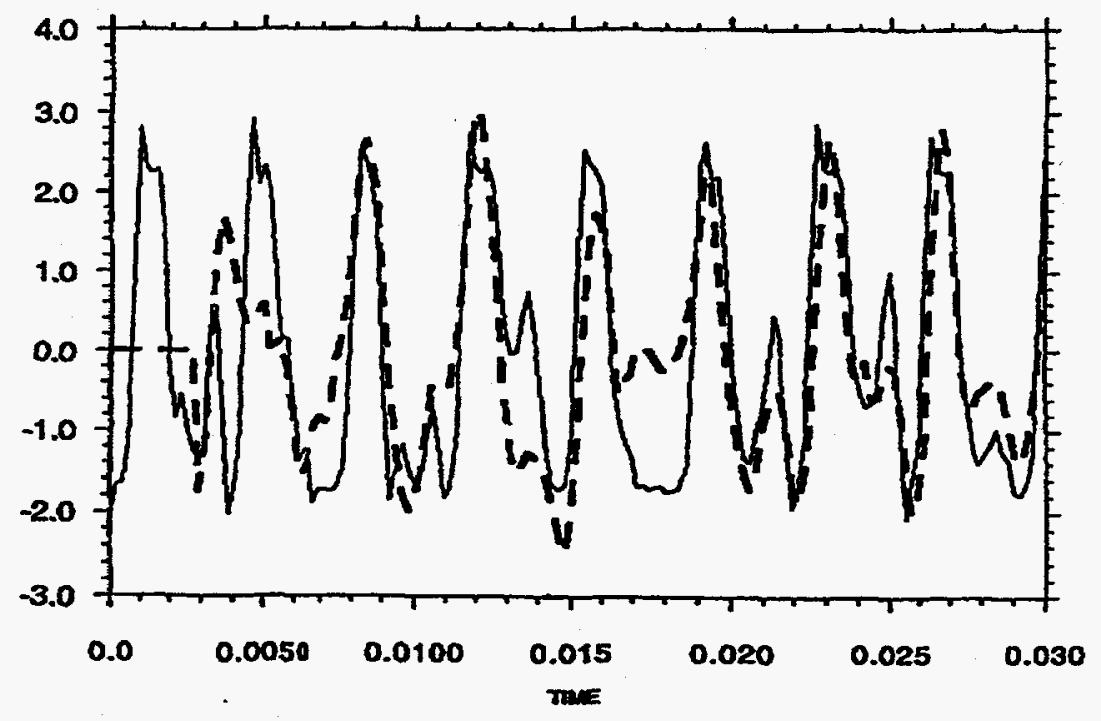

Figure 8-20. Comparison of Simulated Pressure Signal(dotted line) with Actual. Notice the short settling time of the observer software.

The fuel flow modulator furnished for the stabilization control evaluation is a scaled-up version of a prototype modulator that was used previously to demonstrate combustion controllability. Figure 8-21 shows measured combustion responses to fuel flow modulations imposed in test runs on a subscale, gas-fired, rocket engine. The top two graphs are time histories of luminosity signal from open loop control test runs at two different frequencies. The bottom two graphs are their corresponding frequency spectra. The throughput flow requirement for the present demonstration, $0.0013 \mathrm{lb} / \mathrm{s}$ of natural gas at full flow, is substantially greater than that of the prototype modulator. 


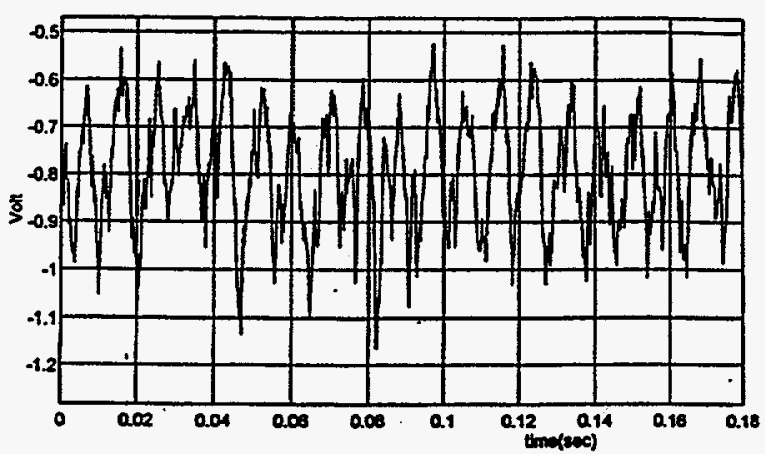

$111 \mathrm{~Hz}$

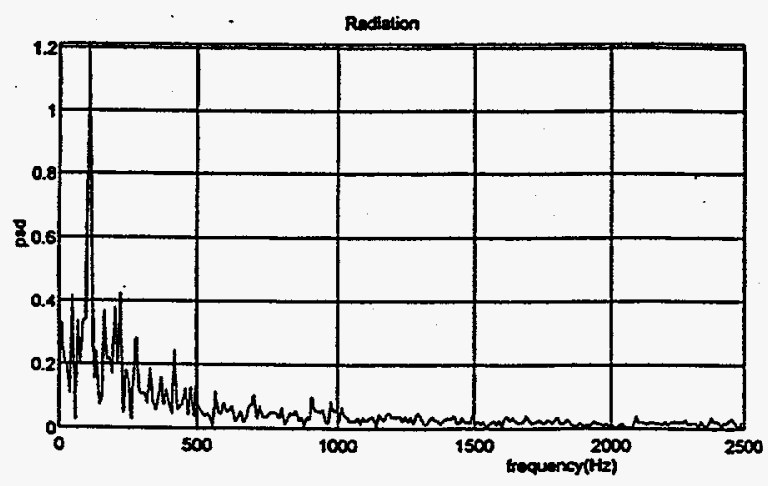

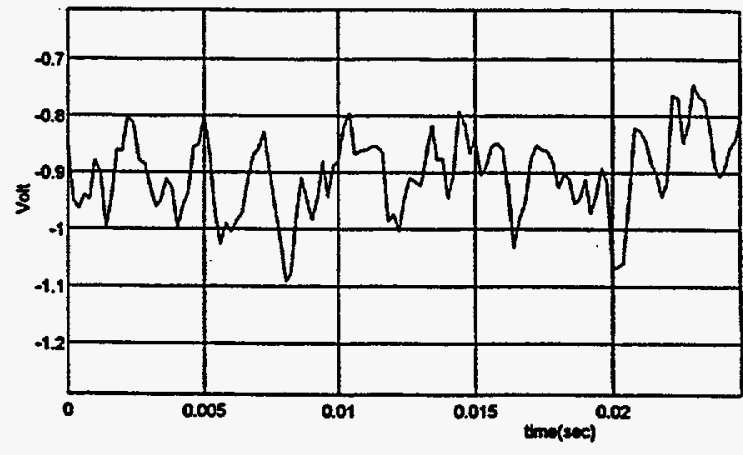

$807 \mathrm{~Hz}$

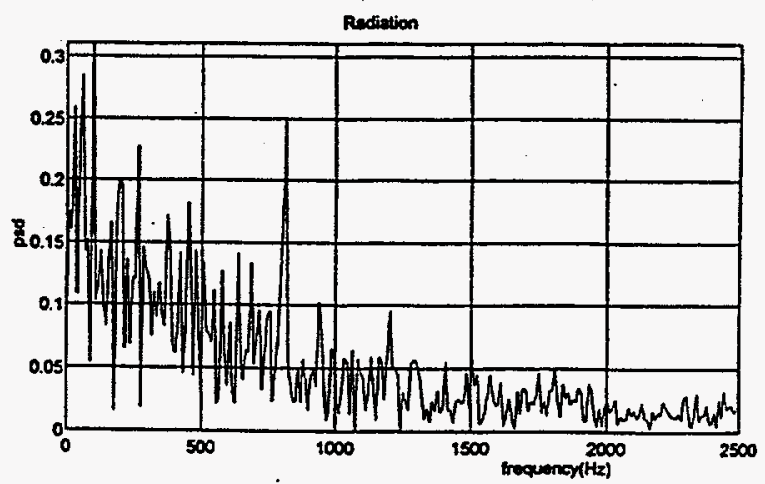

Figure 8-21. Combustion Fluctuation Response to Secondary Fuel Oscillations. The oscillations were intentionally generated by the flow modulator over a wide frequency range.

\section{Sub-Scale Combustor Test Section Design}

The primary subscale combustor requirements which were to be met in designing the test section included:

- main combustion to occur in a lean, premixed, single-stage natural gas flame with fuel gas introduced through a single primary fuel manifold and nozzle assembly;

- modulated secondary fuel flows for combustion stabilization to be introduced through a separate manifold and nozzle assembly;

- central disc for flame anchoring with integral igniter; and

- maximum total fuel flow rate of $0.013 \mathrm{lb} / \mathrm{s}$.

The test section has been intentionally designed to have acoustically coupled combustion instabilities at full-flow conditions. As seen in Figure 8-22, the test section includes an inlet air vessel that acoustically isolates the combustor from the upstream compressed-air supply system; a spray cooler plenum isolates it from the exhaust system. Installation of the test section in the Westinghouse STC high-pressure, preheated-air test facility enables stabilization testing at gas-turbine operating conditions.

The test combustor, Figure 8-23, resembles a simplified version of a Westinghouse engine combustor having dimensions that are scaled down about 10 -fold radially but having axial dimensions to keep the acoustic frequencies representative of full-scale 
combustors. Modulated flow of secondary fuel is injected at the slot between the flame holder and its thermal barrier in the stabilization test combustor. A fuel/air premix swirler was added at the premix primary fuel nozzle location upon the suggestion of DOEMETC. $\mathrm{A} \mathrm{ZrO}_{2}$-coated, secondary-fuel-cooled thermal barrier precludes erosion of the flame holder. A mounting platform, not shown in the figure, is provided for the mounting of the Georgia Tech fuel modulator on the OD surface of the pressure vessel.

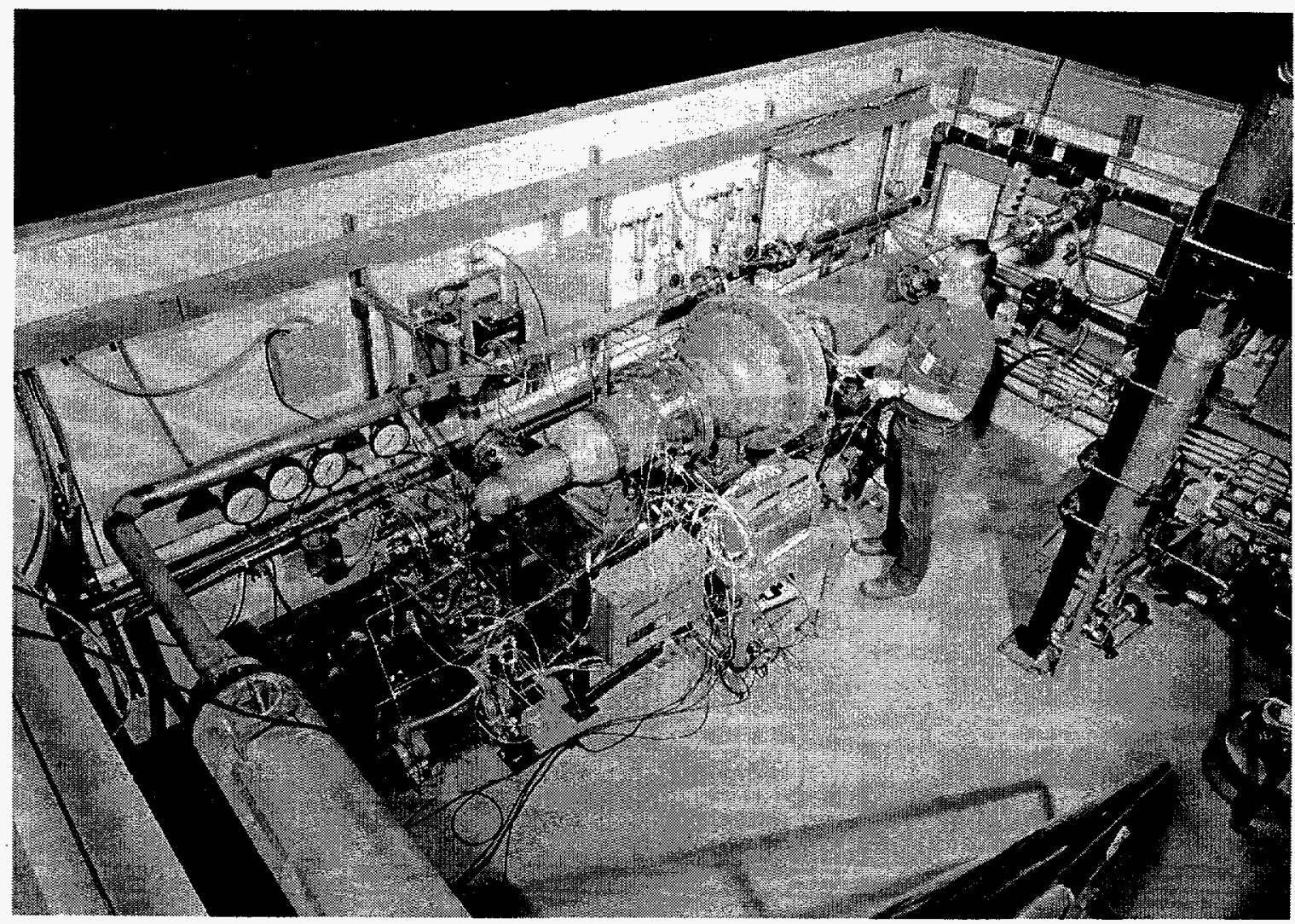

Figure 8-22. High Pressure, Preheated Air Test Facility The portion of the vessel to the immediate right of the inlet air flange(center of far wall) acoustically isolates the combustor from the air supply system. The spray cooler plenum on the right isolates it from the exhaust system. 


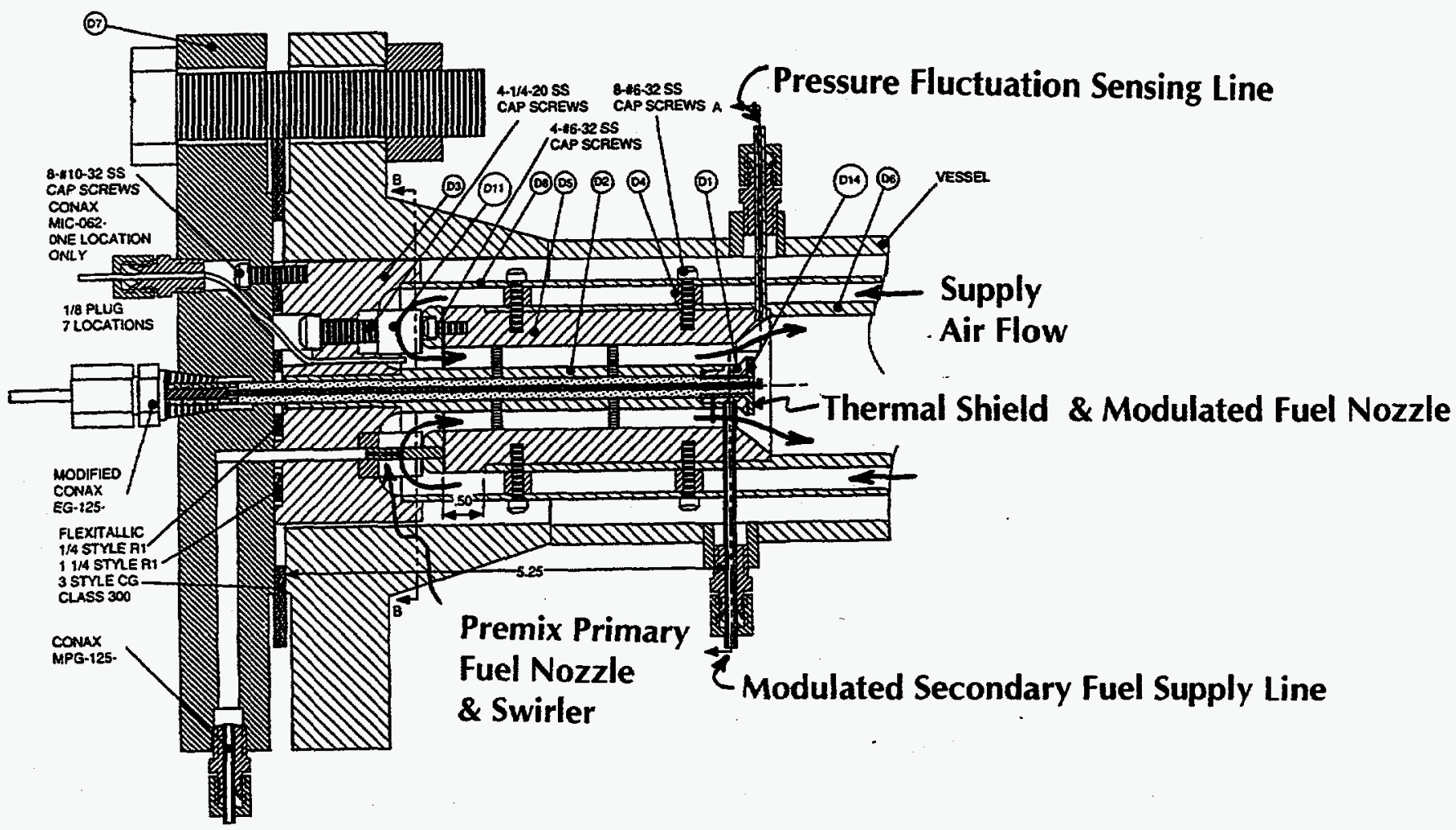

Figure 8-23. Scaled Down Test Combustor

\section{Experiment Construction}

Georgia Tech investigators designed and fabricated a new, larger modulator to accommodate the needs of this program. Some minor design revisions to reduce backtransmission of combustor pressure oscillations to its internal components were completed after initial testing. Open-loop combustion tests in a sub-scale, gas-fired rocket engine verified that the enlarged modulator provided the necessary flow modulation amplitudes over the desired frequency range (frequencies up to nearly $1 \mathrm{kHz}$ ).

Software and electronics for the state observer and control algorithms were assembled into a stand-alone controller module. The module and fuel modulator were shipped to the Westinghouse Science \& Technology Center for integration into the sub-scale combustion test setup.

Several design iterations were completed to resolve issues of safety, access, ignition and flame anchoring, and accommodation of high temperatures. The assembled components were instrumented for steady and fluctuating pressures, temperatures, and flow rates. Features were added for mechanically interfacing the fuel modulator to the combustor. 
Procedures were established for lighting off the combustor and ramping up to full-power conditions in a manner that was compatible with the operation of the test facility's safety system. Changes made to the test combustor to enable lightoff at higher mass flows and stronger modulation of the combustion rate included:

- relocation of the secondary fuel nozzle to the slot between the flameholder and the thermal shield, and

- enlargement of the premix primary fuel nozzle orifices to reduce the fuel flow resistance.

\section{Test Results}

Variations in overall mixture ratio and main/secondary fuel flow split were introduced so that the operating regions of combustion instability could be mapped out. Instabilities such as shown in the Figure 8-24 waterfall plot were observed. The waterfall plot shows the frequency spectra of the test section prior to the installation of the active stabilization system. Instabilities were observed at about 220 and $530 \mathrm{~Hz}$ at $150 \mathrm{psig}, 720^{\circ} \mathrm{F}$ and .007 $\mathrm{Ib} / \mathrm{sec}$ inlet air flow.

The active cancellation of lean-premix combustion instabilities under combustion turbine operating pressures, temperatures and flow velocities was successfully demonstrated at reduced scale as illustrated in Figure 8-25. Future efforts to improve control effectiveness will include optimization of actuator location, scale up of combustor/actuator and more extensive system characterization.

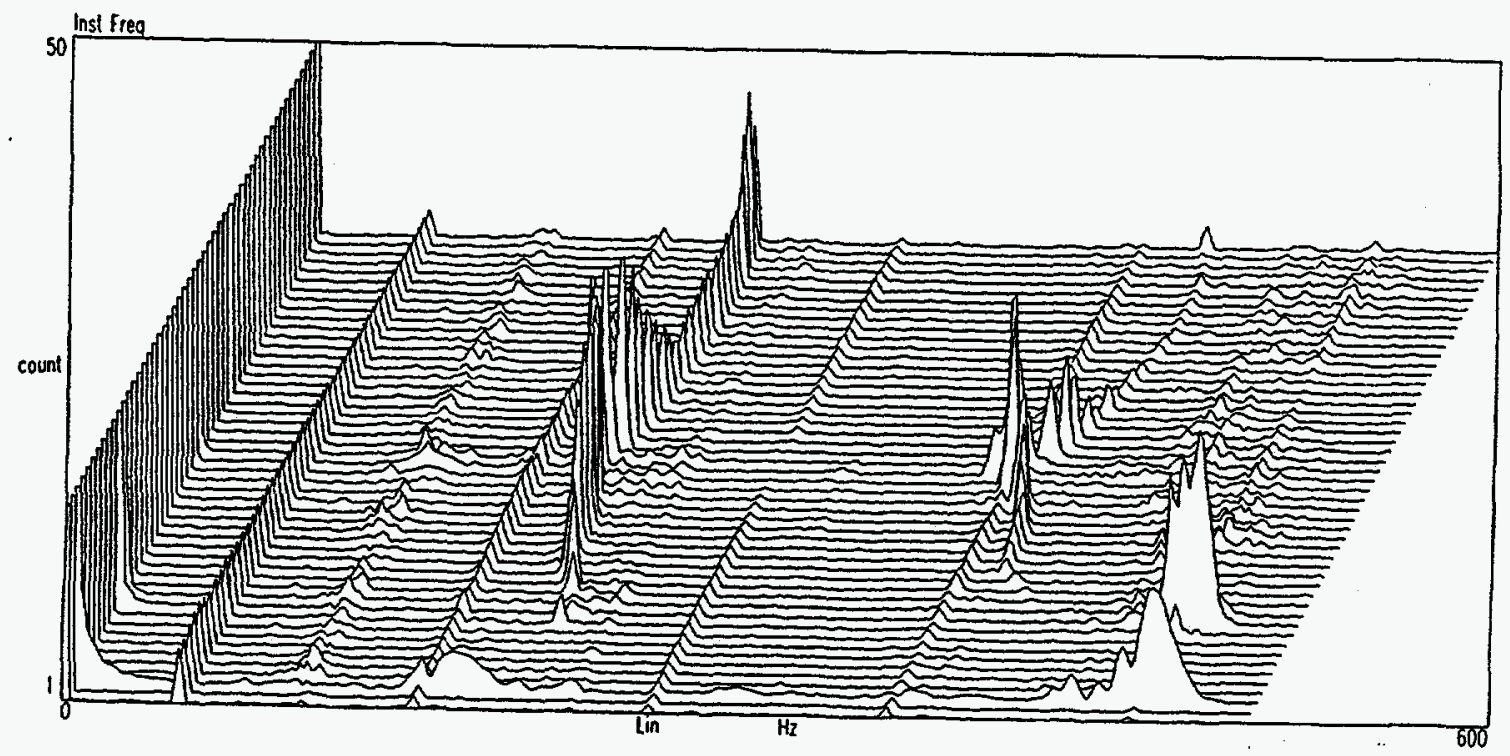

Figure 8-24. Frequency Spectra of Oscillations Before Active Stabilization 


\section{Conclusions}

This effort on active combustion stabilization has increased the viability of advanced ultra-low $\mathrm{NO}_{\mathrm{x}}$ gas-turbine power generation by demonstrating a control approach that:

- enables operation at leaner fuel/air ratios and lower $\mathrm{NO}_{\mathrm{x}}$ emission levels than otherwise possible;

- increases engine component life by reducing damaging pressure oscillations; and

- may reduce far field sound pressure levels, allowing attainment of noise guarantee

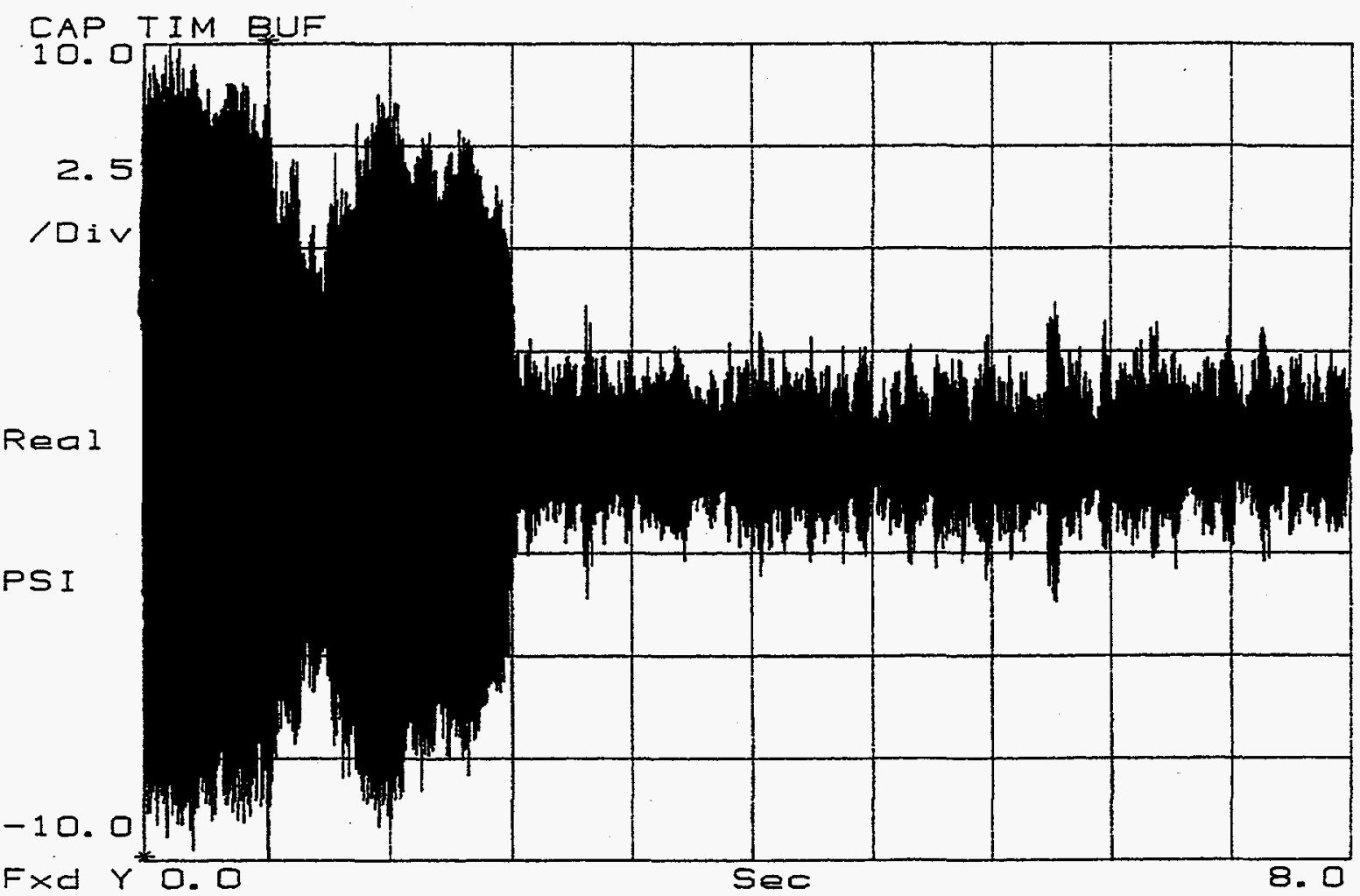

Fig. 8-25. Measured Pressure Responses Before and After Active Cancellation. Four fold reduction in pressure oscillations occurred within 0.1 seconds.

\section{$\underline{\text { Seal Development }}$}

Over the last decade, research and development of brush seals has flourished in response to potential uses and leakage superiority of brush seals over conventional labyrinth seals in aero gas turbines. Brush seals can be installed wherever labyrinth seals are currently located in a gas turbine, with significant leakage reduction. Applying brush seals to industrial combustion turbines is attractive because the engines run primarily at constant speed where the seals do not encounter radial clearance excursions with the mating rotating surface and have significantly fewer transient closure cycles than aero engines. 
The ATS Phase 2 advanced air sealing development effort focused on applying brush seals in the ATS combustion turbine engine.

Design requirements for applying brush seals in combustion turbines include:

- Good durability to accommodate handling, field installation and operation

- Being segmented because combustion turbines have a horizontal split casing,

- Run against uncoated rotors because of cost and manufacturing issues associated with large combustion turbine rotors,

- Good sealing even after wear from repeated stait-up cycles.

The program examined brush seals for large combustion turbines that could significantly reduce leakage flows while meeting design, life, durability, and cost requirements. The development effort consisted of:

- A preliminary investigation to look at the benefits, potential locations, feasibility of running against uncoated surfaces, and validation required in applying brush seals to combustion turbines

- A focused development effort for one selected engine location. Focused efforts for other engine locations are the subject of subsequent efforts..

The seal effort included:

- A concept study

- Tribology testing

- Fabrication of rig hardware

- Rig testing of candidate brush seals

\section{Preliminary Investigation}

The first task done in the preliminary investigation was a cost/benefit analysis of replacing labyrinth seals with brush seals at various locations. Locations considered included the turbine interstage seal and rim, the compressor diaphragm seals, and the turbine front seal. Representative results showed that reduced leakage's from incorporating brush seals would improve plant efficiency by one-sixth to one-fourth of a point depending upon location. Further, the reduced leakage also increases system power output. 
A second task was to determine the start-up and steady-state operating conditions for the various seal locations. This task is ongoing as the ATS engine is being designed. Transient variations of seal inlet pressure, pressure drop, air temperature, speed, and closure were determined from engine start-up conditions and finite-element analyses. Figure 8-26 shows transient trends of engine speed and seal closure for the turbine interstage.

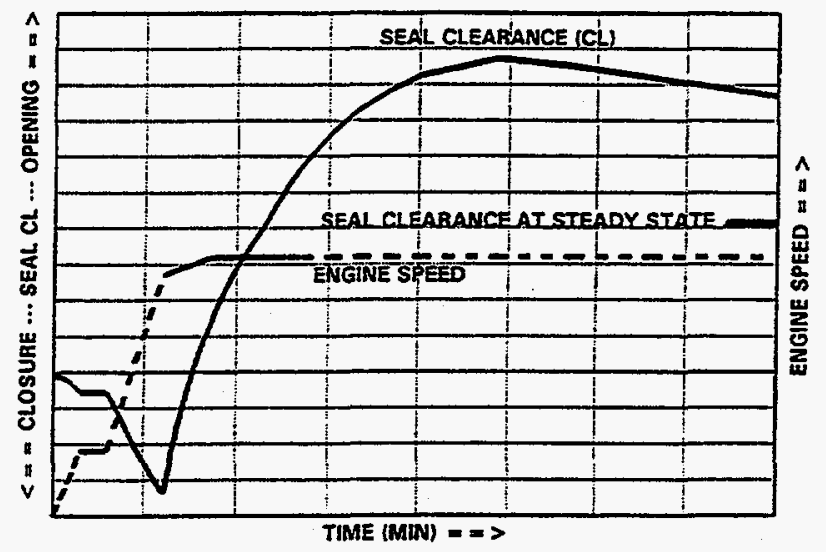

Figure 8-26. Start-up Cycle for a Turbine Interstage Location

A brush seal operating with the start-up closure characteristic in Figure 8-26 will initially wear line-to-line at steady-state. Each time a start cycle is incurred, cumulative bristle wear occurs as a result of the interference. Because of the relatively short duration of the start-up cycle, many start cycles are required before a brush seal would wear line-to-line at the maximum closure point. But even after such wear, the leakage rate will still be less than with labyrinth seals because the bristle tip clearance will be less than labyrinth seal operating clearances.

A third task in the preliminary investigation was to conduct preliminary tests to determine the feasibility of running brush seals against uncoated rotors. In the preliminary tests, the turbine interstage seal location was chosen to model engine operating conditions and geometry. Two dynamic, subscale tests were run at ambient temperature: one where the rotor was offset repeatedly for many cycles to model the interstage seal conditions during engine start-up, and the other was with a constant interference equal to the maximum interstage closure level. Both tests were run with rotors made of a material having a composition, surface roughness, and hardness matching Westinghouse turbine rotors. The seals tested had similar stiffness, bristle pack thickness, backplate gap, etc. as would be expected for a full-size brush seal.

Figure 8-27 is a photograph of one of the turbine rotor tested. A polished wear track can be seen on the outer diameter where the seal bristles ran against the surface. Leakage, wear, and surface characterization results demonstrated that a brush/uncoated rotor 
surface seal configuration could have a service life approaching that required for CT's. Based on these preliminary tests, the focused brush seal development tasks were initiated.

A fourth task in the preliminary investigation was to determine possible validation tests. A search was made of available host Westinghouse combustion turbines. The $501 \mathrm{~F}$ and $501 \mathrm{G}$ engines were selected for the validation tests.

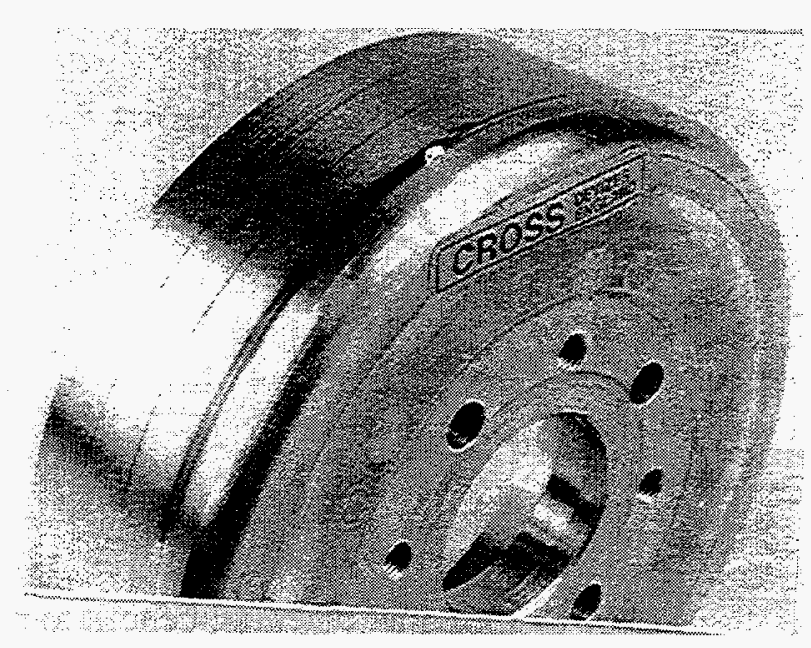

Figure 8-27 Uncoated Rotor Used in Test

Note polished bristle wear track.

\section{Focused Seal Development}

The initial development for these ATS activities was for brush seals to be incorporated into the turbine. This location was chosen because of its higher potential benefit to plant performance.

The focused development addressed the technical challenges of sealing in the given location, i.e., running a brush seal against an uncoated rotor, and design optimization for negotiating transient radial closure while still achieving minimal leakage at steady state. The development consisted of three separate efforts:

- Design of seals to meet the operational requirements,

- Tribological study in which various bristle alloys are run against current and future rotor materials, and

- Extensive subscale rig testing to assess performance of selected design configurations. 
The overall objective of the design effort was to identify and include features to accommodate the transient closures, subsequently evaluated during the subscale testing effort. A specific objective was to estimate the transient variation of interference, surface speed, and pressure drop that can be accommodated by these designs. This was also evaluated later during subscale testing. Engine operating conditions were taken from the preliminary investigation. The materials selected for the subscale rotor were identical to the engine rotor materials for the selected location. This is important from the standpoint of reproducing the engine tribological environment. The bristle alloy selected for the seal designs is in accordance with tribological test results. A chart depicting the design methodology being used in design selection is given in Figure 8-28.

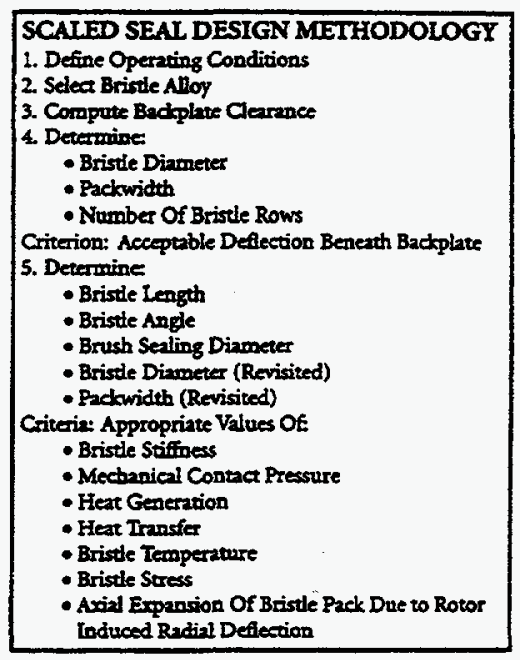

Figure 8-28. Subscale Seal Design Methodology

Seal design operating interference was selected in order to obtain a minimum steady-state clearance (i.e., leakage rate) after the cumulative wear of many starts (i.e., several hundred cycles). A large initial interference could result in excessive heat generation, high temperature, and rapid wear. Conversely, a low initial interference would yield a clearance larger than necessary at steady state, hence higher leakage.

The tribological testing was done using a high speed friction test rig (Figure 8-29). Miniature brush seals were run against uncoated rotors in the absence of a pressure drop to quantify friction and wear behavior under aggressive conditions.. Tribopair combinations of five different bristle alloys and two rotor materials. Each tribopair was first tested under cyclic conditions. After ten cycles, each tribopair was then tested for one hour at constant speed and temperature. Rotors were tested with two different surface roughness' to determine the effect of roughness on frictional heating and wear of the bristle alloys. 
DE-AC21-93MC30247

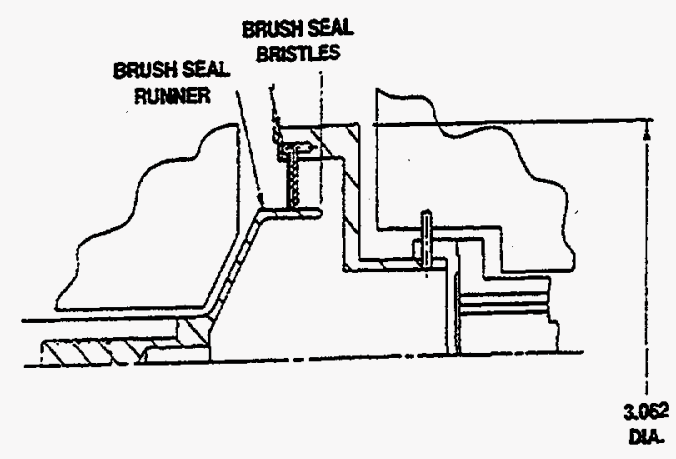

Figure 8-29. High Speed Friction Test Rig Used in Tribological Testing

Approximately forty different tribopair tests were conducted. Bristle wear and frictional heating results confirmed the feasibility of running against uncoated rotors, indicated the best bristle allows to run against the two rotor materials, and quantified a maximum desired rotor surface roughness

In the subscale rig tests, one-fourth size brush seals were tested under the severe cyclic conditions representative of an actual engine turbine location. The important cyclic conditions modeled were pressure drop, air inlet temperature, surface speed, and interference (both decreasing and increasing closure). Cyclic interference was simulated by a prescribed variation of axial location on a stepped rotor with an intervening cone and speed. Prior to commencing cyclic tests, the seal was run dynamically at room temperature and viewed with a borescope from the upstream and downstream sides. During cyclic testing, seal leakage characteristics were determined every 50 cycles or so, and the seal was periodically removed to measure bristle and rotor wear. High magnification photographs were taken of the rotor surface and seal to define the tribological surface conditions. A special eccentric rotor test was also conducted with a rotor having an offset center to model whirl at engine rotor critical speeds.

Seals were tested for hundreds of cycles until the bristles wore line-to-line at the maximum interference point in the cycle. The expected seal leakage increase with wear was quantified under the simulated engine conditions. Measured flow characteristic data are directly applicable to engine conditions to define the flow savings over conventional labyrinth seals versus the number of start-up cycles. The data indicated the relative merits of the seal designs. The separate eccentric rotor tests showed how brush seals respond and wear when the engine rotor whirls as it passes through critical speeds.

These ATS activities were very successful and showed the feasibility and benefit of implementing brush seals in the CT turbine interstages. Results are being used to define the best brush seal configuration for turbine interstage engine validation testing and guide seal selection for the compressor diaphragm, turbine rim and turbine front seal in ATS. 


\section{Diagnostics Instrumentation}

New materials and turbine design require diagnostic instruments to measure the performance of critical parameters. These instruments were critical to optimizing combustor and blade design Two developments from previous ATS work were continued.

The first development involved an optical diagnostics probe to observe the dynamics of combustor basket internals. The new combustors must be tested to verify performance. A means to monitor flow and composition undisturbed is necessary to obtain in situ maps of flow/composition gradients. Understanding the dynamics of the combustor internals enables the designer to locate localized sources of $\mathrm{NO}_{x}$ generation. Design optimization can proceed with this knowledge.

The second development involved a turbine blade vibration monitor. Modifications to engine cylinders, combustors, transitions and blade rings change the flow and thermal characteristics in unpredictable patterns. The blades must tolerate many different forces in adverse conditions. Blade vibration is a parameter that reveals the forces and conditions subjected to the blade. Indeed, vibration monitoring is used extensively to gauge the health of rotating machinery before a catastrophic event occurs. Field testing of the first ATS installation requires blade vibration monitoring for performance verification.

\section{Optical Diagnostics Probe}

The optical diagnostics probe was developed to allow measurement of important parameters inside combustor baskets without disturbing the main flow. This probe is instrumental in designing combustor cylinders. In situ mapping of fuel/air mixing aids in optimizing flow patterns that reduce harmful emissions.

A non-intrusive optical diagnostics probe, using laser induced fluorescence technique, was developed (see Figure 8-30). The probe was designed, fabricated and tested in a small scale test rig. The probe was tested successfully at ambient temperature and atmospheric pressure, as well as at elevated temperature and up to 10 atmospheres. Limitations in cylinder accessibility and probe reach became apparent. A second generation probe (see Figure 8-31) was designed to overcome these limitations. The new probe was approximately twice as long as the original probe. The modified probe incorporated a new metal mirror, a target collection lens, and a thermocouple located at the tip to measure probe tip temperature. Provision was made for water cooling. The probe was calibrated at high temperature and pressure. Testing proceeded at atmospheric pressure and high temperature. Good results were obtained in both fired and unfired tests. The next series of tests will be on the K-point type combustor, that has a complete set of CFD analyses solutions for comparison with the test results. 


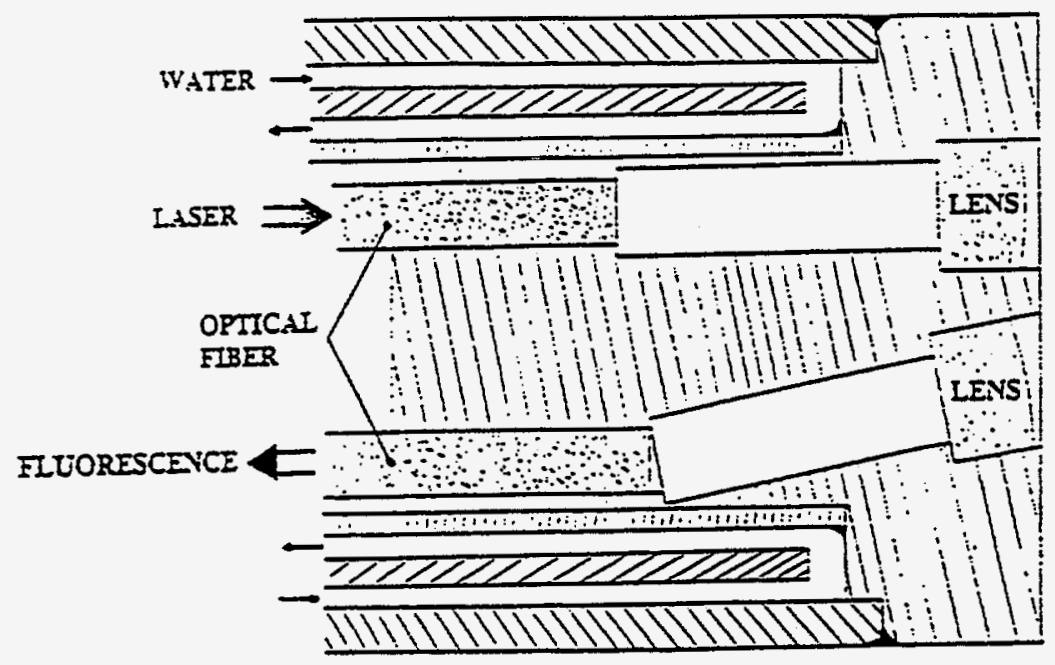

Figure 8-30. First Generation Optical Probe

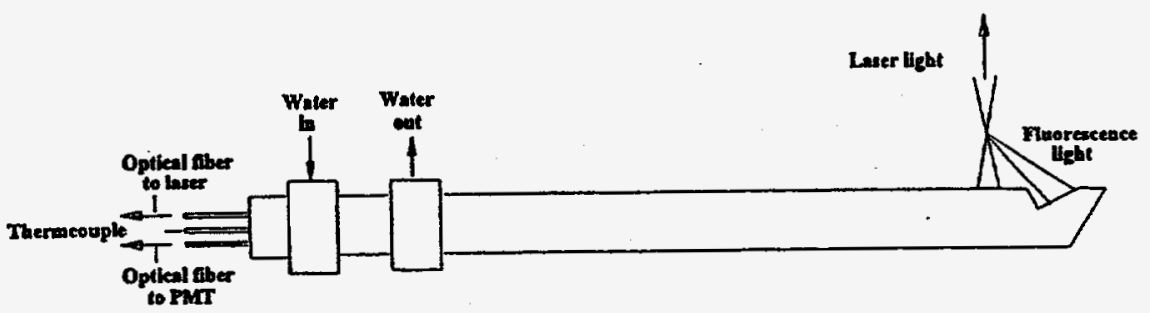

Figure 8-31. Second Generation Optical Probe 


\section{Combustion Turbine Blade Vibration Monitor System}

Current methods used to verify turbine blade stresses in the field rely upon instrument strain gages placed on several blades in the row. This method of testing is limited since: (1) strain gages tend to fail after short periods of time, and, (2) only a small portion of the blades can be instrumented simultaneously, due to cost constraints. Westinghouse developed a BVM system for steam turbine application because of these limitations. The monitor incorporates eddy current or magnetic proximity probes that detect blade tip deflection. Blade stresses are derived from the deflection measurements.

Based upon the success of the steam turbine BVM, Westinghouse has pursued the development of a BVM system for use in high temperature combustion turbine applications. Combustion turbines run at much higher temperatures than a steam turbines. An infrared (IR) sensor and a 2-probe sapphire lens IR system was developed to overcome the potential overheating conditions. The combustion turbine BVM was installed in one unit at a customer site in the Fall of 1994. The 2-probe system has a limitation that allows monitoring at nonmultiple running speed frequencies ("nonsynchronous") only. Based upon the subsequent success of the 2-probe system, a 16-probe CT-BVM IR system was developed and installed into a unit in the Spring of 1995.

Two systems were developed for field testing at a customer site. A 2-probe system was initially developed to verify the design basis. After the design basis was field proven, an improved model was conceived. A 16-probe system was subsequently developed with necessary modifications. The BVM consists of a set of IR probes mounted through the blade ring. The probes are directed to view the top of row 4 turbine blade shrouds (Figure 8-32). IR sensors detect changes in emissivity. The 2-probe system is limited to determining nonsynchronous (non-multiple of running speed) frequencies while the 16probe system can obtain synchronous and nonsynchronous frequencies.

All work, including field testing, has been completed. Turbine blade frequencies and vibratory stresses have been verified against known stress levels. Instrument software and reporting functions have been refined. The sixteen probe version of the BVM is ready for its intended function when ATS becomes operational. 


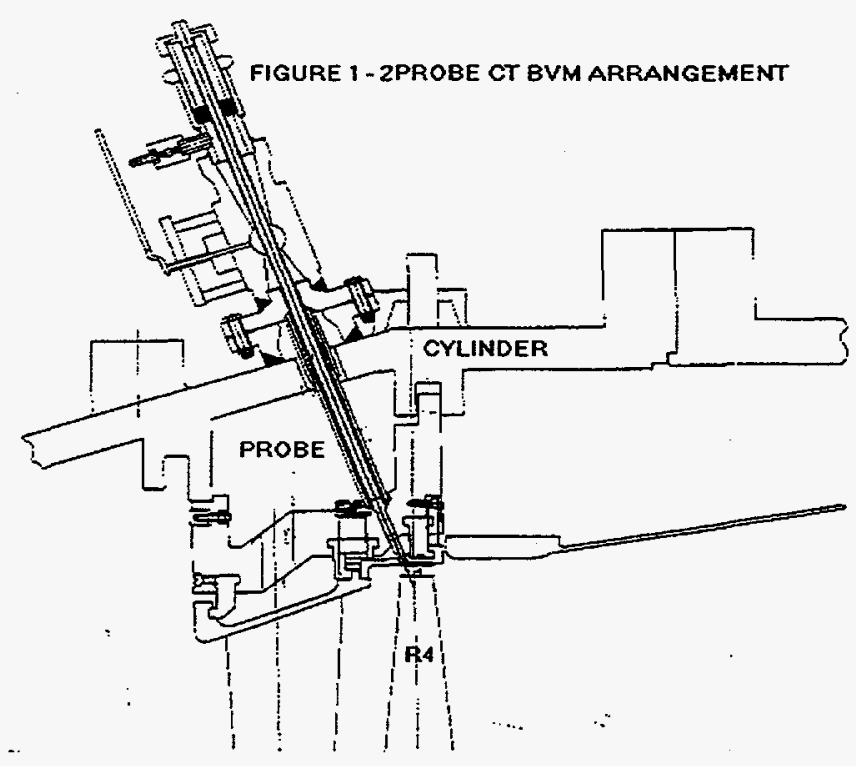

Figure 8-32. Two Probe CT Blade Vibration Monitor

\section{Forged Disc Materials}

New materials for production of high temperature discs and shaft components in the ATS Engine are required. Commercially available material in sizes needed for the ATS engine components that were sought to control costs. Developing and qualifying at least one supplier of high temperature disc and shaft components would proceed after identification of material suppliers.

Temperature and stress data for the various components of the turbine rotor was collected. The data revealed that turbine discs will be exposed to temperatures and stresses above allowable levels for alloy steels. A review of the materials available for extended high temperature service was conducted using the design requirements as the basis. Materials from several different alloy systems were evaluated with regard to mechanical properties, availability, processing capabilities and cost. Results from the review identified $\mathrm{IN}-706$ as the alloy that could meet design requirements.

Suppliers of IN-706 alloy were identified.. Discussions with suppliers concluded that IN706 discs could be produced in sizes large enough for the ATS engine. A specification for IN-706 discs was developed after meeting suppliers of the material. 
A specimen of an IN-706 disc forging was obtained from both suppliers. A test plan was developed for measuring various material properties. Two suppliers of large Inconel 706 discs allows flexibility in material sourcing. An additional benefit of testing forgings from two different suppliers is that the data obtained will help identify the variance in properties from supplier to supplier and heat to heat. Sectioning and machining has proceeded on schedule. Material property testing is in progress and will be completed in Phase 3.

\section{$\underline{\text { Diffuser Design }}$}

The flow structure within the diffuser/combustor section of an advanced Westinghouse gas turbine has been studied. This study was conducted to provide information which can be used to minimize pressure losses, optimize air flow uniformity into the combustors and evaluate the effect of air extraction for advanced integrated gasification combined cycle(IGCC) applications. The work was performed in several stages:

- Computational study was made to provide direction for the experimental portions of the study

- Experimental studies were performed to determine the flow characteristics of a baseline case with no air extraction and

- Experimental studies were performed to evaluate the effect of air extraction through a single port on the wall of the combustion shell

The results of this study are being applied to development of the pre-diffuser/combustion shell of an ATS combustion turbine.

\section{Computational Study}

The diffuser/combustor section includes components from the exit of the compressor to the inlet of the turbine. The turbine utilizes a can-annular arrangement with 16 combustors. The major components consists of the turbine casing, the annular prediffuser, the dump diffuser, the combustor "top-hat" and the combustor/transition assembly. A solid model of the diffuser/combustor section of the turbine under consideration was constructed. Except for the rotor cooling pipes, the geometry is periodic every $1 / 16$ th $\left(22.5^{\circ}\right)$ in the circumferential direction (one combustor/transition assembly). Within the 1/16th sector, a plane of symmetry runs through the middle of the combustor transition assembly. Thus, a $1 / 32$ nd sector was modeled to direct the experimental effort and provide information that would not have been obtainable through computational means.

Figure 8-33 shows velocity vectors on a plane that passes through the machine and combustor centerlines. Figure 8-34 shows similar results on a mid-plane between 
combustors. These results show that the majority of the flow exiting the pre-diffuser passes between the combustor-transition assemblies into the upper portion of the dump diffuser. Only a small amount of air flows through the lower section of the dump diffuser. Hence, air enters the combustor top-hats preferentially from the upper dump diffuser. This air then flows through the annular passage between the top-hat and the combustor liner; past the cross-flame tubes and into the combustor. Velocity profiles in the annular passage were integrated across the annular gap and the mass flow distribution was determined.

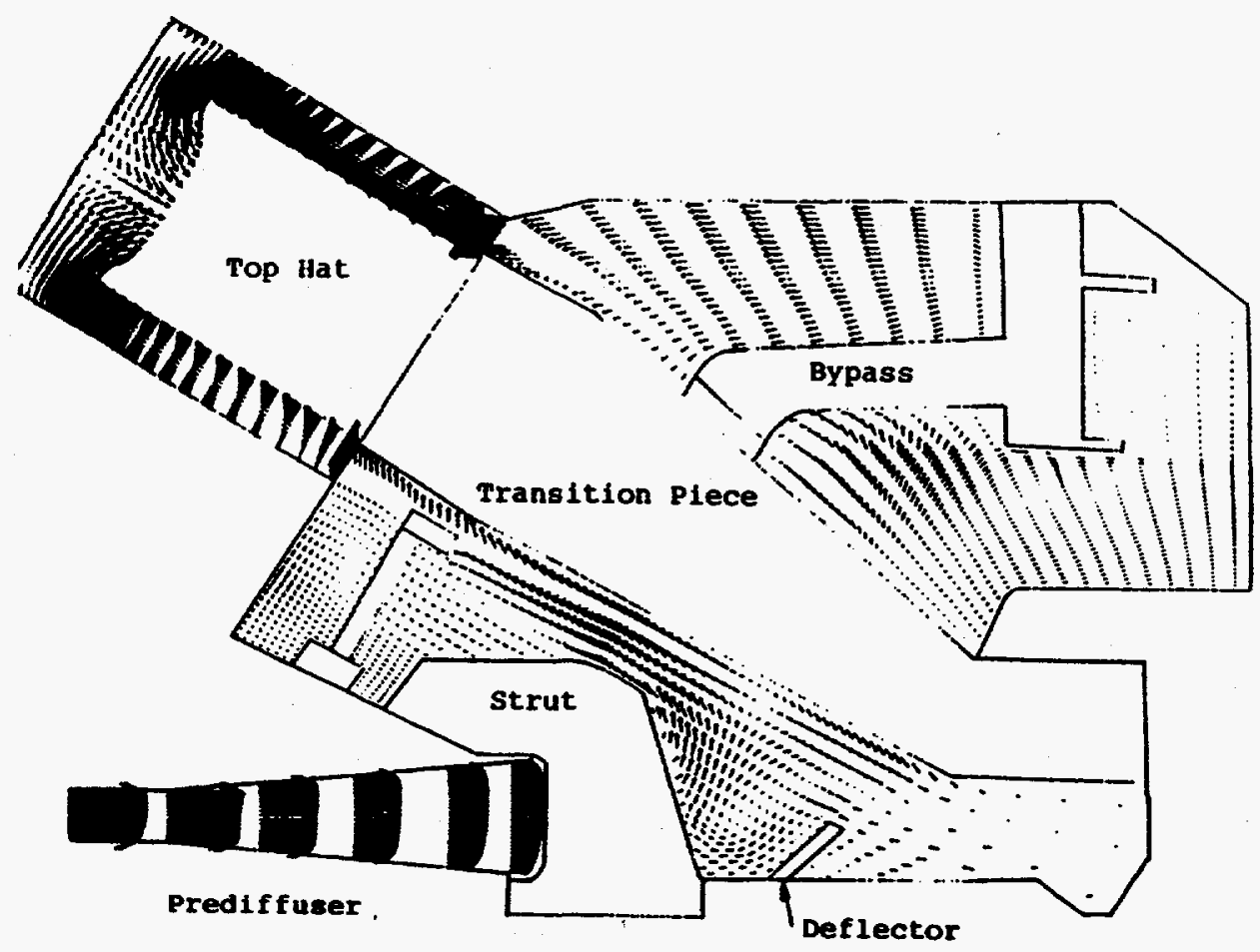

Figure 8-33. Flow Structure on a Plane Through the Combustor Centerline 


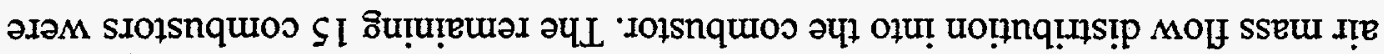

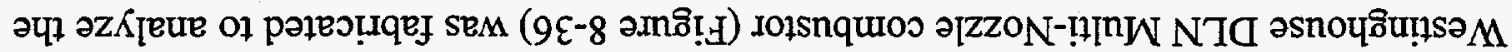

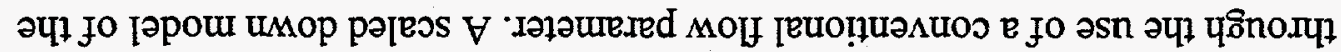

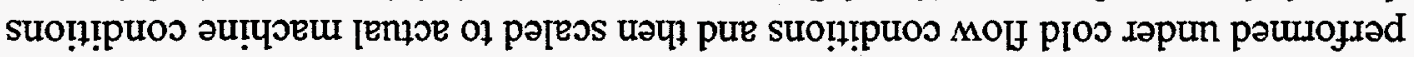

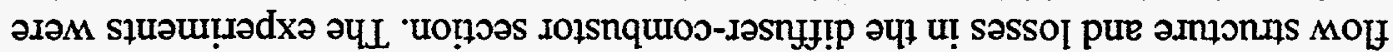

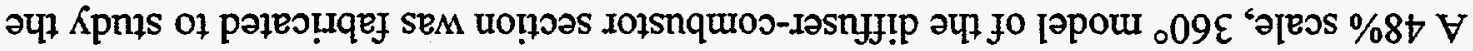

?PQY-doI

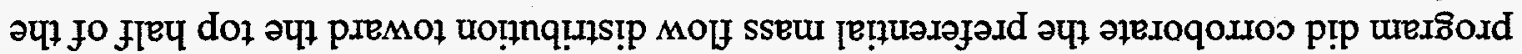

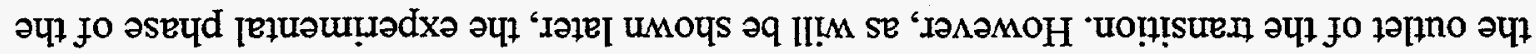

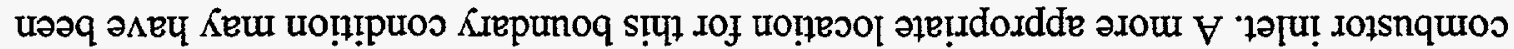

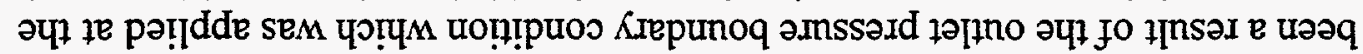

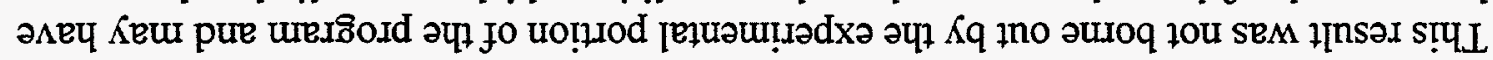

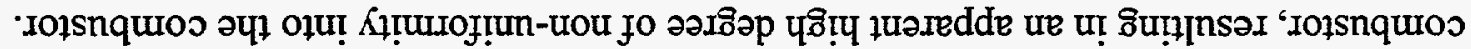

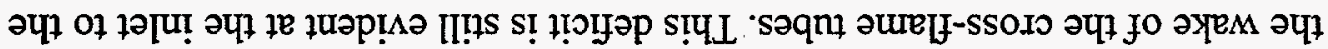
u! pəurof s! 1 !

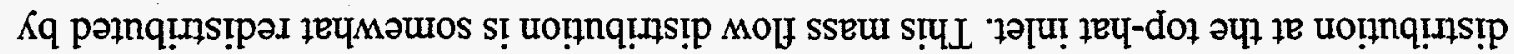

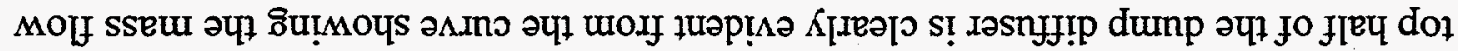

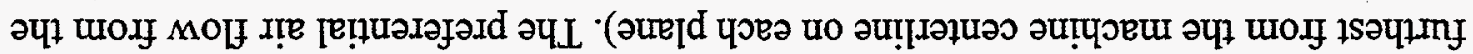

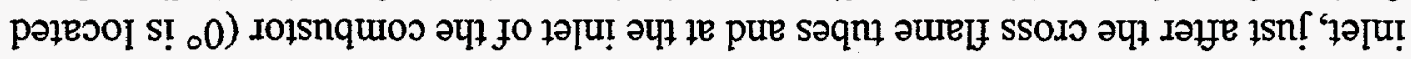

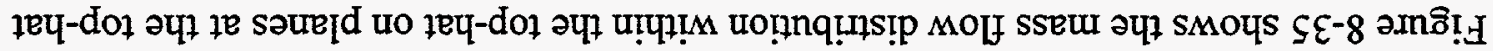

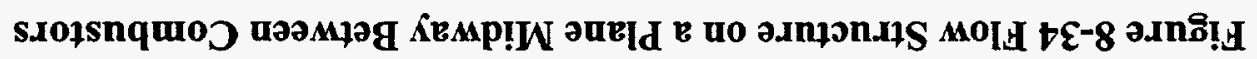

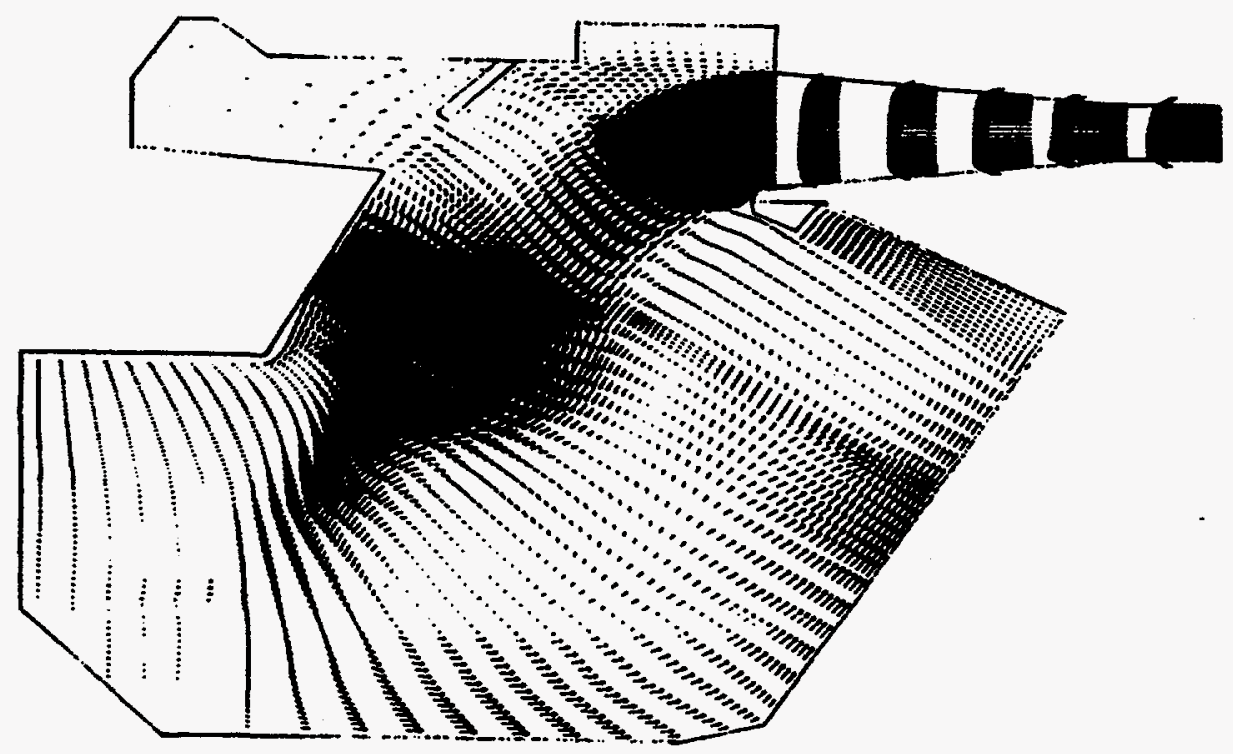




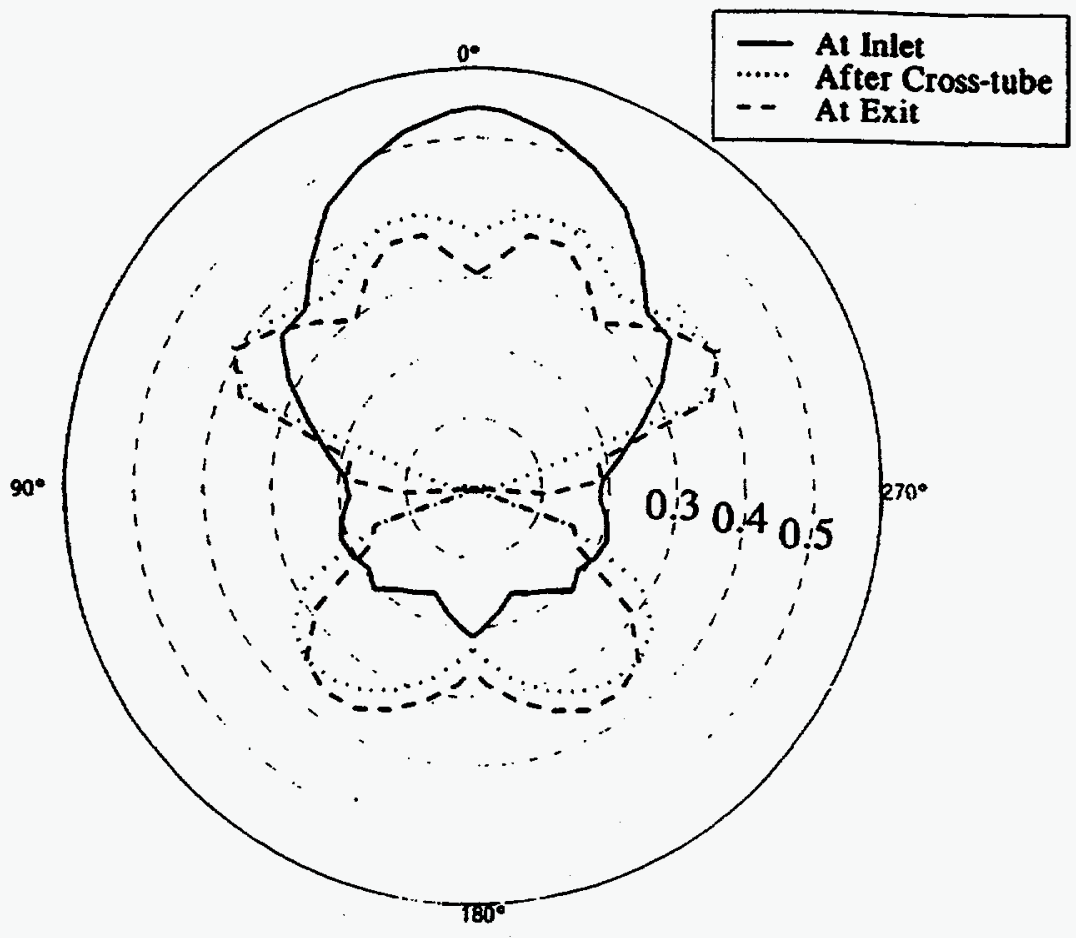

Figure 8-35. Mass Flow Distributions in the Top-Hat Passage

simulated using cylinders containing orifice plates that were sized to yield the same effective area as the scaled combustor.

Static pressure was measured at regular intervals along the inner and outer surfaces of the annular pre-diffuser and the pressure recovery coefficient was defined as

where;

$$
\mathrm{C}_{\mathrm{P}}=\frac{2\left(\mathrm{P}_{\mathrm{S}}-\mathrm{P}_{\mathrm{S}, \mathrm{in}}\right)}{\rho_{\text {in }} U_{\text {in }}^{2}}=\frac{\left(\mathrm{P}_{\mathrm{S}}-\mathrm{P}_{\mathrm{S}, \text { in }}\right)}{\mathrm{h}_{\mathrm{dyn}}}
$$

PS - Local Static Pressure

$P_{S, \text { in }}$ - Static Pressure at the Inlet to the Pre-Diffuser

$r_{\text {in }}$ - Air Density at the Inlet to the Pre-Diffuser

$\mathrm{U}_{\text {in }}$ - Air Velocity at the Inlet of the Pre-Diffuser

$\mathrm{C}_{\mathrm{P}}$ - Static Pressure Recovery Coefficient

$h_{d y n}$ - Dynamic Head at the Inlet of the Pre-Diffuser

It represents the fraction of the dynamic head into the pre-diffuser that is recovered as static pressure. Figure 8-37 shows the variation of the pressure recovery coefficient from the inlet to the exit of the pre-diffuser along three different planes in the circumferential 
direction. Ideally, the pressure recovery coefficient can reach unity if the flow was decelerated to zero velocity in a reversible process. For the geometry studied, the velocity exiting the pre-diffuser is not zero, thus, based on the pre-diffuser inlet to outlet area ratio, the optimum (lossless) recovery coefficient that can be realized is 0.78 . Inevitable losses and the presence of the boundary layer reduce the pressure recovery coefficient below the optimum value. Table 8-4 shows the pressure recovery coefficients on the three planes at the exit of the pre-diffuser.

\begin{tabular}{|c|c|c|c|}
\hline & $\begin{array}{l}\text { Inner } \\
\text { Wall }\end{array}$ & $\begin{array}{c}\text { Outer } \\
\text { Wall }\end{array}$ & Average \\
\hline $\begin{array}{l}\text { Plane } 1 \\
\text { Plane } 2 \\
\text { Plane } 3\end{array}$ & $\begin{array}{l}0.68 \\
0.68 \\
0.67\end{array}$ & $\begin{array}{l}0.55 \\
0.61 \\
0.56\end{array}$ & $\begin{array}{l}0.62 \\
0.65 \\
0.62\end{array}$ \\
\hline \multicolumn{4}{|c|}{$\begin{array}{c}\text { Average Value }=0.63 \\
\text { Benchmark Value }=0.65 \\
\text { Theoretical Value }=0.78 \\
\end{array}$} \\
\hline
\end{tabular}

The benchmark value is based on studies of optimum diffuser geometries. The close agreement between the values measured for the Westinghouse pre-diffuser and the benchmark value indicates that the Westinghouse pre-diffuser is very efficient at recovering static pressure. Based on this finding, the ATS pre-diffuser design will be based on the current pre-diffuser design.

A number of measurements were performed to determine the velocity field at various locations throughout the combustion shell in order to characterize the performance of the dump diffuser. The experimental data confirms the CFD results that showed the majority of the flow passing through the top section of the dump diffuser with the lower section of the dump diffuser containing low velocity, recirculation zones. Measurements in the annular gap between the combustor liner and the top-hat also confirm the CFD result which showed air entering the top-hat preferentially from the top section of the dump diffuser. Air flow then partially redistributes around the top-hat as the flow moves toward the combustor inlet. The large flow deficit regions behind the cross-flame tubes, which were predicted by CFD, were not evident in the experimental measurements.

The effect of 5 and $20 \%$ air extraction through a single port in the side of the combustion shell was studied for use in rotor cooling and IGCC applications. The data taken in this portion of the study is still undergoing analysis; however, some important conclusions have been made regarding air extraction. 
Air extraction of $5 \%$ (typical of rotor cooling needs) does not seem to significantly effect the flow field in the combustion shell, pressure drop or air mass flow distribution into the combustor. On the other hand, 20\% air extraction (typical of IGCC application needs) through a single port has a significant effect on the flow patterns within the combustion shell. Perhaps the most significant manifestation of this effect can be seen in the mass flow distribution into the combustors. One of the main nozzles in the scaled down combustor (see Figure 8-36) was fitted with a hot-wire probe such that the tip was just upstream of the swirler inlet. The mounting technique allowed it to be rotated within a main swirler such that the average velocity into each main swirler (eight main swirlers per combustor) could be determined. Preliminary results of this study are shown in Figure 8-38. The swirler located at $0^{\circ}$ is furthest away from the machine centerline and $180^{\circ}$ is closest to the machine centerline. All sets of data show the trend of preferential mass flow through the upper half of the combustor (since air flows preferentially into the upper half of the top-hat). The first dataset shows a $0 \%$ extraction case.

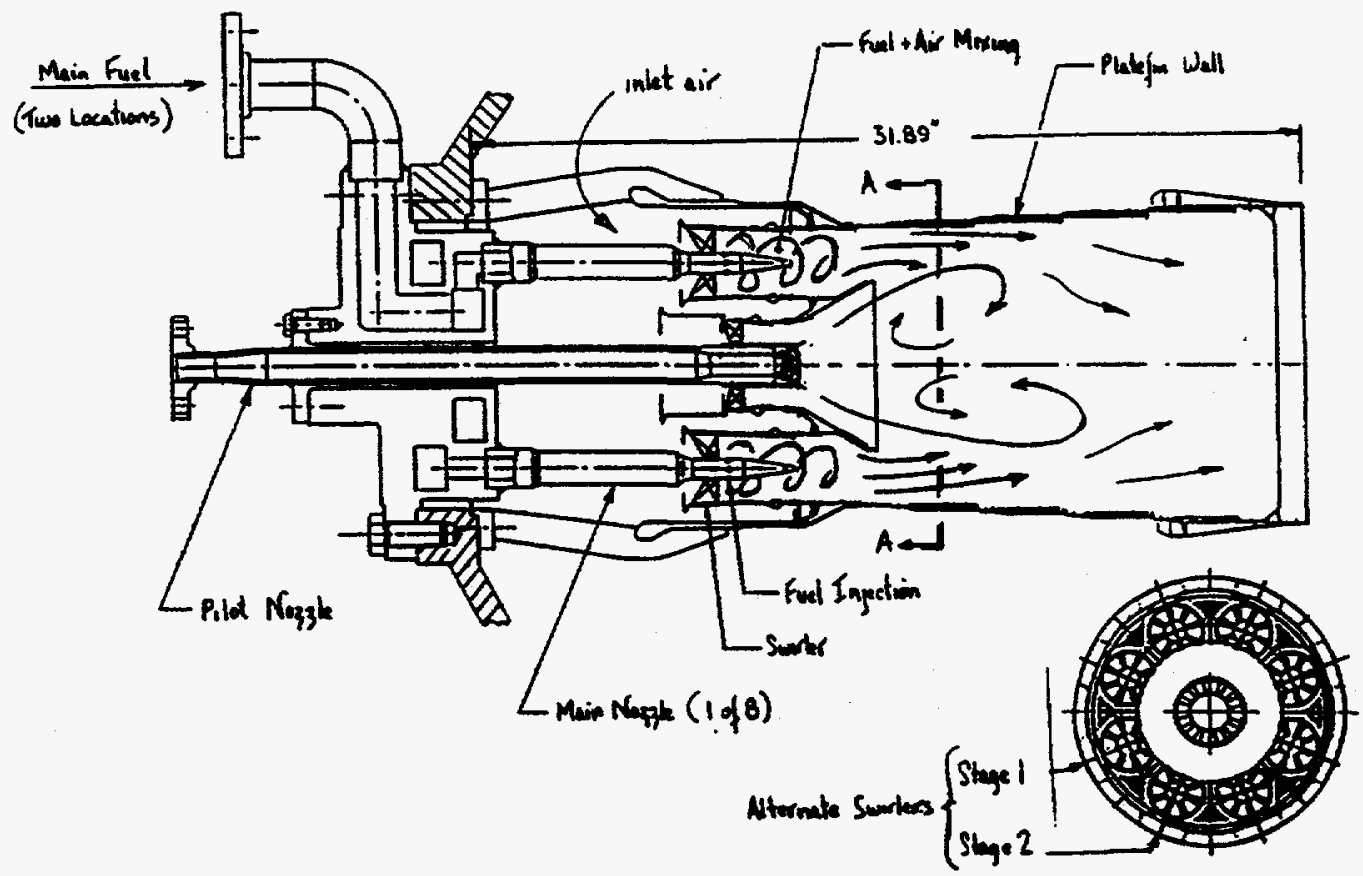

Figure 8-36. Multi-Nozzle Combustor Schematic

The second data set is a repeat of the first dataset. The difference between both curves is an indication of the error/repeatability of the measurements. The third dataset shows a $0 \%$ extraction case; however, the combustor under consideration is directly above a rotor 
cooling pipe. Apparently, the presence of the cooling pipe increases the flow into the combustor.

The fourth and fifth datasets show the effect of $20 \%$ extraction on the flow into the combustors. The fourth dataset shows the flow distribution into the combustor nearest the extraction location and the fifth dataset shows the flow distribution into the combustor $180^{\circ}$ away from air extraction. Clearly, $20 \%$ air extraction significantly reduces the air flow into the combustor closest to the point of extraction. The type of flow deficit depicted in figure 8-38 would be extremely detrimental to emissions would probably lead to damage of one or more of the combustors. For IGCC applications, air extraction should distributed at several locations around the combustion shell to alleviate this problem.

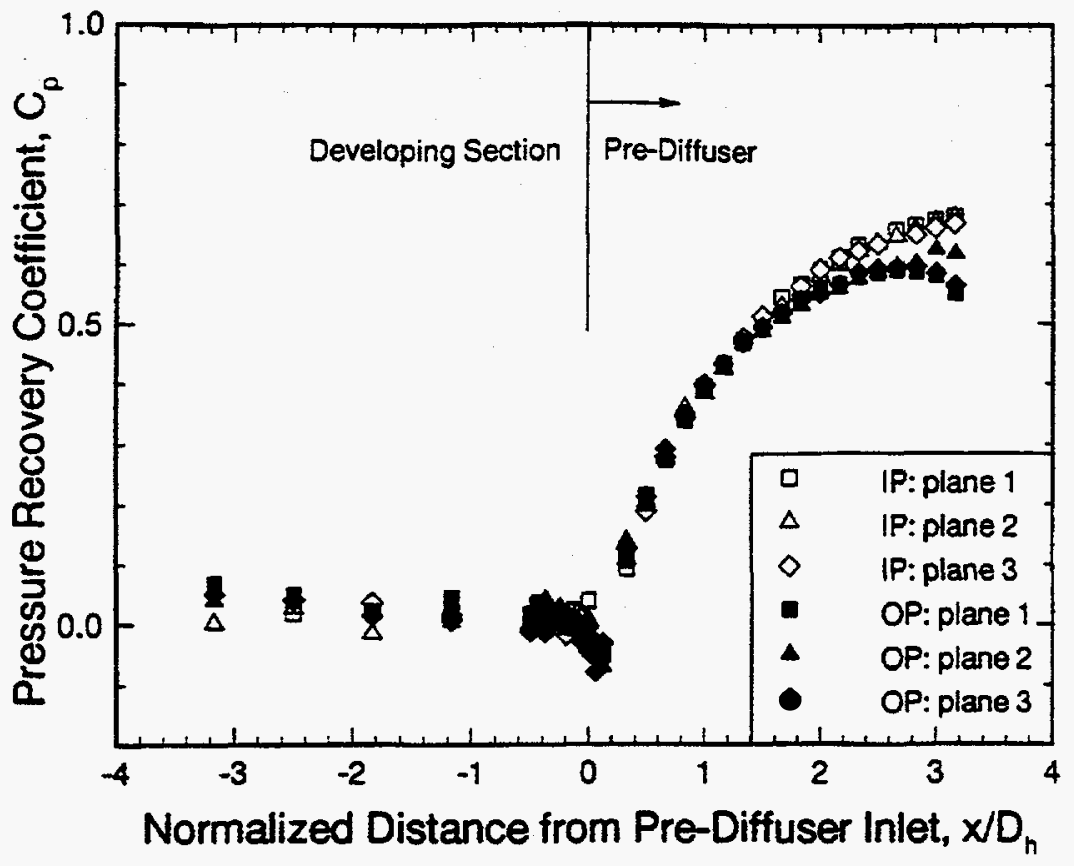

Figure 8-37. Variation of Pressure Recovery Coefficients Along the Pre-Diffuser. (IP-Inner Surface of Pre-Diffuser, OP - Outer Surface of Pre-Diffuser) 
The flow structure within an advanced Westinghouse gas turbine was studied using a computational fluid dynamics model and a $48 \%$ scale experimental model. The major findings of this study were

- The current annular pre-diffuser design at the exit of the compressor performs very well and will be incorporated into the ATS design,

- $\quad$ Air flow is unable to make the sharp turn at pre-diffuser exit required to flow into the lower dump diffuser and most of the air flows into the upper dump diffuser,

- Air flows preferentially into the upper half of the top-hat and hence, into the top of the combustor.

- $\quad$ Five percent air extraction through a single port on the combustion shell does not significantly effect flow characteristics within the combustion shell, and

- Twenty percent air extraction through a single port on the combustion shell significantly effects flow characteristics within the combustion shell and should be avoided.

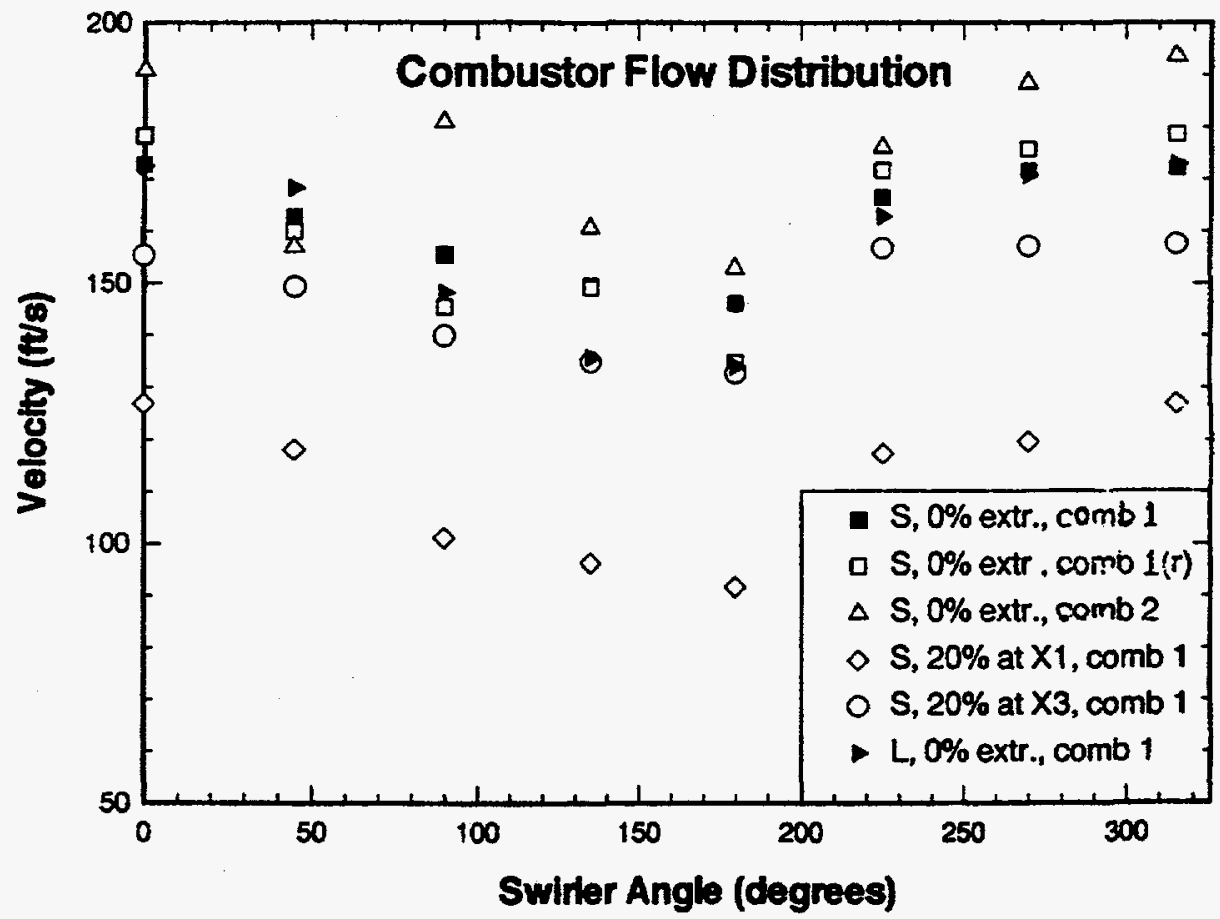

Figure 8-38. Combustor Inlet Air Flow Distribution 


\section{High Efficiency Compressor Design}

Westinghouse's ATS engine is based upon a single shaft combustion turbine operating at an optimized pressure ratio (PR). The PR was selected to maintain optimum exhaust temperature. All components must operate at optimum levels to achieve the target overall ATS efficiency of $60 \%$. The compressor designs used in previous Westinghouse models had to be modified for increased efficiency.

The development of the ATS compressor has been accomplished in two steps:

- Advanced aeroengine aerodynamic and mechanical design tools were used to develop the blading 19:1 PR compressor, and

- Using the first 13 stages from the 19:1 compressor design, slightly modifying the blading in stages 14 through 16 , and adding 4 additional stages (16 through 20 ).

The first step was completed and is explained below. The second step will be completed in Phase 3.

Step one in the high efficiency compressor design was carried out using the following process:

- Meanline aerodynamic models were created for a series of compressors with gas path geometries varying from constant outer diameters, through gooseneck, to a $501 \mathrm{~F}$ clone. Stage aerodynamics were optimized under each configuration, and results were compared in terms of efficiency, surge margin and risk.

- Further refinement of design point aerodynamics was made until each stage was operating near its maximum efficiency.

- Off-design prediction of compressor performance to verify that operating extremes would not result in major problems.

- $\quad$ CDA (controlled diffusion) airfoil shapes were designed along flow surfaces to maximize efficiency. Leading and trailing edge minimum radii were imposed to maintain reliability. Maximum thickness was set through repeated interations to achieve rigorous frequency and stress requirements. Optimization of each stage was driven by minimizing thickness(lowers profile losses) against acceptable mechanical properties(i.e., stress, vibration, speed, etc.).

- Hot running clearances were calculated considering transient differential thermal growths, centrifugal stretching and all mechanical and build tolerances.

- Three dimensional viscous analyses were performed on each row during the design process to check on aerodynamics, and to produce surface pressure distributions for mapping directly onto the airfoil for mechanical analysis. 
The analysis system was verified against the known characteristics of the $501 \mathrm{~F}$ compressor. It was found that the model predicted mass flow and efficiency within a tolerance band acceptable for design purposes.

The results of analysis at off design conditions prompted changes in the axial chords in the initial stages to allow for better hot weather, under frequency operation. Analyses were conducted at the extremes of cold weather and hot weather, near $25 \%$ surge margin. Compressor operation was stable for a temperature range of $-40^{\circ}$ to $122^{\circ} \mathrm{F}$ and under frequency condition at $57 \mathrm{~Hz}$. 


\section{SECTION 9}

\section{NATIONAL ENVIRONMENTAL POLICY ACT (NEPA)}

\section{INFORMATION}

A description of the environmental, safety, and health (ES\&H) information was provided by each subcontractor to enable DOE to prepare the appropriate NEPA documentation for the project. The ES\&H information included, but was not limited to:

- Brief, nonconfidential description of the project including project objectives, project schedule, summary of test plans, map location(s), description of existing facilities, and description of facilities to be constructed for the project. If appropriate, the subcontractor provided process flow diagrams, and plan and elevation views. The subcontractor provided sizes and capacities for major equipment. Discussion on the quantities and types of materials to be used in the project including feedstocks, utilities, fuels, reactants, products, effluents, unrecovered materials, and solid waste was included.

- Discussion regarding current environmental characteristics of the site(s) and any potential environmental impacts from the project. Information on environmental impacts provided data in terms of minimum, maximum, and average values rather than qualitative statements, such as "insignificant" or "minimal", which are subject to interpretation.

Discussion regarding compliance with Federal, state, and local environmental regulations was submitted. The following is a list of environmental impacts included in the discussion.

Air Quality -- Discussion regarding potential environmental impact from the seven criteria pollutants in the Clean Air Act (i.e., sulfur oxides, nitrogen oxides, carbon monoxide, hydrocarbons, particulate matter less than 10 microns (i.e., $\mathrm{PM}_{10}$ ), lead, and ozone) and the Hazardous Air Pollutants (i.e., air toxics) list in the 19900 Title III amendment to the Clean Air Act was included. Discussion regarding other potential air pollutants including carbon dioxide, air emission rates, and duration of emissions was included.

Water Resources -- Discussion regarding potential environmental impact to surface and ground waters including changes to water quality and quantity was provided. The use of the surface and ground waters were included in the discussion. The discussion included sources of water supply (e.g., public water supply or dedicated well) and any National Pollutant Discharge Elimination System (NPDES) permit(s). Discussion regarding on-site treatment of waste-water was included in discussion regarding compliance with local, state, and Federal environmental regulations was included. The status of local, state, and Federal permits for water use and discharges was included. Any stream diversions caused by construction activities were described. 
Land Use -- Discussion on the amount of land at the existing site and the amount that will be used for construction of the project was included. The discussion included the current use of the land, zoning requirements, and current access to the land. A discussion on the uses and zoning of surrounding property was included. The discussion included any modifications needed for access to the land as a result of the project. Discussion on impacts to visual and aesthetic values was included.

Waste Management -- Discussion on solid and liquid waste management including waste characteristics, quantities, pretreatment, storage, transportation, and disposal practices was included. Any potentially hazardous waste materials were identified. Any results from analyzing solid waste in accordance with the Resource Conservation and Recovery Act characterization tests were included. Discussion regarding compliance with Federal, state, and local environmental regulations. Discussion on the status of Federal, state, and local permits was included.

Ecological Impacts -- A discussion regarding potential environmental impacts to vegetation, terrestrial wild-life, aquatic wildlife, threatened and endangered species, critical habitats, floodplains, and wetlands was included.

Socioeconomic Impacts -- Information regarding availability of labor for the project, availability of transportation, and any potential impact on public services was included. Information on impact to visual or aesthetic quality was included.

Archaeological, Cultural, and Historical Resources -- Information regarding contacts with state agencies to assess project impact on archaeological, cultural, and historically significant resources was included.

Noise -- A discussion on possible environmental impacts from noise generated by the project was included. A discussion on current noise levels and any possible increases in noise levels from the project was included. In general, the noise level is measured at the nearest point of public access. A discussion regarding proximity and any possible impact to noise-sensitive sites such as schools, hospitals, and nursing homes was included.

Occupational Safety and Health - A discussion on plans to protect worker safety and health on the project was included (e.g., clothing, hearing protection, operating practices).

If the project presents a potential safety hazard beyond the project boundaries, emergency response plans were included in the discussion. Information on compliance with Occupational Safety and Health Act and facility designs related to mitigation of occupational impacts was included. Hazards and mitigation measures related to construction activities and exposure to hazardous substances, heat, noise, and odor were discussed. 
Cumulative Impacts -- The cumulative impact is the impact to the environment which results from the incremental impact from the proposed action when added to impacts from past, present, and reasonably foreseeable future actions. Individual impacts may be minor, but the combined impact (i.e., cumulative) can be significant. A discussion on the contribution of environmental impacts from the proposed action to the cumulative impact was included. Each of the potential environmental impacts described above was considered relative to their impact on the existing environmental setting and emissions. Generally, impacts which contribute to the cumulative impact included air emissions, water and liquid effluent treatment, solid waste management, and land use.

Summary of Environmental Impacts -- A factual summary of potential environmental impacts was included.

- A table was prepared that identified all Federal, state, and local permits and licenses required for the project, if any were required. The table provided information on the permitting and licensing schedule and current status of each permit and license. A discussion on the allowable releases of solid, liquid, and air pollutants under the permit(s) and license(s) was included.

- Compete addresses and phone numbers for agencies and persons contacted to collect information on the ES\&H aspects of the project was provided. 